\title{
A COMPARISON OF OCEANIC PARAMETERS \\ DURING UPWELLING OFF THE \\ CENTRAL COAST OF CALIFORNIA
}

\section{by}

Arthur Bishop Shepard 



\section{United States \\ Naval Postgraduate School

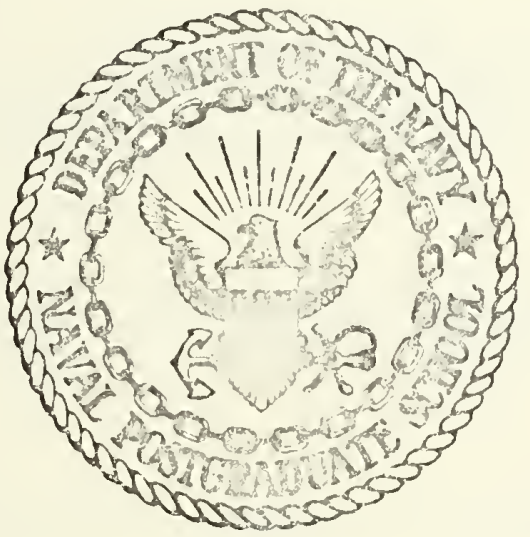

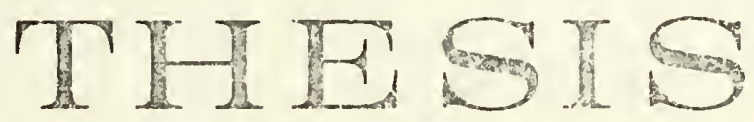

A COMPARISON OF OCEANIC PARAMETERS DURING

UPWELIING OFF THE CENTRAL COAST OF CALIFORNIA

by

Arthur Bishop Shepard

This document has been approved for public release and sale; its distribution is unlimited. 
FETBRABY
NAVAL POSTGRADUATE SCHOOLI
HONTEREY, CALIF. 93940 
A Comparison of Oceanic Parameters During Upwelling off the Central Coast of California

by

\author{
Arthur Bishop Shepard \\ Lieutenant, United States Coast Guard \\ B.S., United States Coast Guard Academy, 1963
}

Submitted in partial fulfillment of the requirements for the degree of

MASTER OF SCIENCE IN OCEANOGRAPHY

from the

NAVAL POSTGRADUATE SCHOOL

September 1970 



\section{ABSTRACT}

An examination of the region between Monterey Bay and San Francisco Bay, California was conducted from 29 April to 5 May 1970 to study the effects of upwelling on the Central California, coastal region. Six parameters: temperature, phosphate, beam transmission for light, chlorophyl1 a, Coulter particle size distributions, and oxygen were observed at eighty-five stations from the surface to $100 \mathrm{~m}$ in the cruise area. The data gathered are presented in the form of horizontal contours and profiles which indicate: (1) Almost the entire surface layer was saturated with respect to oxygen. (2) there were four areas, at the northern and southern ends of Monterey Bay, off Point Montara, and west of the entrance to San Francisco Bay, which exhibited hish values of chlorophyll a , oxygen, and particle count, for correspondingly low phosphate values and low beam transmission. (3) These productive areas are inshore, gencrally within 5-10 miles of the coast. (4) A peak in the size distribution of particles was evident in the productive surface layers, within the observable range of particle diameters $(1.59$ to $32.0 \mu)$. (5) Plots of oxygen versus phosphate showed that similar slopes of about $-3.1 \frac{\mathrm{Hg}-\mathrm{at} / 1 \mathrm{PO}_{4}}{\mathrm{ml} / 1 \mathrm{O}_{2}}$ were observed for inshore and offshore regions. The inshore regions exhibited higher phosphate values for a given value of oxygen which is probably a result of upwelling. (6) There was a fair correlation between beam transmittance and particle count. High values of beam transmittance were generally associated with low total Coulter count, e.g., 90\%/m and 6000 counts per $2 \mathrm{ml}$. Conversely, low values of beam transmittance were associated with high particle counts, for example 5\%/m and 85,000 counts per $2 \mathrm{~m} 1$. 



\section{TABLE OF CONTENTS}

I. INTRODUCTION . . . . . . . . . . . . . . 9

A. ENVIRONMENTAL FACTORS . . . . . . . . . . . 9

B. BACKGROUND . . . . . . . . . . . . . . . 13

1. Phosphate . . . . . . . . . . . . 13

2. Dissolved Oxygen ............. . . . . 14

3. Chlorophyll a . . . . . . . . . . . . 14

4. Beam Transmittance............ . . . . . . 5

5. Particulates ................ . . . .

6. Temperature ............. . . . 20

7. Upwelling . . . . . . . . . . . .

C. OBJECTIVE ................... . . . . . . 1

II. OBSERVATIONAL PROCEDURES . . . . . . . . . . . . . . 23

A. STATION LOCATIONS . . . . . . . . . . . . . . . . . .

B. DATA COLLECTION . . . . . . . . . . . . . . . . 33

C. INSTRUMENTATION . . . . . . . . . . . . 26

1. Beam Transmissometer . . . . . . . . . 26

2. Sound Velocity-Temperature-Depth Probe . . . .26

3. Fluorometer . . . . . . . . . . . 26

4. Particle Counter . . . . . . . . . . 26

III. DATA ANALYSIS . . . . . . . . . . . . . . .28

A. INTRODUCTION . . . . . . . . . . . . . . .28

B. METHODS OF ANALYSIS . . . . . . . . . . . .28

1. Horizontal Contours . . . . . . . . . 28

2. Vertical Contours . . . . . . . . . 36

3. Graphical Comparisons . . . . . . . . 39 

IV. CONCLUSIONS . . . . . . . . . . . . . . . . . . 49

V. SUGGESTIONS FOR FUTURE RESEARCH . . . . . . . . . . . . 51

APPENDIX - Bathythermograph Traces . . . . . . . . . . 203

BIBLIOGRAPHY . . . . . . . . . . . . . . . . . . . 208

INITIAL DISTRIBUTION LIST . . . . . . . . . . . . . . 210

FORM DD 1473 . . . . . . . . . . . . . . . . . 217 



\section{LIST OF TABLES}

Table

Page

I

Station Data: Location, Time, Depth, Weatner,

Sound Velocity, Temperature, Transmittance,

Oxygen, Chlorophy 11, and Phosphate . . . . . . .

Particle Size Distributions . . . . . . . . . . 169 

6 



\section{LIST OF FIGURES}

Figure

Page

1

2

3

4

10-39

$40-81$
Arrangement of SV/T/D Probe and Beam Transmissometer . 17

Cruise Track Showing Station Locations . . . . . . 24

Locations of CALCOFI and NPS Stations in

Monterey Bay . . . . . . . . . . . . . . . . 33

Particle Size Distribution Observed at Station

$\mathrm{I}-1$ at $100 \mathrm{~m}$. . . . . . . . . . . . 40

Particle Size Distributions observed at Station

A-6 in Monterey Bay, from 0-100 m . . . . . . . 42

Chlorophyll a as a Function of Oxygen . . . . . . 43

Total Particle Count as a Function of Beam

Transmittance . . . . . . . . . . . . . 45

Beam Transmittance as a Function of

Chlorophyll a . . . . . . . . . . . . . 46

Oxygen as a Function of Phosphate . . . . . . . 48

Horizontal Contours for $0,10,20,40$, and $75 \mathrm{~m}$

Depths for Chlorophyll a, Oxygen, Total Particle

Count, Phosphate, Temperature, and Beam

Transmittance .. . . . . . . . . . 53-82

Vertical Profiles of Chlorophyl1 a, Oxygen, Total Particle Count, Phosphate, Temperature, and Beam Transmittance $83-124$ 



\section{ACKNOWLEDGEMENTS}

At this point the author desires to express his deep gratitude to those who have made this project possible. First and foremost, I want to thank Stevens P. Tucker, who helped initiate this study while he was a member of the teaching faculty (1968-1970) and who aided and encouraged me throughout, for his enthusiasm and willingness to provide assistance at any time. Secondly, I wish to thank Professor Eugene C. Haderlie, my faculty thesis advisor, for his help and understanding. My thanks are also extended to the Pacific Support Group of the U. S. Naval Oceanographic Office and to the captain and members of the crew of the USNS BARTLETT (T-AGOR-13). There were many others who helped, but without the aid of the members of my section, LCDR Sexton, LCDR Lynch, LCDR Jensen, LCDR Wunderly, LT Drennan, LT McKay, and LT Chandler, who voluntarily assisted in the data gathering portion of the study, it would have been impossible to complete the eighty-five stations in six days. Finaliy to my wife, Sharon, who cheerfully assisted, spending long, tedious hours copying data and typing, and who accepted the neglect of the author during the preparation of this report. 



\section{INTRODUCTION}

\section{A. ENVIRONMENTAL FACTORS}

Our knowledge of the ocean depends on sampling and collecting data over a period of time and is based on composite pictures of regions of interest. The upwelling areas of the world are of particular interest because of the high productivity associated with them, and because existing or proposed waste disposal sites are located in some of these regions. An estimated one-half of the world's supply of fish comes from upwelling regions, even though the total surface area involved is but one-half of one percent of the total surface area of the oceans. This can be explained in terms of the food chain, that is, the number of steps from photosynthetic phytoplankton, through grazers, to the ultimate consumer. Due to both the colonial habits and the large size of phytoplankton in upwelling areas, food chains in such regions tend to be shorter than where there is no upwelling [19].

Production of a standing crop of phytoplankton in upwelling areas is limited to the surface layers, where there is a favorable total concentration of nutrients, which for phosphate, for example, can be as low as $1.0 \mu g-a t / 1$ and stil1 permit vigorous growth. Since photosynthesis is limited to the euphotic zone, that region for which the intensity of light is greater than approximately one percent of that incident on the surface, productivity is 1 ight-limited as well as nutrient-limited. The availability of light in the euphotic zone depends on three principal factors: productivity, land runoff (which contributes particulates and disolved organic matter), and, in regions adjacent to densely populated metropolitan centers, waste discharge. Of the three factors, both runoff 

and productivity are natural features of a region normally not subject to control. Waste discharge however can be controlled.

The problem of waste disposal by dilution in the ocean, a practice commonly followed in coastal regions, is becoming more and more acute. With increasing population growth, present disposal methods are proving to be inadequate to handle the increasing quantities of waste which are being generated. Generally the ocean has been considered a great sump into which wastes can be pumped with no danger.

Experience has shown that dilution of wastes pumped into the sea is in fact much less than expected. Attempts have been made to design outfalls and diffuser systems to minimize the adverse effects of such disposal. It nevertheless remains to be seen what will be the short and long term effects of the enormous volume of wastes ( 1.4 billion gallons per day) expected by the year 2000 on the coastal waters of central California. As Smith [21] points out: "If waste is to be pumped into the sea off coasts where upwelling is prevalent, it is apparent that adequate scientific knowledge of the upwelling process is needed".

of the world's fish supply not associated with upwelling areas, i.e. approximately one half of the total supply, almost the entire quantity is to be found in the shallow regions of the continental shelves where waste disposal is a more apparent problem. Nutrients in these regions are supplied to the euphotic zone by runoff from the land and by other hydrographic features like turbulence and convection. Turbulence tends to homogenize the water mass and thus distribute dissolved nutrients to considerable depths.

For maximum phytoplankton production turbulence must be followed by a stratification or stabilization of the water mass to allow phytoplankton to remain in the euphotic zone [22, p. 941]. Thus turbulence as well as 

upwelling raise the level of nutrients at the surface; indeed, one-half of the phosphate enrichment of surface waters off Peru, for example,appears to be due to turbulence and the other half to upwelling [21].

Thorade in 1909 postulated that the anomalously cold water along the California coast was due to upwelling. He showed that vertical advection of deep water was needed to replace surface water transported offshore by the northerly winds paralleling the coast, which, because of the Coriolis effect, causes a net transport in a direction $90^{\circ}$ to the right of the wind. This was the first application of Ekman's Theory [21].

Skogsberg [20] was the first to treat the oceanographic climate of the Monterey Bay region as being divided into three distinct seasonal phases, namely the cold and warm water phases and the low thermal gradient phase. These three features were later referred to and described by Bolin [4] as the Upwelling Period, the Oceanic Period, and the Davidson Current Period.

The Upwelling Period is initiated by the change in the surface winds of January and February to a generally northerly flow paralleling the coast. Water is transported away from the coast and replaced by deeper water advected vertically upward from depths probably not exceeding 200 meters according to Sverdrup [22]. This period is characterized by: the lowest surface temperatures in the annual cycle; salinity values which rise to the high point of the year and are followed by a subsequent decline; and a strong vertical temperature gradient of more than $1^{\circ} \mathrm{C}$ per $16 \mathrm{~m}$.

The steady northerly winds of spring become intermittant in late summer and provide interruptions in the coastal upwelling, which allow the cold dense water to sink, causing convergences. Warm inshore surface water flowing offshore and an inflow of oceanic surface water to replace 

the sinking, denser water establish a sharp thermocline in the first few meters. The Oceanic Period is characterized by surface temperatures as much as $2-3^{\circ} \mathrm{C}$ higher than the peak temperatures during the upwe 11 ing season, by a continuation of the strong vertical gradient established during the period of upwelling, and also by calm conditions which constitute a transformation between the northerly winds of the Upwelling Period and the southerly winds of the Davidson Current period. The influx of ocsanic surface water, the rise in the surface water temperatures, and the decrease in nutrient levels due to a lack of upwelling, lead to a decrease in the productivity of the local phytoplankton. With the influx of oceanic surface water a number of offshore phytoplanktonic species are brought into the Monterey Bay region, an environment more fertile than the open ocean but less fertile than during the height of upwelling. The inoculum finds conditions for growth more favorable than norma 1 and multiplies, increasing the diversity of forms in the coastal water. Therefore, a progressive reduction in the productivity for the area is checked. Thus, although initial local populations may require highly fertile waters, subsequent oceanic inputs are able to subsist at lower nutrient levels, and an average supply of plants is maintained for the grazers in the area. In their study of the marine climate of central coastal California Bolin and Abbott noted that if upwelling is intermittant, plankton volumes are high, and if upwelling is steady, plankton volumes are lower [3].

After the calm of the Oceanic Period the winds become southerly in November. The Coriolis effect causes a shoreward transport of water and an accumulation of low density water along the coast. This has two primary effects on the California coastal environment. A current is formed as a result of the piling up of light waters, which parallels and reinforces 

the wind driven current; sinking of the surface waters occurs, and relatively isothermal conditions are established to a considerable depth. The Davidson Current period lasts until February and provides the only sharp climatic change in the cycle. Its onset is characterized by an abrupt decline in surface temperature.

\section{B. BACKGROUND}

In general the distribution of oceanic parameters in the study region is complicated by vertical advection, entrainment, biologic activity, and, near the entrance to the San Francisco tidal prism, brackish discharge during the upwelling period. Of particular interest is the altering of the individual physical and chemical properties, especially in the first 100 meters, during this period.

\section{Phosphate}

Phosphate increases with depth to a maximum that corresponds to the oxygen minimum. The lowest values generally are found at the surface, where the usual concentration at mid-latitudes is of the order of $0.2 \mu g-a t / 1$ [21]. In the California coastal region phosphate concentration changes in an abrupt manner in the late winter and spring. The suddenness of the change can be attributed to upwelling of nutrient enriched water into the surface layers, which replenishes the water depleted in phosphates throughout the fall and early winter. The abundance of nutrients in the euphotic zone is a stimulus for growth of phytoplankton, and patchy areas of productivity become evident, further complicating the analysis of observations. Measurements of phosphorous in the form of phosphate conducted off the central California coast by the California Cooperative Fisheries Investigations (CALCOFI) in July 1950 indicate values of $2-2.5 \mu g-a t / 1$ to be present at $100 \mathrm{~m} \mathrm{[5].}$ 



\section{Dissolved Oxygen}

Oxygen is generally at or above saturation at the surface, due to aeration and photosynthesis, but decreases in concentration with depth to a minimum at some intermediate depth. The saturation value of oxygen depends upon both salinity and temperature. The latter is the dominant factor off the central California coast. Since oxygen is replaced in the surface layers and is consumed throughout a water column by respiration and decay, the subsurface waters tend to be low in dissolved oxygen. When upwelling occurs, such oxygen-low waters are brought to the surface and are typically undersaturated. Park, Pattullo, and Wyatt observed values of dissolved oxygen concentration to be 60 - $70 \%$ of saturation during upwelling off the Oregon coast [15].

During upwelling, a fair correlation may be observed, though generally not at the surface, between oxygen and temperature. Pytkowicz [16] showed correlations between oxygen and inorganic phosphate for Oregon coastal waters and suggested that a subsurface oxygen maximum is formed as a result of the summer upwelling, when the rate of escape of oxygen exceeds its rate of production by photosynthesis.

A subsurface oxygen maximum was observed by Stefansson and Richards in the same coastal region and was attributed, not to photosynthesis, but to a sinking along isentropic surfaces of water which had been enriched previously by photosynthesis nearer shore. They also noted a good statistical correlation between dissolved oxygen and density, except in the upper layers.

\section{Chlorophyl1 a}

Chlorophyll a is perhaps the most important of the plant pigments, and observations of the concentrations of chlorophyll a can give indications of the production of phytoplankton. In the first ten meters 

chlorophyll a undergoes greater diurnal changes than any other plant pigment, which indicates that it is more quickly synthesized and decomposed. Concentrations which were up to five times greater at midnight than at noon were observec, for example, in East Sound, Washington, a stratified inlet with little exchange [25]. Ramsey [17] on the basis of tests of the remote sensing of ocean color indicated that definite changes in the spectrum of the upward flux from the sea occur with varying chlorophyllcontent. An aircraft has been used as a platform for the TRW spectrometer ${ }^{1}$ in the analysis of the backscattered light from the sun and sky and the highest percentage of the backscattered light was observed in the green portion of the spectrum [6]. This spectral peak was compared to concentrations of chlorophyll measured with a continuous reading Turner fluormeter.

Yentsch and Scagel [25] agree with Sverdrup, Johnson, and Flemming $[23,25]$ : For primary productivity to take place a certain degree of stability must be reached in a water column, since pigment synthesis or decomposition depends on the duration of exposure to, as well as on, the intensity of light.

\section{Beam Transmittance}

The primary task of optical oceanography is to find out which ingredients in sea water are optically active and to study scattering together with absorption in order to understand the propagation of light in an oceanic medium [9, p. 1]. Scattering in the sea is primarily what may be described as Mie scattering, that is scattering due to particles and living organisms having sizes of the same order of magnitude as the

$1_{\text {The TRW spectrometer is an electro-optical sensor of the off-plane Ebert }}$ type with a spectral range of 400 to $700 \mathrm{~nm}$ and a spectral resolution of 5 to $7.5 \mathrm{~nm}$. 

wave length of light [7]. For large suspended particles the intensity of light scattering according to the Mie theory is predominantly in the forward direction. Scattering of light by highly filtered sea water, however, may be considered as being similar to scattering by pure water, a problem of molecular or Rayleigh scattering, since there is no noticeable effect from the various solutes [7, p. 22, 53]. Rayleigh scattering is a maximum in the forward and backward direction and a minimum in the plane at right angles to the incident 1ight. Absorption, on the other hand, can be attributed to suspended particulate matter as well as to solutes.

A beam transmissometer is used to measure the total beam attenuation coefficient, $c$, which may be represented as the sum, $c=a+b$, where a is defined as the total absorption coefficient, and b is defined as the total scattering coefficient. ${ }^{1}$ In a beam transmissometer a light source which emits a collimated beam of light is housed at one end of the instrument, and a detector is housed at the other end of a fixed path-length to receive the parallel rays.

The beam transmissometer may be used in situ with a depth sensing device to record transmittance as a function of depth (Figure 1). Beam transmissometers may be used with scattering meters to study two constituents of sea water, namely particles and "yellow substance". The oceanographic interest in the distribution of these components is

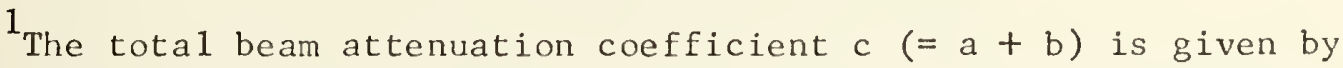
$c=-(1 / I) d I / d x$, where $I$ is the radiant flux incident on a thin layer of thickness $\mathrm{dx}$ normal to the beam and $\mathrm{dI}$ is the radiant flux lost to the beam due to the effects of scattering and absorption. If this equation is integrated, $I(x)=I(0) e^{-c x}$, where $I(x)$ is the radiant flux of the beam at a distance $x$ in the direction of propagation from a point where the flux has the value $I(0)$. Normally $x$ is taken to be $1 \mathrm{~m}$, so that $I(1)=I(0) e^{-c}$ The transmittance per meter, $T$, is then defined as the ratio $T=I(1) / I(0)=e^{-}$ Sometimes the term "beam attenuation", A, is used. It is related to the transmittance: $\mathrm{T}+\mathrm{A}=1$. 



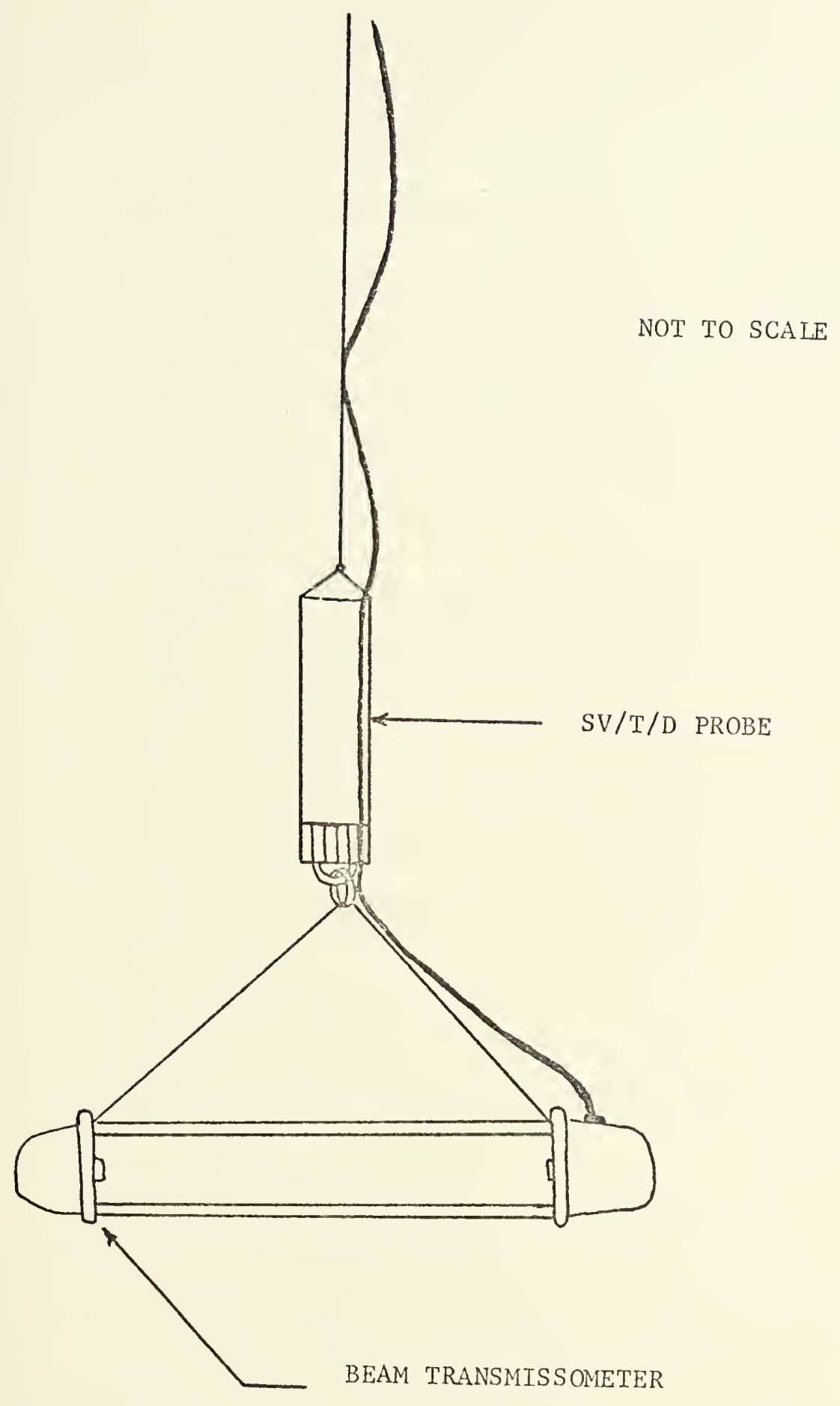

Figure 1 

dictated by the desire to find suitable parameters to characterize water masses [9, p. 155]. "Yellow substance" is a collective name for dissolved organic substances probably formed from carbohydrates and amino acids. The yellowish end product is fairly stable in sea water and is found in coastal areas and regions of upwelling. An inverse proportionality seems to exist between the decomposition of chloroplastic pigments and the production of the yellow absorbing substances. This relationship indicates that yellow substance may be a derivative of protein carriers coupled to the chlorophyll chromophores [24].

\section{Particulates}

The optical properties of a water mass to the extent they differ from those for pure water are largely due to dissolved matter and suspended particulates $[9, \mathrm{p} .1]$. A determination of particulate concentrations may be accomplished by weighing. Size distribution and total counts may be determined either with a microscope or electronically, for example with a Coulter counter, which measures the diameter or the volume of particles suspended in an electrolyte. The Coulter counter provides a rapid means of analyzing a particulate sample, and satisfactory results can be obtained as long as the particles to be counted are not less than about $1.5 \%$ of the aperture size [8].

Measurements by Yeske and Waer [26] indicated that approximately $96 \%$ of the suspended particles in Monterey Bay were less than $8.5 \mathrm{H}$. Labyak [11] found that approximately $90 \%$ of the particles affecting beam transmittance in the coastal region between Monterey and San Francisco Bays were less than $12 \mu$ in diameter. Baker [1], who examined the same region as Labyak, concluded that $74 \%$ of a 11 particles examined had a diameter less than $6.2 \mu$. However, the tota 1 counts observed in these studies were extremely low when compared with the results obtained for 

the May 1970 cruise. Therefore, for purposes of comparison, examples of counts for turbid, intermediate, and clear waters were sought. The following are examples of particle counts per milliliter of sample for a threshold ${ }^{1}$ size of $1.0 \mu$ : Bahama Banks-50-70 × $10^{3}$; Sargasso Sea surface water-12-20 × $10^{3}$; Sargasso Sea deep water (below the mixed layer) $-3-8 \times 10^{3}[8]$.

Suspended particles, either organic or inorganic, affect light attenuation; for example, heavy concentrations of particulate matter diminish the vertical extent of the euphotic zone. During upwelling high particle counts and low transmissivity are to be expected. Joseph [10] has pointed out the need for more measurements of beam attenuation in upwelling waters. A good relationship between suspended matter and chlorinity has been noted by Manheim [12], who found a gradual and linear decrease in the concentration of suspended matter with increasing chlorinity. This suggests that initial concentrations are being diluted with sea water as they progress seaward. A general trend has been observed toward decreasing numbers of particulates with increasing depth and distance from the coast, which can be altered by tidal and wind driven currents, local winds, land runoff, mixing, and upwelling. Changing particulate concentrations can leave areas of patchiness in the sea and can make observations based on single observations at fixed points misleading. Turbulence can alter near-bottom particulate distributions.

${ }^{1}$ When referring to particulate counts with the Coulter counter, the word "threshold" is used to refer to a size range into which particulates can be separated electronically after the instrument is calibrated with particles of a known size. Hereafter, "threshold setting" will refer to that channel number or equivalent spherical diameter from which reliable counts (free of background noise) can be obtained; e.g. channel 13 which corresponds to an equivalent spherical diameter of $1.59 \mu$. 

Thus, clouds of particles are frequently encountered at levels 10 to $50 \mathrm{~m}$ above the bottom [9].

\section{Temperature}

In order to appreciate more fully the impact of upwelling on the climate of the central California coastal region it is necessary to note that the yearly average offshore surface temperature of the Pacific Ocean for the latitude of Monterey Bay is $21^{\circ} \mathrm{C}$, while the average annual surface temperature for the Bay is approximate $1 \mathrm{y} 13^{\circ} \mathrm{C}$. The annual range of surface water temperatures is less for regions where summer upwelling occurs. Thus, along the western coast of the United States the annual range of surface water temperatures is less than $3^{\circ} \mathrm{C}$, while west of the California current the range exceeds $7^{\circ} \mathrm{C}[21]$.

The suppression of surface water temperatures due to upwelling contributes to differential heating and increases the atmospheric pressure gradient and associated winds. It can be seen, therefore, that through depression of sea surface temperatures upwelling strengthens the diurnal sea breeze and brings cool, moist air inland [21].

Examination of vertical temperature sections from offshore to the coast shows marked horizontal and vertical gradients and sharply ascending isotherms. According to Stefansson and Richards [22] in a study of the Washington and Oregon coastal region during upwe11ing, the temperature structure is formed as cold, originally deep, water mixes upward in a stepwise fashion, the ascending water mixing with the overlying warmer water.

There is an indication that upwelling follows certain routes in Monterey Bay, along the axis of the Monterey Submarine Canyon, and that strong upwelling along the upper reaches of the canyon lowers the surface temperatures over and adjacent to this feature during the spring and summer [3]. 

Upwelling can be expected in areas where there is a divergence of surface flow. On the western coasts of continents, for example, during certain periods when the winds parallel the coast and blow equatorward, a characteristic single-sided divergence occurs, which transports light surface waters offshore. To maintain continuity, dense, cold, oxygenpoor, and nutrient-enriched waters are advected vertically from intermediate depths. The anomalies produced by the upwelled waters impinging on the surface layers are evident as strong horizontal gradients of physical and chemical properties, which normally only have marked vertical gradients. The California coastal region represents such a situation and is characterized by a narrow strip of cold water which exerts a strong effect on the climate of the region. Surface anomalies may be used as indicators of upwelling, but the mere presence of anomalies does not necessarily indicate the existence of upwelling. Similar effects have been caused temporarily by wind mixing or baroclinic adjustment of the density field associated with an increase in the geostrophic transport of a current. Persistence of the indicators, however, is probably possible only with upwelling [21].

The vertical advection of denser waters to the surface leads to a change in the distribution of mass, and, as the upwelled water accumulates along the coast, a current is established that flows in the direction of the wind along the coast to the south [23, p. 501].

\section{OBJECTIVE}

The objective of the present study is to examine the effects of upwelling on a central California coastal region, to compare the observed data to that obtained earlier, and finally to compare the various individual parameters observed. Achievement of these objectives was thought to 

be best accomplished by a close examination of the region which includes the area between Monterey and San Francisco Bays. The region, still highly productive inshore, once supported a large fishing fleet, which moved to other areas when the sardines disappeared.

The constancy of climate in the area encourages population growth and tourism. The increased numbers of people represent an ever increasing demand on the coastal communities for waste disposal. The coastal communities of central California can be divided into two types: a highly industrial megalopolis to the north and a suburban and rural area to the south.

The area is affected by the flow of the largest river system in California, which empites into San Francisco Bay and is subsequently discharged into the sea. The region has been previously examined by Labyak [11] and Baker [1], whose data, especially Labyak's for May 1969, was hoped to be useful in establishing comparisons.

Comparisons were made between the physical and chemical variables observed during the cruise, which lasted from 29 April to 5 May 1970. The observed ranges for these parameters were large due in part to several significant plankton blooms which were observed. 



\section{OBSERVATIONAL PROCEDURES}

\section{A. STATION LOCATIONS}

Station data were collected during the period 29 April - 5 May 1970 aboard the USNS BARTLETT (T-AGOR-13). The area under investigation, the coastal region between Monterey Bay and San Francisco Bay, is presented in Figure 2 along with the locations of the eighty-five stations occupied. The position, the time, and the weather conditions at each station are presented in Table I. The stations in this coastal region were chosen to cover approximately the same areas and stations covered by Baker [1] and Labyak [11] in order to increase the data available for this important region. Station lines were occupied in alphabetical order starting with station A-1 in Monterey Bay and ending with station M-7 to the south of the entrance to San Francisco Bay. Stations within a given station line were occupied in numerical order. Station positions were determined by radar, loran, and visual means to within an accuracy of from 0.5 to 1.0 nmi.

\section{B. DATA GOLLECTION}

Three hydrographic casts were made at each station. On the first cast, the beam transmissometer and the sound velocity/temperature/depth probe (SV/T/D) were arranged to allow the beam transmissometer to pass through essentially undisturbed water (Figure 1). Variations of temperature, transmissivity, and sound velocity as functions of depth were observed on both the down and up portions of each cast. The readings recorded here, however, are from the down cast only, because both the probe and transmissometer were allowed to remain for some time at a given depth and allowed to equillibrate. 



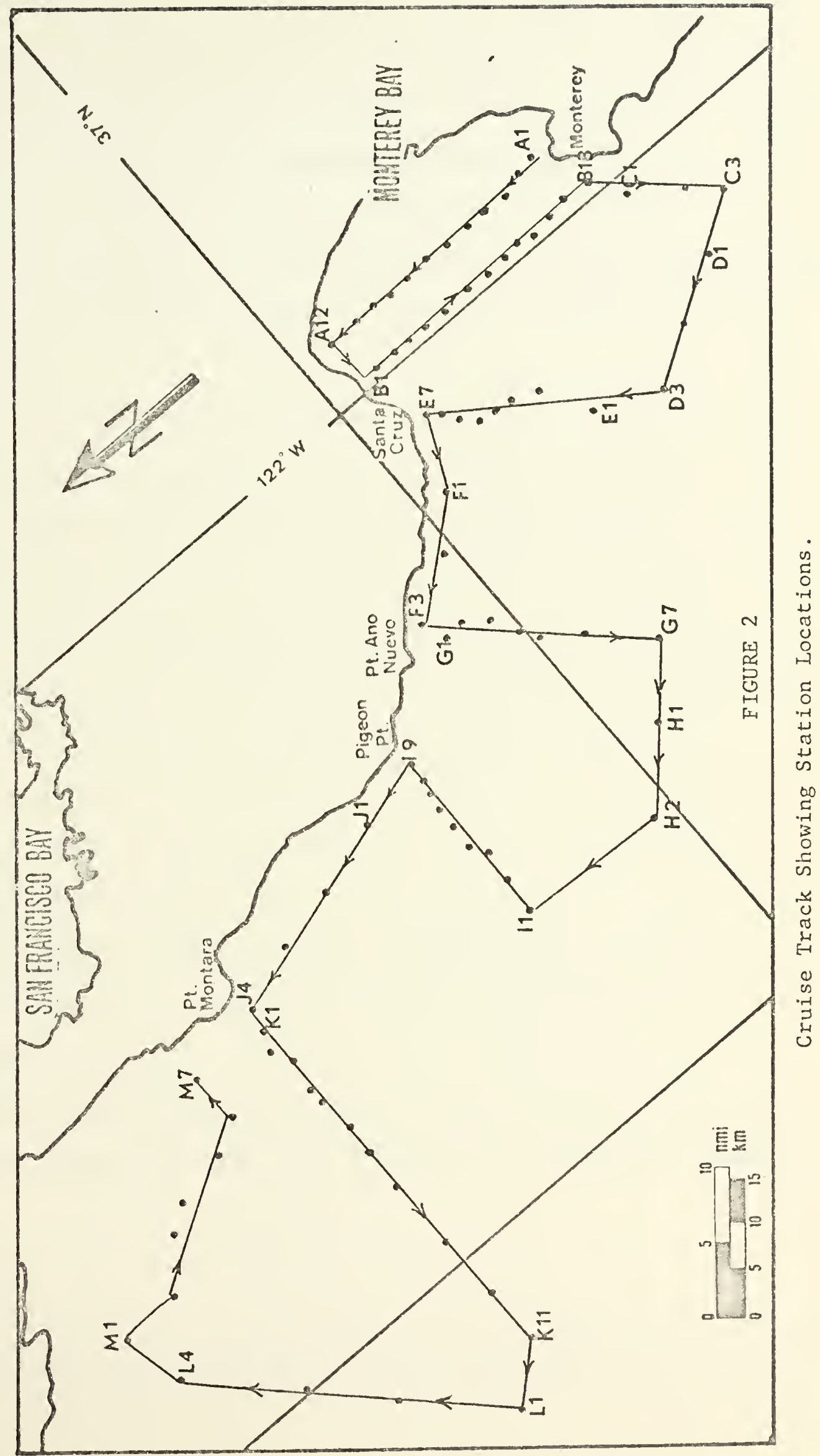



Continuous readings observed on the up cast provided insight into the structure of the water column, but the readings were consistently lower than for the down cast due to lack of time to reach equillibration and due to the passage of the instrument through disturbed water. The transmissivity record was examined to determine optimum depths for locations of sample bottles on the second cast. Expendable and mechanical BT's were taken at various stations to check the calibration of the SV/T/D probe.

On the second cast water samples were collected with Nansen bottles without reversing thermometers and were divided into five groups: $250 \mathrm{ml}$ for oxygen analysis, (2) $100 \mathrm{ml}$ for phosphate analysis, (3) 320 $\mathrm{ml}$ for salinity determination, (4) $120 \mathrm{ml}$ for particulate analysis, and

(5) the remainder for chlorophyll a determination. The oxygen and phosphate analyses were performed aboard the BARTLETT. The particulate samples were placed in $120 \mathrm{ml}$ polyethylene bottles to which $3 \mathrm{~m} 1$ of Lugol's iodine solution was added by means of an automatic syringe. 1 The samples for chlorophyll a determinations were filtered through a Whatman GF/C glass fiber filter on which a small amount of $\mathrm{MgCO}_{3}$ had been placed. The filter papers were folded in half with the filtrate on the inside to prevent loss, hermetically sealed in plastic bags, and immediately frozen.

The third cast was made with a bottom sampler [11] to collect near bottom water samples for particulate, phosphate, and salinity analyses.

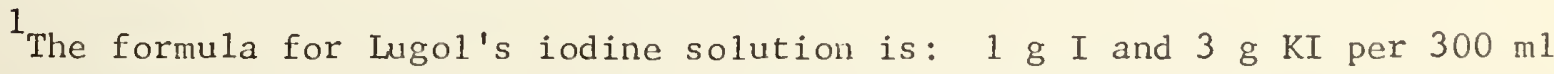
distilled water. The resulting solution is filtered through $0.22 \mu$ Millipore filters and stored in a dark bottle. 



\section{INSTRUMENTATION}

\section{Beam Transmissometer}

Throughout the cruise observations of light transmissivity were obtained by means of a Marine Advisors Model C-2 beam transmissometer (alpha-meter). This instrument is the same one used by Labyak [11] and Baker [1] and is similar to the one described by Yeske and Waer [26]. A tungsten lamp was used as the light source, and the optical pass-band was determined by a combination of Wratten 61 and Schott BG-18 filters which also eliminated wavelengths in the infrared during air calibration.

\section{Sound Velocity-Temperature-Depth Probe}

A Ramsey Engineering Company MK-1 Deep Sea sound velocity-temperaturedepth (SV/T/D) probe was used at practically every station during the cruise. The instrument is described by Labyak [11].

\section{Fluorometer}

A Turner Mode1 111 fluorometer was used in the analysis for chlorophyl1 a. The fluorometer was used with a blue Corning CS.5-60 primary and a red Corning CS.2-64 secondary filter.

\section{Particle Counter}

Analysis for particulate matter in the sea water samples was accomplished using a Mode1 $\mathrm{T}$ Coulter counter to size the particles electrically. The counter separates particle sizes into fourteen size ranges or channels. The data output is on paper tape and is presented in four different modes: differential population, cumulative population, differential volume, and cumulative volume.

To calibrate the counter $3.49 \mu$ polyvinyltoluene latex spheres were used. The calibration adjustment is set to give equal counts in two adjacent channels, so that the peak in the particle size distribution of the standard spheres occurs at the division between the two channels. 

The location of the peak of the calibration standard and the aperture size determine the range of sizes which can be counted. The aperture size is most important, as it determines an absolute upper bound of particle diameters. In practice the lower bound results from electrical noise. The overall effective range of the counter for a $100 \mu$ orifice, as it was used, was from $1.59 \mu$ to $32.0 \mu$, corresponding to channels 13 to 0 . Noise in channel 14, at the small size end of the range, prevented its use.

\section{A proportionality constant can be computed to convert directly}

from a number of counts observed for a specific size range or channel number to an actual volume of particles in cubic microns $\left(\mu^{3}\right)$, which were drawn through the aperture:

$$
K=V_{d} /\left(P_{d} \times \frac{\pi D^{3}}{6}\right)
$$

where:

$$
\begin{aligned}
\mathrm{k} & =\text { constant of proportionality } \\
\mathrm{V}_{\mathrm{d}} & =\text { differential volume }\left(\mathrm{u}^{3}\right) \\
\mathrm{P}_{\mathrm{d}} & =\text { differential population } \\
\mathrm{D} & =\text { equivalent spherical diameter for the channel }(\mu) .
\end{aligned}
$$

It is to be emphasized that the particulates suspended in the sea are not regularly shaped and that sizes obtained with the Coulter counter or any such counter at best furnish "signatures" which are representative of the approximate particle volumes. 



\section{DATA ANALYSIS}

\section{A. INTRODUCTION}

The distributions of temperature, phosphate, chlorophyll a, beam transmittance, oxygen, and suspended particulate matter,during upwelling off the California coast were studied in some detail. Of the observable oceanic parameters, temperature and salinity normally provide the best indication of upwelling in an area. Cold, saline, deep water which wells upward is casily detected. In the absence of either temperature or salinity data combinations of pairs of the above parameters, i.e., beam transmittance and particulate count, or oxygen and phosphate, may also be helpful in characterizing a water mass. Therefore to describe the region the observed data were plotted, and contours were drawn in vertical and horizontal sections for the six parameters listed above, using continuity of flow of the associated pairs of parameters as a check.

\section{B. DESCRIPTIVE TECHNIQUES}

\section{Horizonta 1 Contours}

Horizontal layers at $0,10,20,40$, and $75 \mathrm{~m}$ were considered. The first four depths were chosen to coincide with and to allow comparisons with Labyak's data. The fifth level was chosen as $75 \mathrm{~m}$ rather than Labyak's $61 \mathrm{~m}$ in order to arrive at a better picture of the deeper, near-bottom waters. The parameters temperature, phosphate, beam transmittance, oxygen, particulates, and chlorophyll a, will be presented in this order, and each will be examined from the surface to $75 \mathrm{~m}$.

The greatest horizontal gradients for all parameters occur at the surface. Predominant features occur in the surface layers at the southern end of Monterey Bay and off Point Pinos, in the northern end of the Bay 

near Santa Cruz, in an area approximately $10 \mathrm{~nm}$ off Point Montara parallel to the coast, and west of the entrance to San Francisco Bay (Figures 10, 15, 20, 25, 30, 35).

The surface temperature section (Figure 30) shows the characteristic packed isotherms which are indicative of upwelling. The greatest horizontal gradient for the entire cruise, $0.25^{\circ} \mathrm{C} / \mathrm{nmi}$, was observed off Pigeon Point on roughly the same line of bearing as station line I. As successive levels are examined, it is seen that temperature increases with increasing distance from the coast and decreases with increasing depth. A predominant feature of the shallow, northern, inshore portion of Monterey Bay, in the region of stations A-10 through A-12, is its essentially isothermal water. The shallow water - the stations are within the 30 meter contour - responds quickly to solar heating, but there is no evidence of replenishment at depth with colder waters. This fact has been explained by Bolin and Abbott [3] as follows: In Monterey Bay colder water is welled upward to the surface and, in certain places, previously upwelled water may remain in local areas close to shore as circular eddies on the surface, particularly at the northern and southern ends of the Bay, and under these conditions solar heating raises the temperature of the body.

Examination of the phosphate contours (Figures 25 to 29) shows that there was a general decrease of fertile waters in the seaward direction due to the strong coastal upwelling experienced in the inshore regions. Anomalies in distribution, or patchiness, are probably due to high productivity, which depletes the supplies of nutrients in the euphotic zone. Such patchiness is to be expected of a non-conservative element in sea water. Phosphates exhibited an increase with depth, but no noticeable, 

disproportionate increases were detected under areas of high productivity due to an increase of organic material which could be converted to phosphates through oxidization in situ of the detital material.

Beam transmittance contours for the layers 0 to $75 \mathrm{~m}$ (Figures 35 to 39) displayed the effects of coastal turbidity, runoff, and high productivity. Monterey Bay proved to be the most turbid region in the study area, which agrees with the observations made by Labyak during the same period. Values of light transmission were generally less than $30 \% / \mathrm{m}$ for most of the Bay stations between the surface and $20 \mathrm{~m}$, indicating the effects of the shallowness of inshore regions and of productivity. The 40 and $75 \mathrm{~m}$ contours showed that it is advection of water with high values of transmittance into the Bay at those depths, especially that water which travels over the Monterey Canyon where entrainment of sediments caused by the turbulent advection is not a factor, which contributes to the increased transmissivity of the waters.

Farther to the north, in the area around the entrance to San Francisco Bay, the effects of a flood tide and the resulting tidal currents on 1ight transmission may be seen on the surface chart near stations $M-2$ and $M-3$ to the west of the entrance to the Bay (Figure 35). According to the tidal current chart for San Francisco Bay, the current at a point 5 miles west of the entrance of the bay is to the east (into the bay) and has a value of 0.8 knot one hour after maximum flood; two hours after maximum flood the current direction and set are $090^{\circ}$ and 0.5 knot respectively; three hours after maximum flood the direction changes to east-southeast and is reduced to 0.2 knot.

Station M-2 was occupied from 2320 to 2340 on 4 May 1970; and station M-3 was occupied from 0045 to 0102 on 5 May. The flood tide for 

the Bay was a maximum at 2224 on 4 May; therefore, the tidal currents transport less turbid surface waters in toward the tidal prism, reducing the plume effect at the Bay entrance. It was expected that the waters in the vicinity of these stations (M-2 and M-3) would influence primarily the first few meters of the surface, because the Bay discharge is less dense, due to river outflow, and would spread out over the surface. The plots indicate this to be true, and show increased transmissivity at the 10 and $20 \mathrm{~m}$ leve $1 \mathrm{~s}$.

Transmissivity contours at $10,20,40$ and $75 \mathrm{~m}$ in the region between Point Montara and Pigeon Point show a tongue of upwelled water of high transmissivity (Figures 36 to 39 ). This water below one of the most productive areas in the study exhibits increased light transmission with depth and to seaward.

It was on the contour plots for oxygen (Figures 15 to 19) that the four distinct areas, namely the northern and southern ends of Monterey Bay, the region between Point Montara and Pigeon Point approximately ten kilometers offshore, and the area west of the entrance to San Francisco Bay, were most noticeable. The regions above are "anomalous" in that they show high saturated values of dissolved oxygen for a given salinity and temperature. The positions of these areas coincide well with regions having relatively warm surface temperatures, which indicates there is no impingement of upwelling on these surface layers. The result is a more stable stratum in which phytoplankton may achieve maximum exposure to light and accelerate photosynthesis into bloom conditions.

The surface regions around Point Ano Nuevo and on the axis of the Monterey Canyon approximately eight miles from shore provide examples of "good" agreement of temperature and oxygen, that is, low temperature and 

low oxygen. The stations off Point Ano Nuevo show for oxygen an increase, then the expected decrease with depth. The "anomalous" increase in dissolved oxygen at ten meters may be attributed to the mixing and entrainment of photosynthetically enriched water.

Although salinity data are not yet available from the April-May 1970 cruise, the ten year mean value of $33.50 \%$ [5] was assumed to hold for the entire region and the percentage saturation of oxygen for the waters in the four areas of special interest was computed. The maximum values observed were at stations $\mathrm{I}-5, \mathrm{~K}-2, \mathrm{~K}-3$ and $\mathrm{K}-4$; these values of dissolved oxygen, all above $10 \mathrm{ml} / 1$, gave corresponding saturation values between 173 and 179\%. At the northern end of Monterey Bay and in the Santa Cruz region a percent saturation of from 115 to $139 \%$ was calculated. The southern end of the Bay and the Point Pinos region exhibited values ranging from 118 to 154\%. Finally, in the region encompassing stations L-3 through M-2 to the west of the entrance of San Francisco Bay the percent saturation values were between 135 and $152 \%$. These may be contrasted with the value of saturation for the surface water off Point Ano Nuevo, which was at $81 \%$ of saturation.

The rather high concentrations for dissolved oxygen agree with concurrent, independent observations of oxygen made on CALCOFI cruises on 29 April and 8 May 1970. The levels of dissolved oxygen determined during the California Cooperative Oceanic Fisheries Investigations cruise are shown in Figure 3 alongside the circles which mark the CALCOFI station locations. The NPS stations closest to these are indicated by crosses, and the values of dissolved oxygen are shown within parenthesis.

Examination of the tabulated oxygen data reveals a subsurface oxygen maximum for $56 \%$ of the stations. The existence of the maximum 



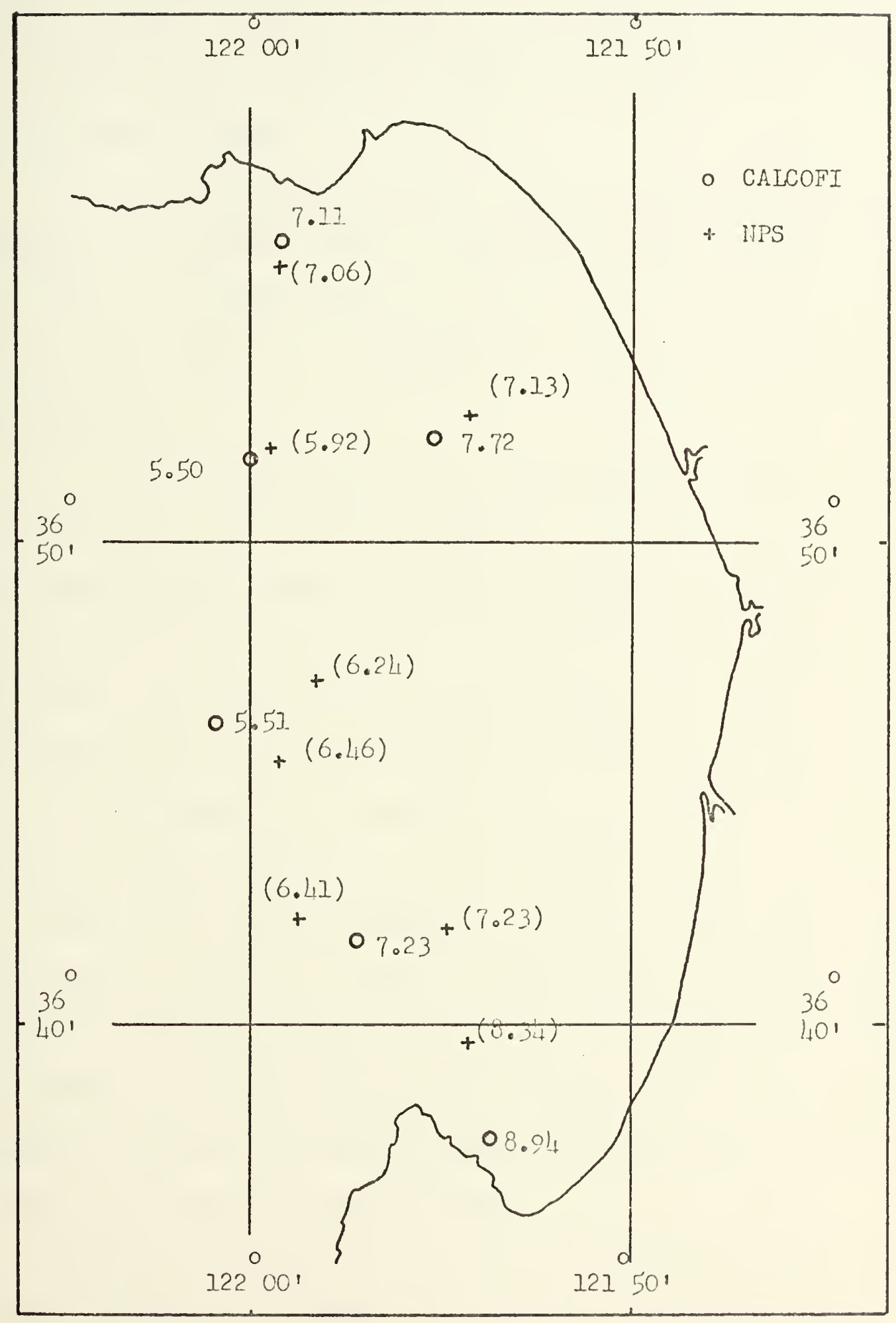

FIGURE 3. Location of CALCOFI and NPS Stations in Monterey Bay. 

is in agreement with the findings of Pytkowicz [16] and of Stefansson and Richards [22]. However it is evident, even though no sigma-t data is yet available, that the origin of this oxygen maximum, especially in the inshore regions, is due to a higher rate of escape than productivity in the surface layers.

When the horizontal contours of total particulate count per $2 \mathrm{~m} 1$ sample for the present cruise are compared to those of Labyak [11] for May 1969, it is apparent that not only were the maximum counts greater for the 1970 cruise, but also the areas of observed maximum counts were more numerous.

The present contours suggest that there are regions of high counts. The positions of four of these correspond to the regions of high chlorophyll and dissolved oxygen. The surface layer at the southern end of Monterey Bay exhibits lower total counts than any of the other four locations, but a comparison of the same regions at a depth of $10 \mathrm{~m}$ shows an increase with depth for the Bay station while for the others, counts decreased with depth. For the fifth area, the surface waters in the vicinity of Point Ano Nuevo, there was a high particulate count, which is assumed to be localized upwelling impinging on the surface. Also, low temperatures, oxygen poor waters and high values of chlorophyll were present near Point Ano Nuevo. The area does not appear to have been a previously localized photosynthetically productive area which had been overturned because of the high values of phosphate which would have had to have been depleted by photosynthesis .

Labyak [11] observed two areas of particulate maxima: a) a relatively large region between the entrance to San Francisco Bay and Pigeon Point, the greatest seaward extent of which was approximately 

$25 \mathrm{nmi}$, and b) a localized offshore area in the vicinity of Point Ano Nuevo of approximate dimensions $5 \times 10 \mathrm{nmi}$. The observations he conducted in the Monterey Bay region indicated low particle counts. Since the counts observed were roughly two orders of magnitude lower than those obtained in the present study, a plausible explanation was sought. A comparison was made of the areas of particulate maxima off Point Montara which occurred in 1969 as well as 1970. Because of the large difference between Labyak's data and that for Apri1-May 1970, it was decided to reanalyze some of the particulate samples taken on Labyak's cruise with the Mode1 $\mathrm{T}$ Coulter counter to establish a better comparison between the two sets of data.

Selected samples from the observed maxima at Labyak's stations $\mathrm{N}-8, \mathrm{~N}-9$, and $\mathrm{N}-10$, where counts of approximately 5000 were reported, were reanalyzed. The samples had been sealed and stored for more than a year and a large concentration of particles was observed in each analysis as follows: optically, physically, in the number of blockages that resulted, and electronically, in the high cumulative count which ranged from $83-114 \times 10^{3}$.

If the number of particles is assumed to have remained constant in storage, then a comparison of the former and present observations can be made. An examination of the Coulter counter print-out reveals that a cumulative count of 5000 corresponds to channe 1 number 6 , and an equivalent spherical diameter of $8.0 \mu$. This seems to indicate that Labyak was probably counting only those particles greater in size than approximately $8.0 \mu$, and the contours for the particulate data obtained on the May 1969 cruise should be used only in a relative sense.

Surface concentrations of chlorophyll a were quite variable throughout the region, but the highest were to be found near Point Pinos, 

off Santa Cruz, off Point Montara, and to the west of the entrance to San Francisco Bay (Figure 10). Maxima were, in general, confined to the first $10 \mathrm{~m}$ or so with unusually high values of chlorophyll a observed in a few instances at greater depths. This may be explained in terms of a cessation of upwelling or a change in the sinking rate of the phytoplankton. With a previous cessation or slackening of vertical advection, dense upwelled water sinks, and the entrained phytoplankton also sink. This process may well have occurred near station $\mathrm{K}-5$ where an isolated pocket having a high chlorophyll a content exists at $55 \mathrm{~m}$. At the same depth are to be found high particle count and low light transmission (Figures 70, 72, and 75). If the process cannot be explained by a slackening of upwelling, it is perhaps best explained by a mechanism proposed by Margalef, i.e., changes in the sinking rate of phytoplankton produce concentrations and rarefactions of populations at different levels [13].

\section{Vertical Contours}

Vertical sections were drawn for station lines A, B, E, G, I, K, and $M$ (Figures 40 to 81 ). Contours were drawn to the data at each station in a given line from the surface to $100 \mathrm{~m}$, except where interrupted by the bottom. Each of these station lines was contoured for the following six parameters: chlorophyll, oxygen, particulates, phosphates, temperature, and light (beam) transmittance.

The influence of the Monterey Submarine Canyon on the parameters observed in station lines $A$ and $B$ in Monterey Bay can be seen in the contours. Bolin and Abbott [3] indicated that the Canyon channels the flow of upwelling water into the Bay, and that deep water follows the axis of this topographic feature and then flows out of the Canyon into the shallow 

regions to the north and south. The 40 and $75 \mathrm{~m}$ isopleths of transmittance, temperature, and oxygen (Figures 41, 44, 45, 46, 50, and 51) show this effect in the Canyon and tend to confirm their suggestion. The first $20 \mathrm{~m}$ at the northern and southern ends of the Bay are oxygenrich, nutrient-poor, highly productive, turbid, and possess high particle counts (Figures 40 to 51,1 ess 44 and 50 ). The northern end of the Bay is essentially isothermal (Figures 44 and 50 ), a feature which was explained [3] as due to a circular eddy of previously upwelled water which is heated by solar radiation. The effects of upwelling can be seen more easily for station line $\mathrm{E}$ than for the Bay stations. There, sharply rising isopleths of transmissivity, phosphate, temperature, and oxygen are found (Figures 53, 55, 56 and 57). Productivity in the inshore regions is evident in the first 10 or $20 \mathrm{~m}$ in the area from E-7 to E-5, especially the first few meters around station E-6 (Figures 52, 53, 54, 55 and 57). The $3 \mathrm{~m}$ depth, in particular, has associated with it one of the largest values of chlorophyl1 a observed on the cruise, $11.98 \mathrm{gm} / \mathrm{m}^{3}$, high particle count, high oxygen content, low transmissivity, and relatively high temperatures. A temperature inversion can be seen at station E-4 at a depth of $3 \mathrm{~m}$. A similar occurrence has been noted during upwelling off the Oregon coast by Pak, Beardsley, and Smith [14].

The profile of chlorophyll at station line $G$ has an unusual feature in that for the entire length of the line, approximately 14 miles, the concentration of chlorophyll a is above $2 \mathrm{mg} / \mathrm{m}^{3}$ in the first $20 \mathrm{~m}$, and, in a great portion of the area between $20 \mathrm{~m}$ and the surface, the concentration exceeds $4 \mathrm{mg} / \mathrm{m}^{3}$ (Figure 58). The contours show upwelled water impinging on the surface layer in the vicinity of station G-2 and what appears to be a sinking of surface water at stations G-4 and G-5 (Figures 59 to 63). 

Farther up the coast a great difference is found between the chlorophyll a content of the water from one end of station line I to the other (Figure 64) and is more characteristic of upwelling, in that the area of high productivity is near shore, and that there is a noticeable decrease of chlorophyll a seaward. Thus, almost uniformly low values of $0.5 \mathrm{mg} / \mathrm{m}^{3}$ or less are found offshore. The high particle count observed (Figure 66) at station I-4 at $60 \mathrm{~m}$ is in conflict with other observed data. The high count may possibly be due to electrical interference. The high particulate counts, high oxygen, low transmissivity, low phosphate, and high chlorophyll a content in the warm, stable, surface layers indicate an extremely productive area between stations I-4 and I-9 (Figures 64 to 69). A similar situation is found between stations $\mathrm{J}-4$ and $\mathrm{K}-5$ (Figures 70 to 75 ).

The highest values of dissolved oxygen for the entire cruise were at the surface of the productive area off Point Montara. There, between 5 and $15 \mathrm{~m}$ is found, the greatest transmission gradient seen on the cruise (Figures 71 and 75). At station K-5, high particulate maximum, high chlorophyll, and low beam transmissivity are found at $55 \mathrm{~m}$. These characteristics probably result from the sinking of phytoplankton.

of all the station lines, $M$ is the shallowest and probably most complicated in terms of both upwelling and tidal effects. As an aid to the interpretation of Figures 76 to 81 a time axis should be imagined as proceeding from left to right with slack water at or slightly after station $\mathrm{M}-3$. The tide was at maximum flood at the time station M-1 was occupied. The tidal currents in the region are, according to the tidal current charts for San Francisco Bay, directed into the Bay until three hours after maximum flood at decreasing velocities until a slack is observed. Tidal currents advect the colder, oxygen poor, chlorophyll 

deficient, nutrient-rich, ocean waters, which have higher light transmission and lower particle counts, in toward the Bay, drastically altering the distribution of parameters in the top $20 \mathrm{~m}$.

The effect of the horizontal advection of water through the dischange plume for San Francisco Bay is exhibited as lower values of temperature, oxygen, chlorophyll $\underline{a}$, and particulate count, and a general weakening of the surface layer gradient. At a time slightly after station M-3 was occupied a slackening and reversal of the tidal current occurred producing an increase in the horizontal gradient for the above parameters. The converse is true for light transmissivity and phosphate.

\section{Graphica1 Comparisons}

To establish logical. comparisons between the data observed on the May 1970 cruise and that obtained from other sources, the cruise data were presented using the same display methods used previously for the same region. The remainder of the data are presented in simple scatter diagrams to provide comparative relationships between pairs of parameters. While working with the Coulter counter, Bader [2] noticed that many natural collections of small particles, for example, suspended mineral and organic matter in sea water, have hyperbolic distributions. While observing the particle distribution in sea water samples from Little Bahama Bank, Bader found that if a log-log plot of equivalent spherical diameter in $\mu$ versus cumulative particle count is constructed, the results are linear with slopes of $0.88-1.45$ counts / $/$. For comparison with the present data a plot was constructed for the cleanest water observed on the cruise, that at station I-1 at a depth of $100 \mathrm{~m}$ (Figure 4), and the slope was calculated to be 0.82 counts $/ \mu$. Bader also observed the influence of slope on the shape of the plot, that 



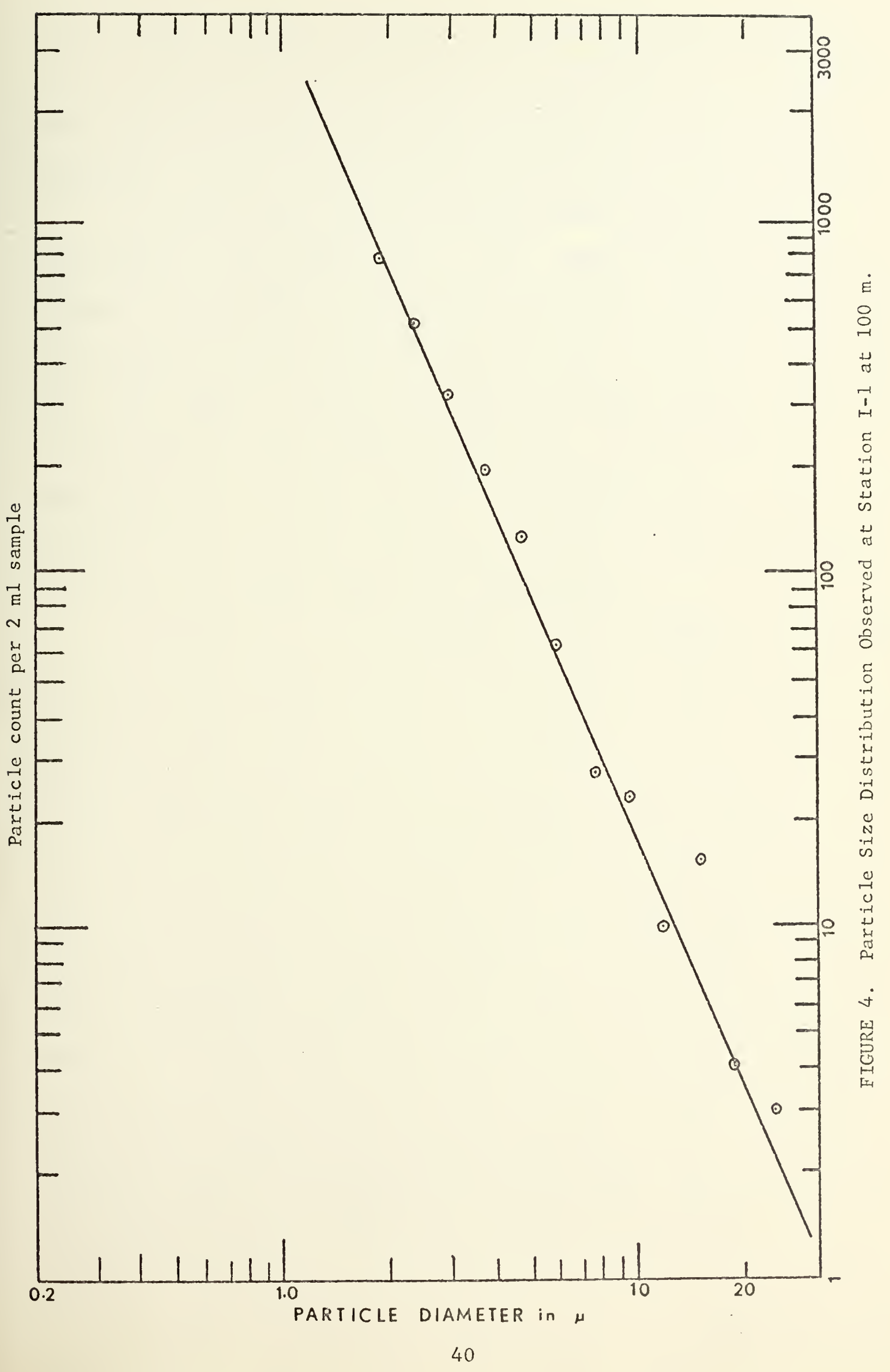



is, the larger the slope the greater the influence of small particles. Natural truncation occurs for large particle diameters due to a settling which takes place despite stirring, thus causing a change in slope and producing a distinct bend at a particular equivalent spherical diameter.

To examine this natural truncation plots similar to Figure 4 were constructed for depths from $0-100 \mathrm{~m}$. Station A-6 was chosen as typically representative of the Monterey Bay region. Examination of the plot (Figure 5) reveals an abrupt change in slope and a dip at a particular size. This seems to indicate the presence of larger amounts of particles of this size than would normally be observed. The peak occurs at approximately $15 \mu$, which is within the nannoplankton range. It is assumed, therefore, that the peak which is evident in the surface layers only is due to an abrupt increase in phytoplankters.

Chlorophyl1 a was plotted against oxygen in Figure 6. An initial plot of selected stations showed that there was no correlation in the scatter of points from the plotted values at each station: values of high chlorophyll a vere observed at both low and high values of dissolved oxygen. Some of the high values of chlorophy11 a corresponding to low oxygen may be explained by the presence of detritic pigments and/or by inactivation of chlorophy11 a as phaeophytin [13]. One hundred percent saturation of dissolved oxygen is assumed to occur at $6.0 \mathrm{~m} 1 / 1$ - a value which is approximately correct for the region considered. All values in excess of this were plotted, but no apparent relationship was revealed between $\mathrm{O}_{2}$ and chlorophy 11 a. More than $70 \%$ of the values greater than $6.0 \mathrm{ml} / 1$ were associated with chlorophyl1 a concentrations of $2.0 \mathrm{mg} / \mathrm{m}^{3}$. of the low values of chlorophyl1 a above saturation, $80 \%$ were associated with offshore stations removed from the effects of upwelling. It is 



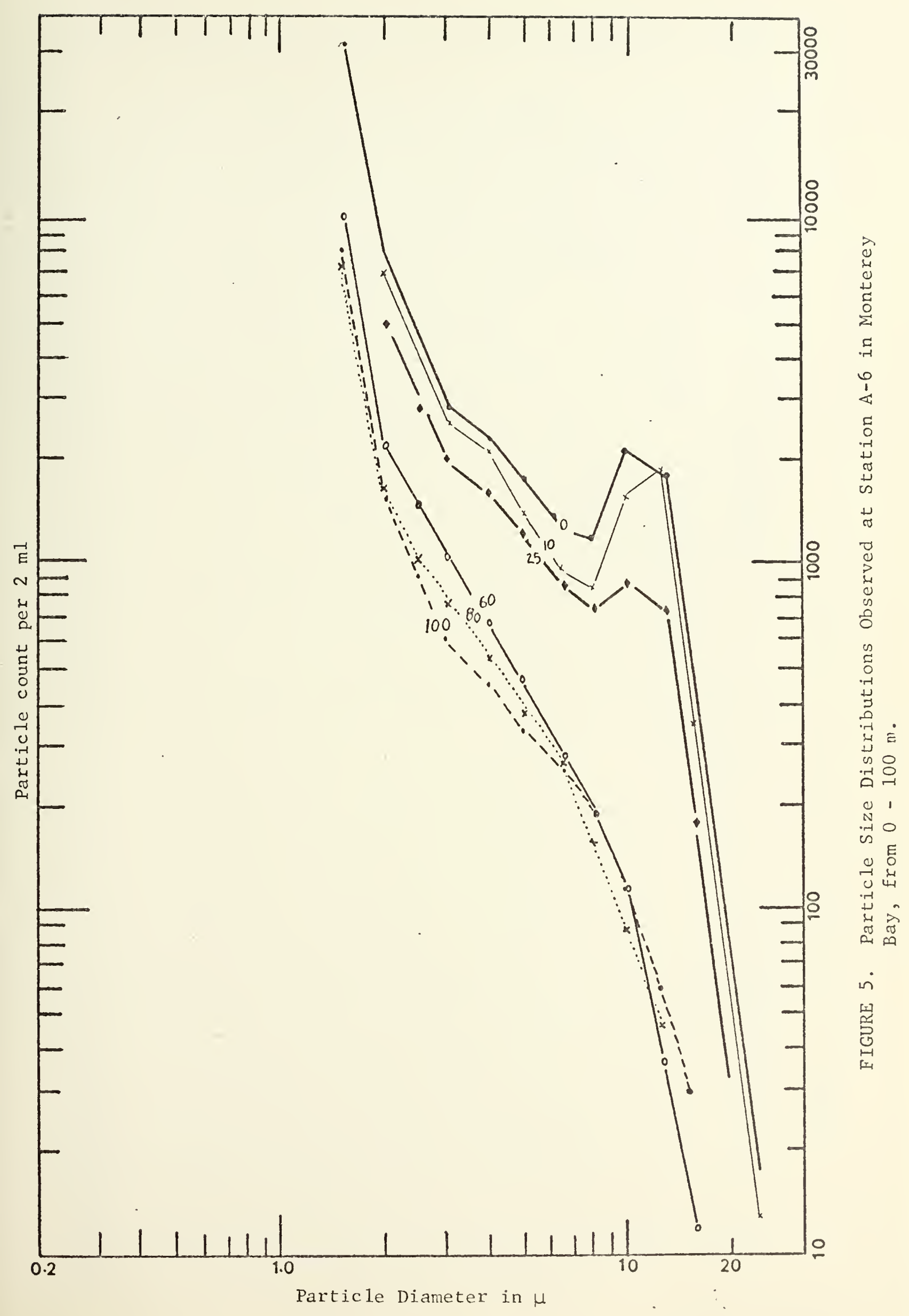





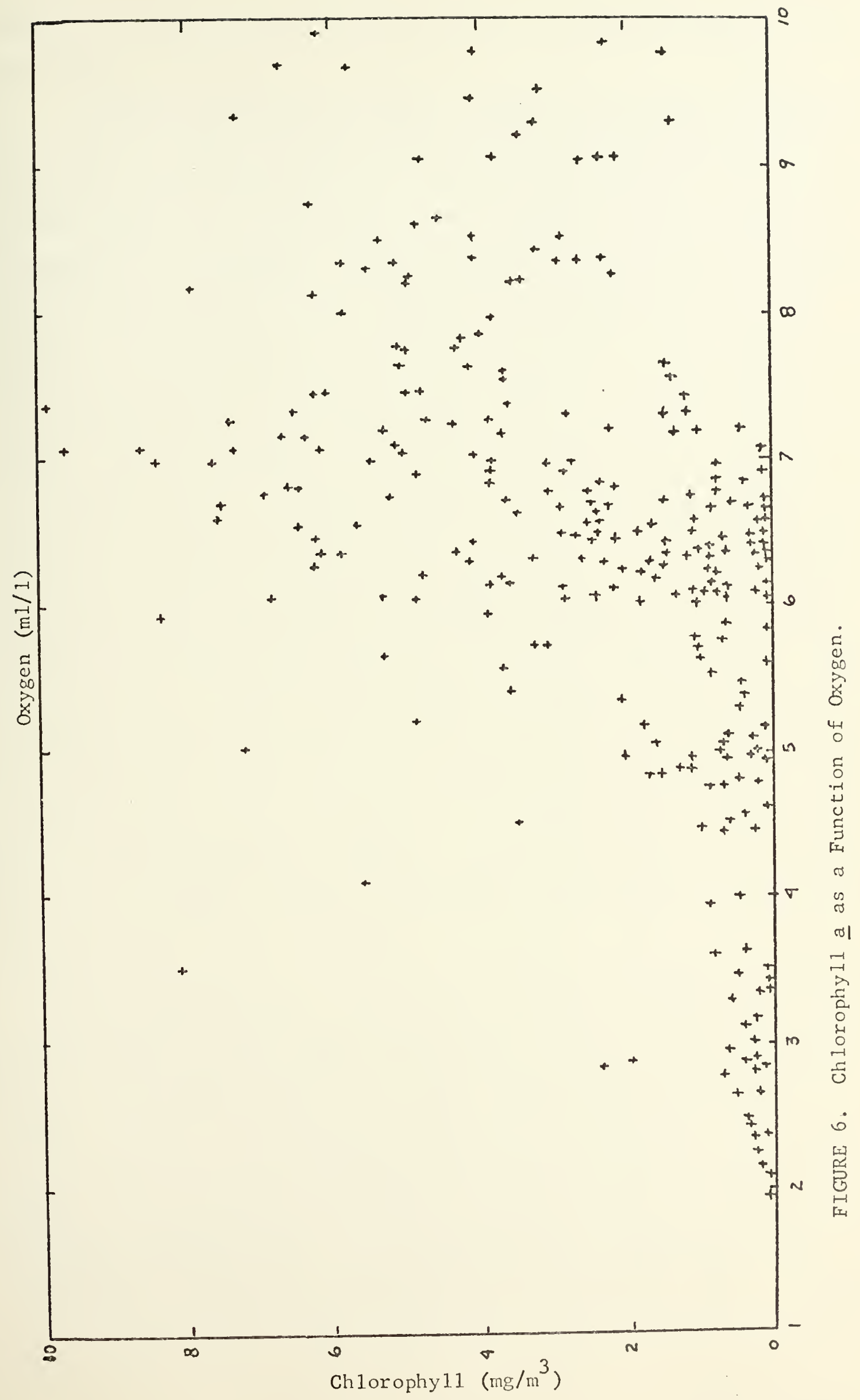



assumed that these values are due to wind mixing which homogenized the water mass.

It has been shown above that in general the regions of high total particulate count were areas of low light transmissivity. Therefore, a scatter diagram was constructed to see if obvious correlation did exist between the two parameters. Values of beam transmittance were plotted against total counts per $2 \mathrm{ml}$ sample for all depths for each of the stations in Monterey Bay as we 11 as for selected stations throughout the entire cruise region, and a fair linear correlation was exhibited between the two. The plot (Figure 7) shows that in general low particle counts accompany high values of beam transmission and conversely, high particle counts are associated with low beam transmission. A few extremely high counts were noted in association with high transmissivity, but it is believed that these values possibly may be due to counting error. If these values are included in the range of counts for a given value of beam transmission then a spread of approximately 35,000 counts occurs at an arbitrary value of transmissivity. A similar range of values exists for low beam transmission. However, it is to be expected that the higher the count, the lower the beam transmission, especially where high counts are concerned.

Beam transmittance was also plotted against chlorophyll a for stations A-1 through E-5. This covered the Monterey Bay area and the southern portion of the study region, and it was hoped that the more than 200 points would show relationships between the two parameters. Figure 8 depicts a rather limited relationship between the two and shows that high light transmissivity is not associated with high concentrations of chlorophyll a. Indeed the chlorophyll a concentration appears to determine the upper limit of beam transmission. The fact that there is no 



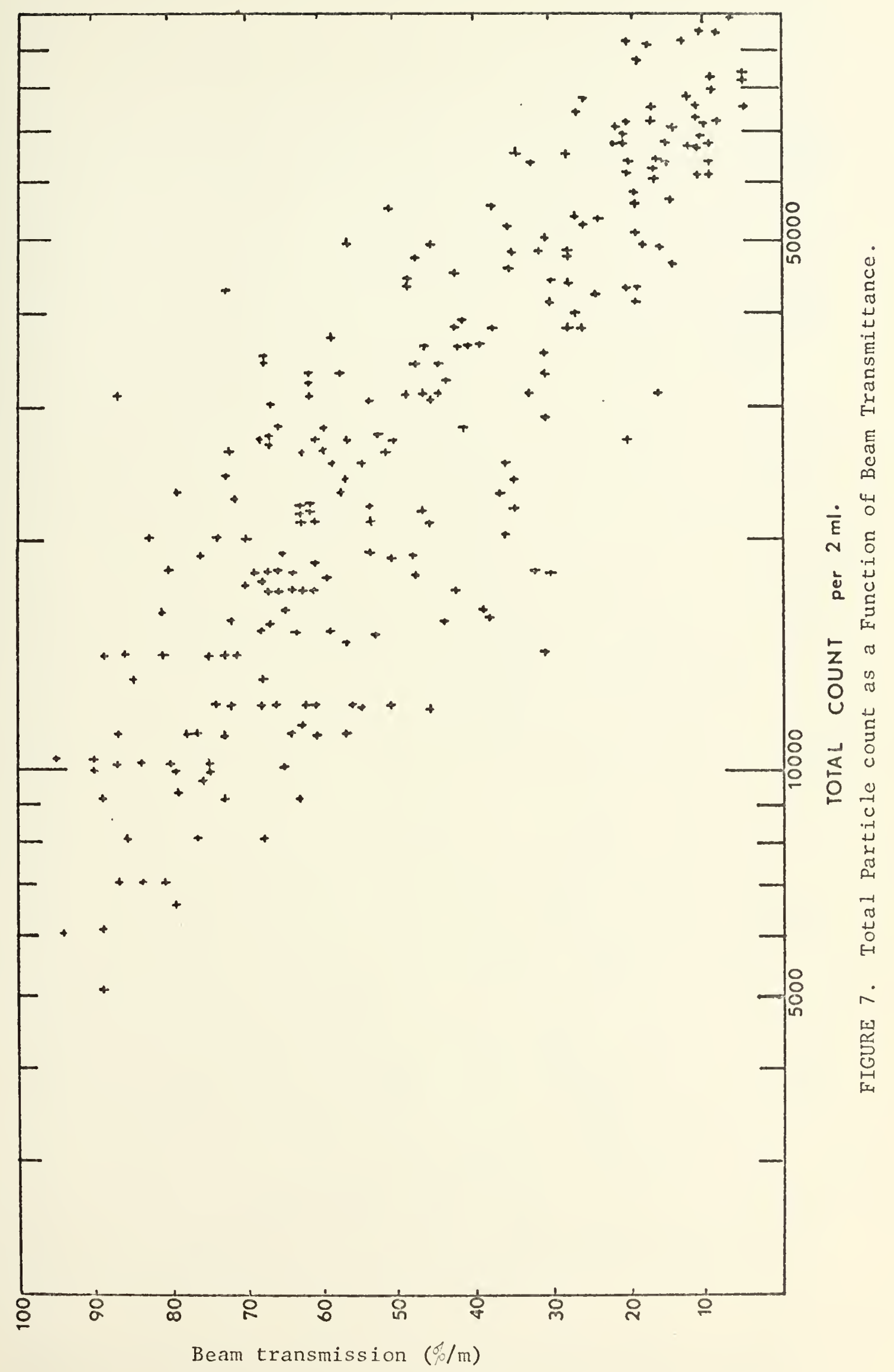





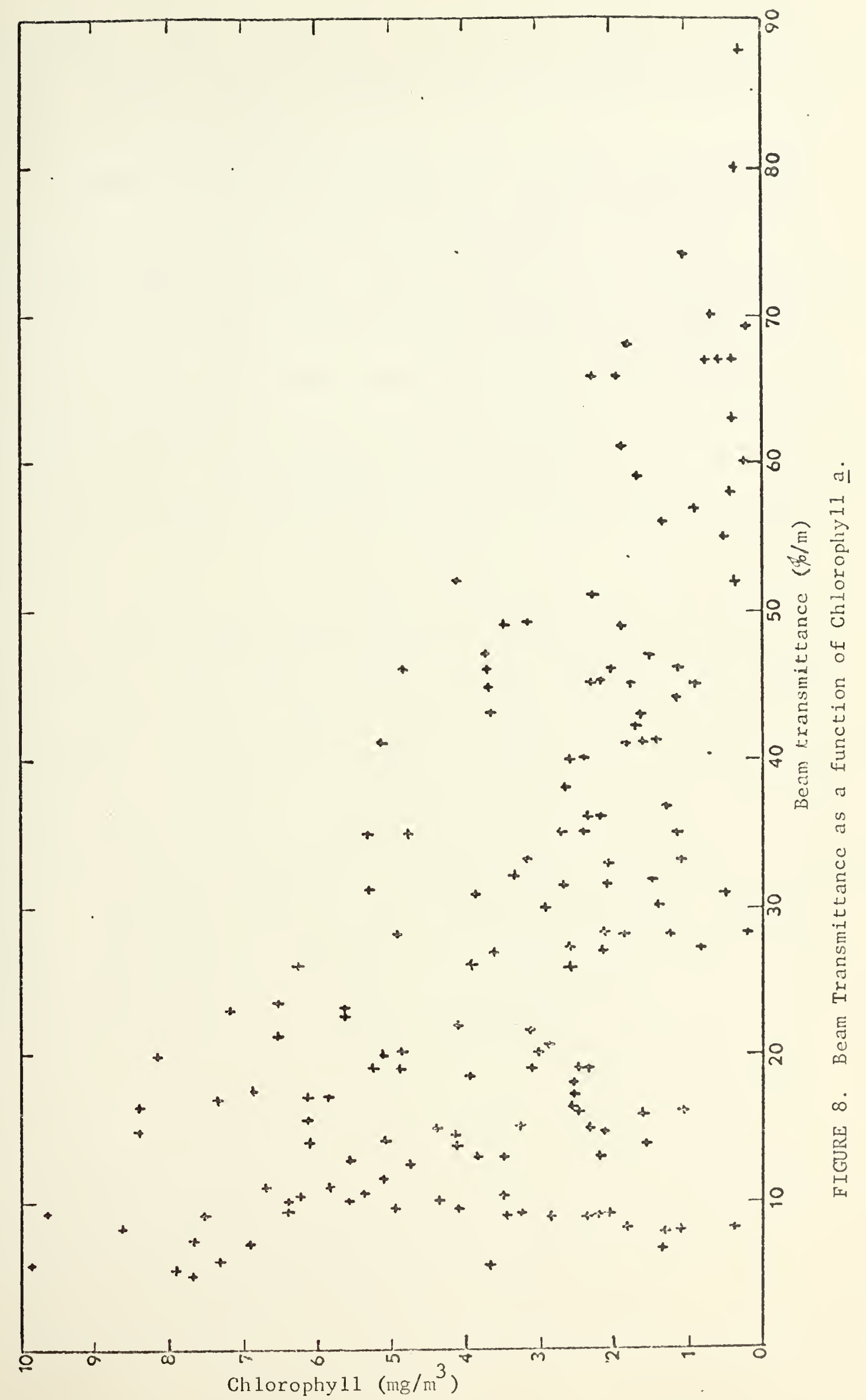



lower limit of light transmission for a given chlorophyl1 a concentration indicates that other factors - such as dissolved organic material - also play a role.

Pytkowicz [16] observed relationships between phosphate and oxygen from the surface to $1000 \mathrm{~m}$ off Oregon before upwelling, at the approximate onset of upwelling, and after upwelling had been established. He assumed that if water was affected by biochemical reactions only, the slope was fixed, and if water masses characterized by differing oxygen phosphate relations were present in varying amounts, then the slope of the linear line would change depending on the proportions of each. Varying slopes were recorded for each of the periods examined off the Oregon coast.

To investigate the possibility of the existence of such a relationship, a plot was constructed for three stations in an inshore region, name $1 \mathrm{y} \mathrm{J}-1, \mathrm{~J}-2$, and $\mathrm{K}-1$, and for three stations offshore, L-1, K-10, and I-1. The results are shown in Figure 9. The inshore stations exhibited higher amounts of phosphate for a concentration of dissolved oxygen which shows the effect of upwelling. The offshore stations showed greater variability especially in the surface layers due to depletion without replenishment. Pytkowicz's best approximation to his data for the upwelling period is presented as a stippled line. 



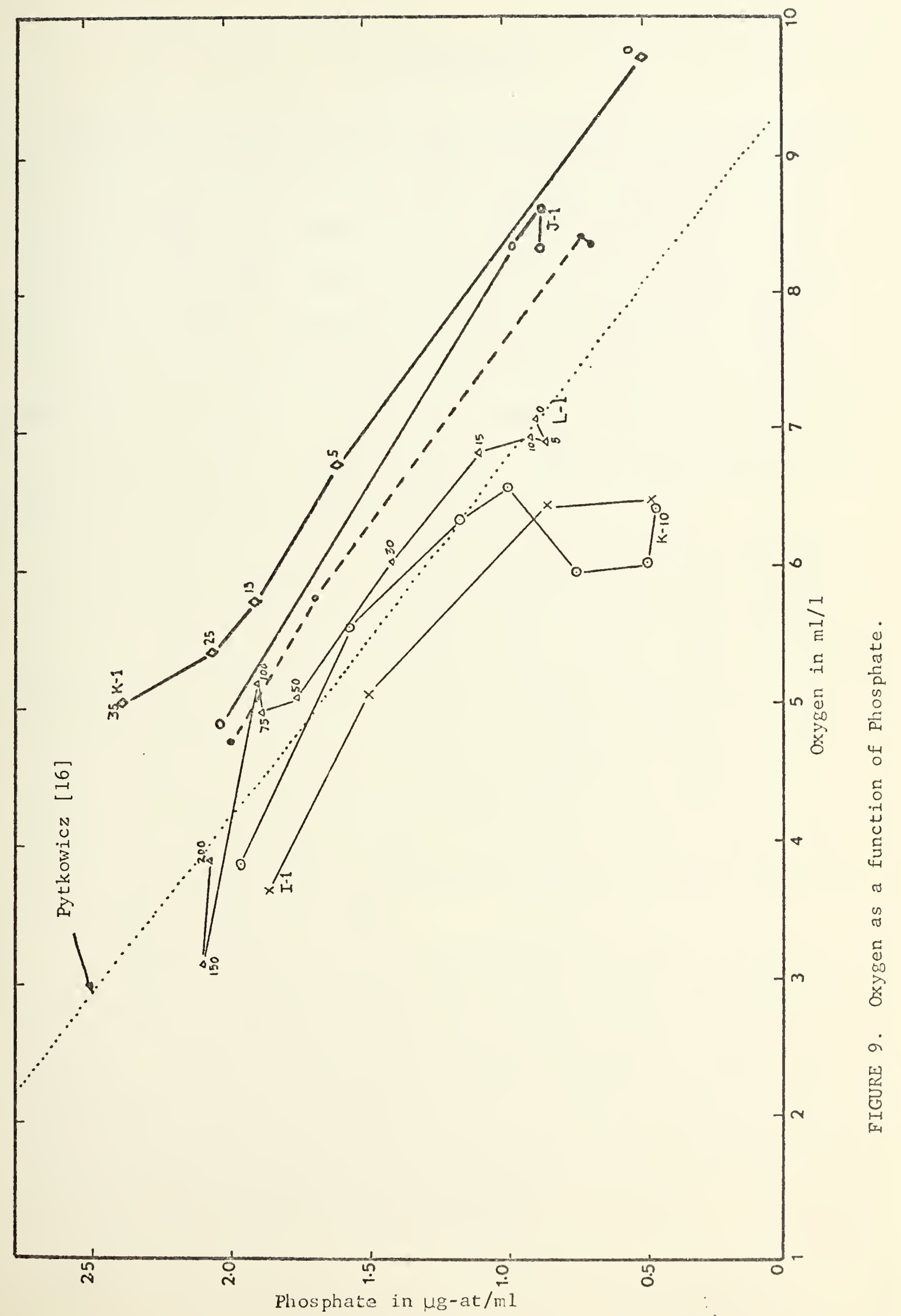





\section{CONCLUS IONS}

Observations off the central coast of California have been conducted on a large scale by California Cooperative Oceanic Fisheries Investigations (CALCOFI) and by Hopkins Marine Station. This present study represents a fine scale survey of the central California region during an upwelling season. The analysis of data was approached in a quasisynoptic manner, due to the spatial and temporal changes that took place during the observations. However, this method provided a broad subjective aid in understanding the upwelling process. From the data and the various modes of presentation it was concluded that:

(1) The region covered in the May 1970 cruise appears to be separated into four distinct regions: the southern end of Monterey Bay near Point Pinos, the northern end of the Bay near Santa Cruz, the region off Point Montara, and the area west of the entrance of San Francisco Bay. All stations within these regions exhibited high oxygen, high particulate count, low beam transmissivity, and high chlorophyll a. This is in contrast to the two productive regions found on the cruise of May 1969: off Point Ano Nuevo and an area the extent of which is larger than any of the regions in the recent cruise.

(2) Upwelling appeared to be stronger in the May 1970 cruise, which can be judged by comparing the surface isotherms decreasing a djacent to the coast. Labyak's 1969 data show isotherms decreasing seaward from $12^{\circ} \mathrm{C}$ along the coast to approximate $1 \mathrm{y} 10.5^{\circ} \mathrm{C}$ and then another increase. The most recent data for the upwelling season show low temperatures along the coast as low as $9.5^{\circ} \mathrm{C}$ increasing seaward. 

(3) A fair relationship exists between particle count and beam transmission. The particle counts observed in the analysis of $2 \mathrm{~m} 1$ samples ranged from a total count of approximately 5000 for the cleanest water to in excess of 200,000 for very turbid water.

(4) The linear relationship that was observed by Bader and Gordon $[2,8]$ for particle distribution in sea water can be distorted in the nannoplankton range by productivity in the upper $10 \mathrm{~m}$ or so.

(5) A subsurface oxygen maximum exists for more than half of the stations, which is probably due to a greater escape than productive rate of dissolved oxygen.

(6) The spread of sizes of particles counted was from $1.59 \mu$ to $32.0 \mu$.

(7) Unlike the results for saturation of oxygen (60-70\%) observed by Park, Pattullo and Wyatt [15] for upwelling waters off the Oregon coast, most of the surface waters appear to be $100 \%$ saturated. The four productive areas 1 isted in (1) above are super-saturated.

(8) Tidal currents in the vicinity of the entrance to San Francisco Bay affect the distribution of the parameters observed in the study, especially in the upper $15 \mathrm{~m}$.

(9) The warm surface layers contain high oxygen, high chlorophyll $\underline{\text { a }}$, and low nutrients, which indicate high productivity. There are also associated with these areas high particle counts and low transmissivity. The warm stable layers allow phytoplankton maximum exposure to light, and with strong thermal gradients below these layers appear also strong gradients for particles and for transmissivity. This is not the rule for all productive areas, because the profile of total Coulter count shows a tongue of water which exhibits high counts extending through the area of sharpest thermal gradient toward the bottom for station line A. 



\section{SUGGESTIONS FOR FUTURE RESEARCH}

There is a distinct lack of data, both raw and processed, for the region described in the study. Still more data are needed to fill this void. The following recommendations are made:

The fluorometric analysis for chlorophyll should be broadened to include a determination of phaeophytin. This would enable high pigment to ox ygen ratios to be explained in terms of an inactivation of the chlorophyll a as phaeophytin. Weekly analyses of chlorophyll a could be run with a continuous reading fluorometer for the Monterey Bay region. These determinations could be made to coincide with spectrophotometric analyses of a larger area from an aircraft. Since an NPS aircraft is already modified for photography, slight additional modifications would allow a rapid determination of surface productivity after an overflight of a surface ship for calibration. In addition to a continuous fluorometric analysis, plankton tows should be obtained in areas of high productivity to identify which species lead to the high observed concentrations .

Since diurnal variations have been observed for both chlorophyll a and for phosphate, hourly observations should be made for a 24 hour period at an anchor station to observe possible variations of these parameters in Monterey Bay.

A more complete study of the nutrients of the area could determine the concentrations of silicates, phosphates, and nitrates, and the effect of each on productivity in the region.

The sigma-t profile for the area, especially during upwelling, should be studied to determine the effects of vertical advection on the water 

column and to investigate offshore sinking of more dense water along isentropic surfaces. The sigma-t data should then be examined to see if possible relationships exist with oxygen, both below the surface layer and in regions of particulate maxima. Additional samples should be taken from areas of past particulate maxima to observe light scattering, and possible relationships between scattering and particle size distribution should be investigated.

Finally, cumulative volumes of particulates should be compared with the beam attenuation coefficient to see if possibly a better relation cannot be obtained than that between beam transmission and total count shown in Figure 7 . 



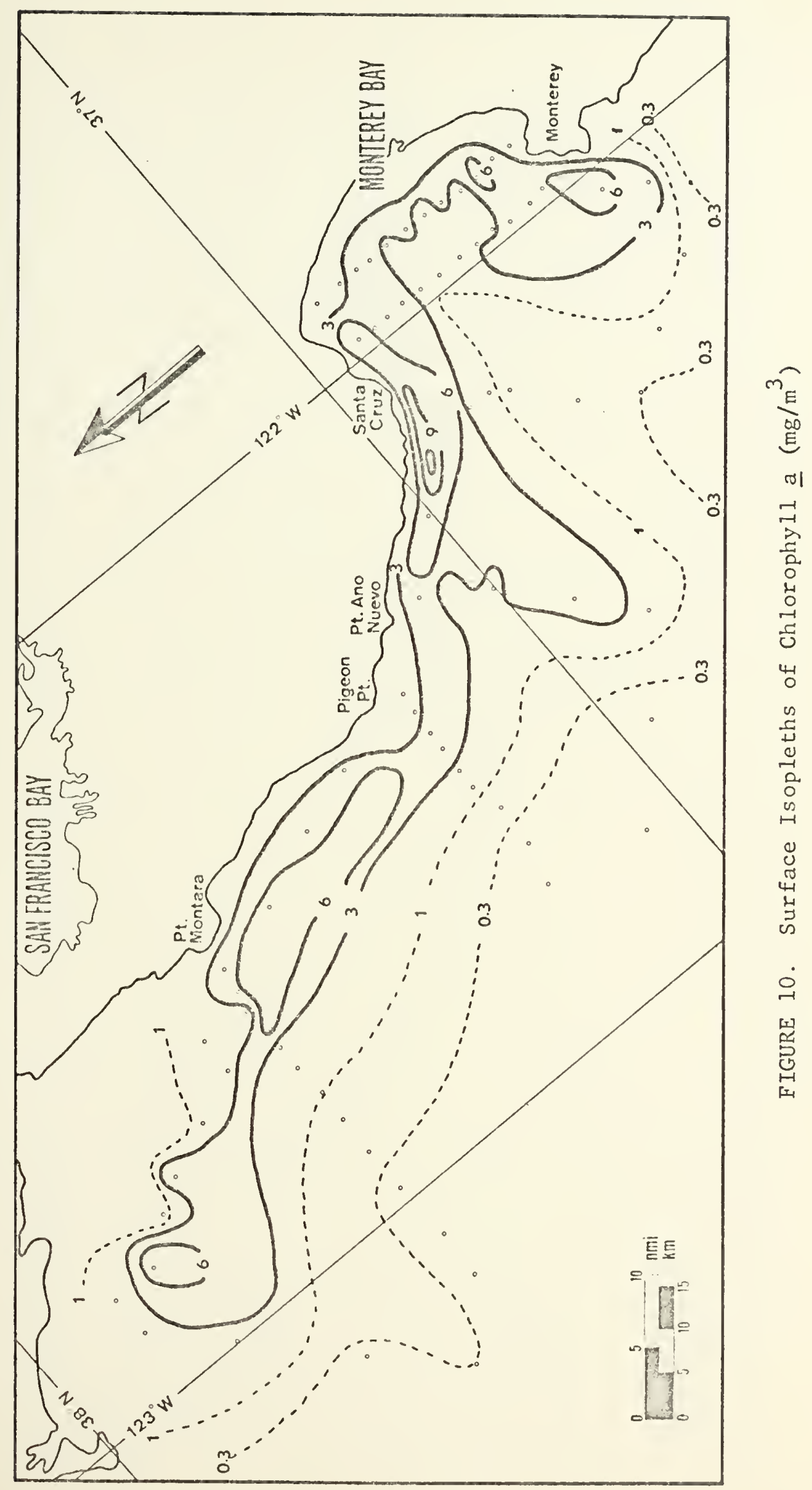





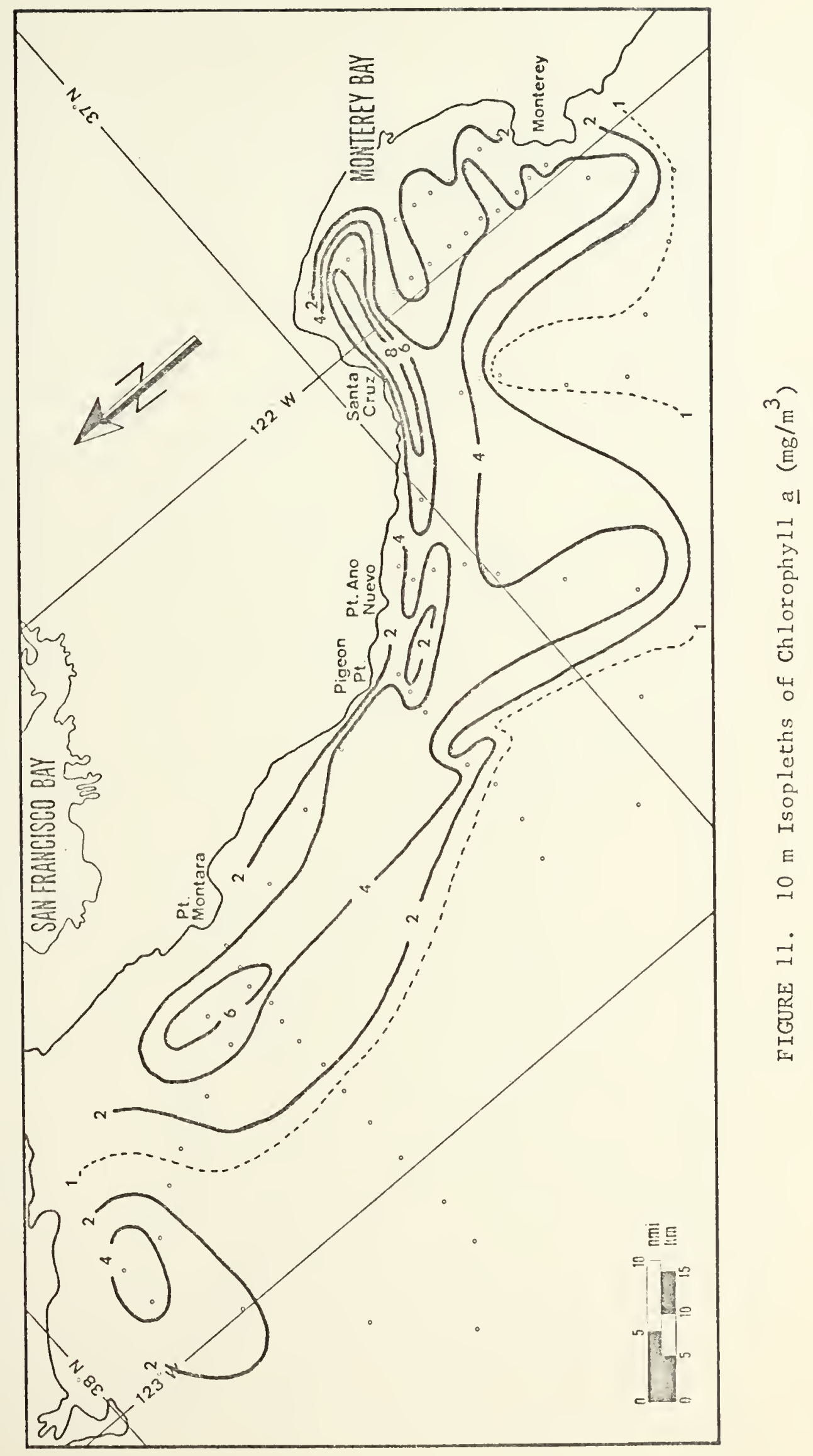





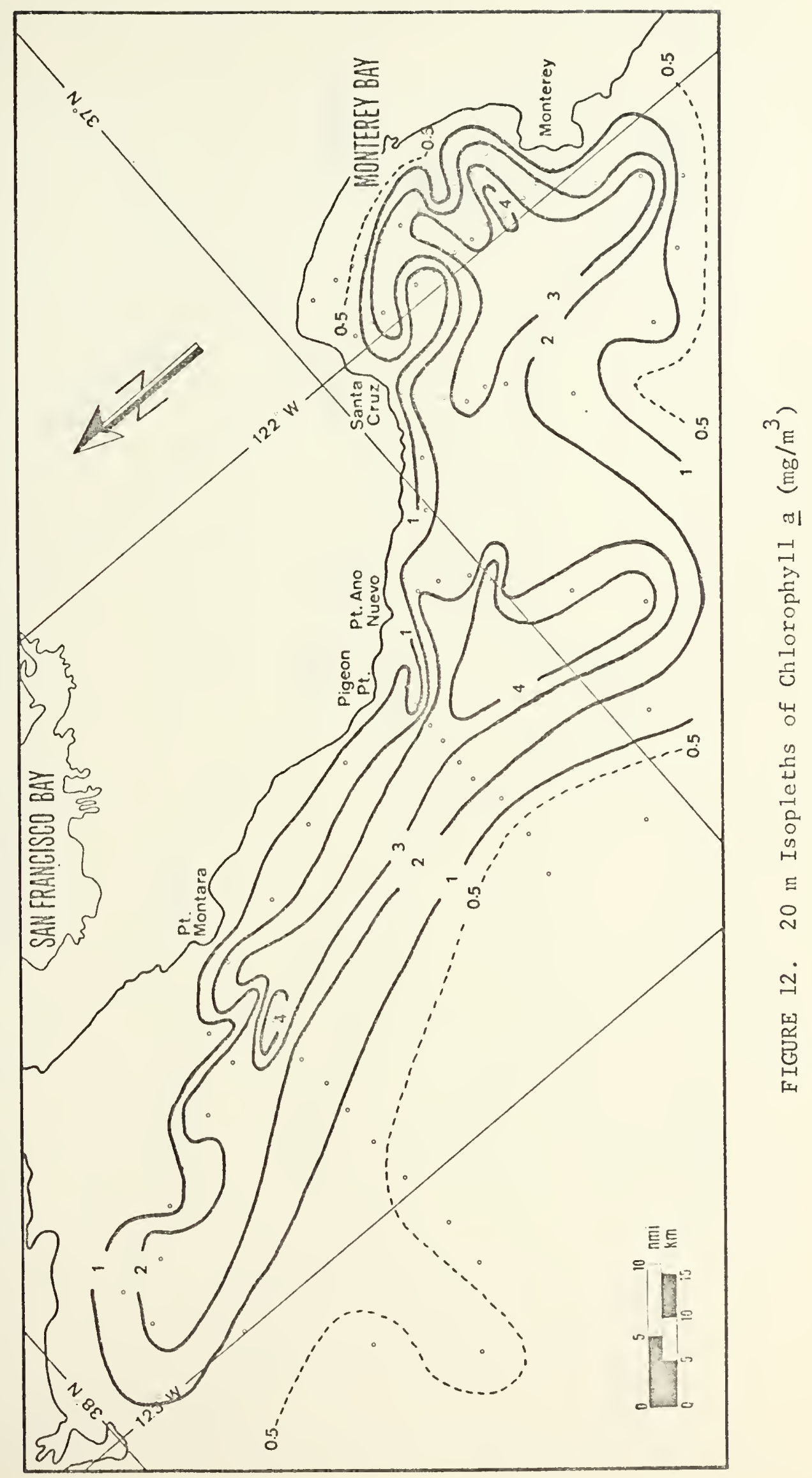





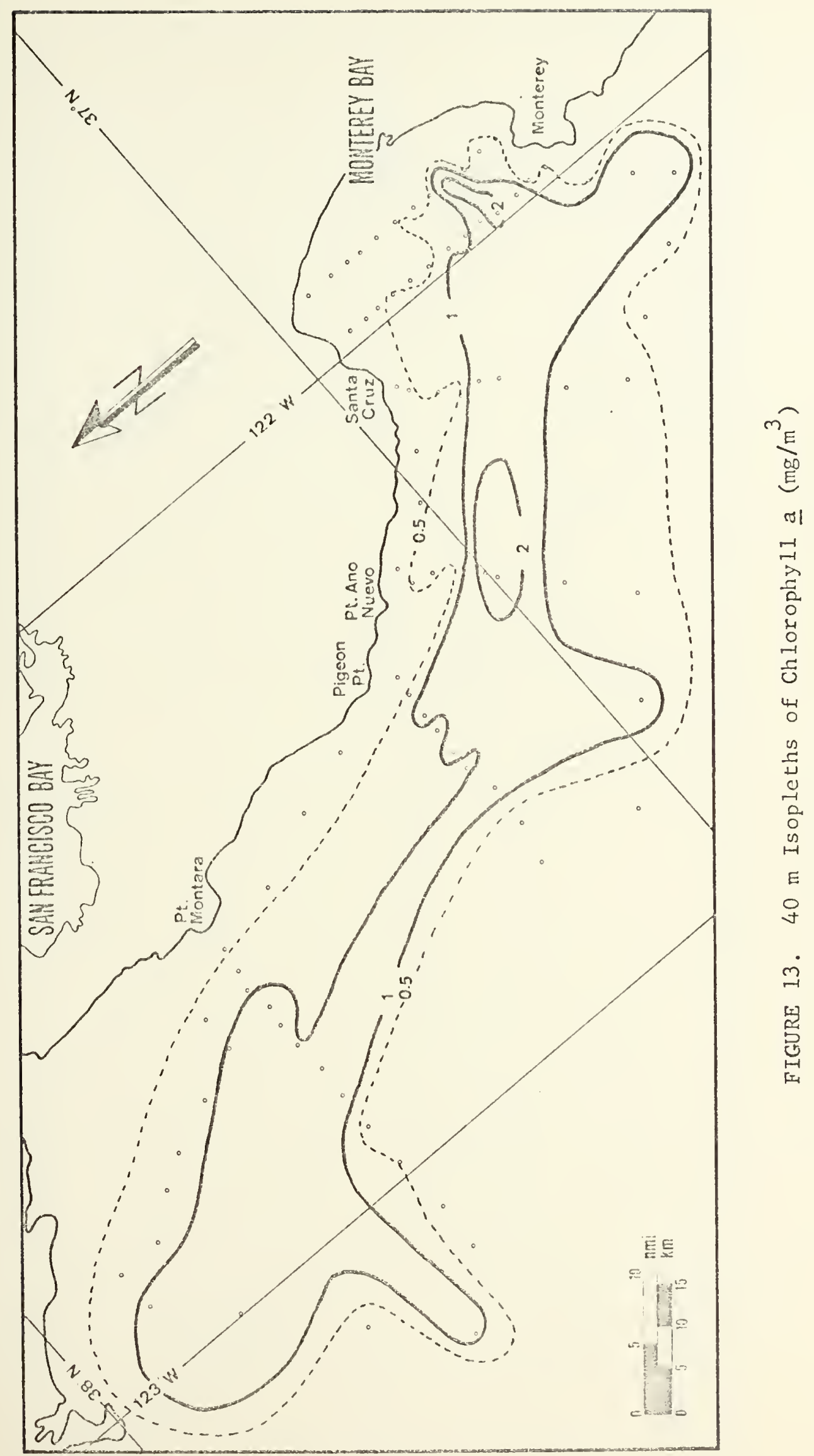





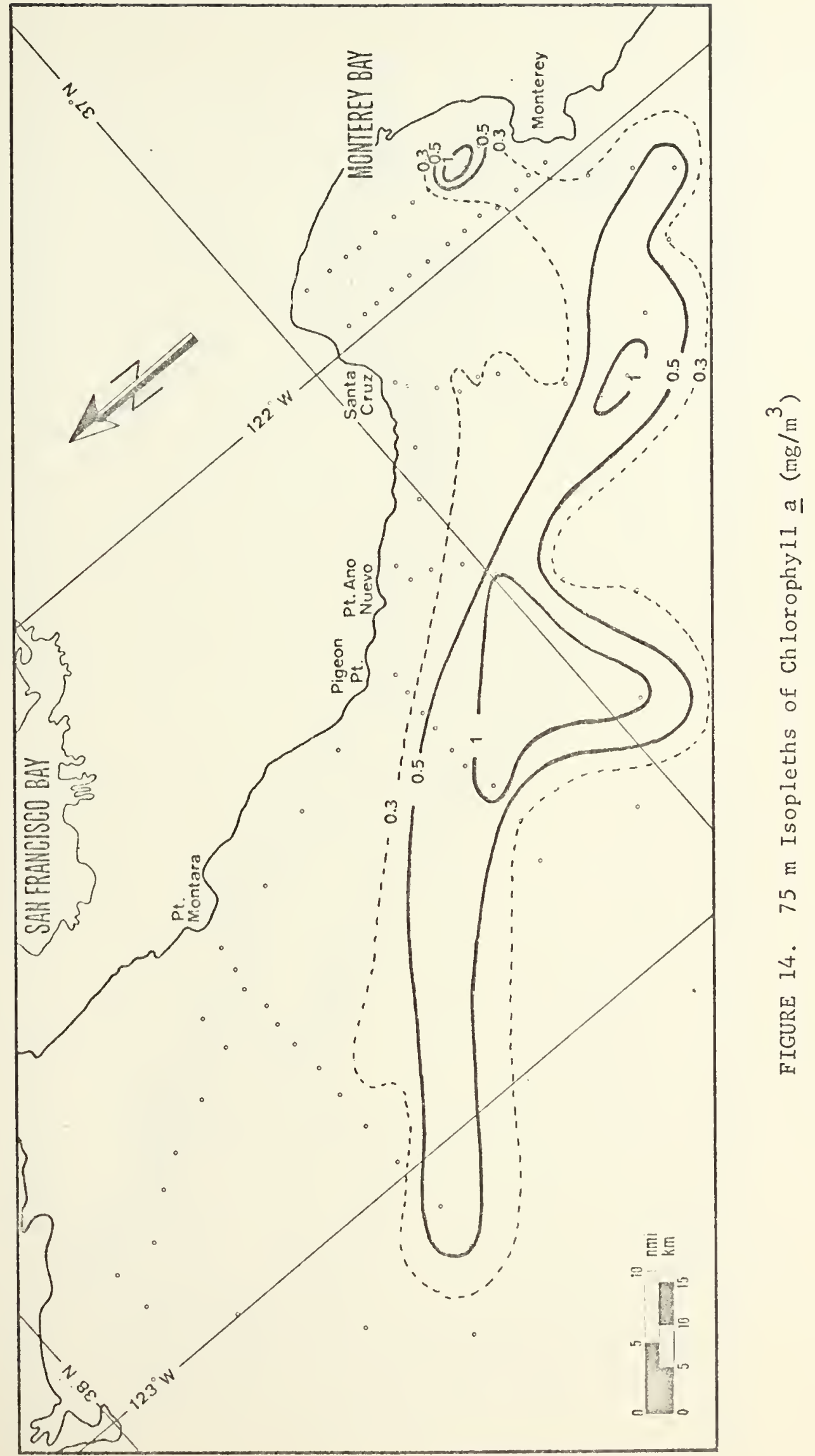





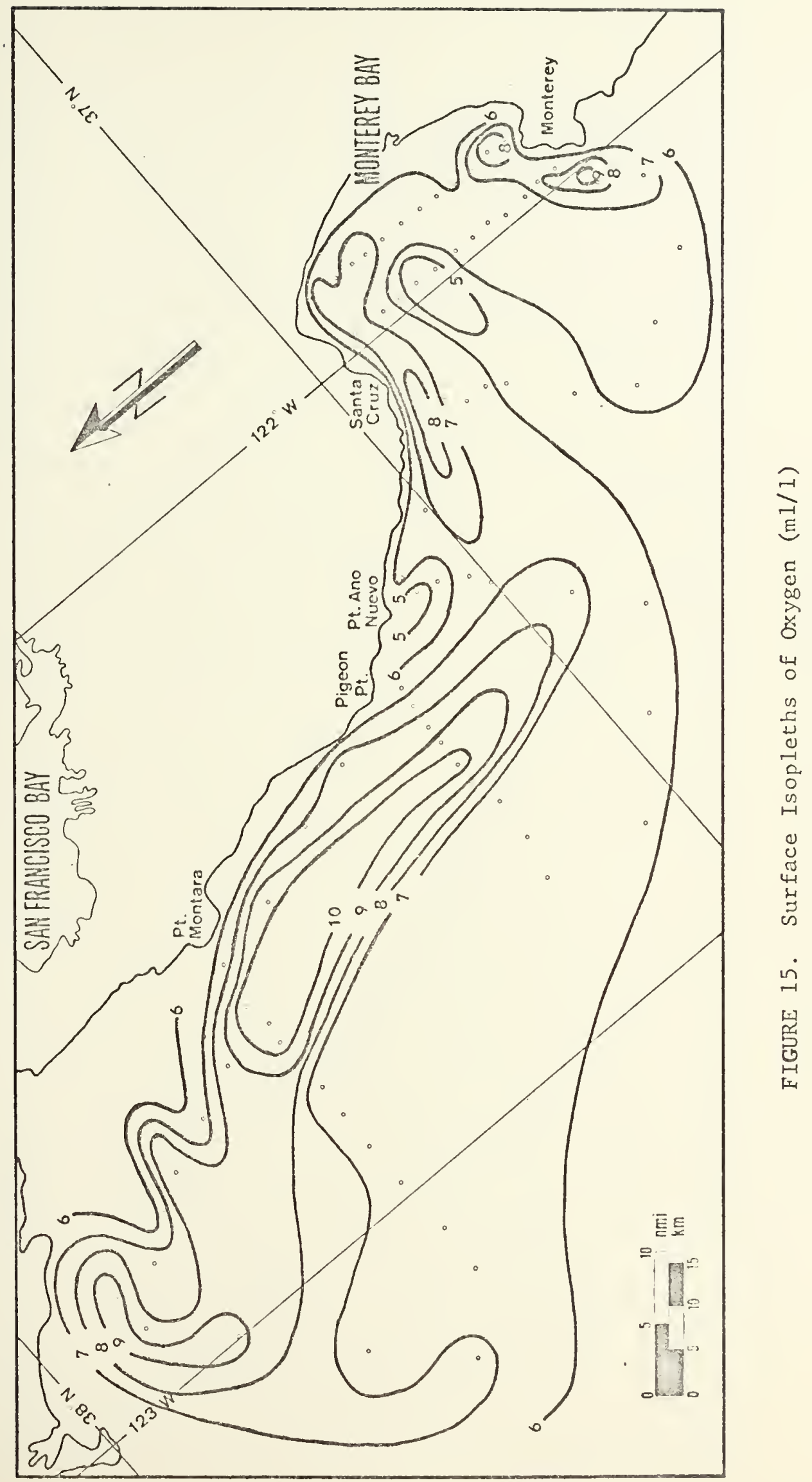





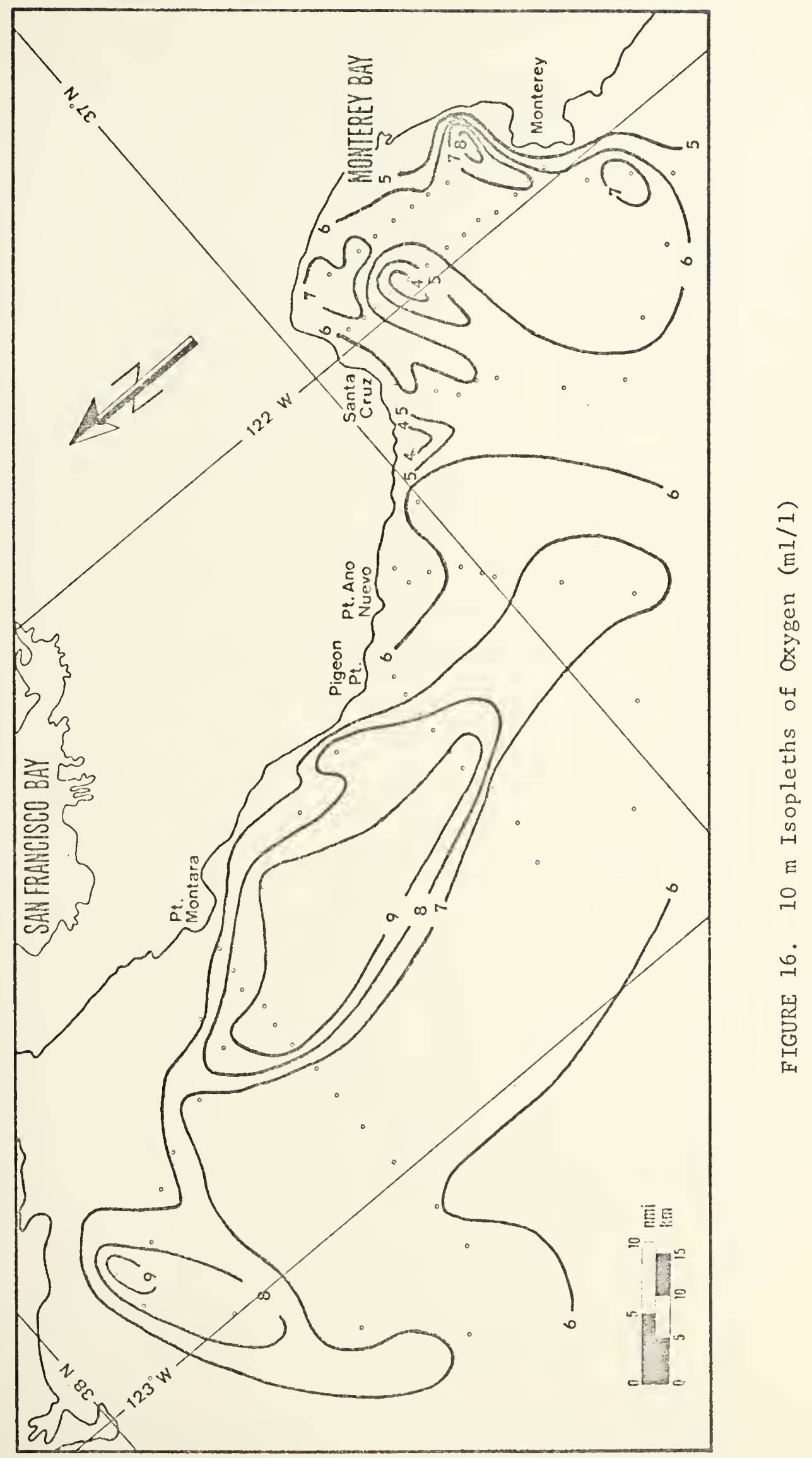





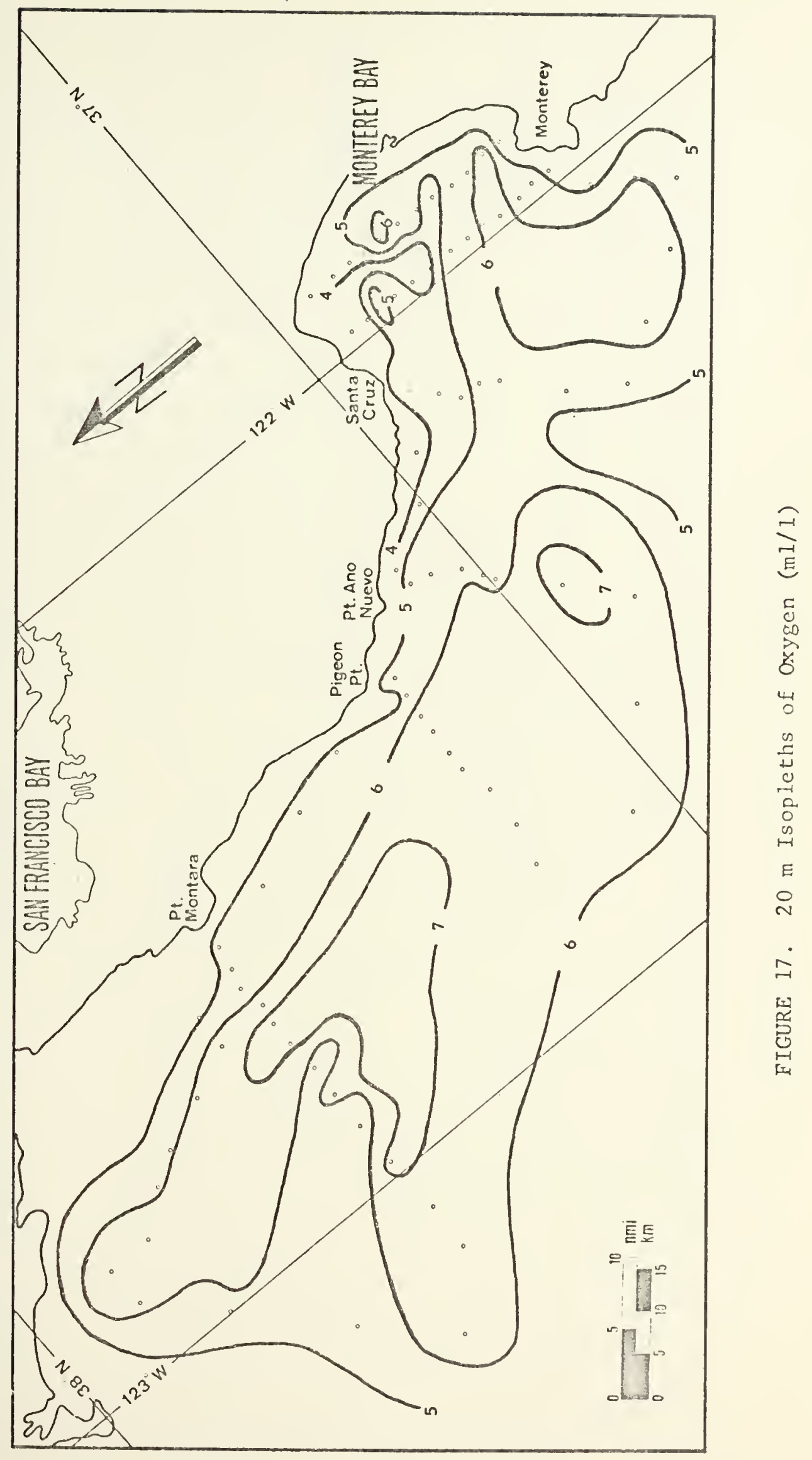





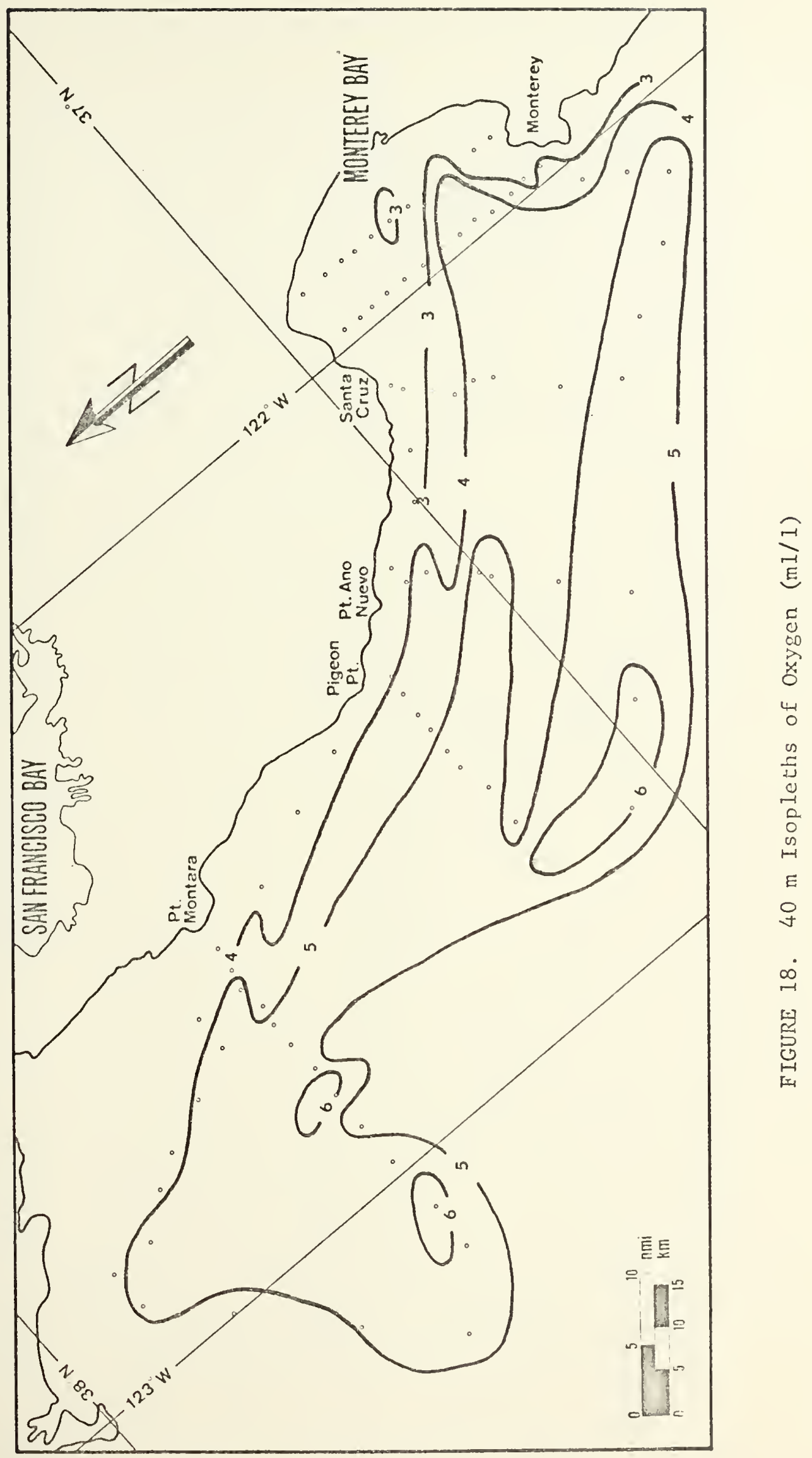





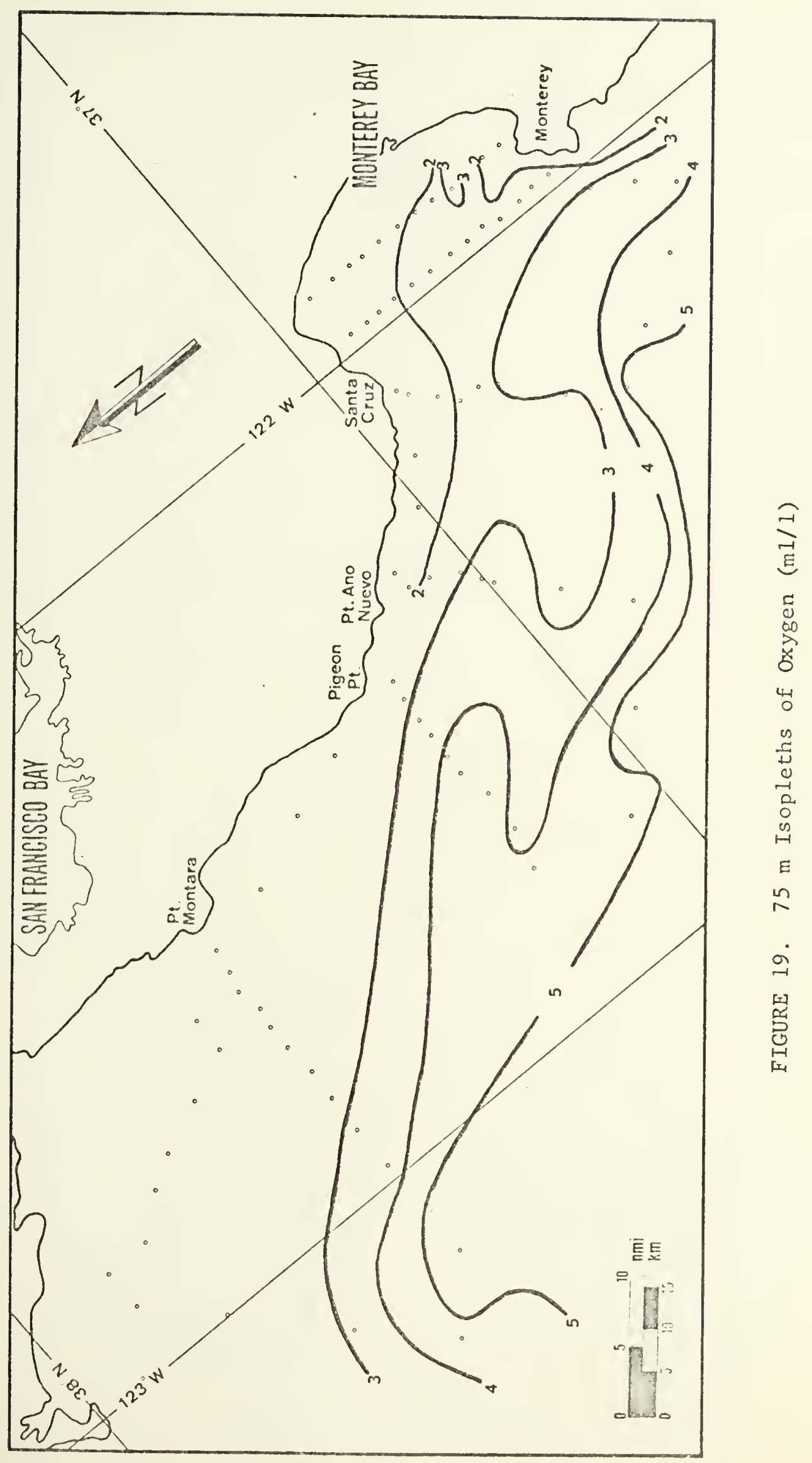





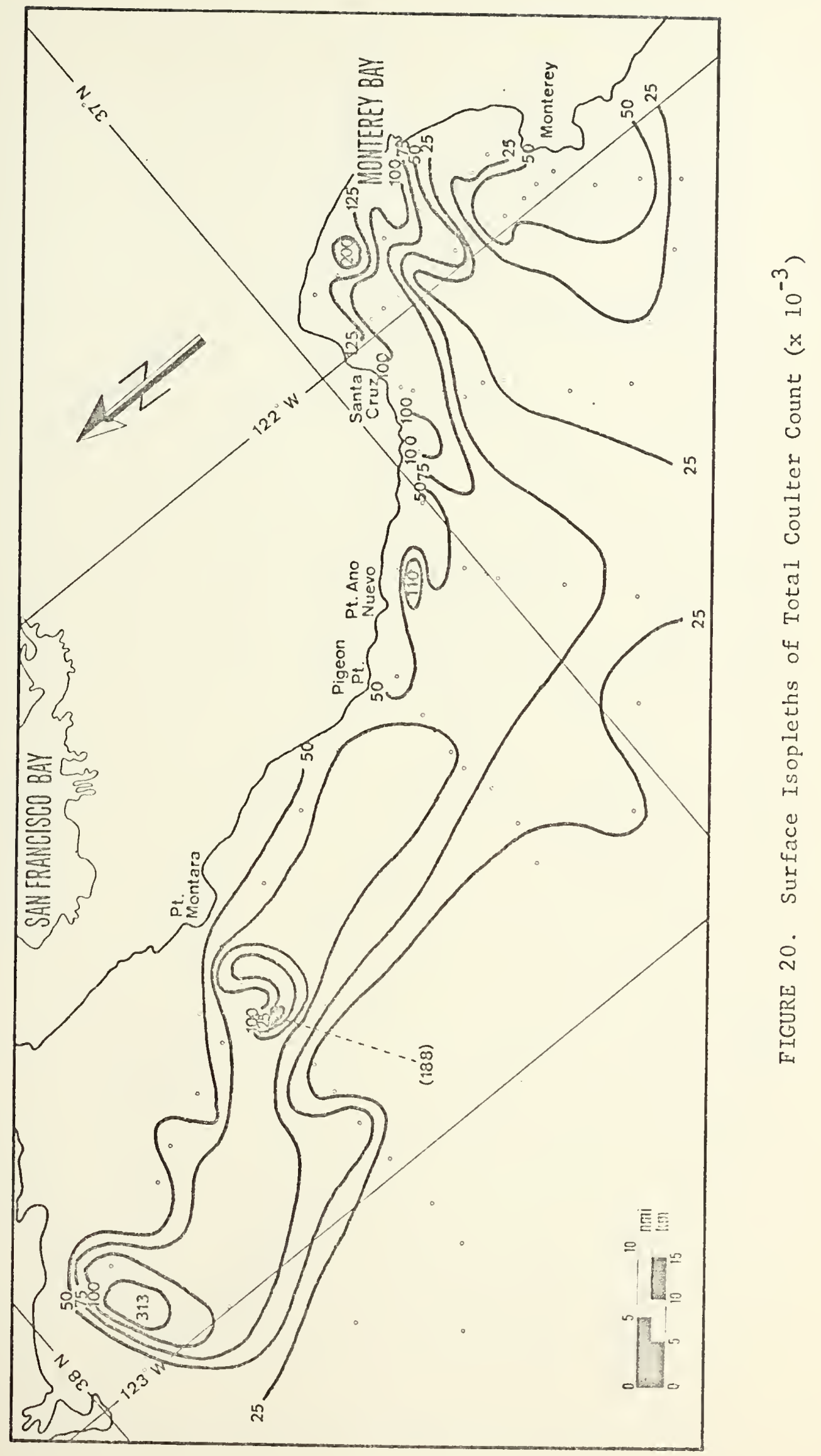





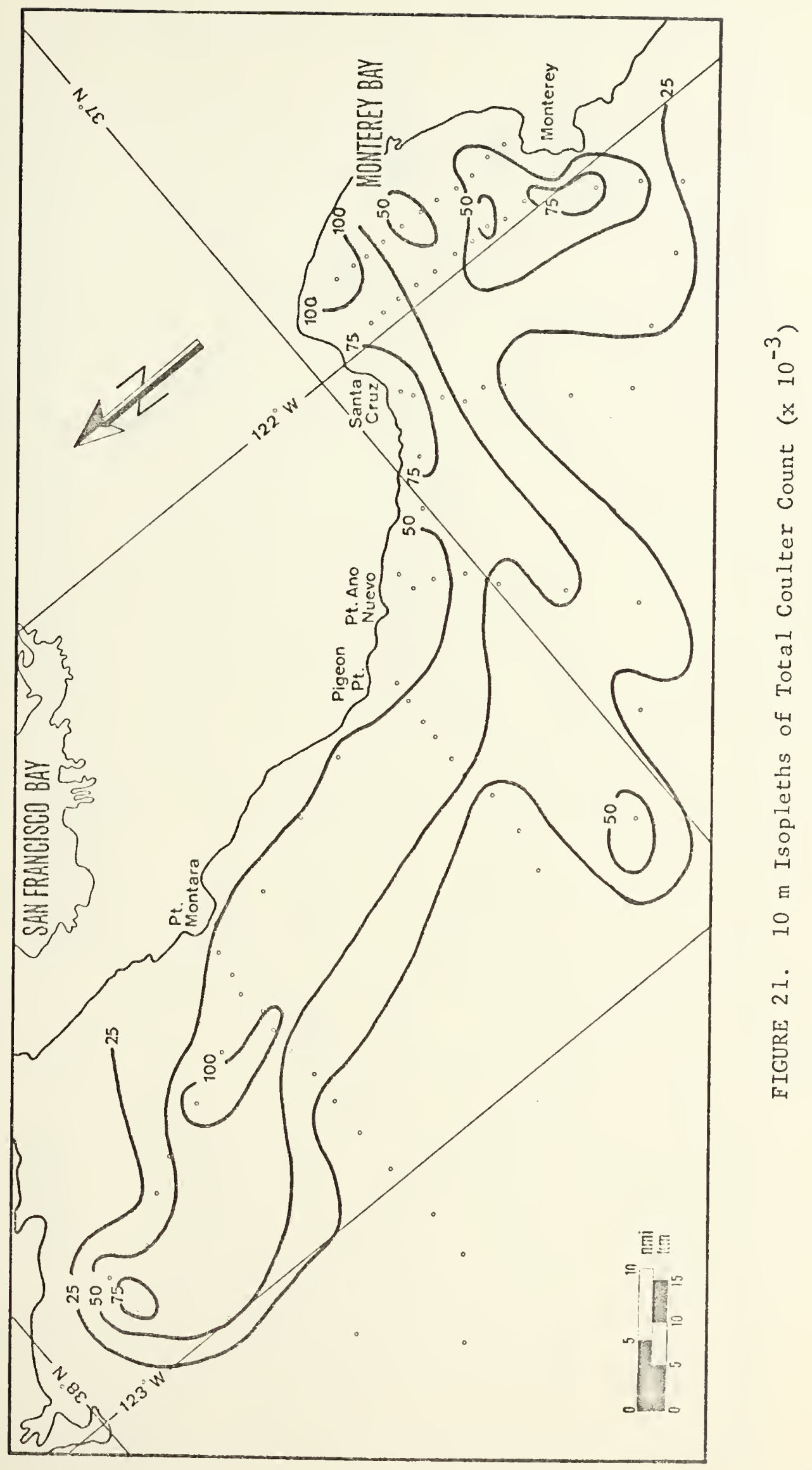





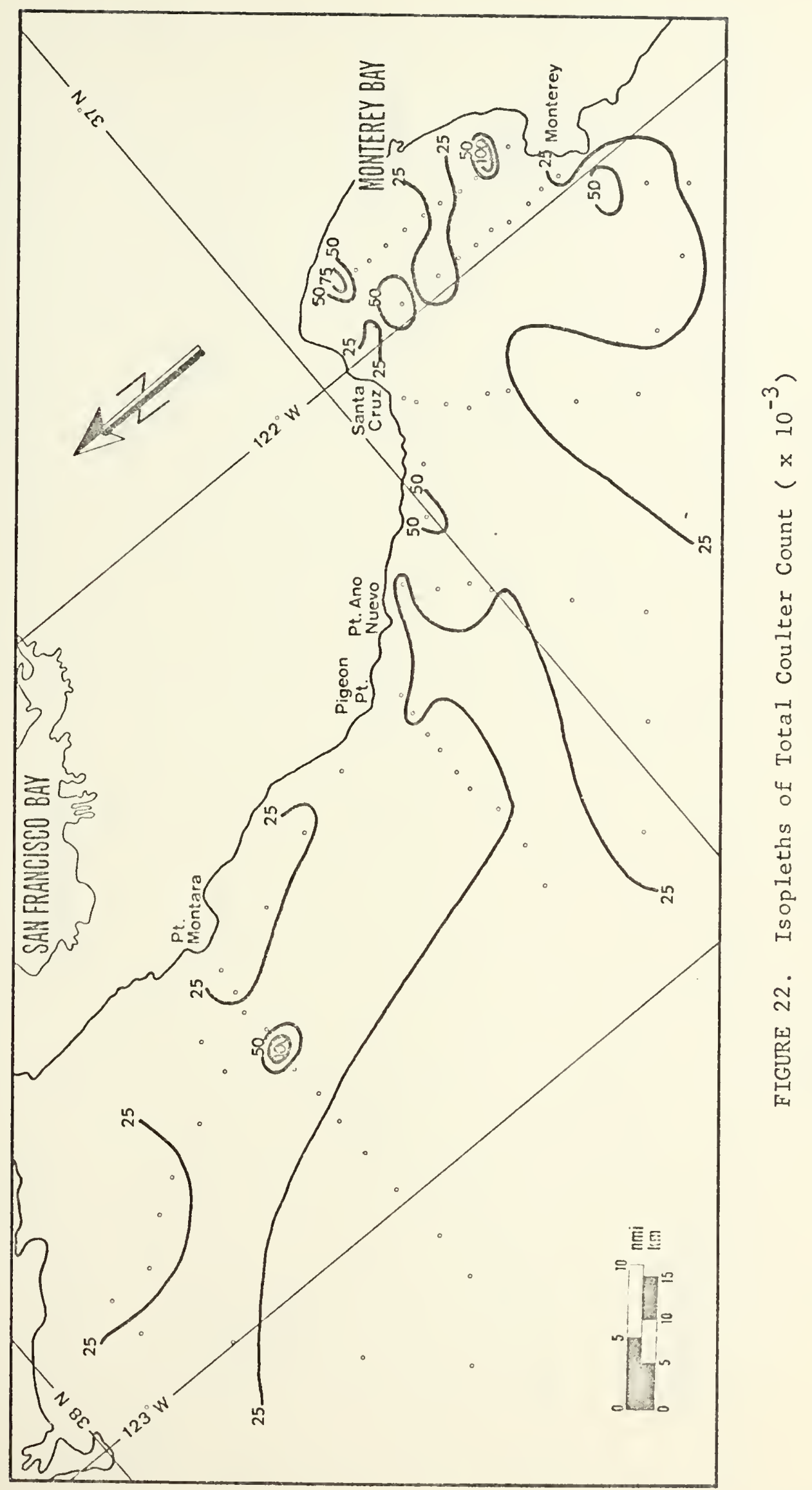





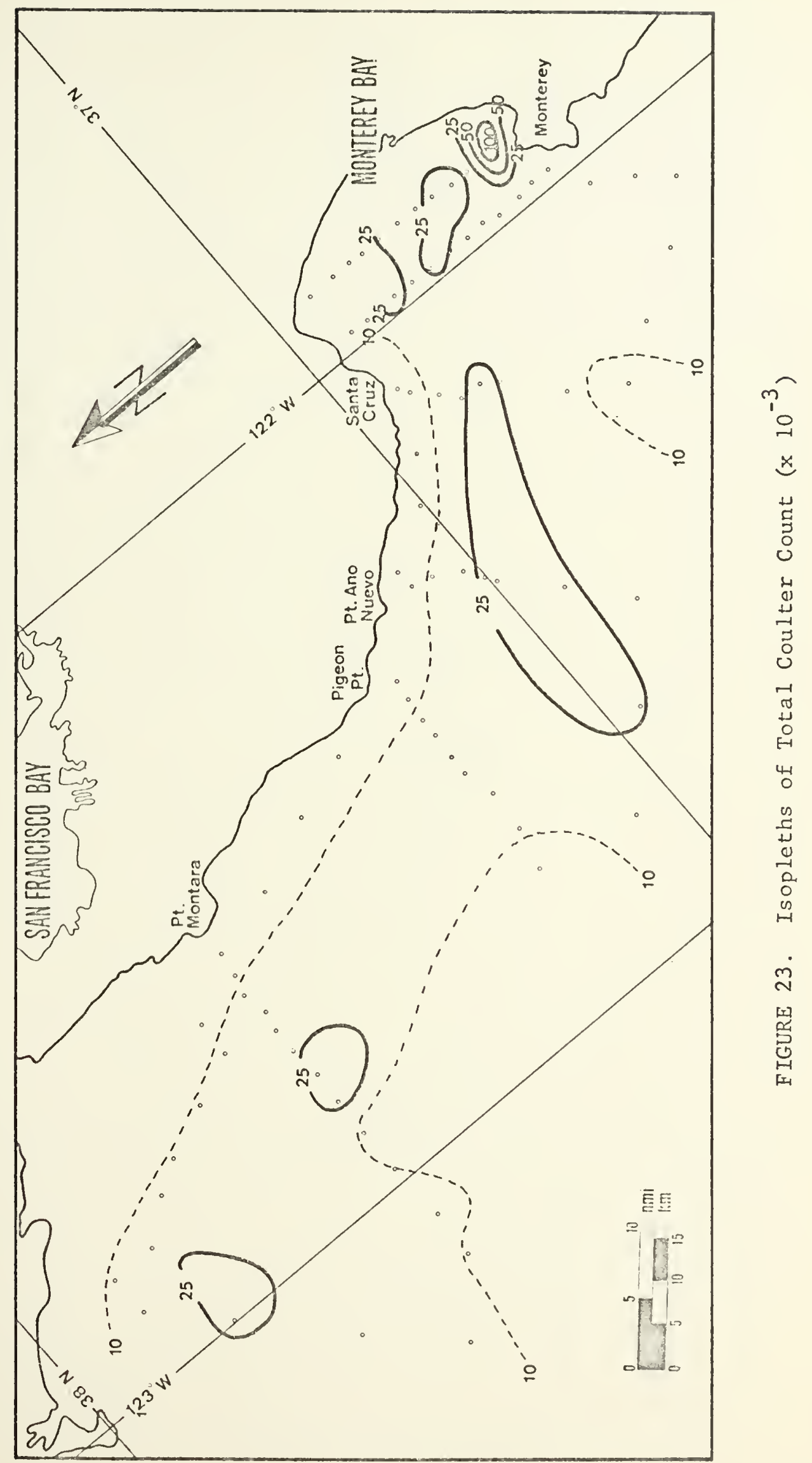





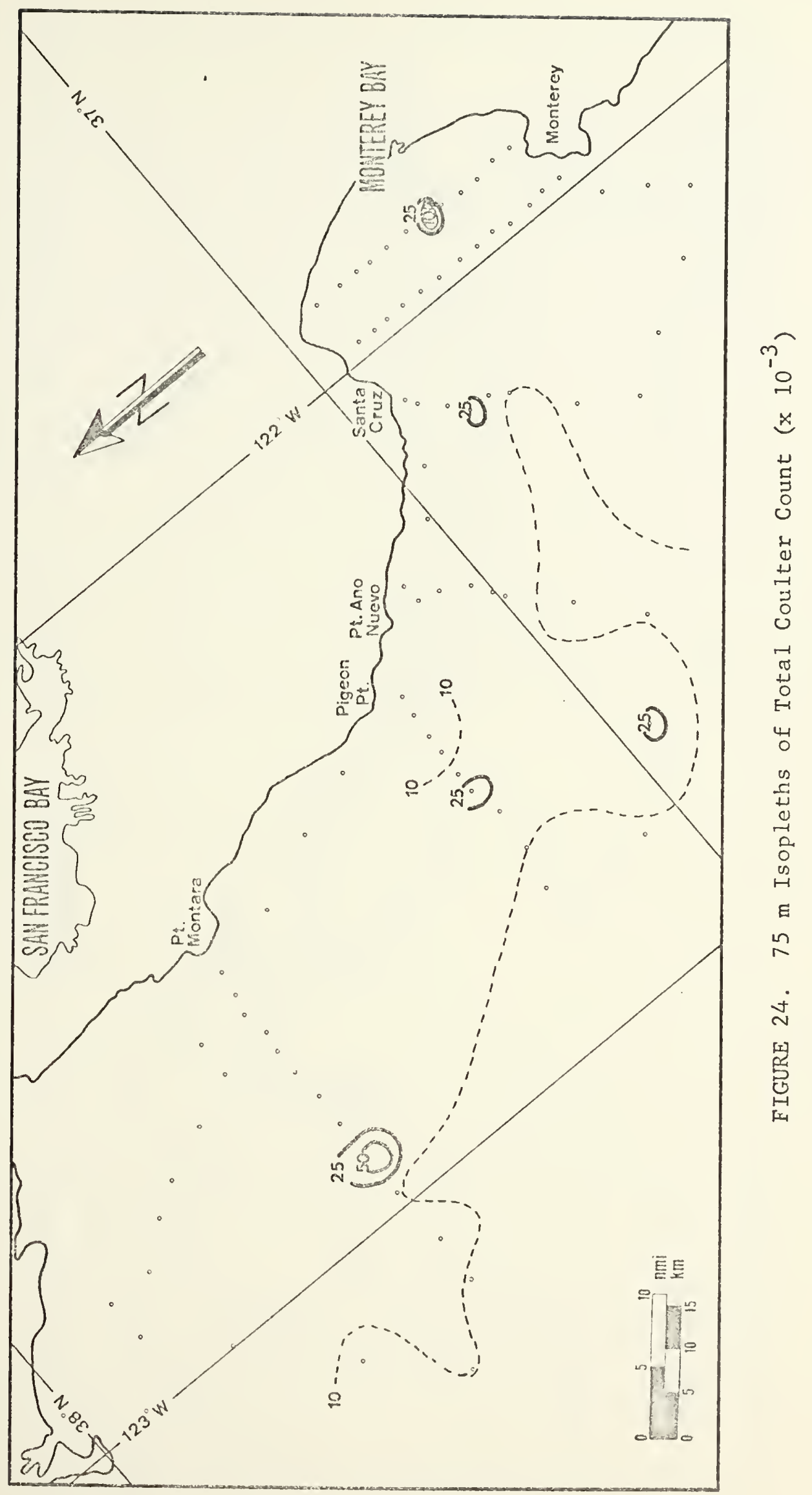





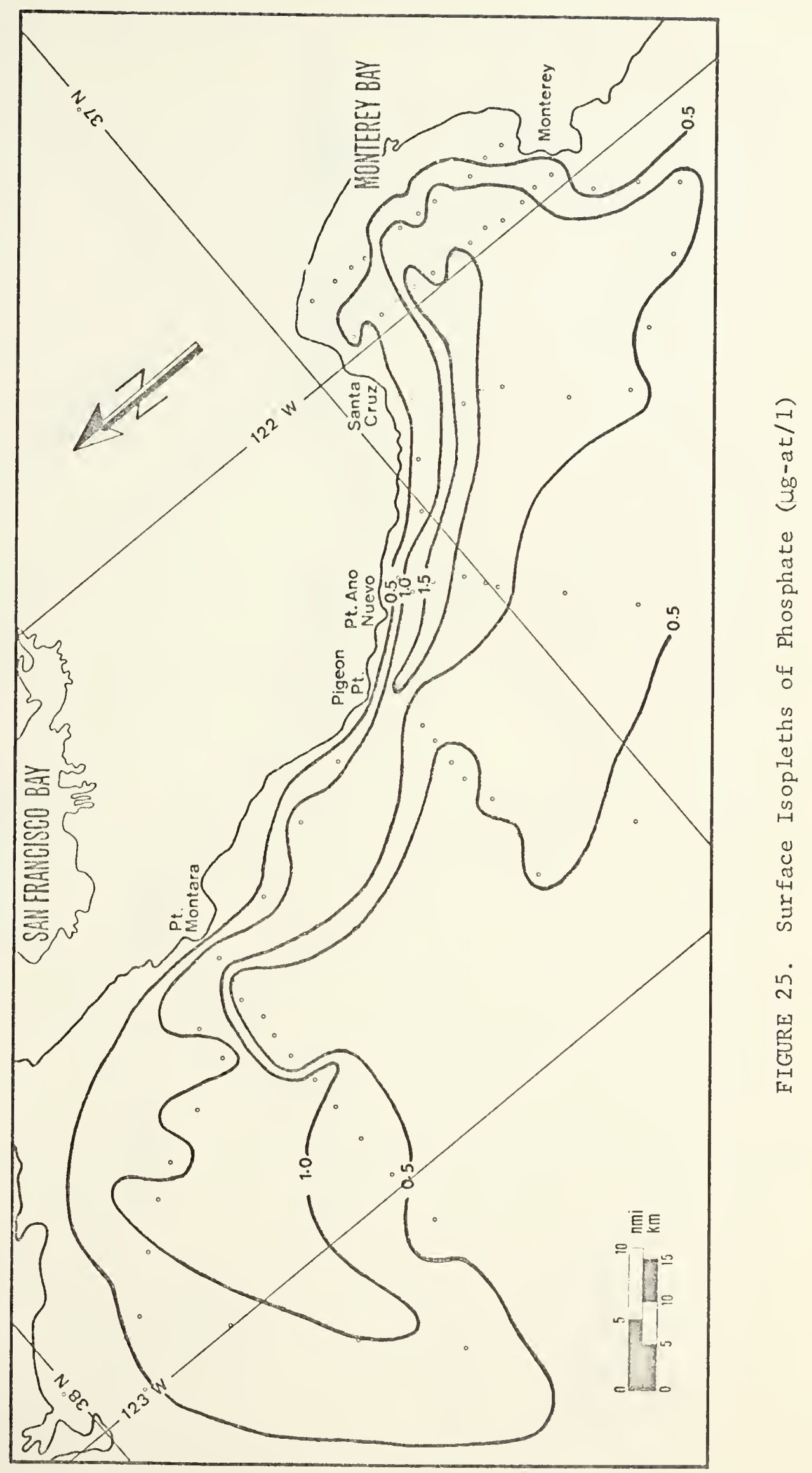





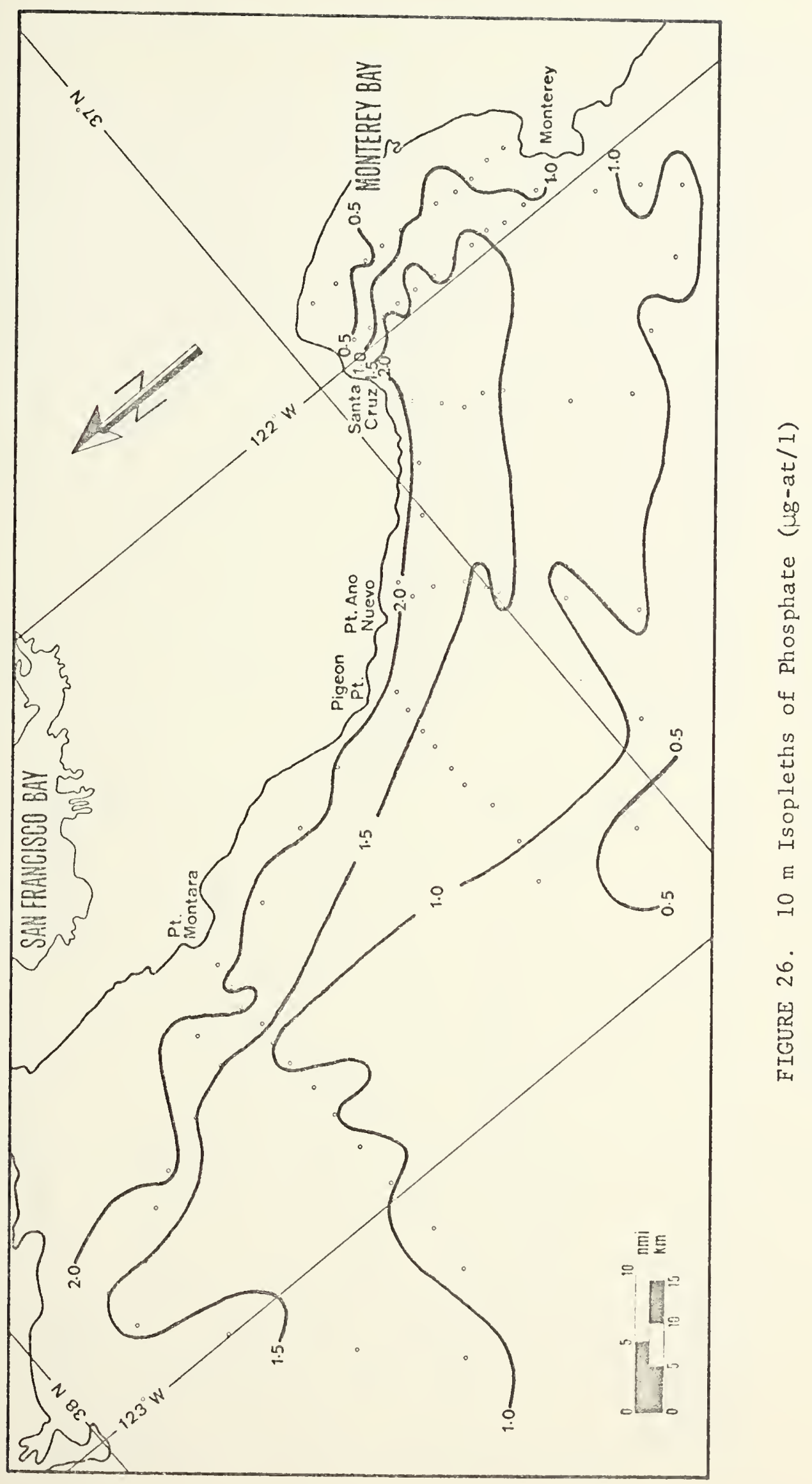





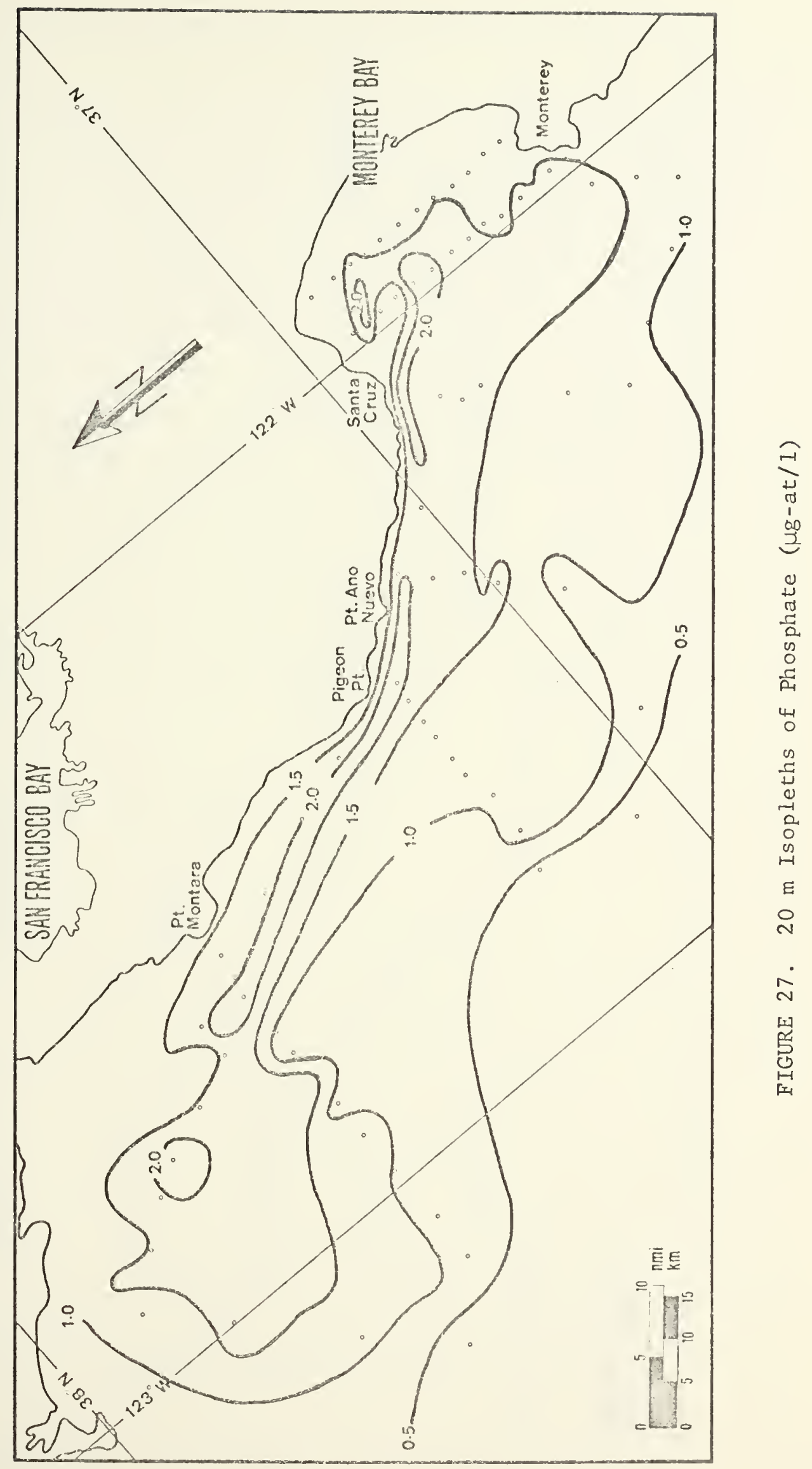





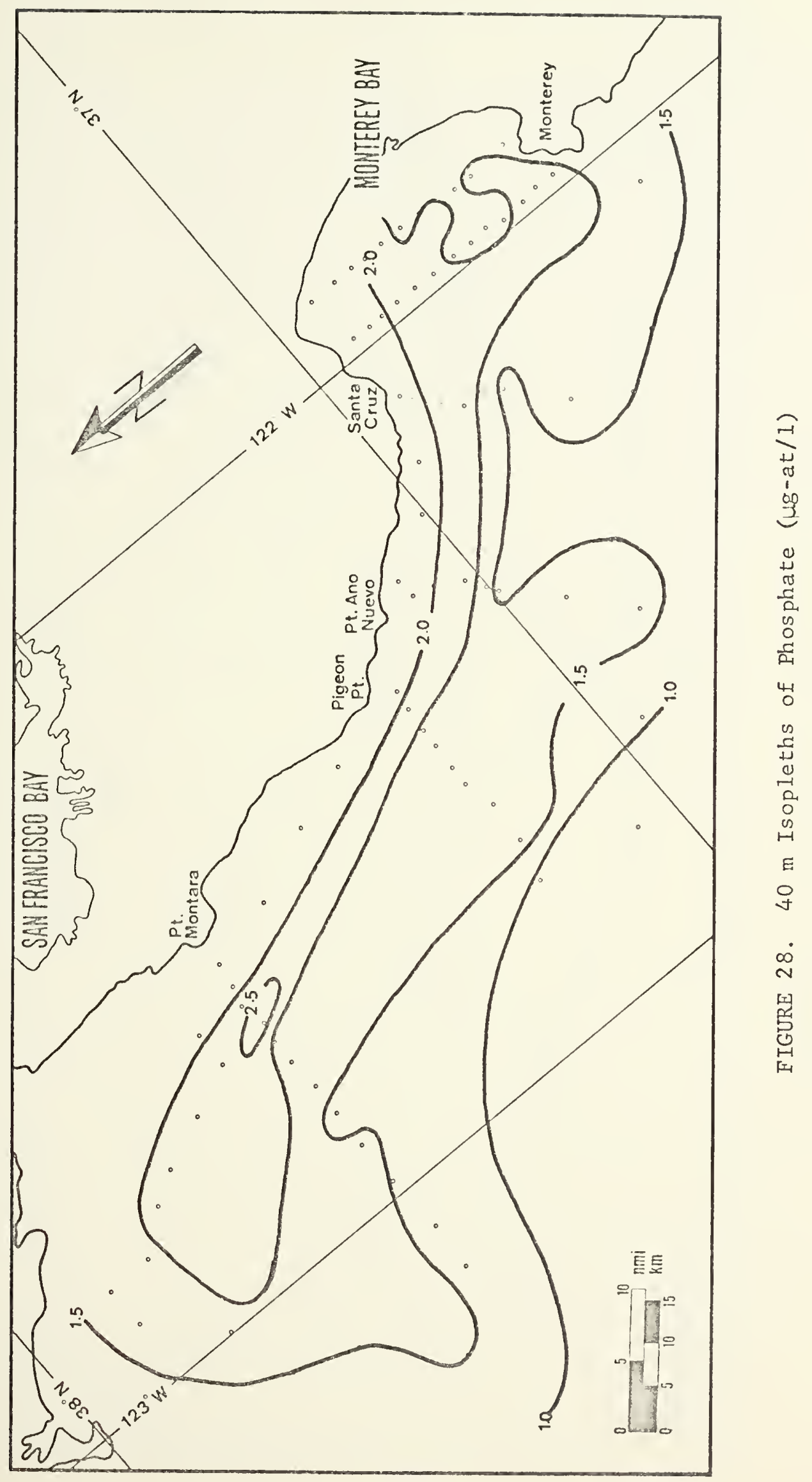





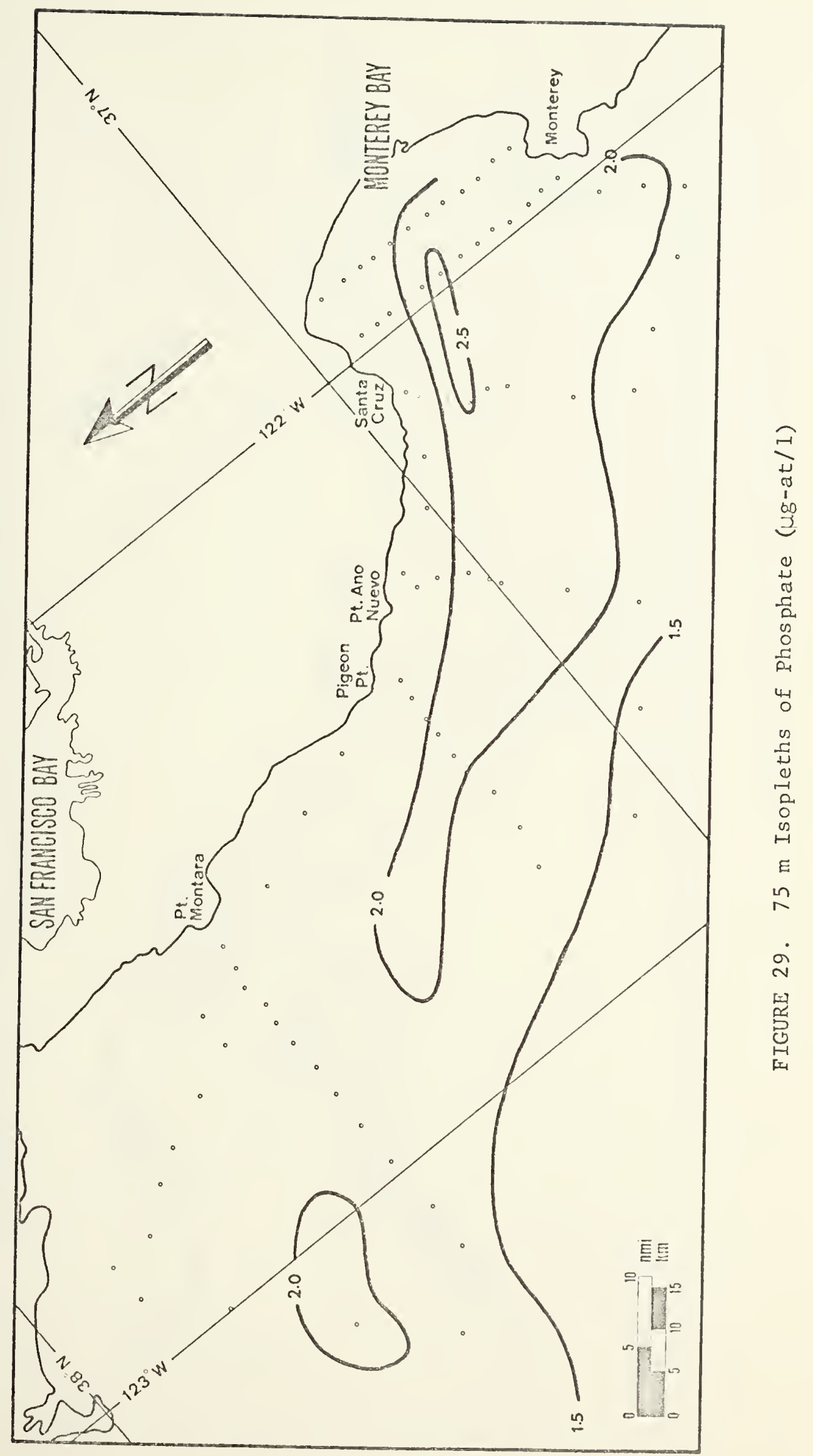





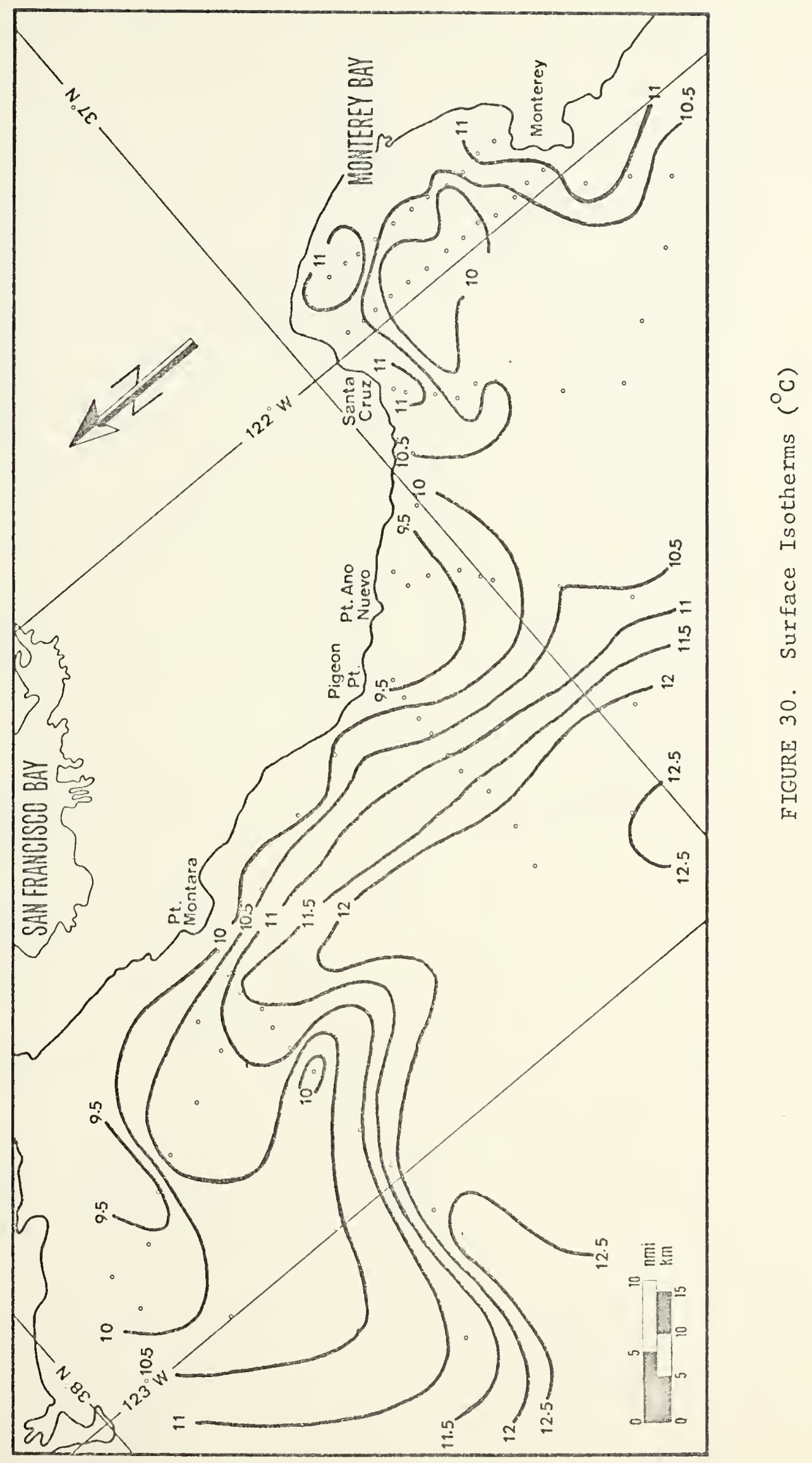





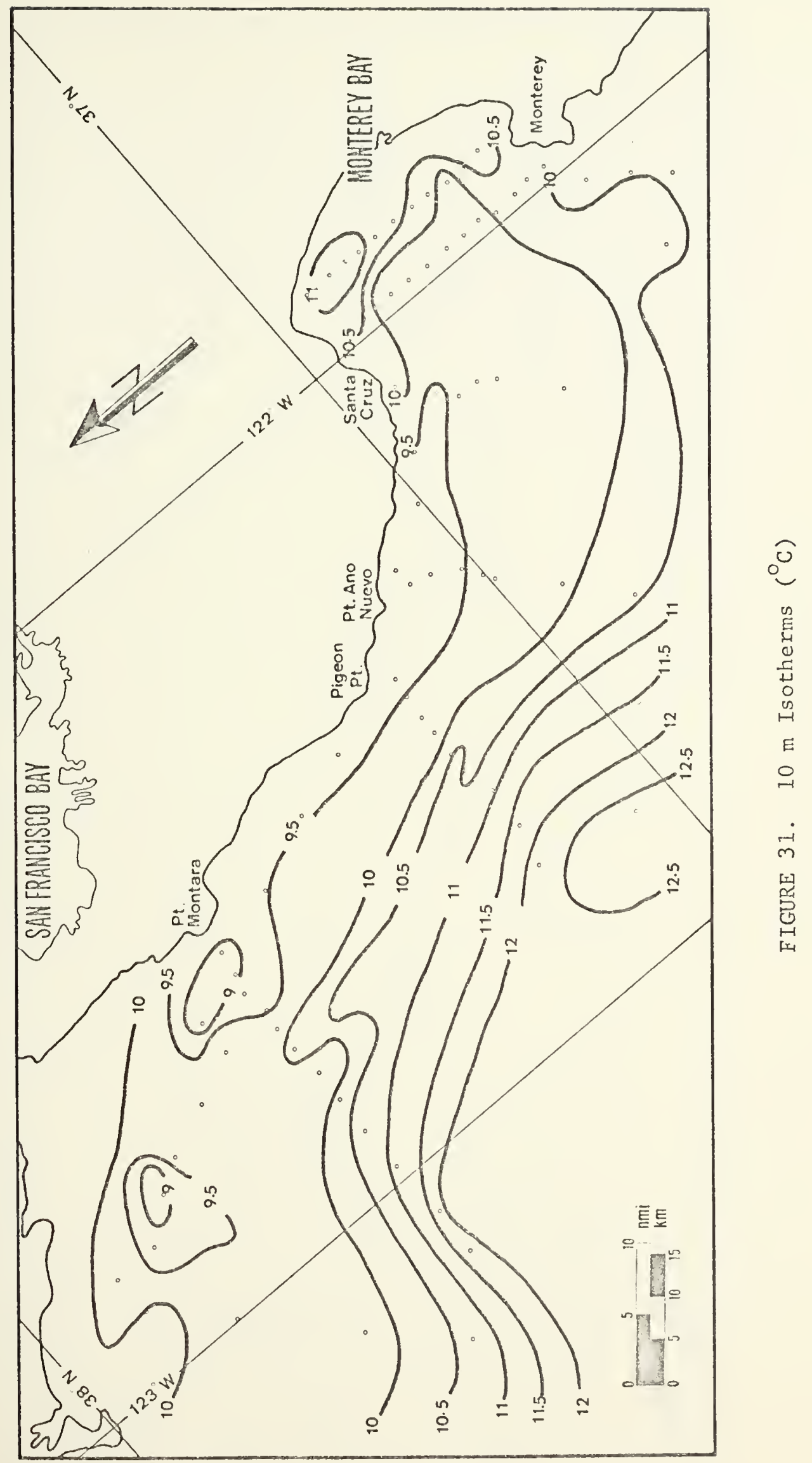





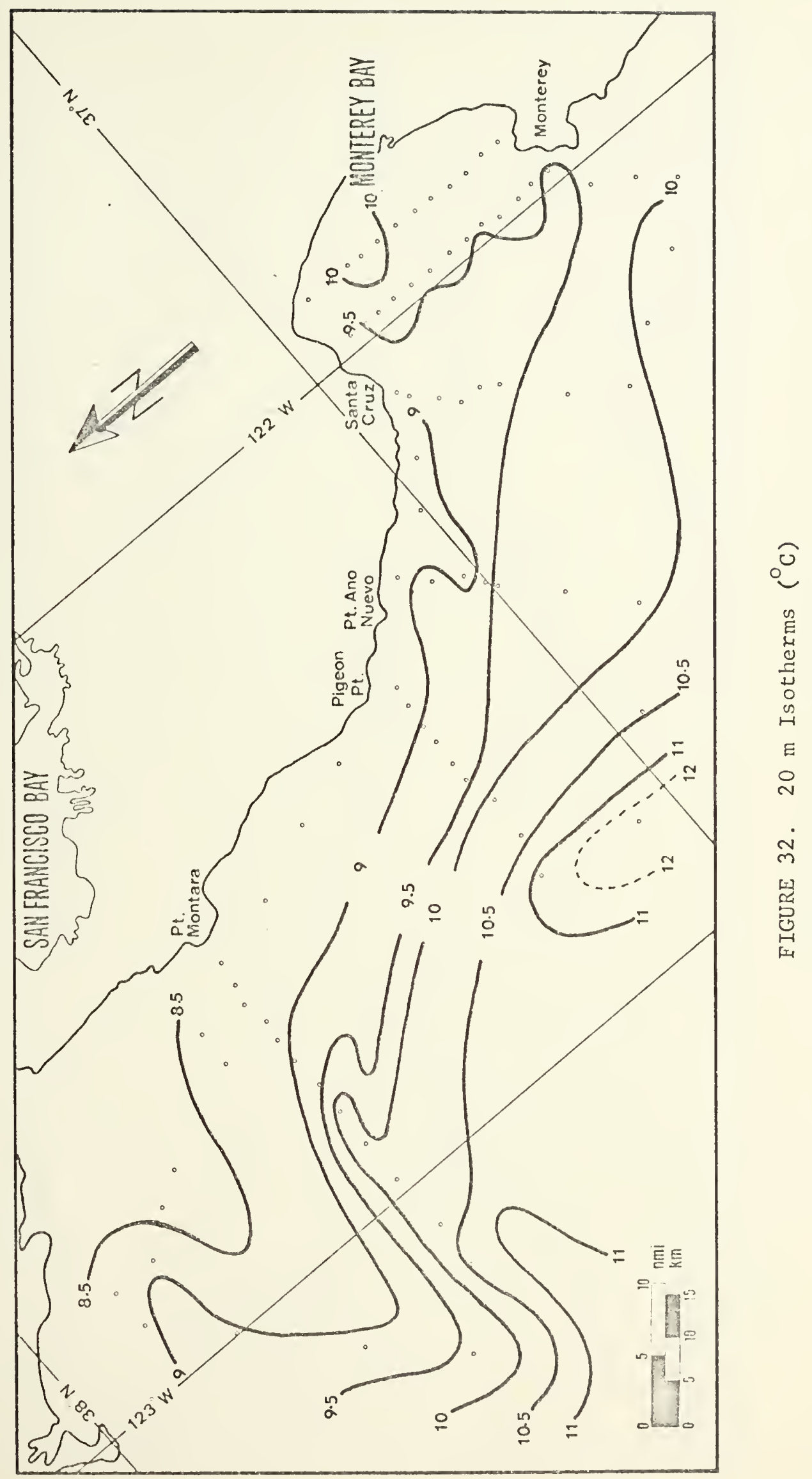





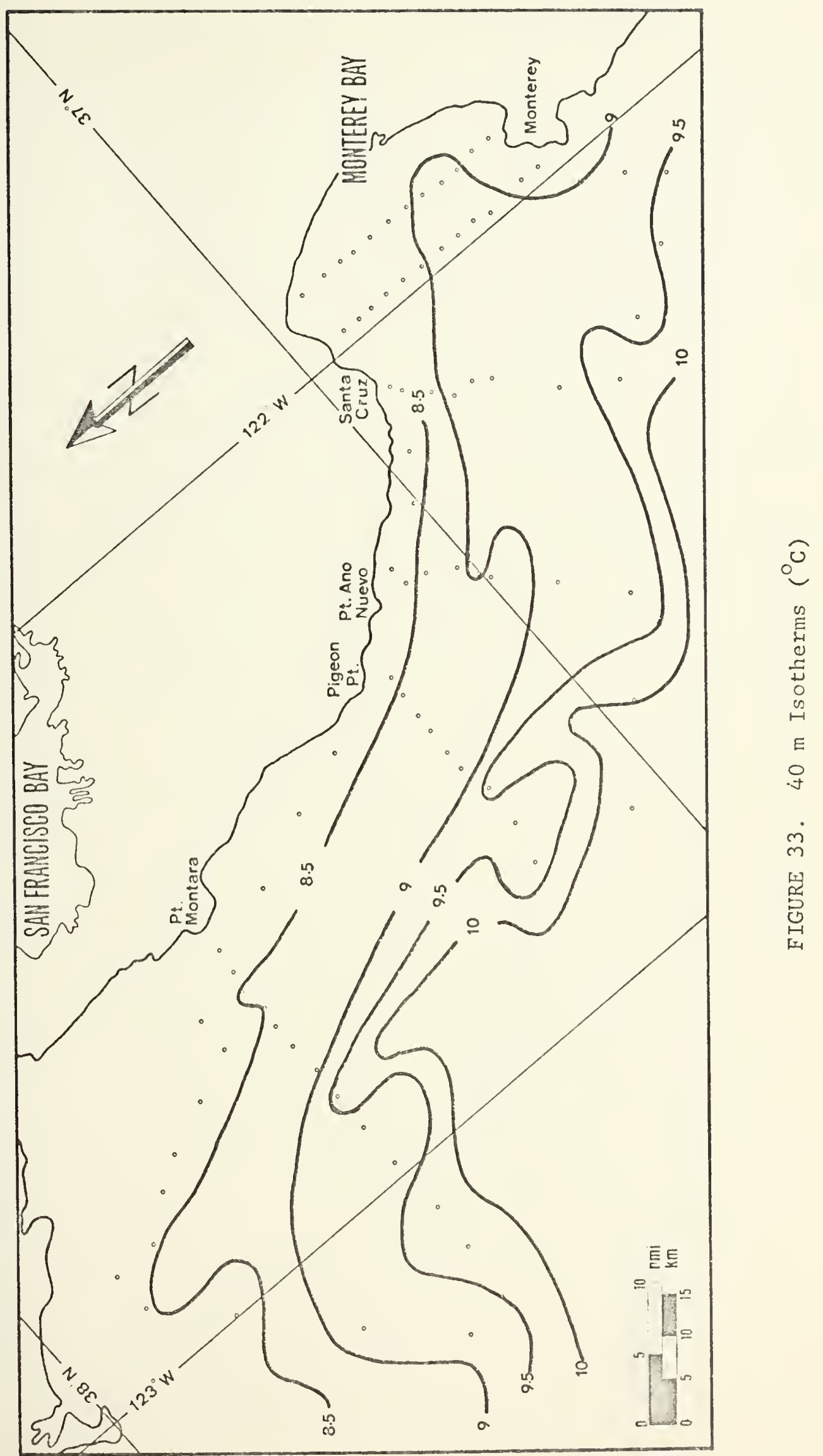





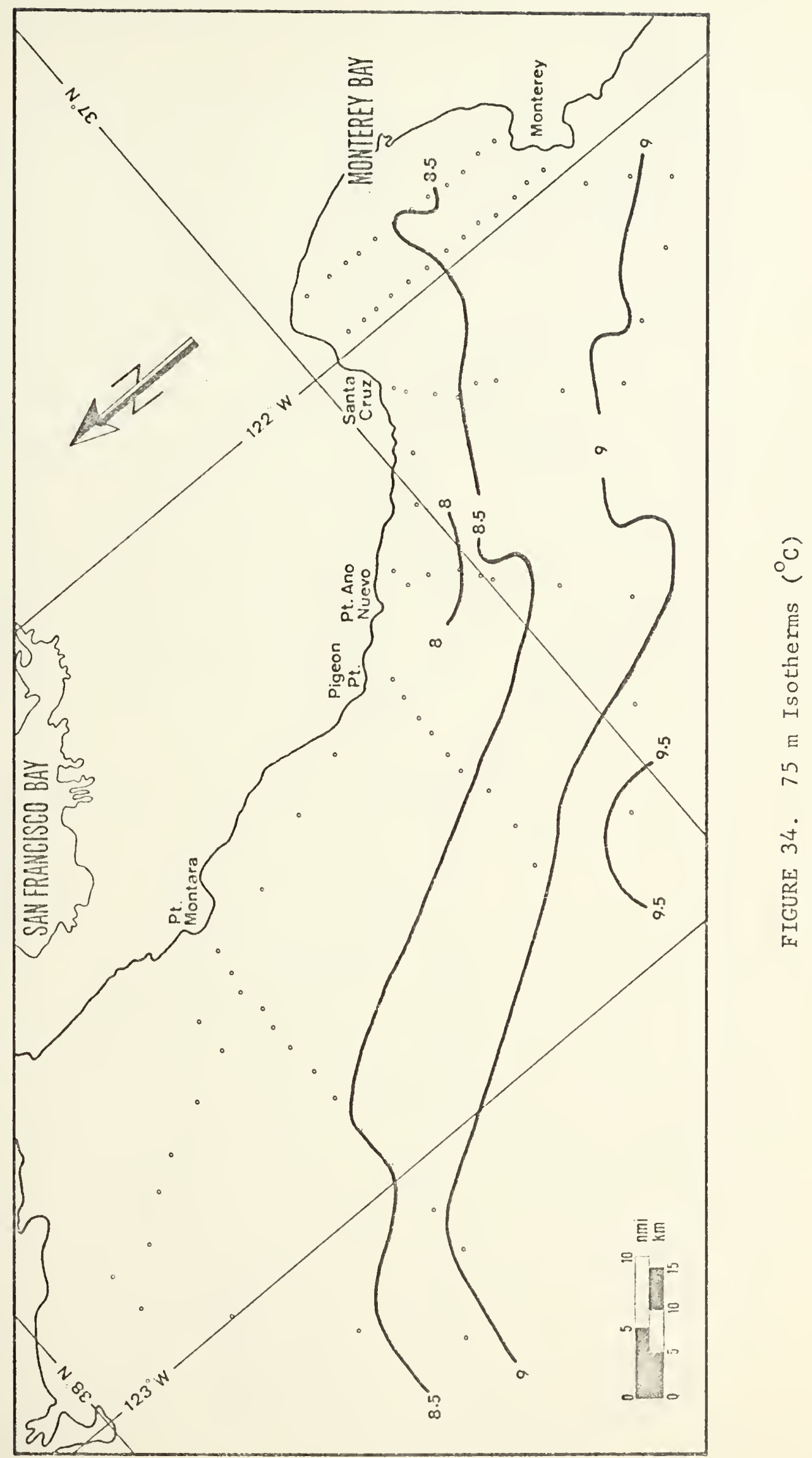





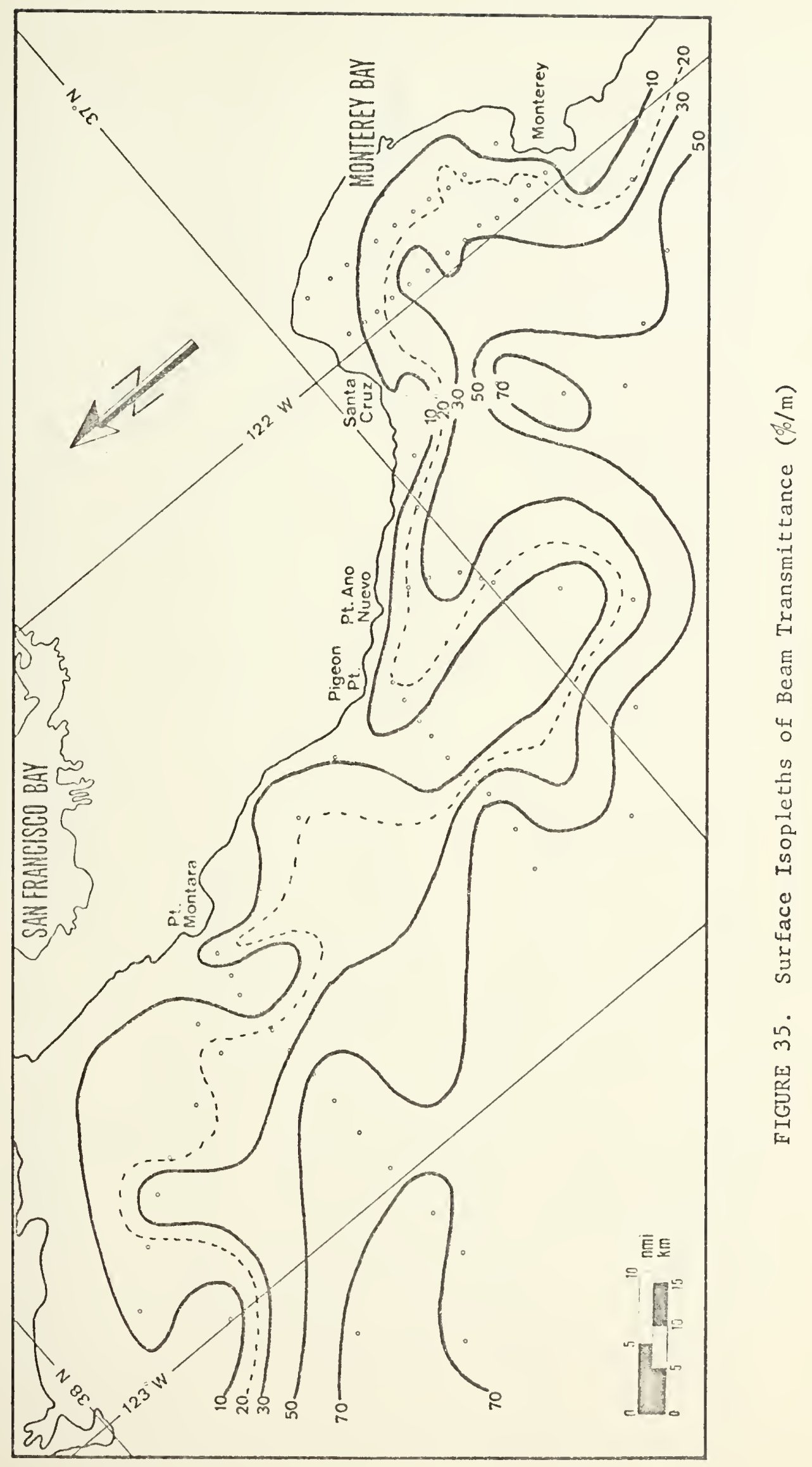





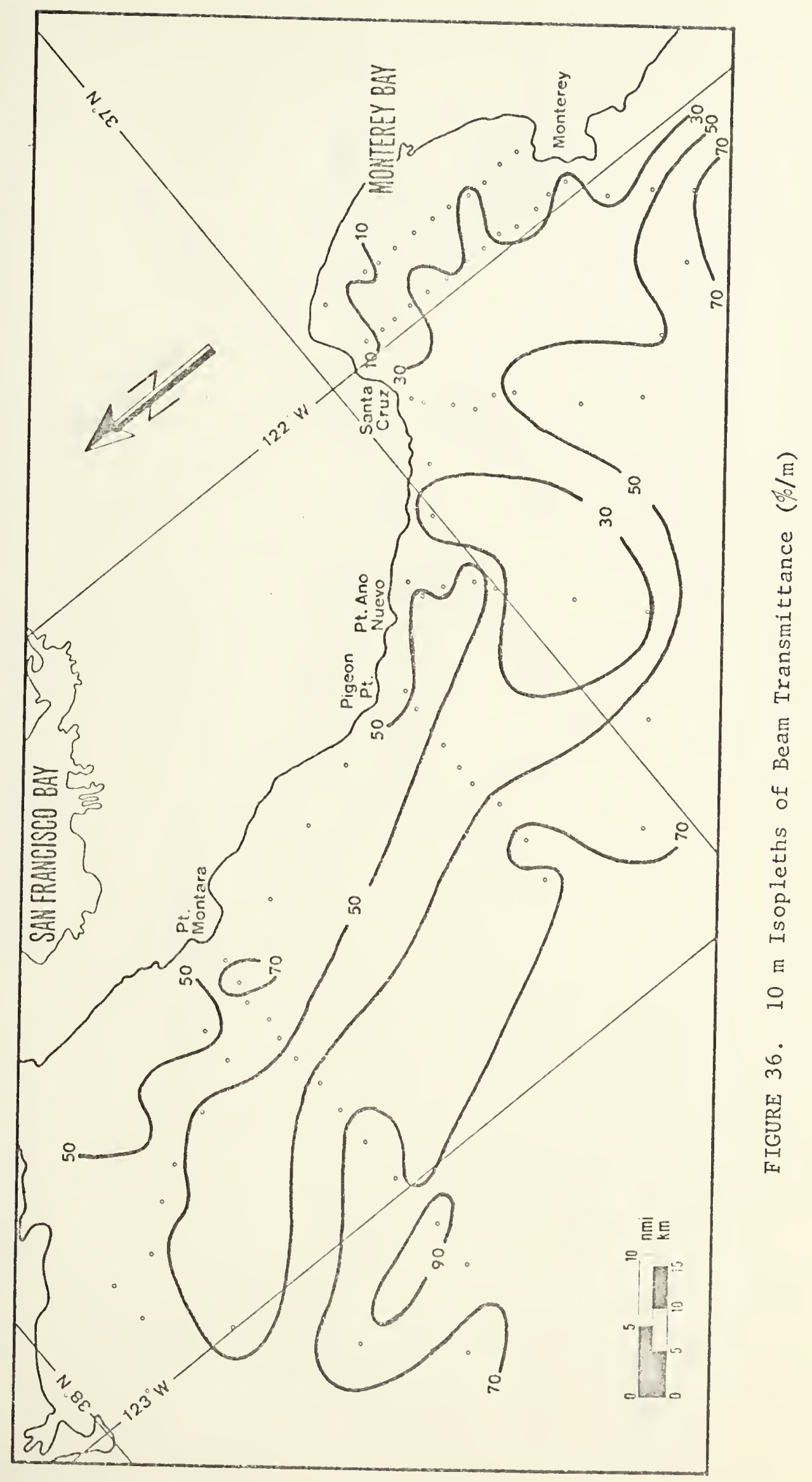





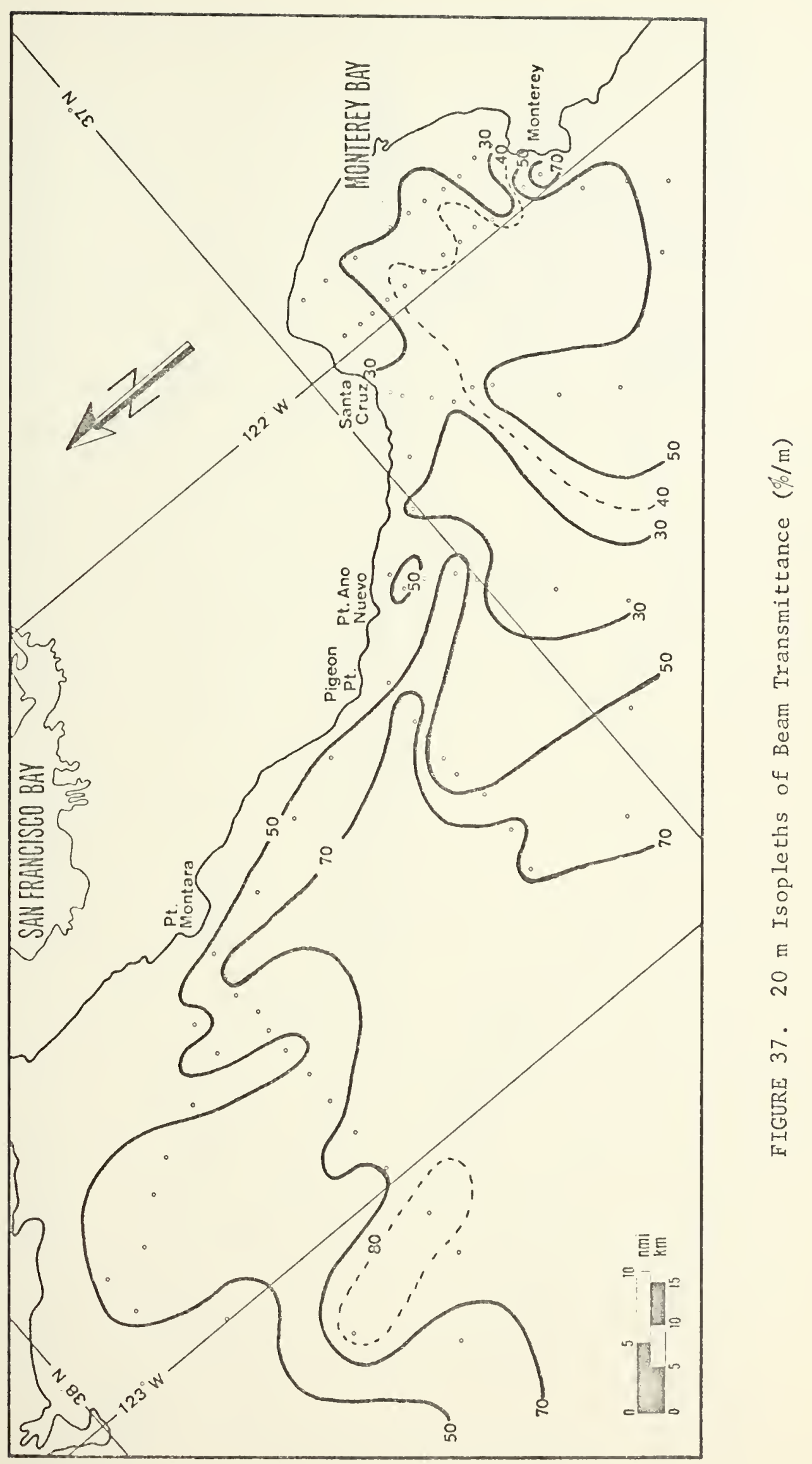





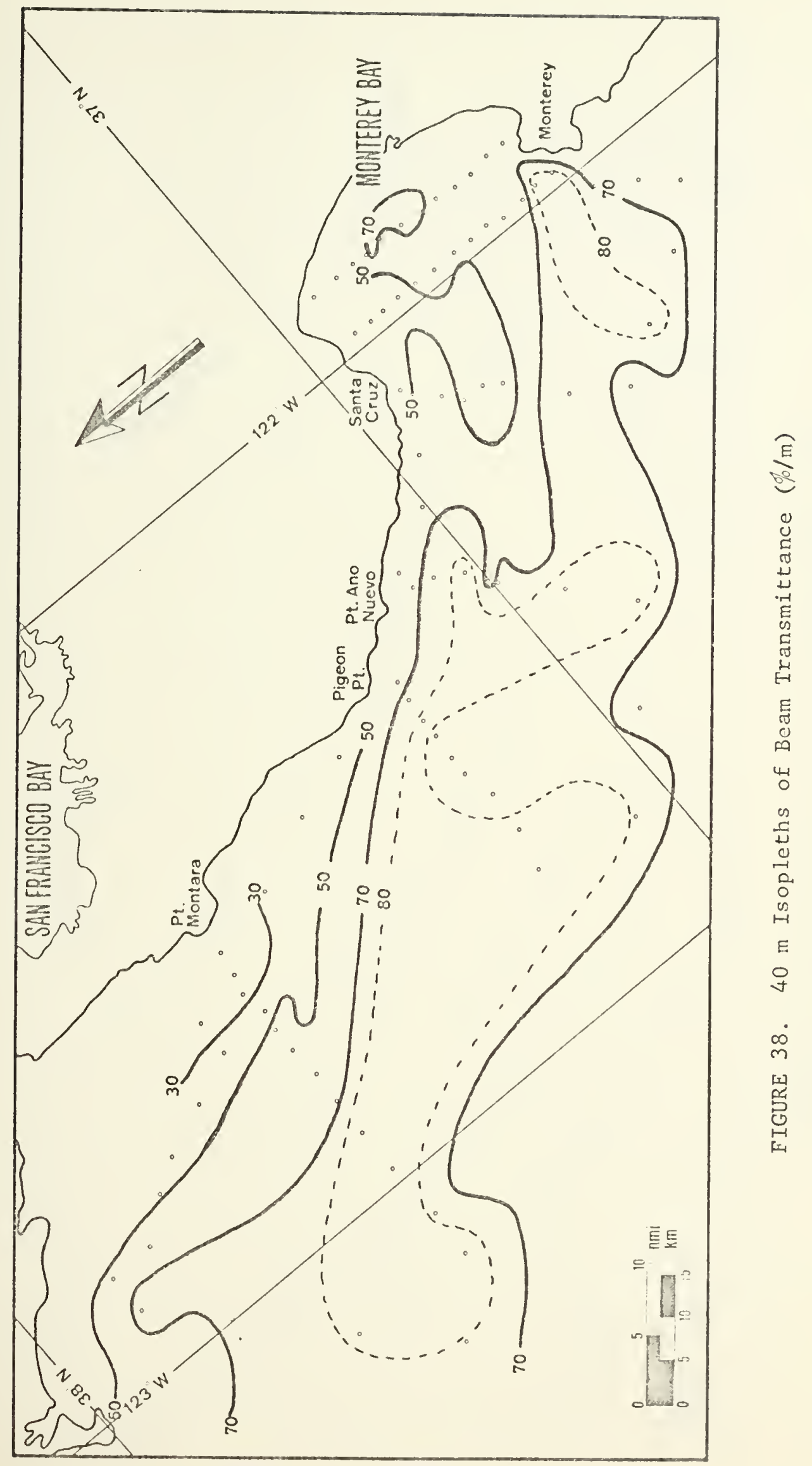





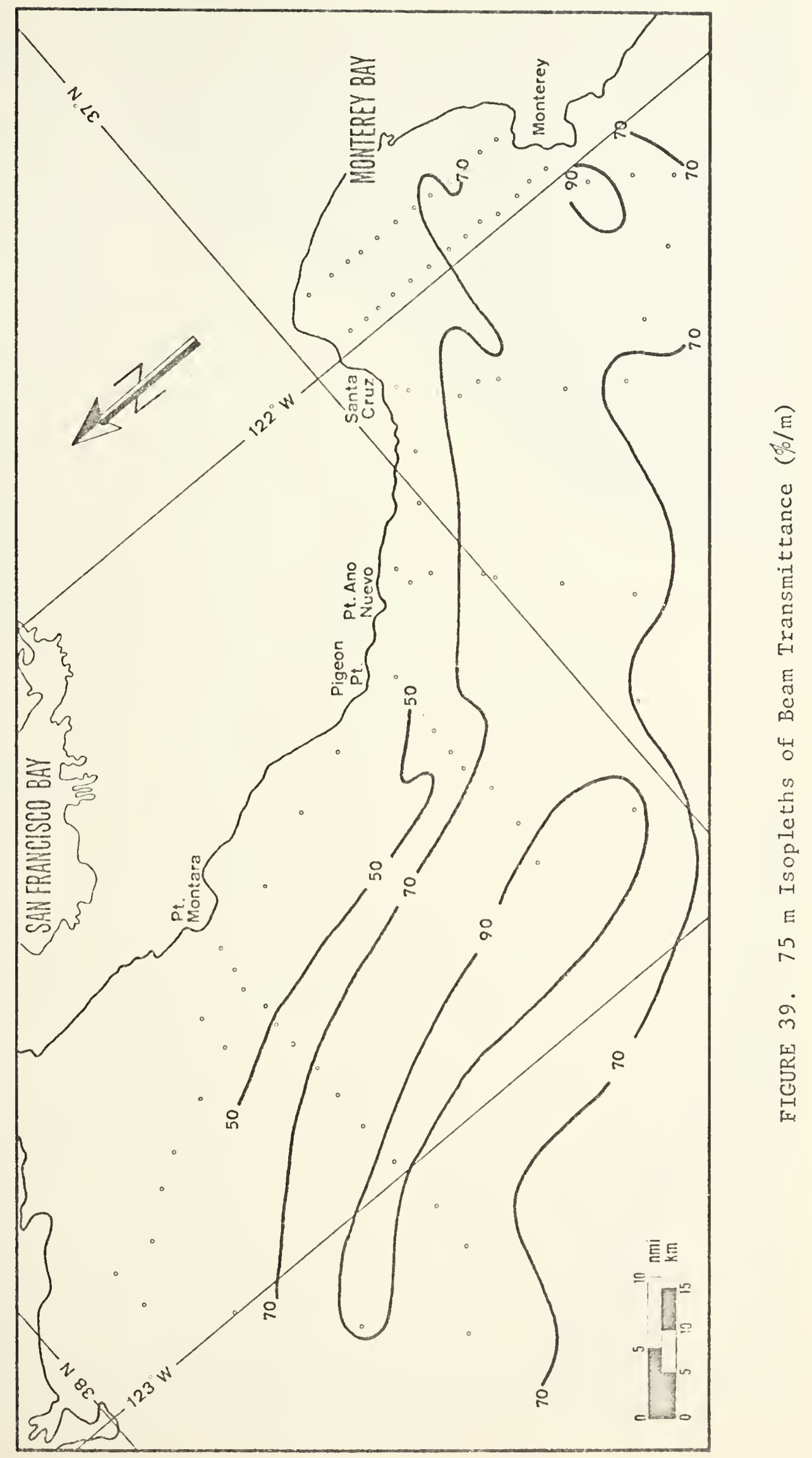





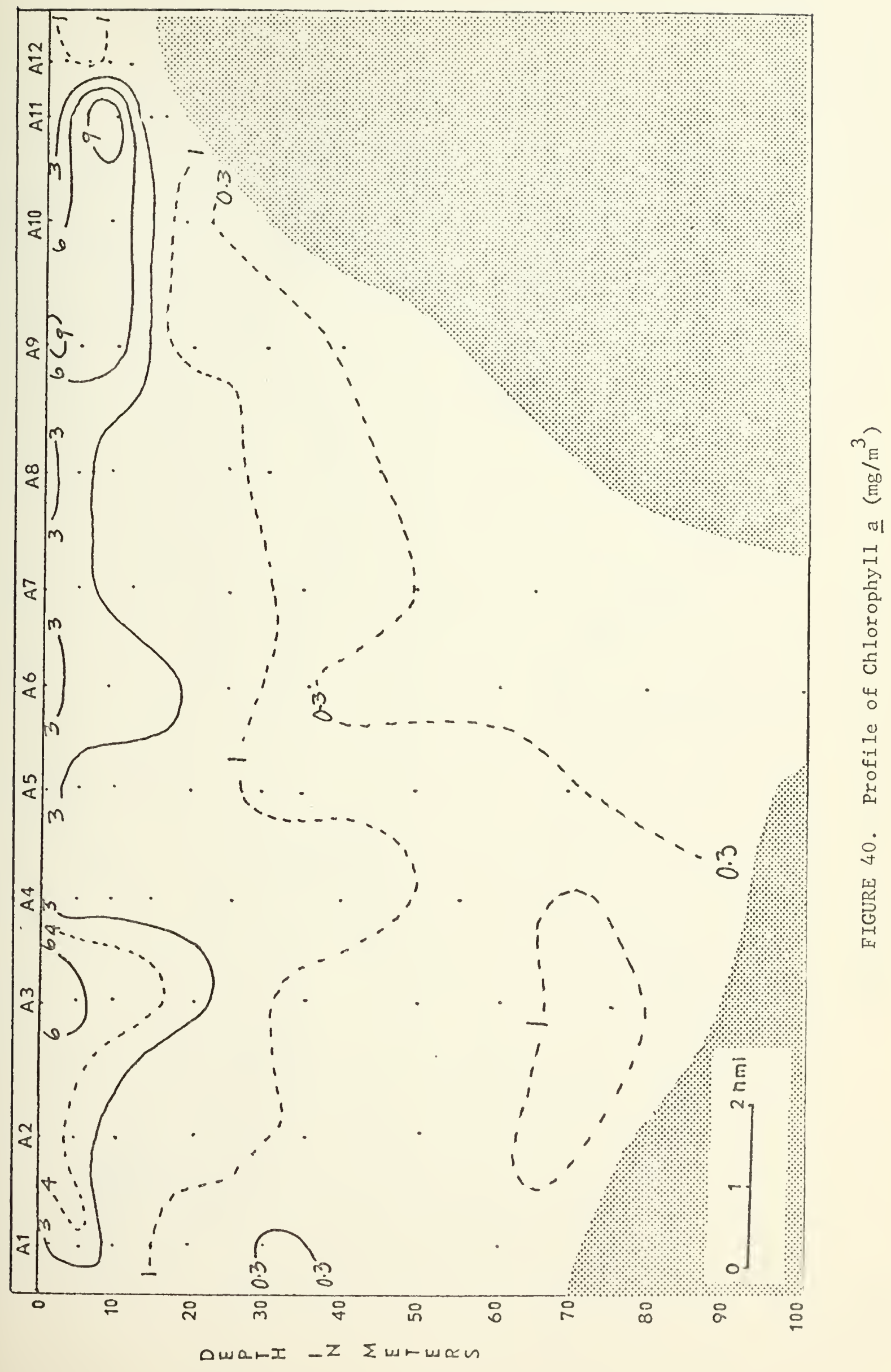





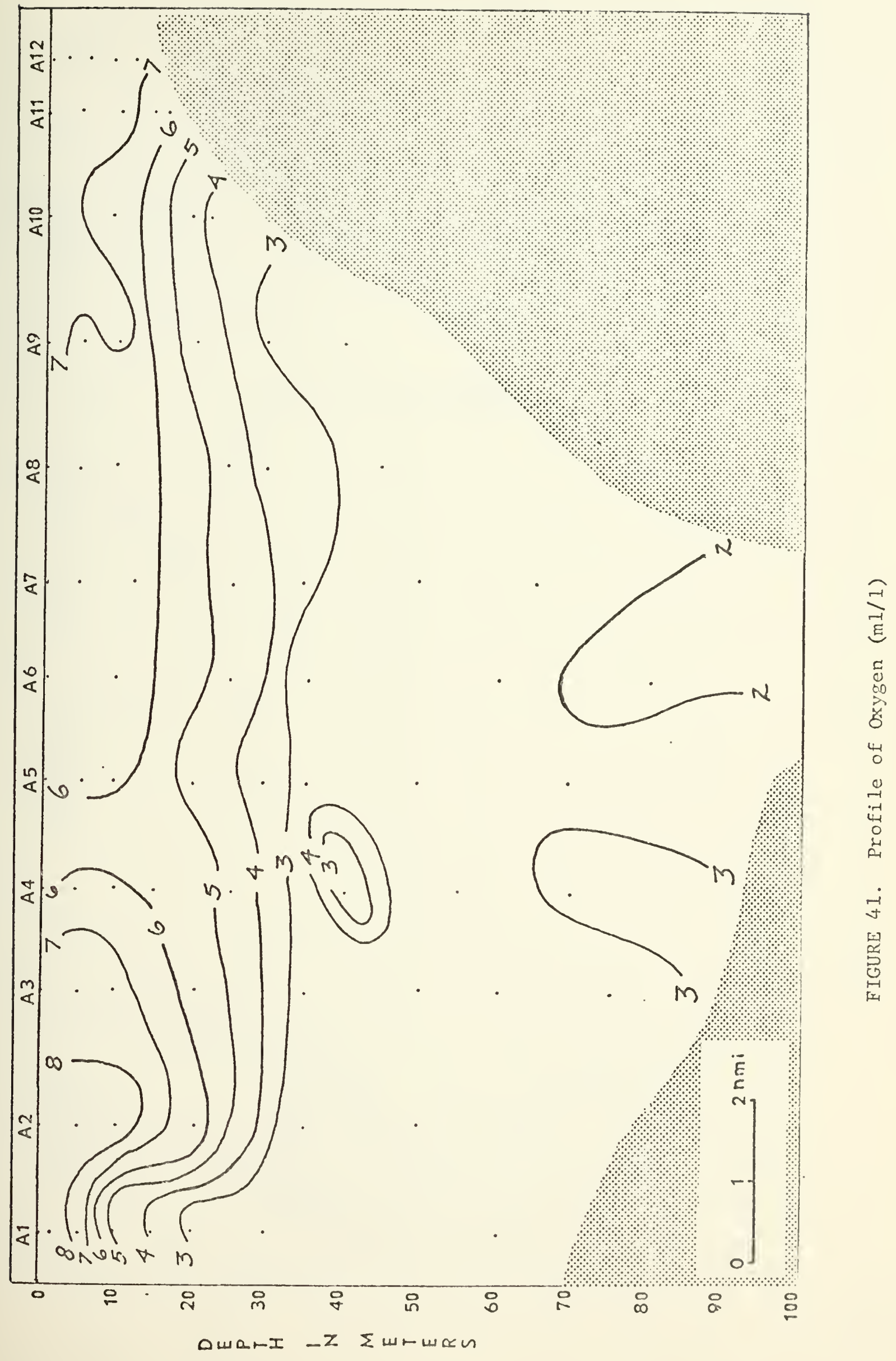





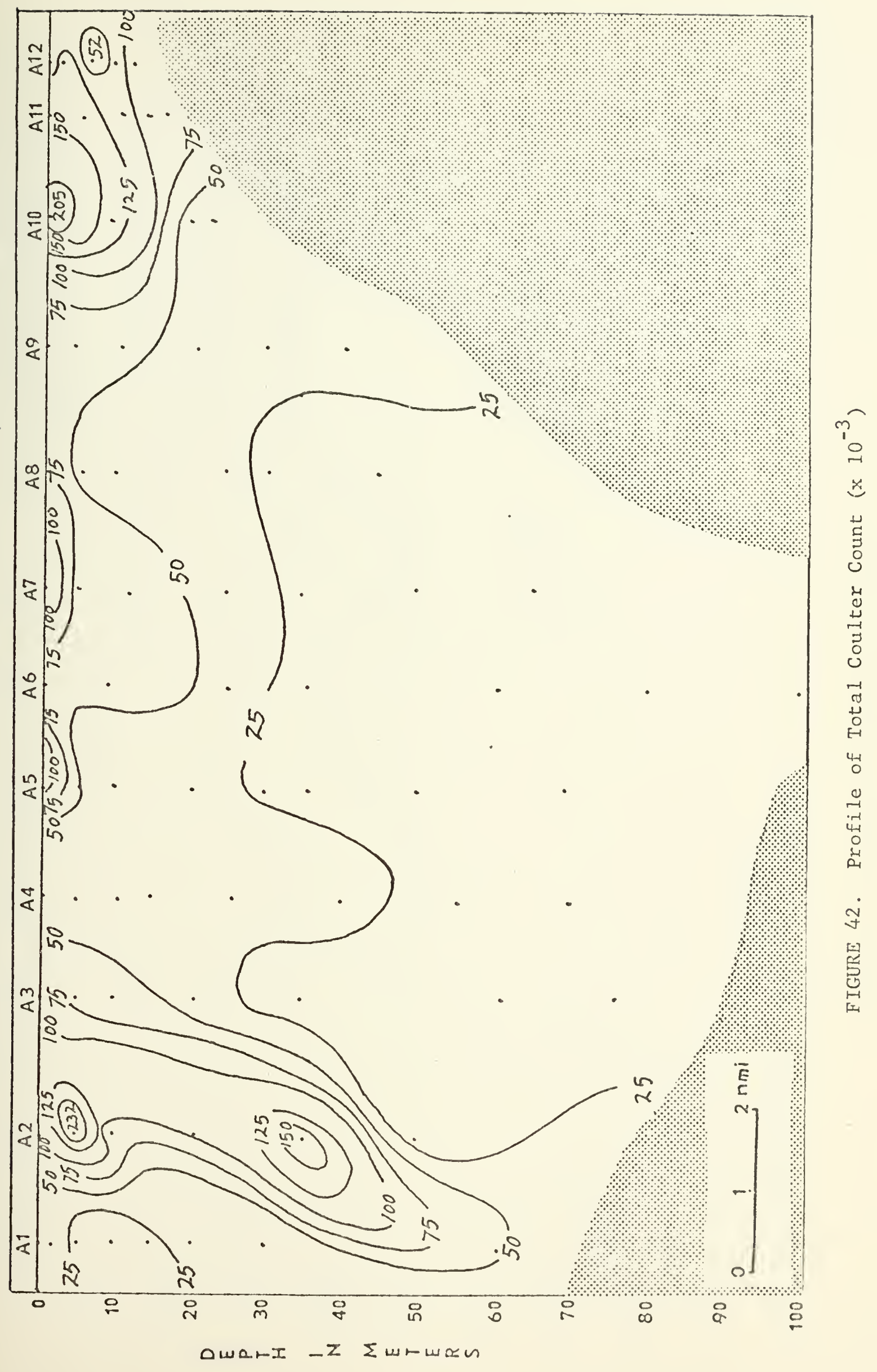





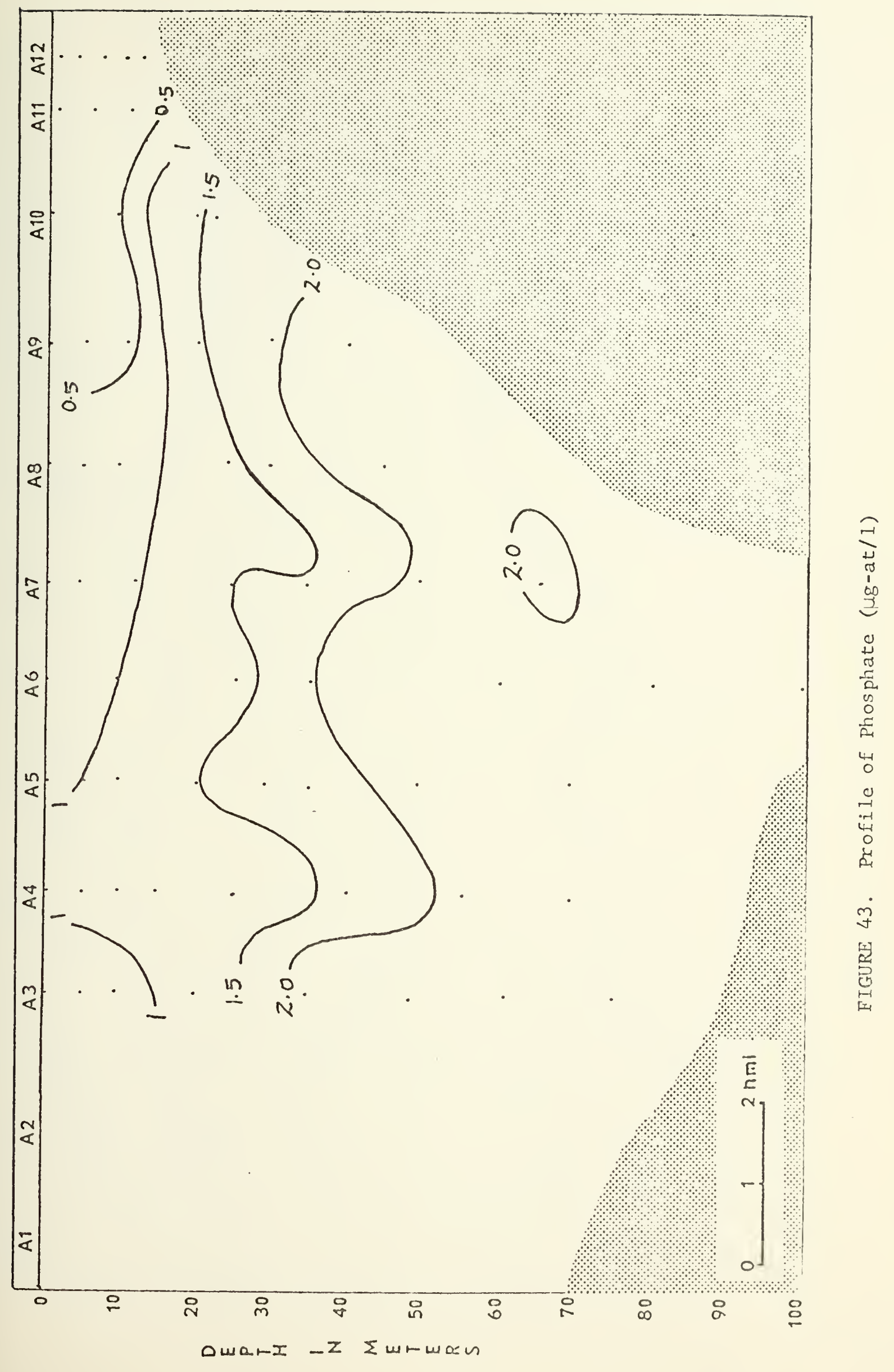





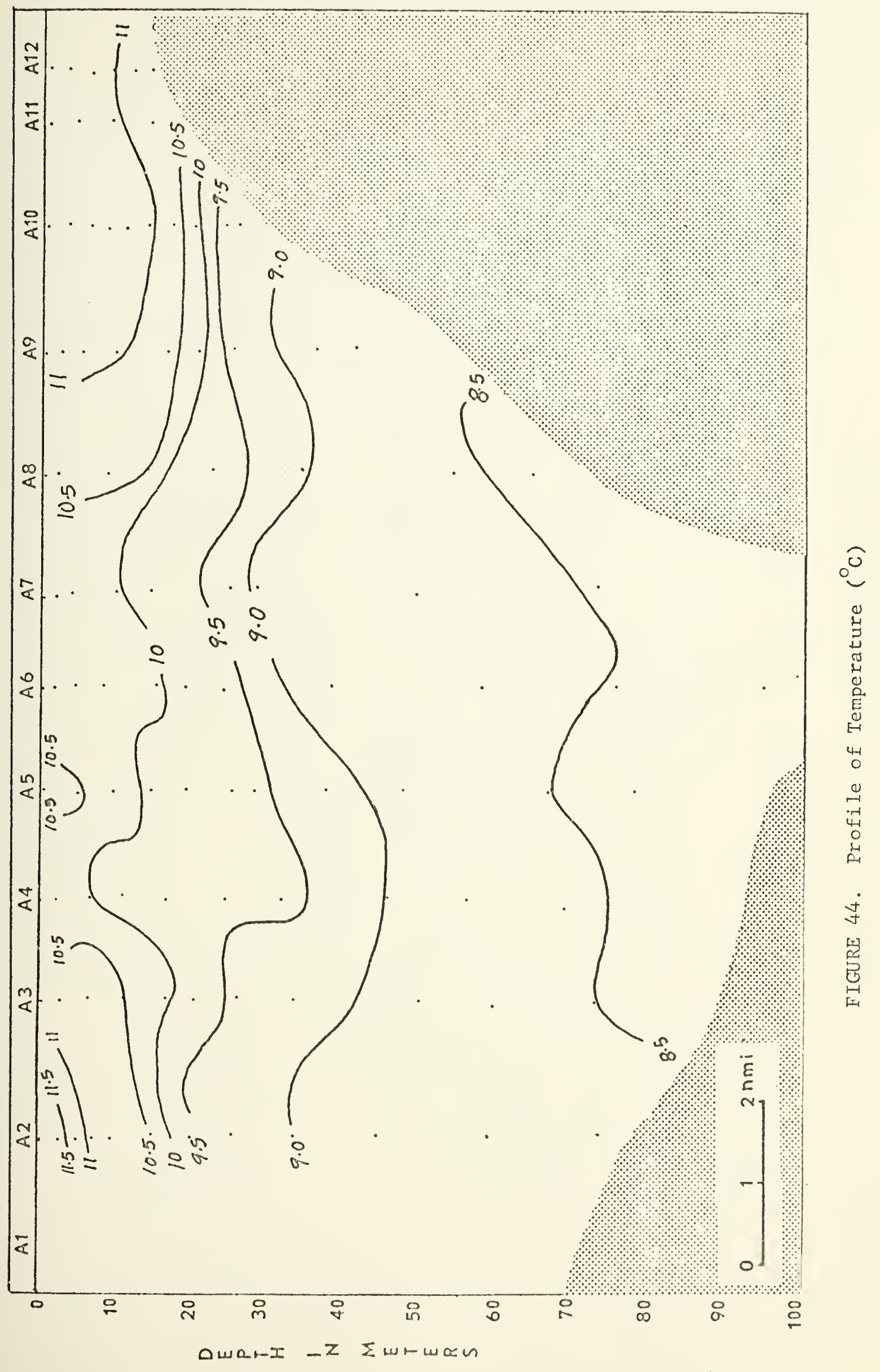





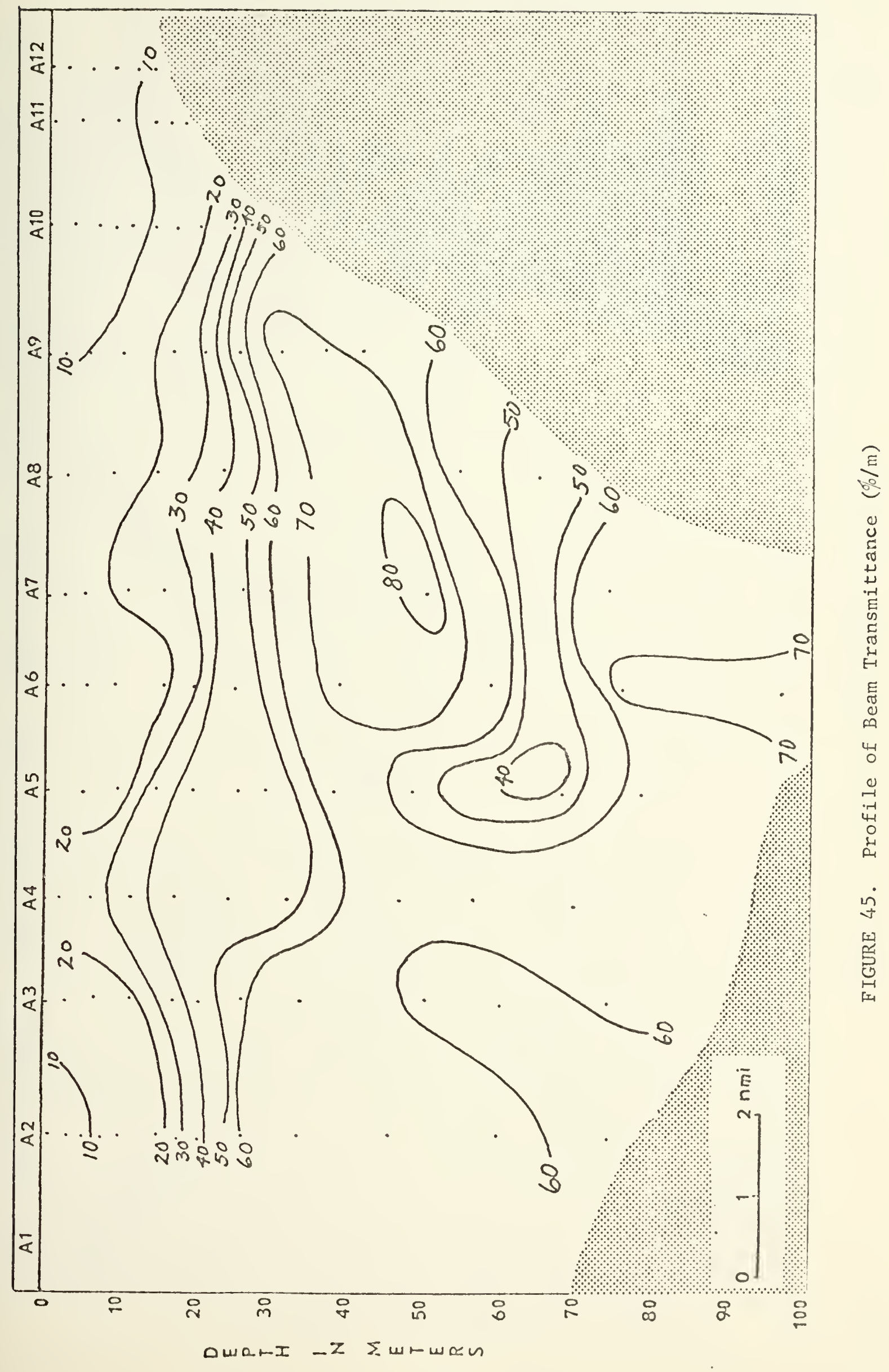





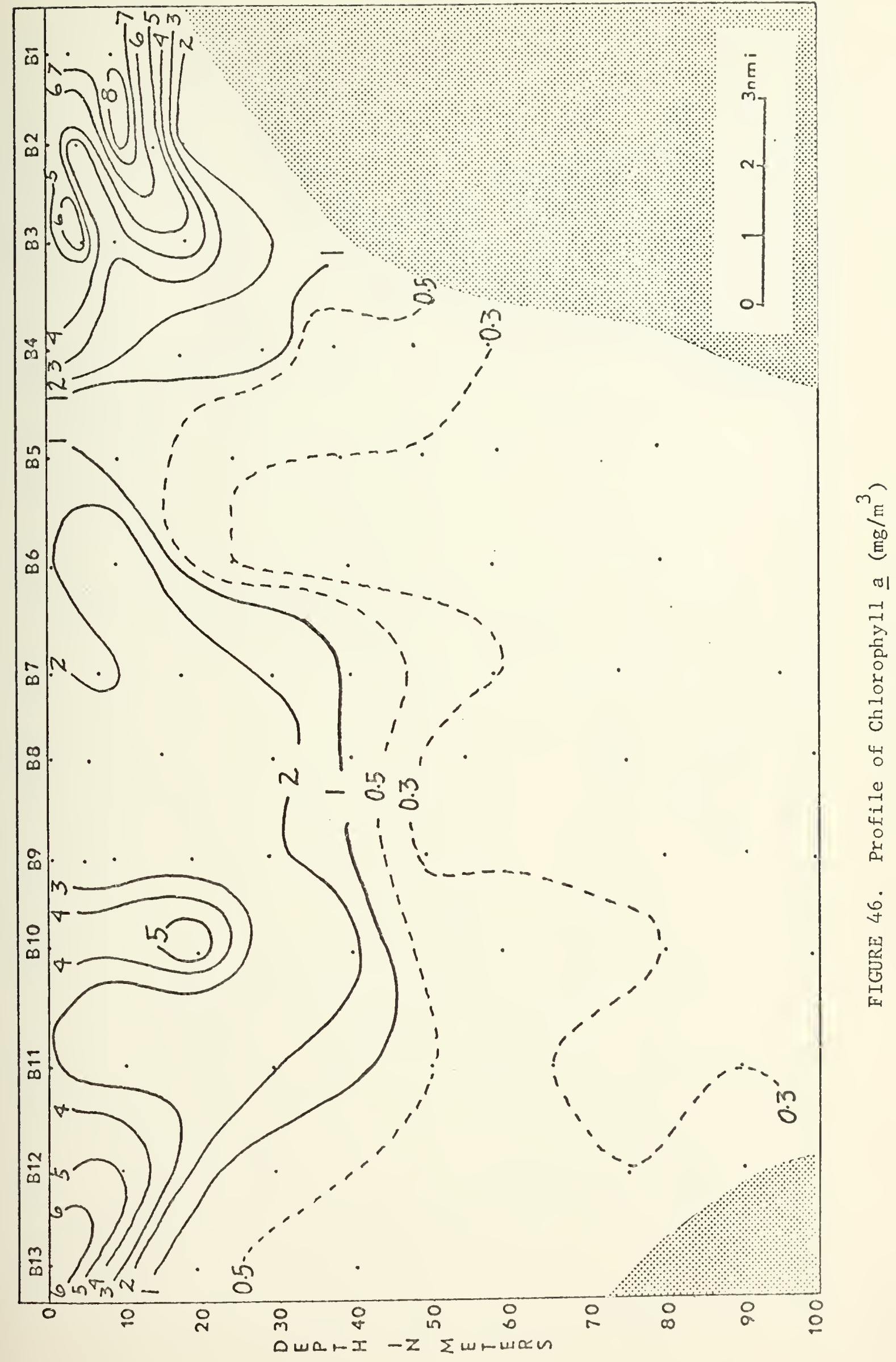





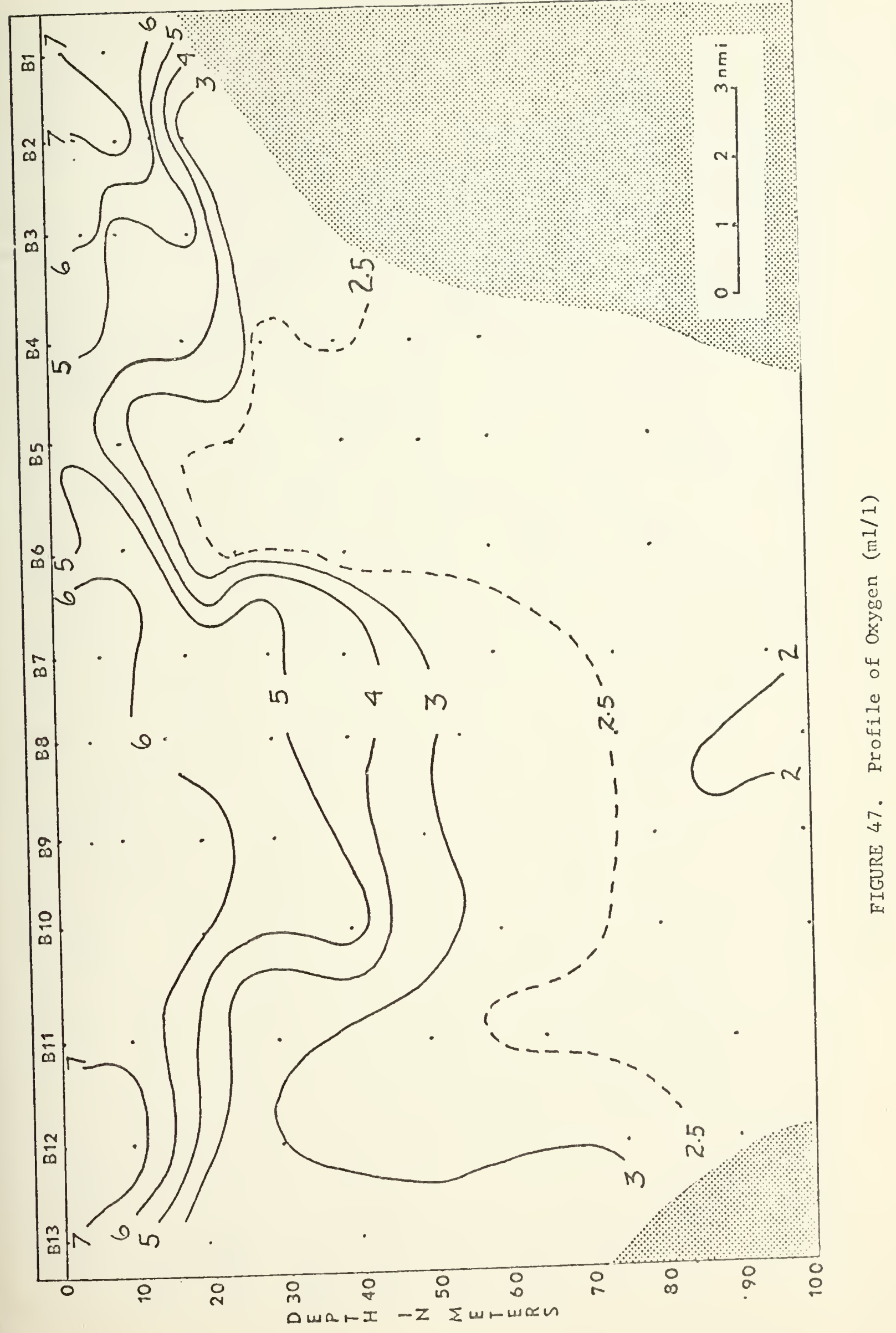





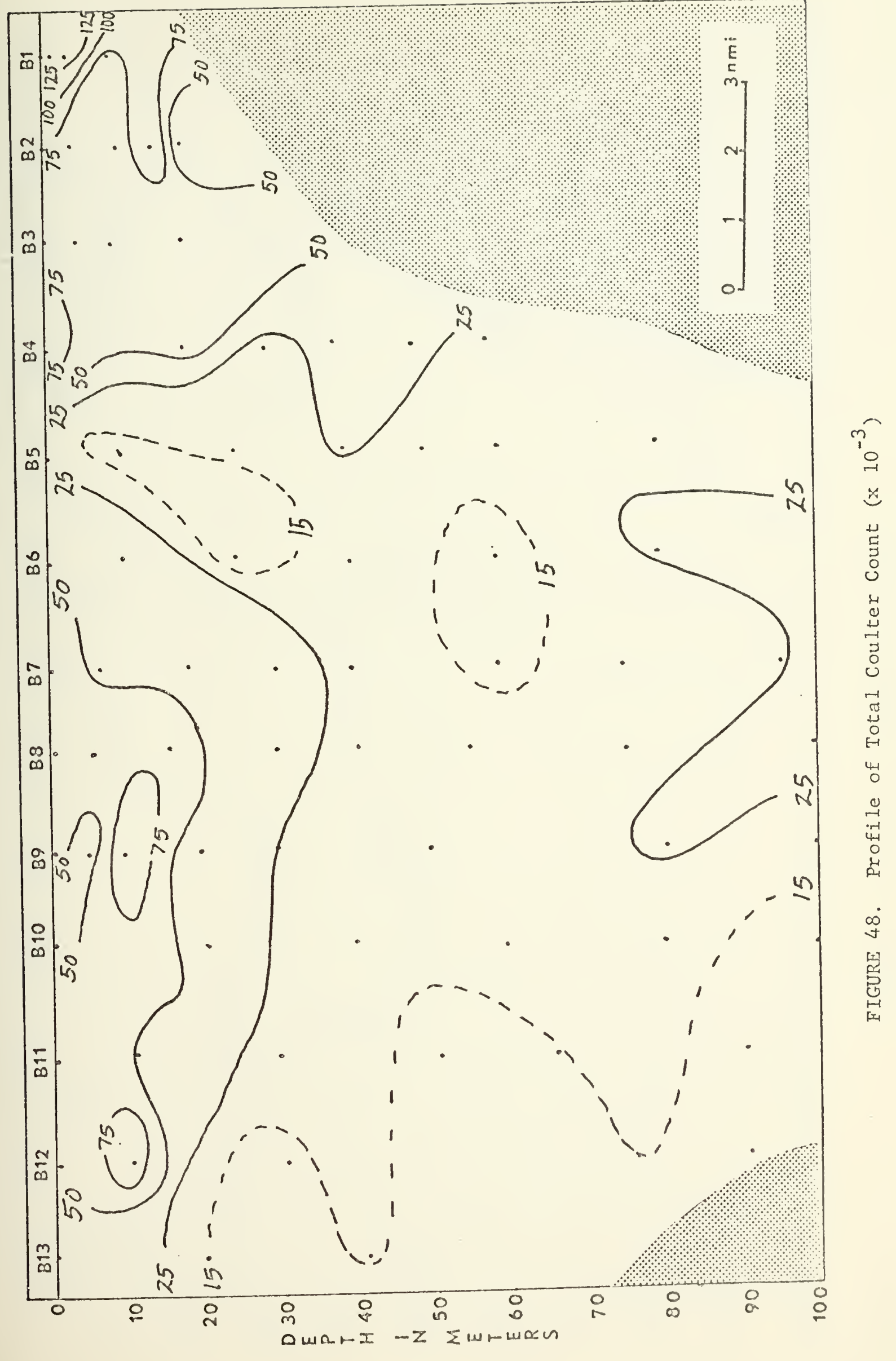





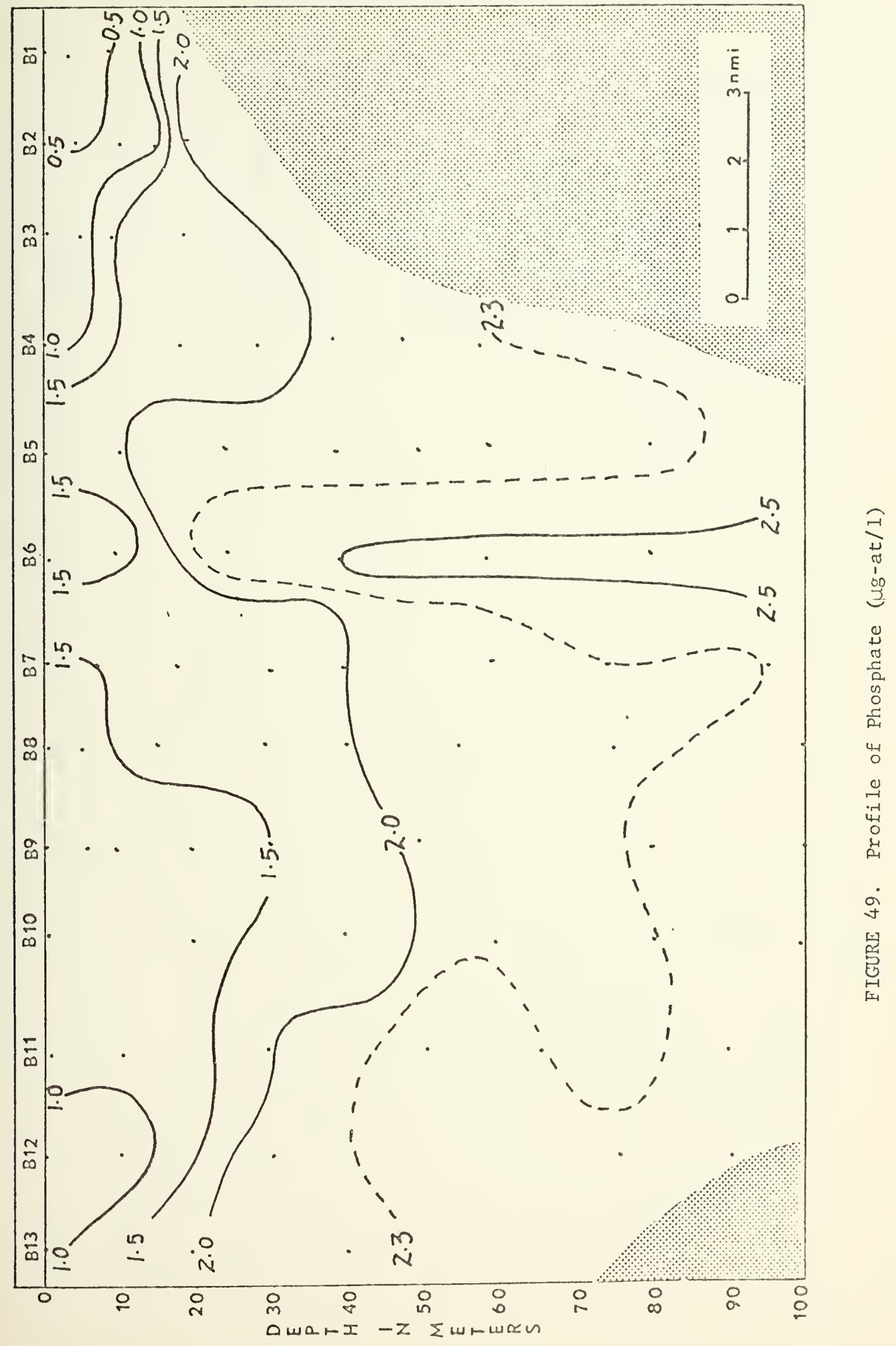





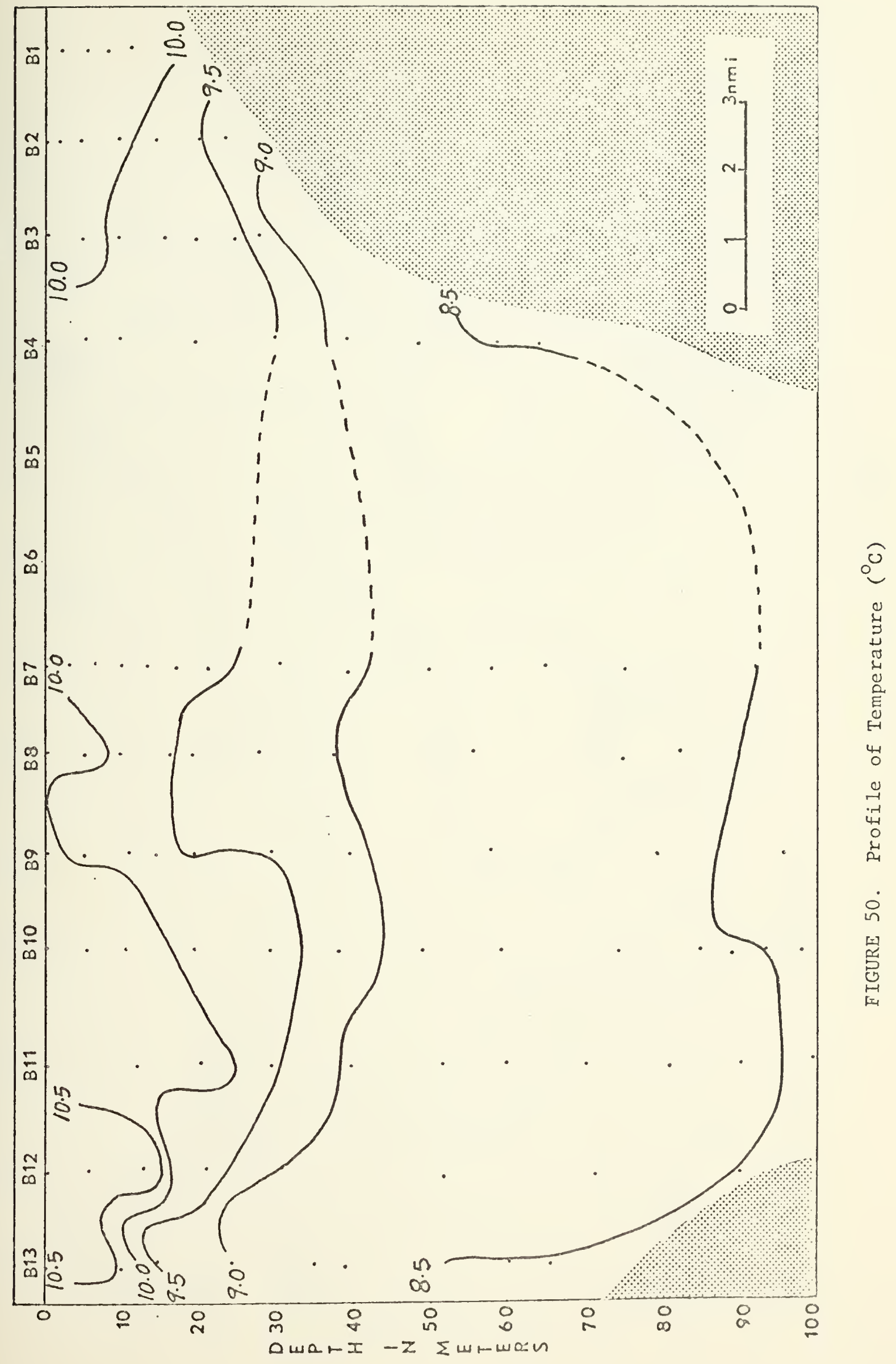





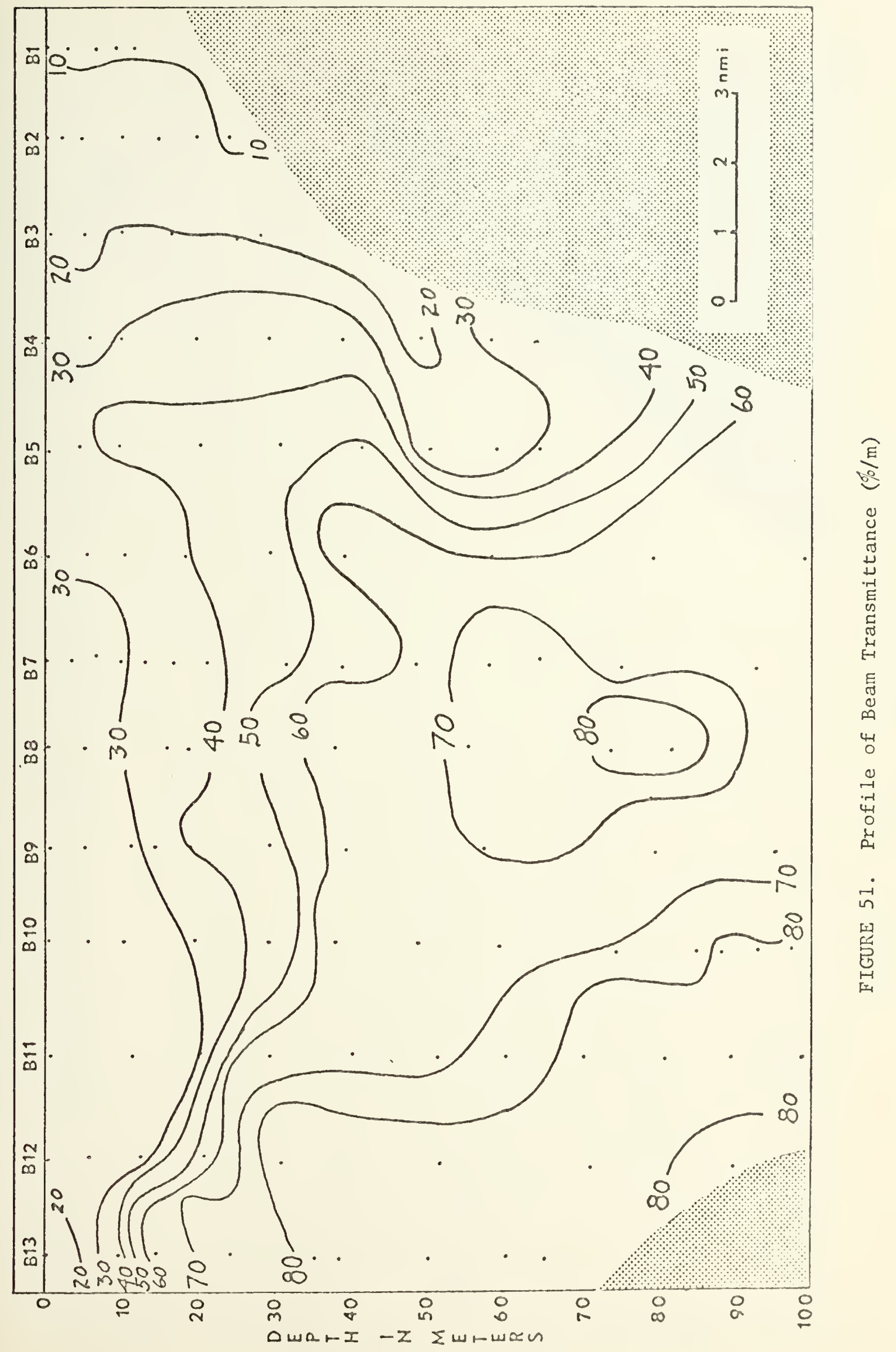





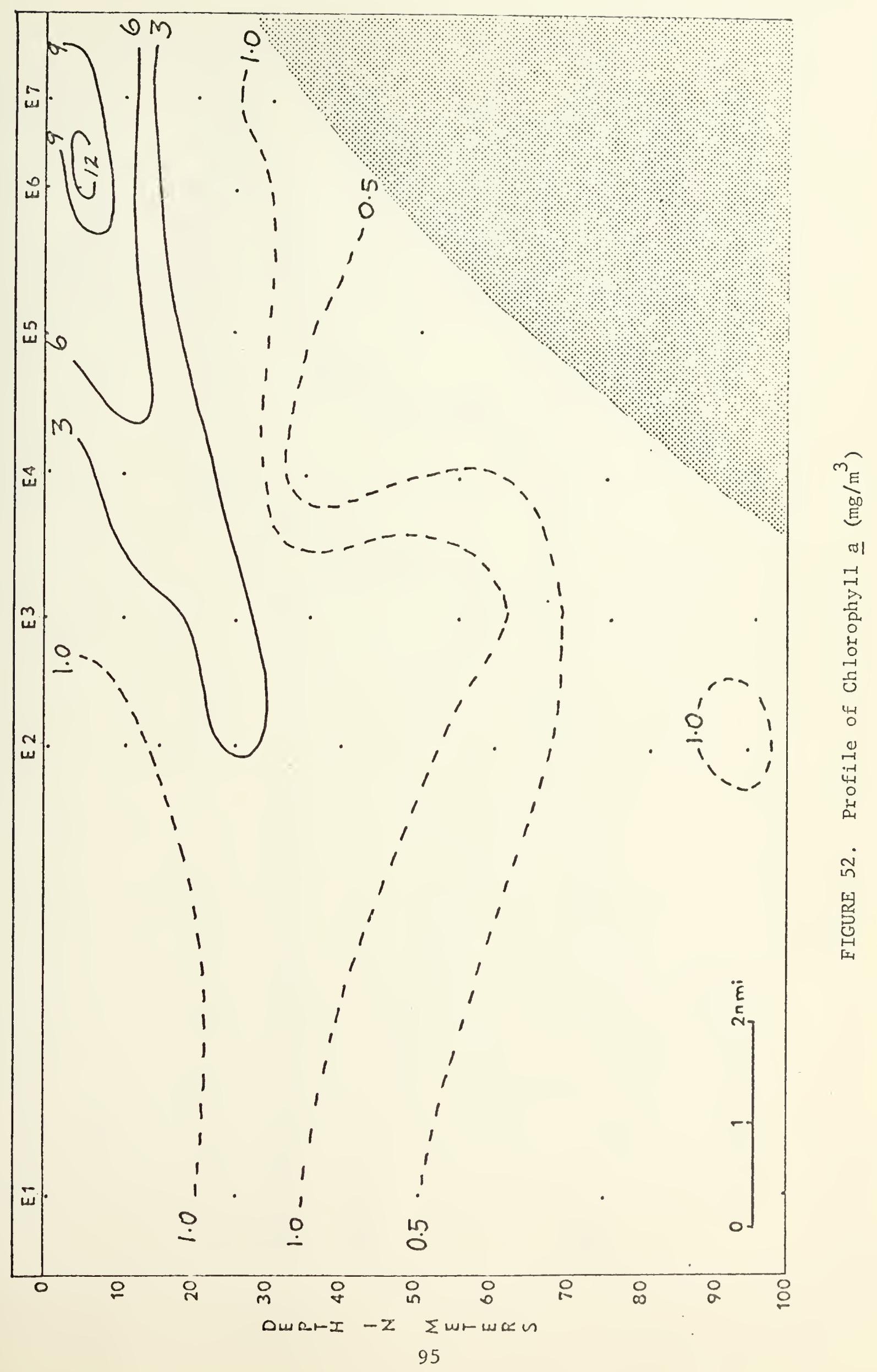





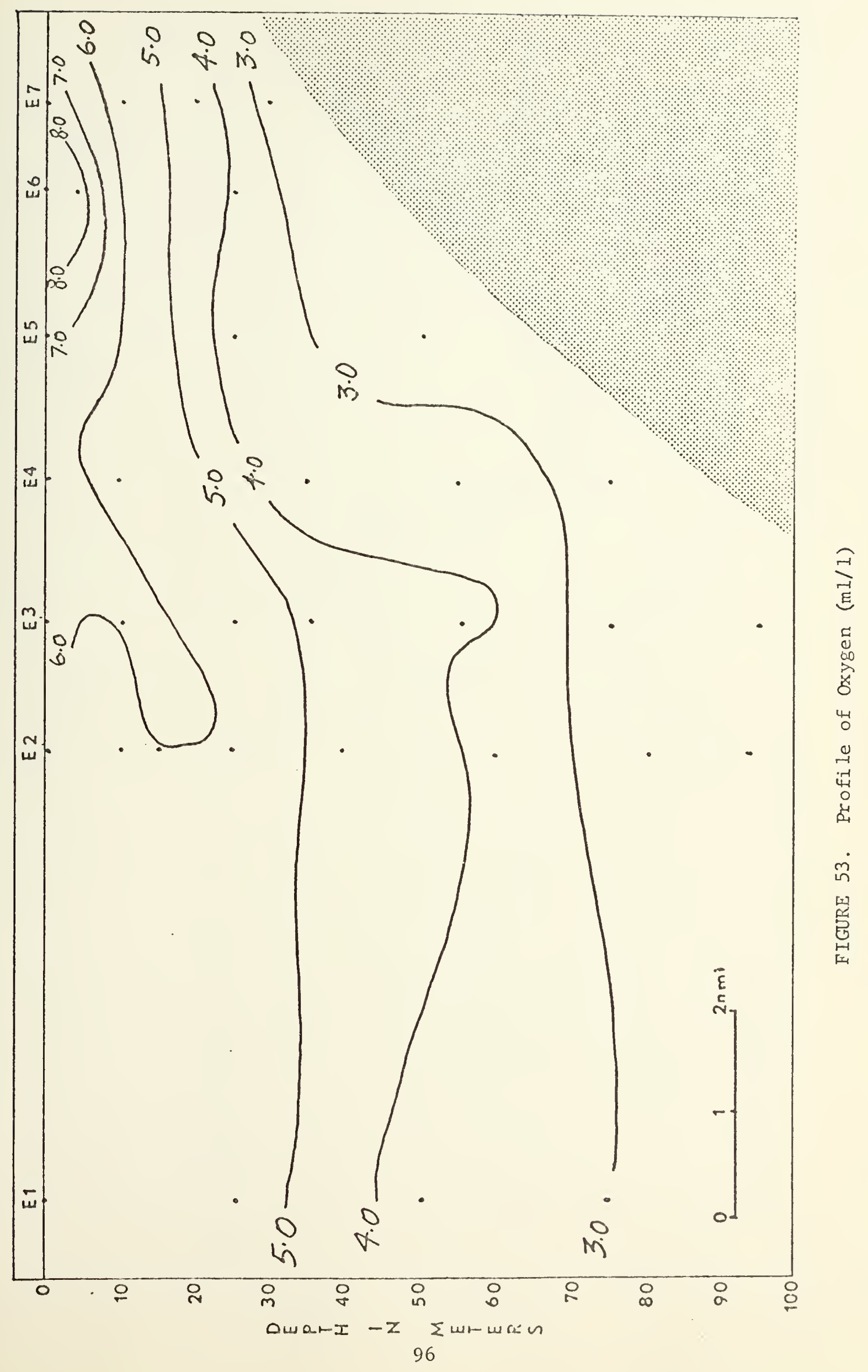





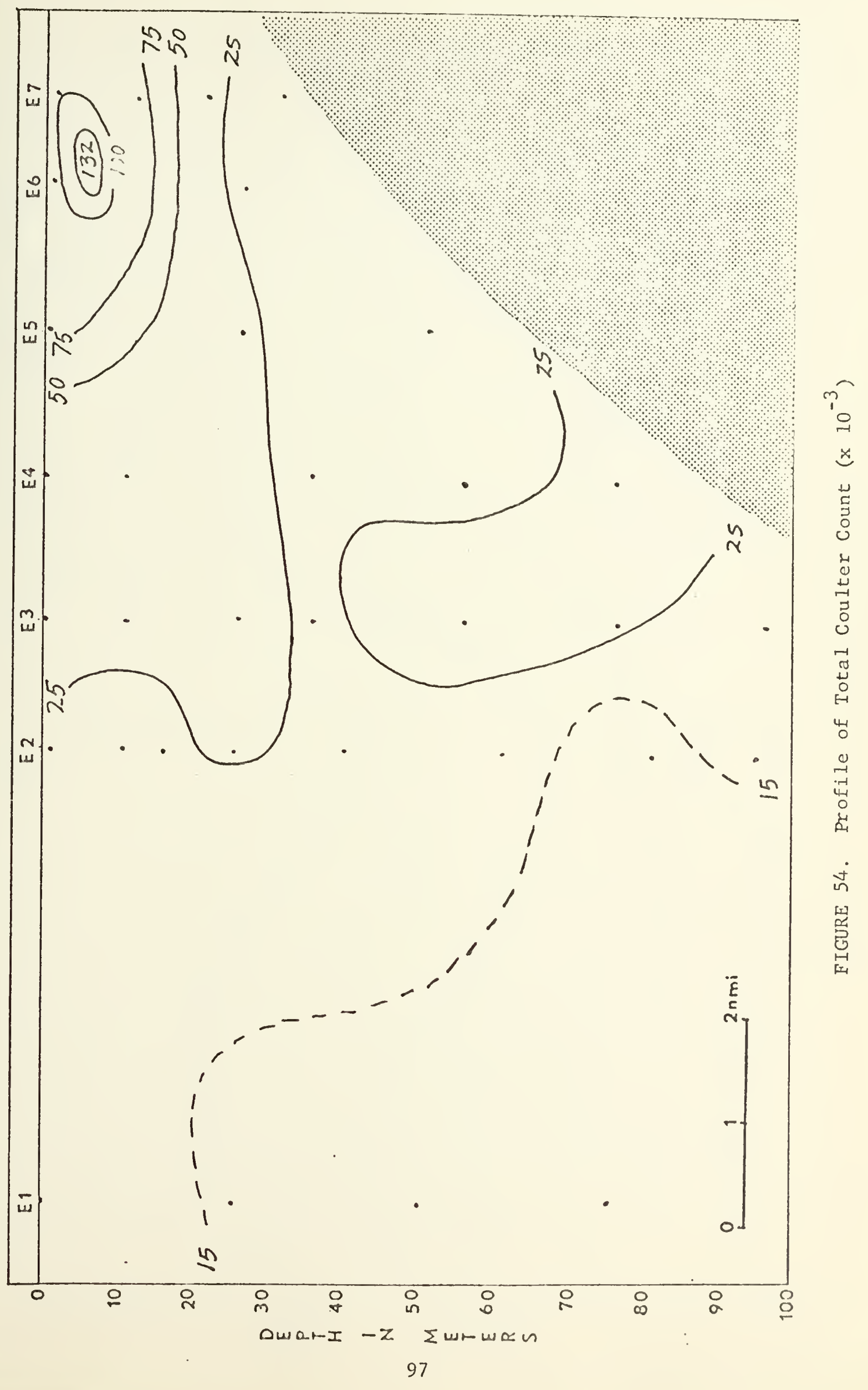





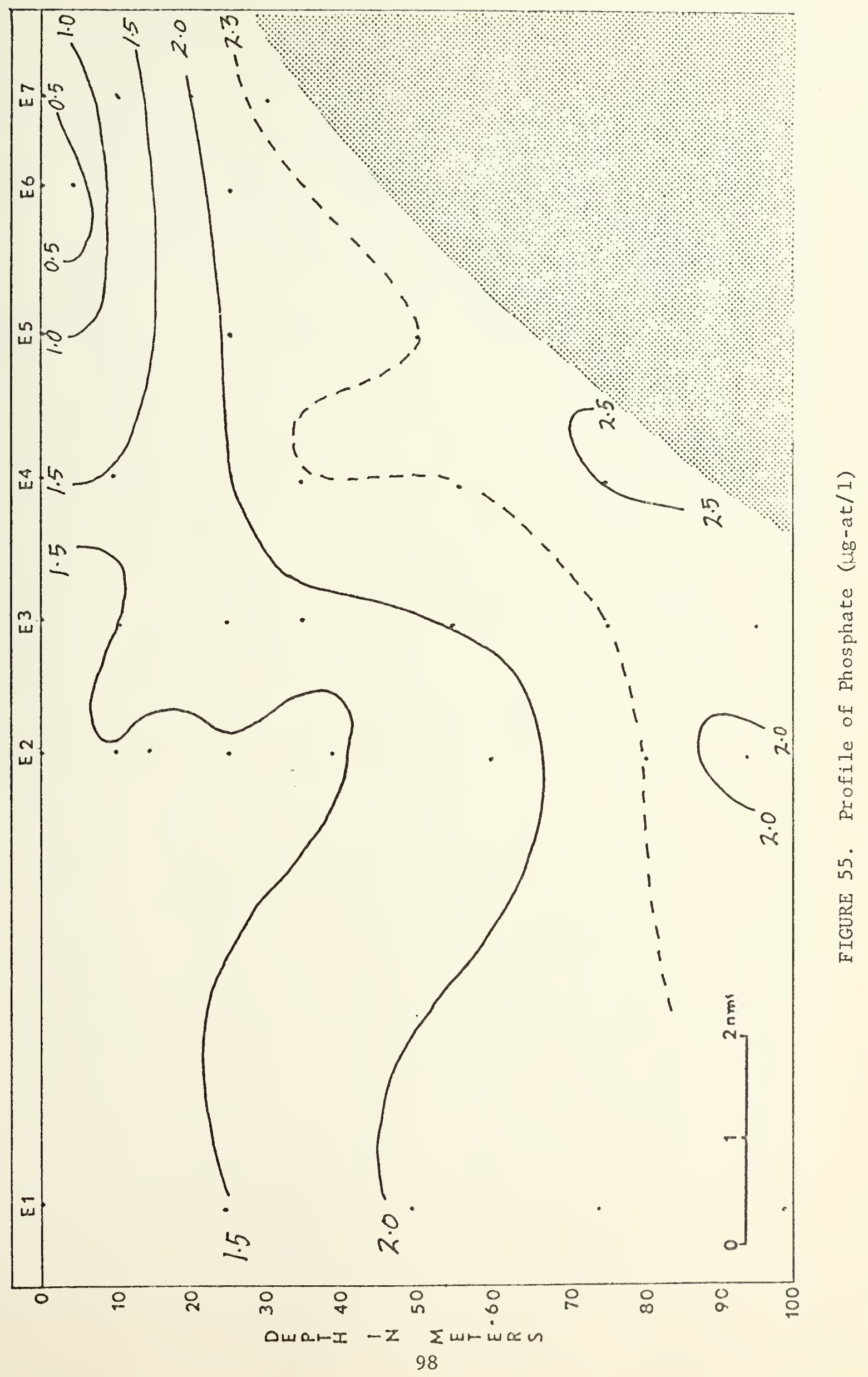





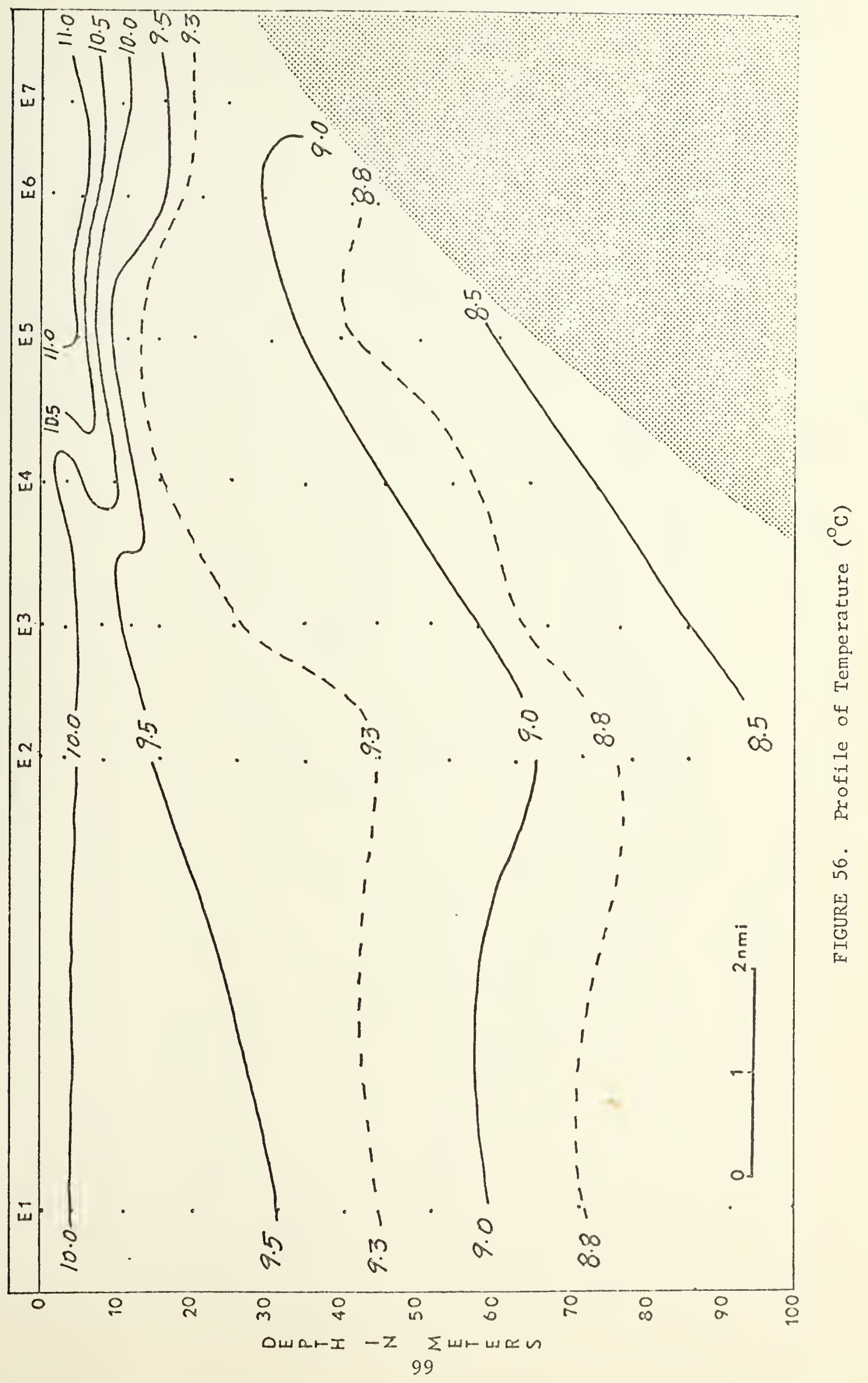





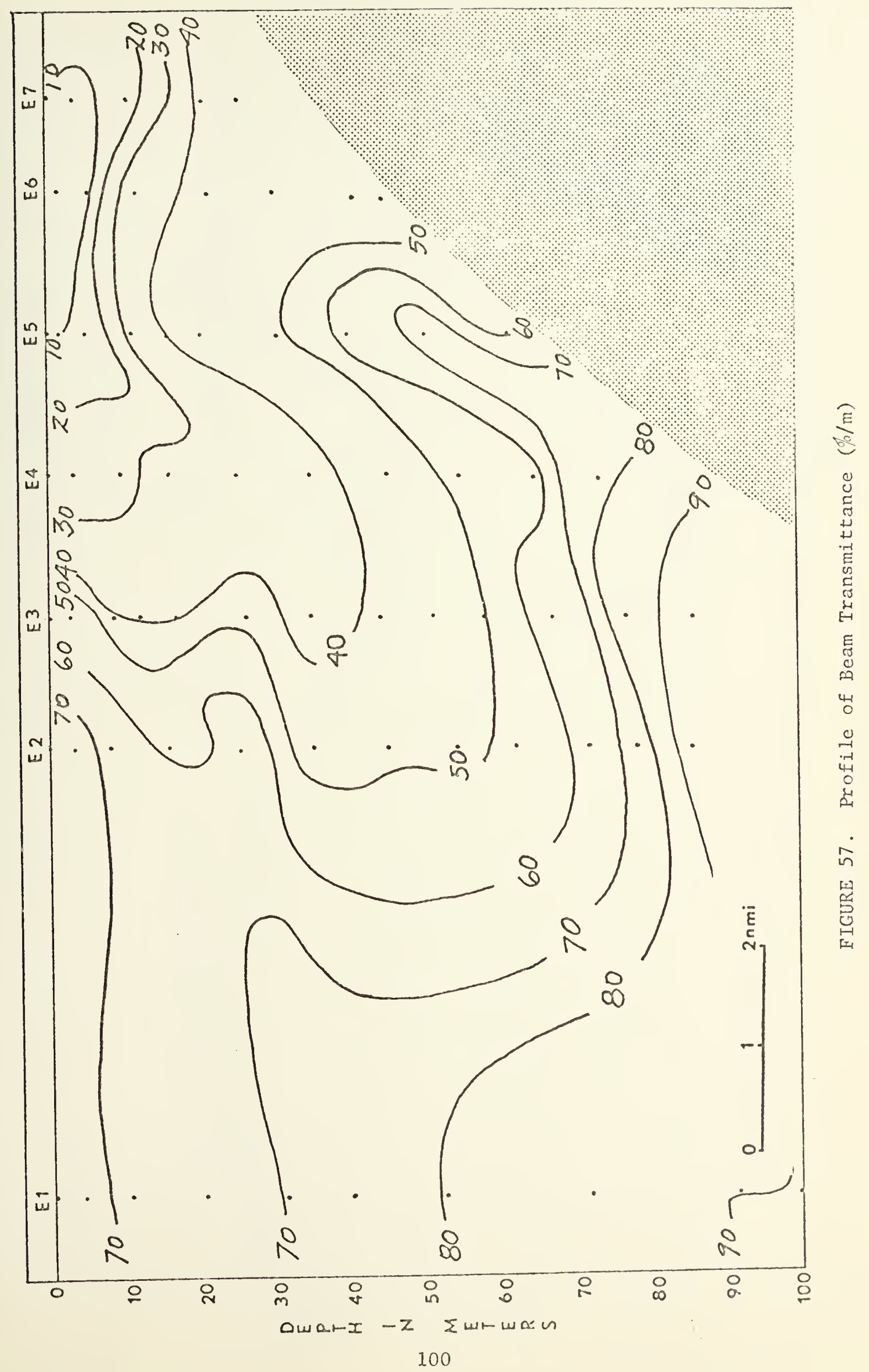





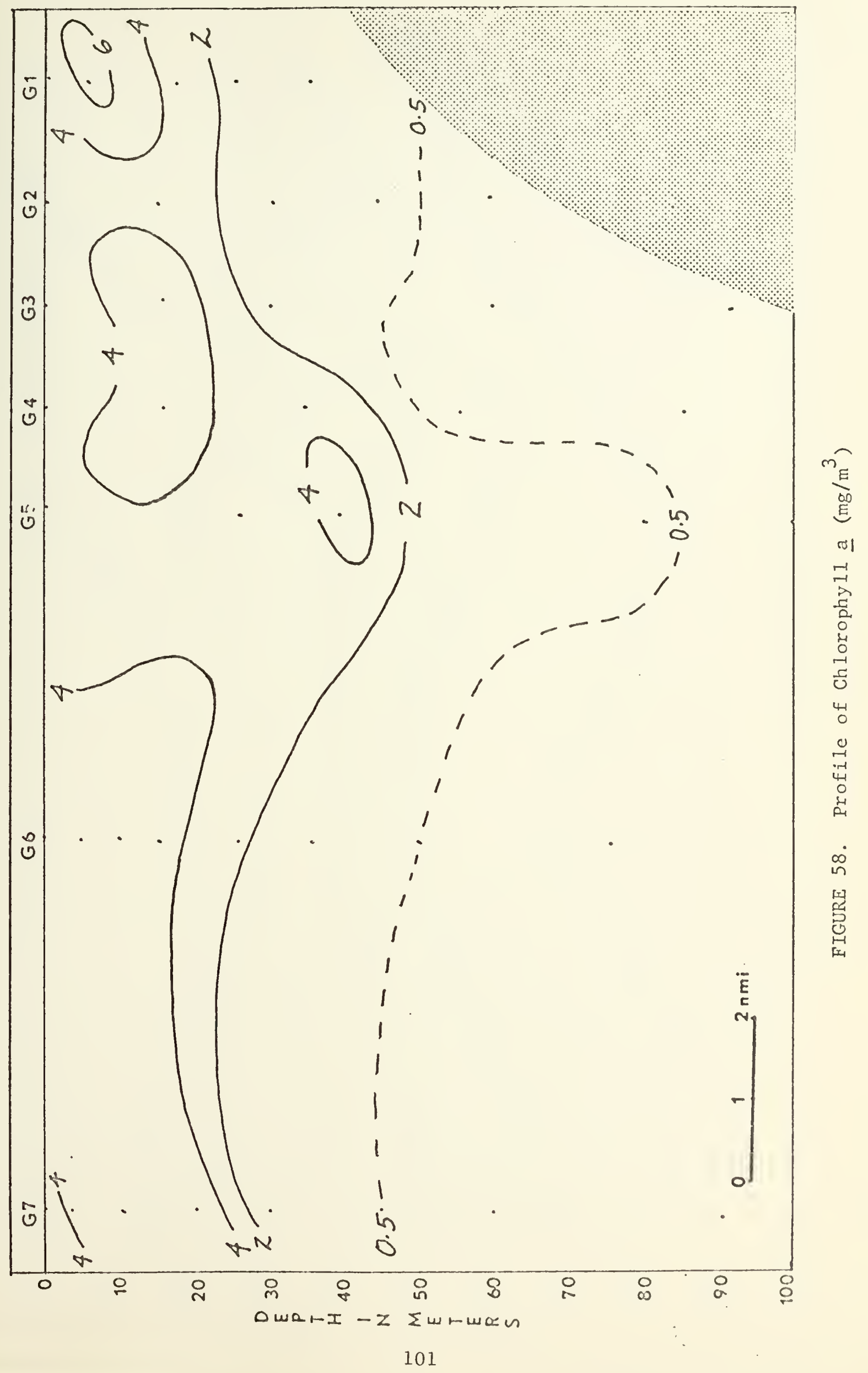





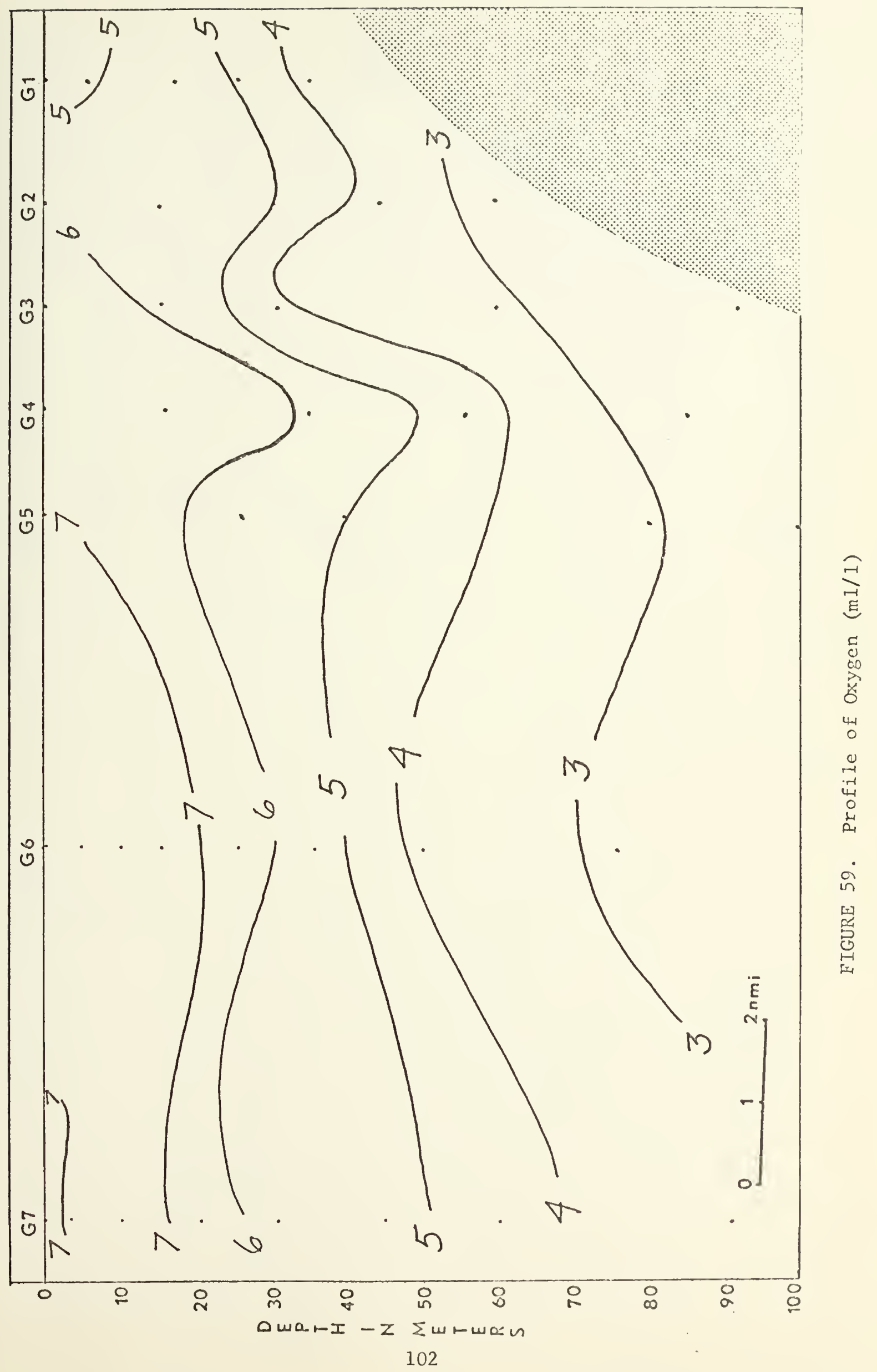





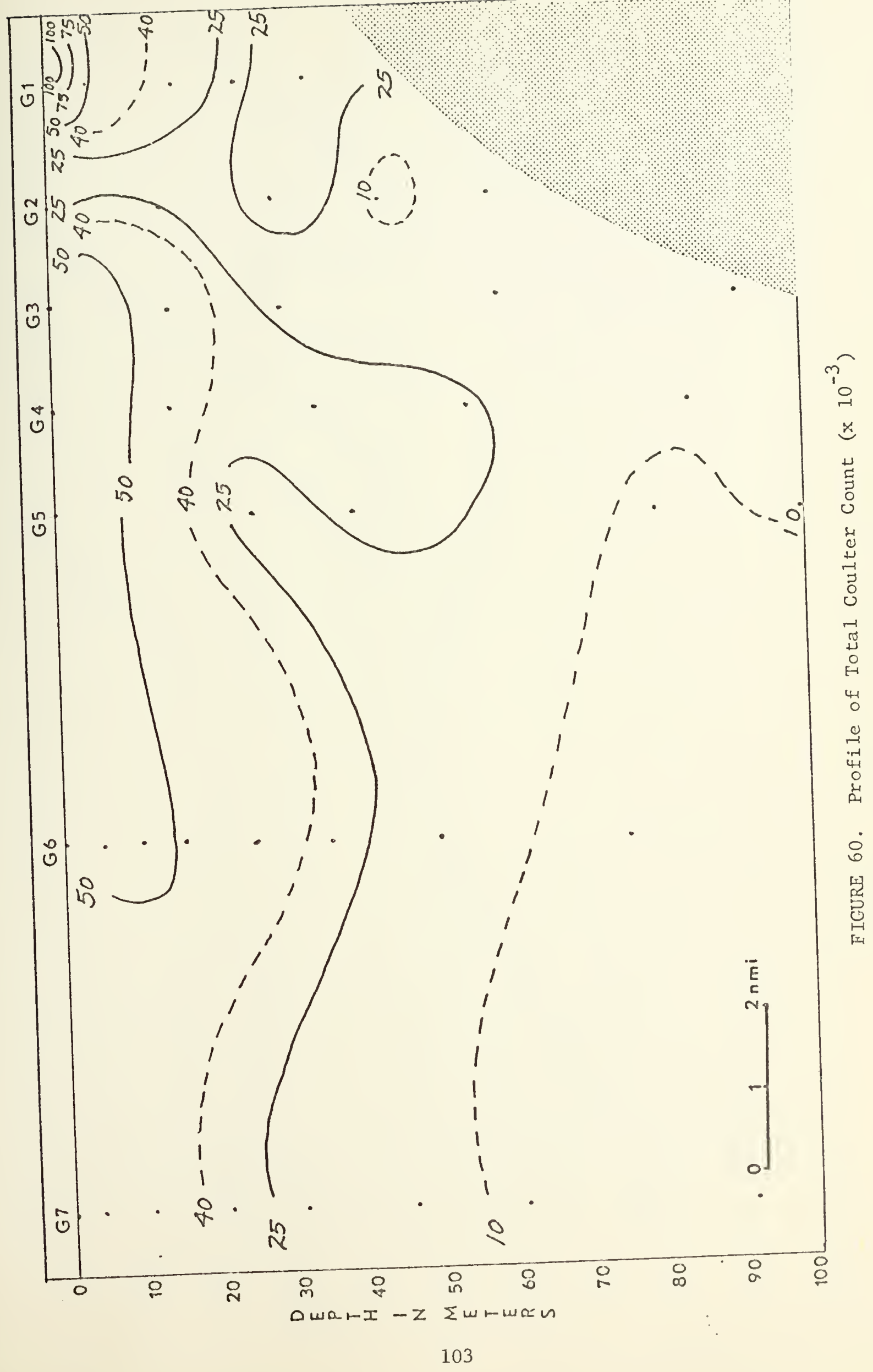





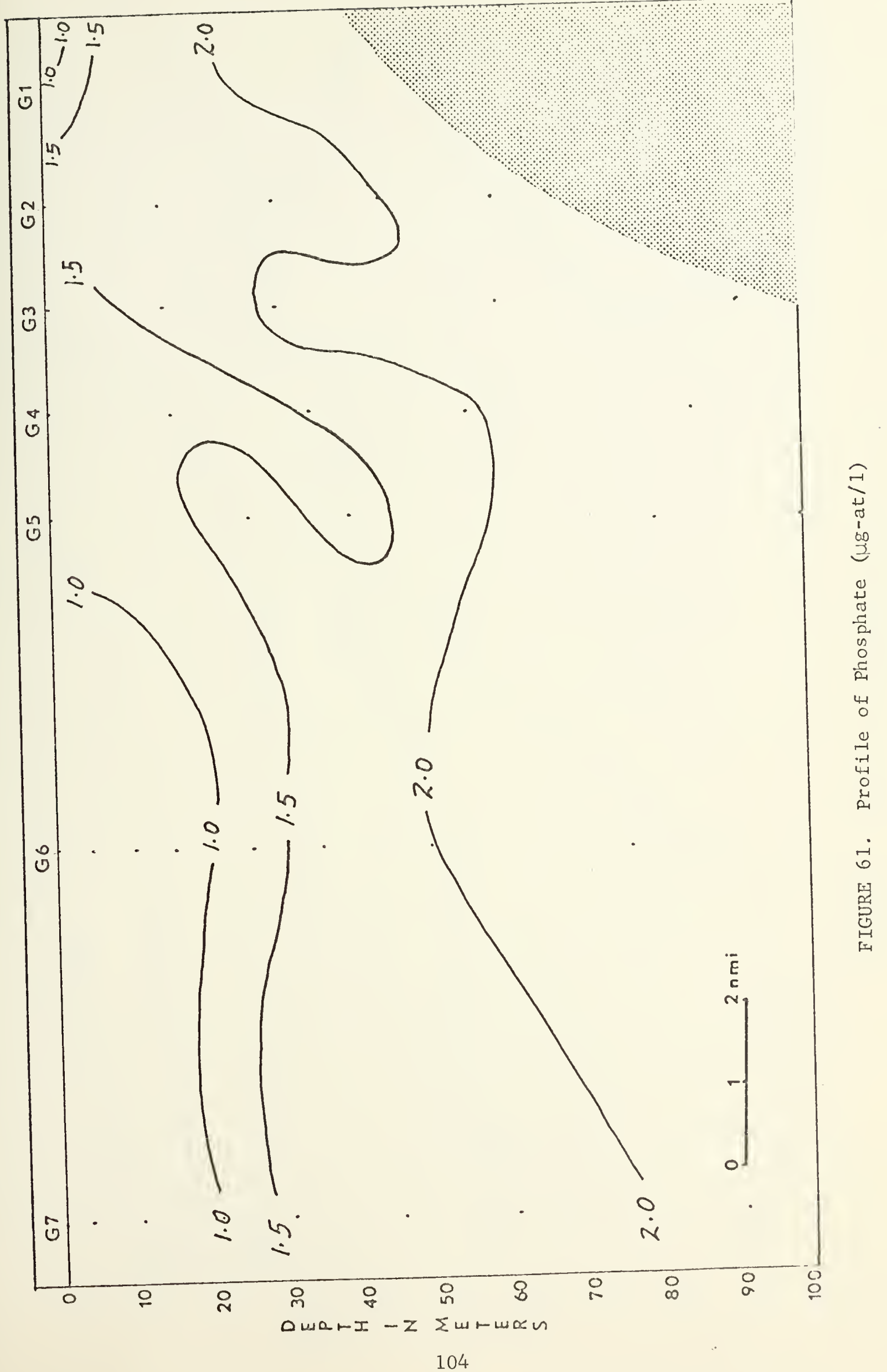





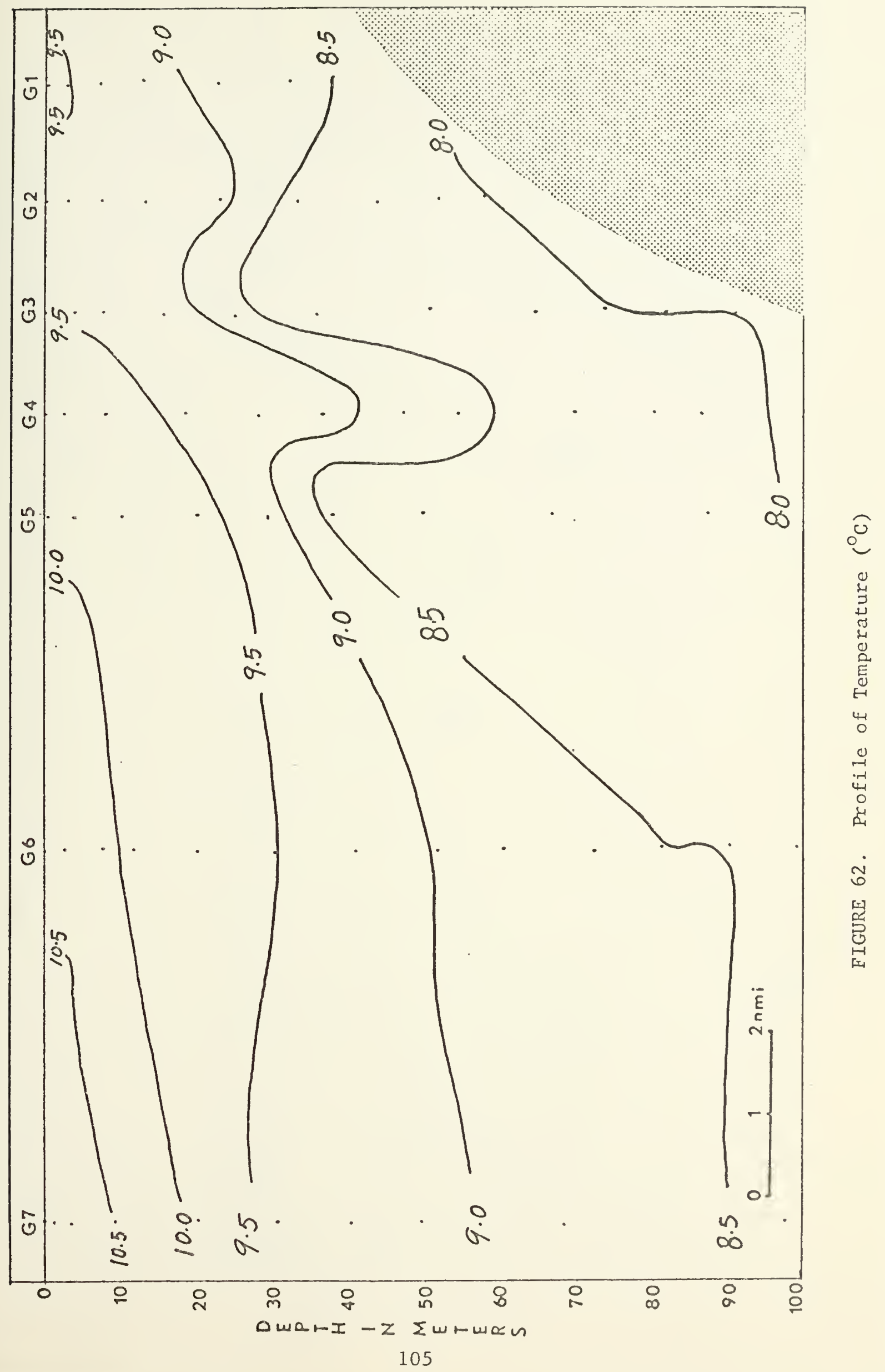





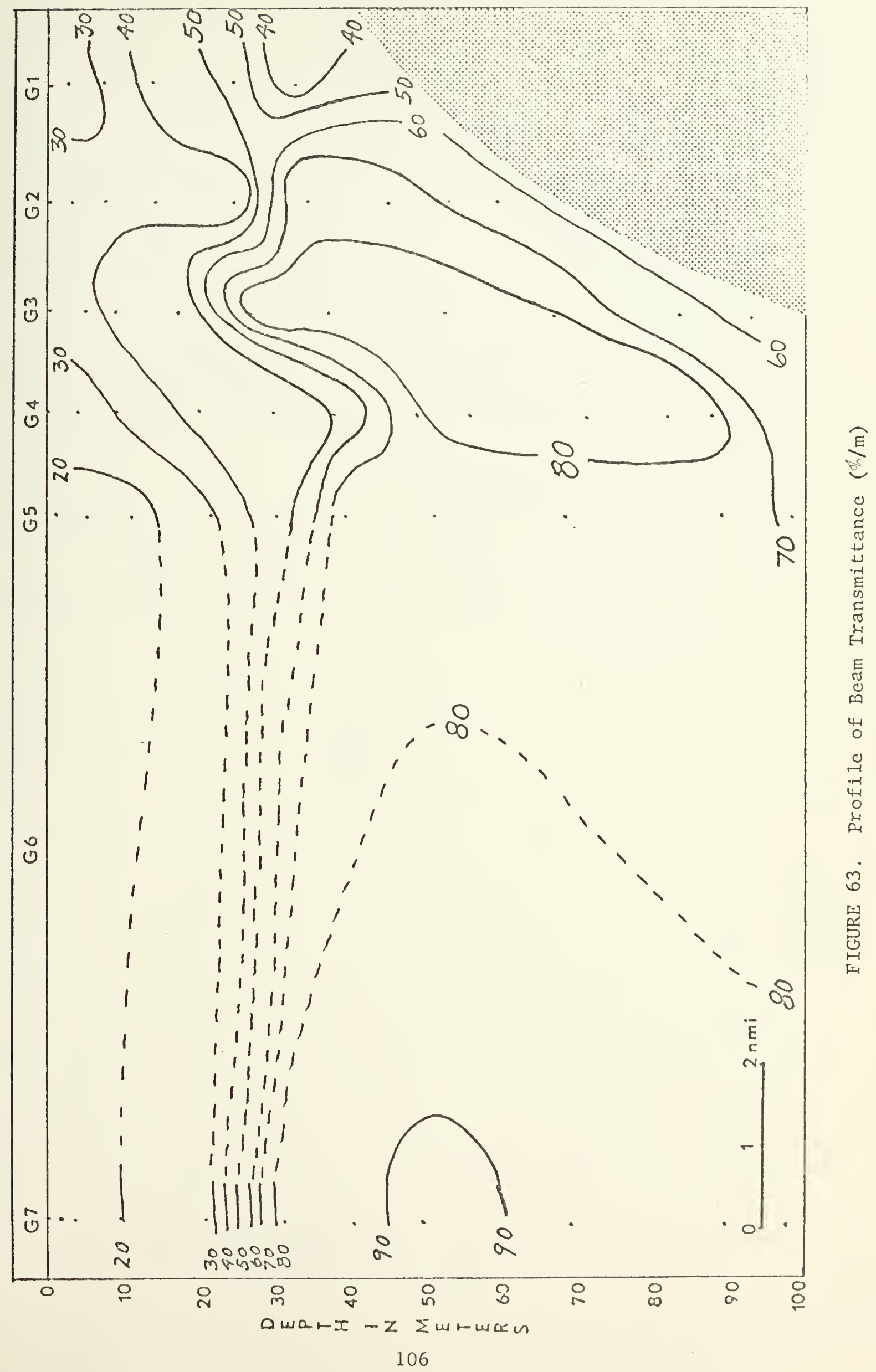





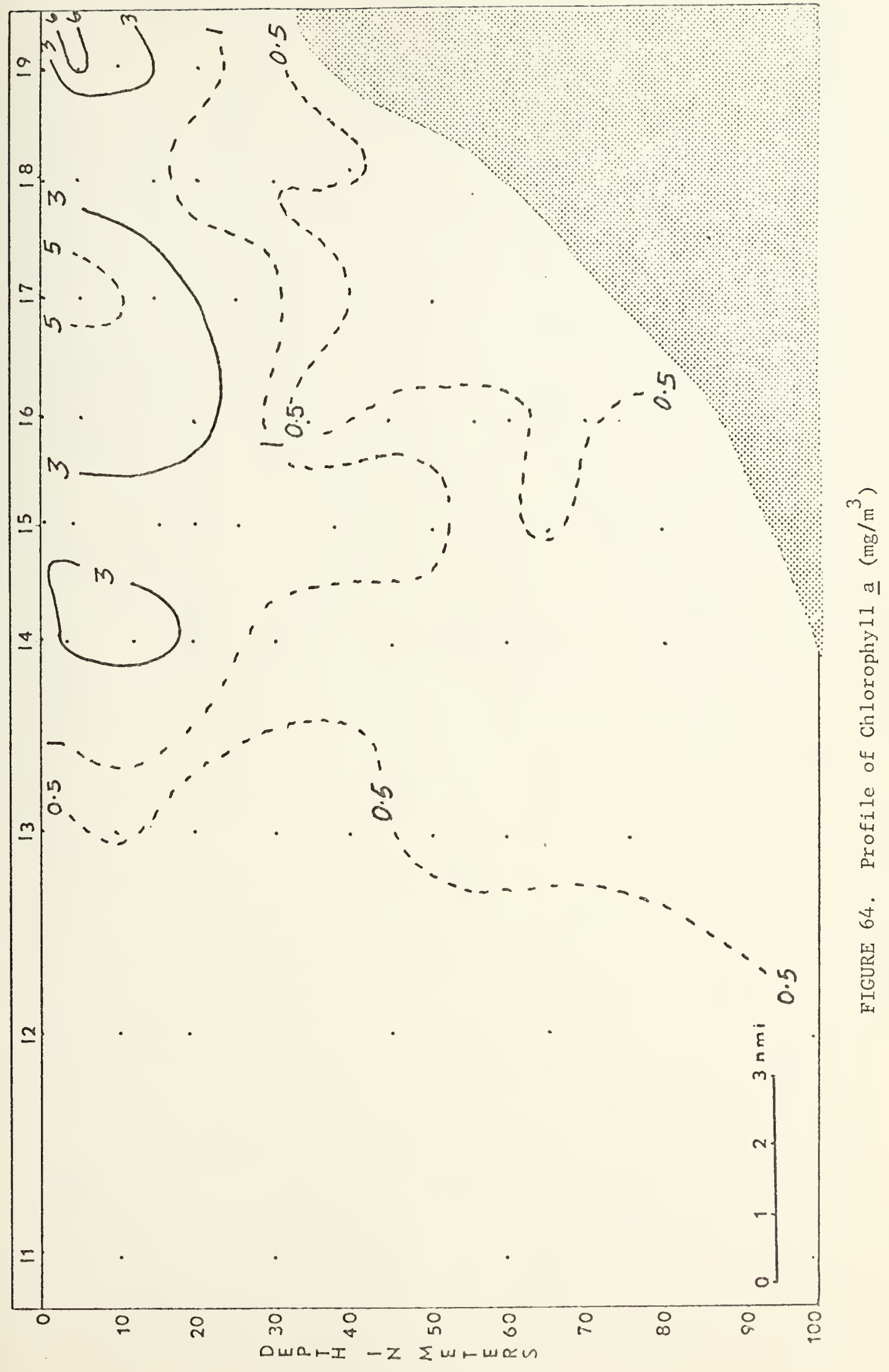





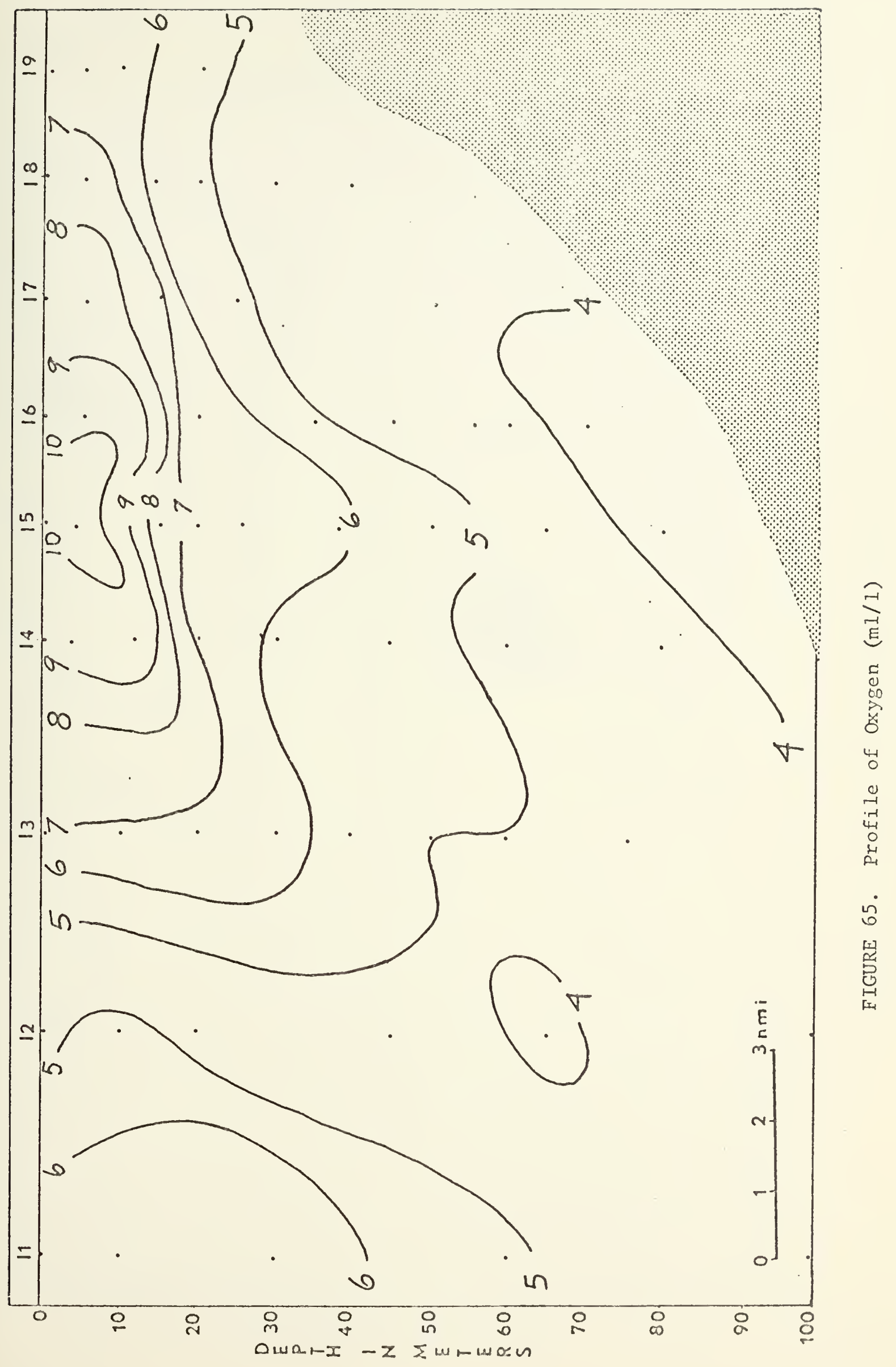





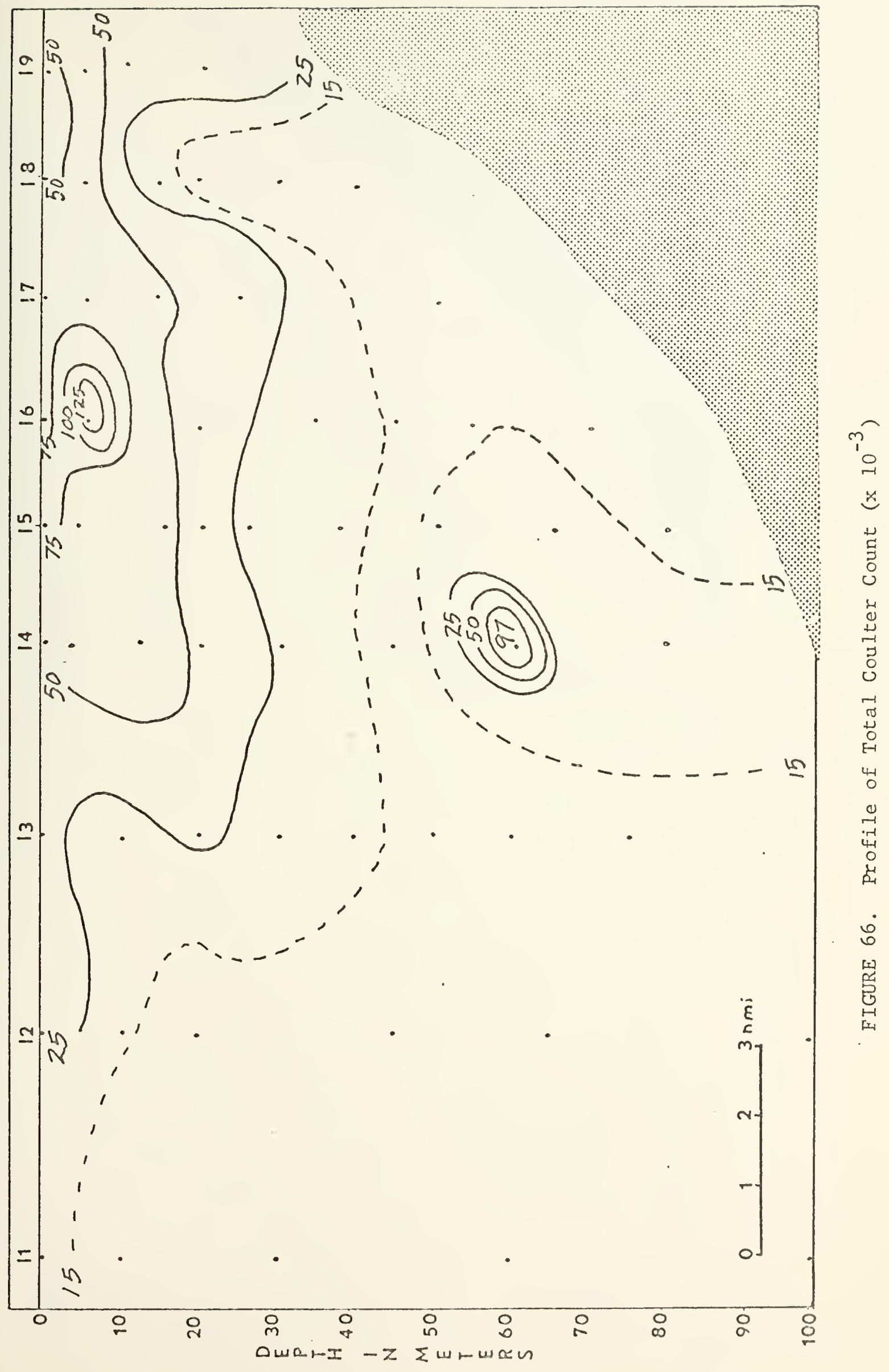





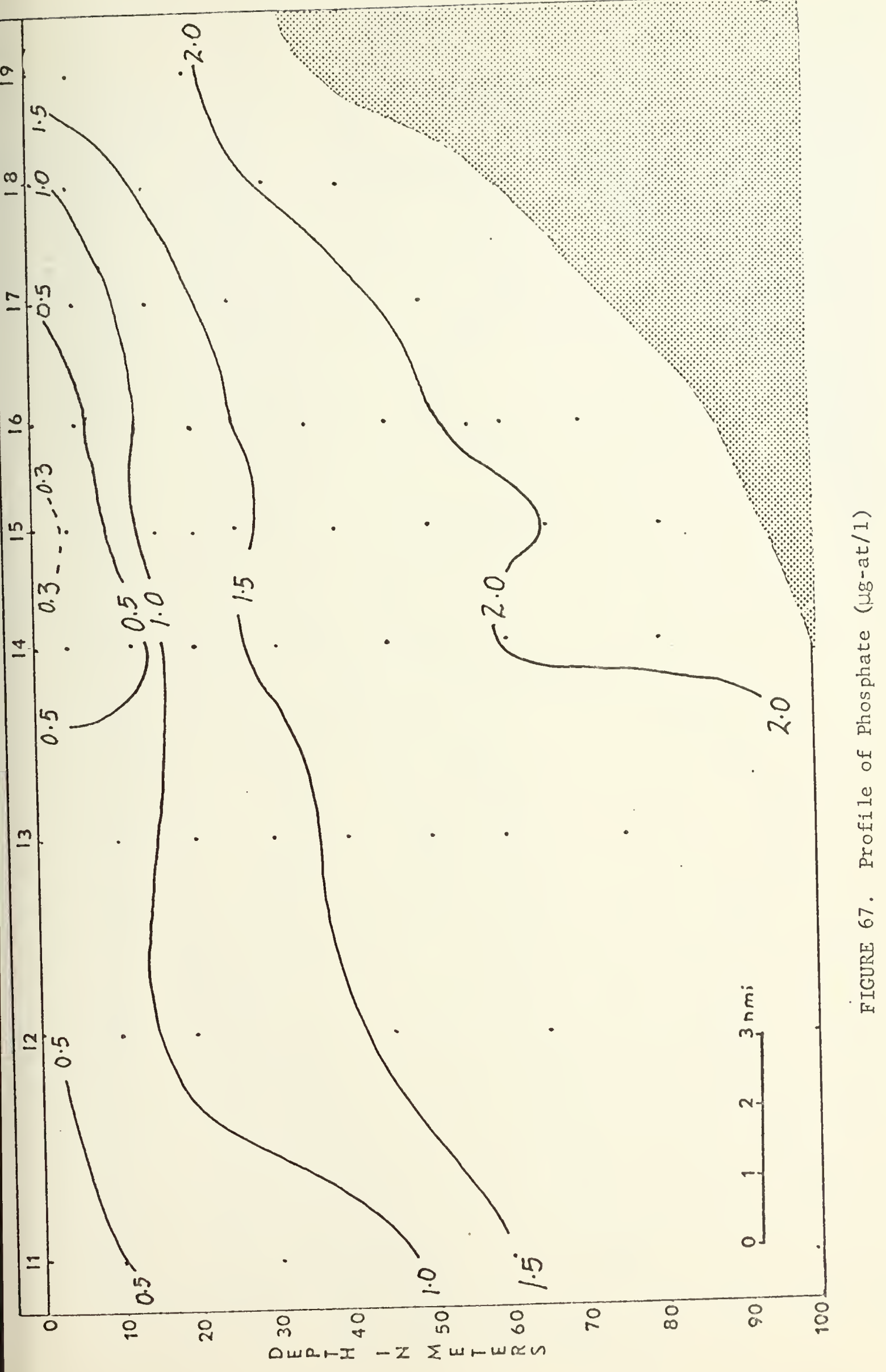





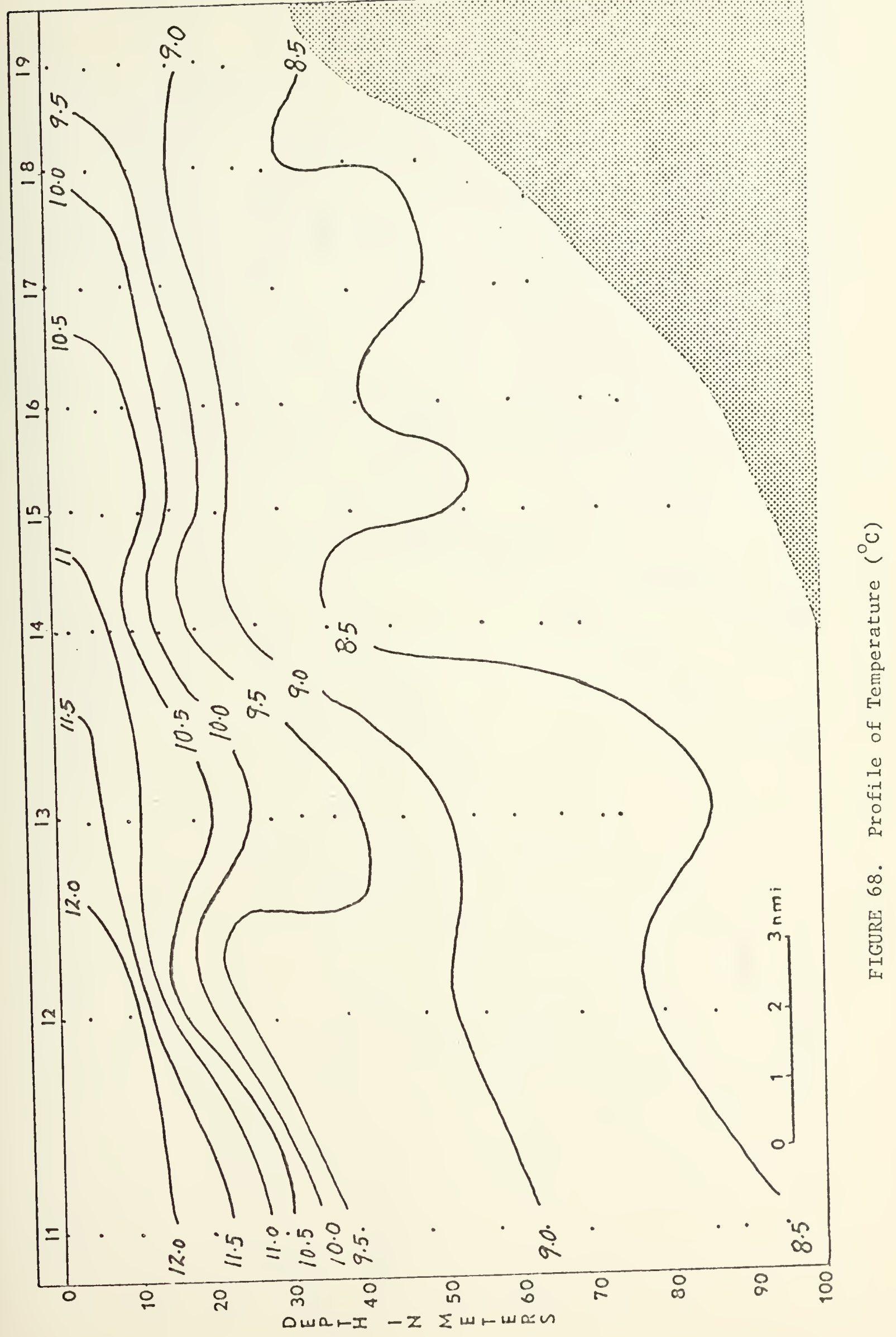





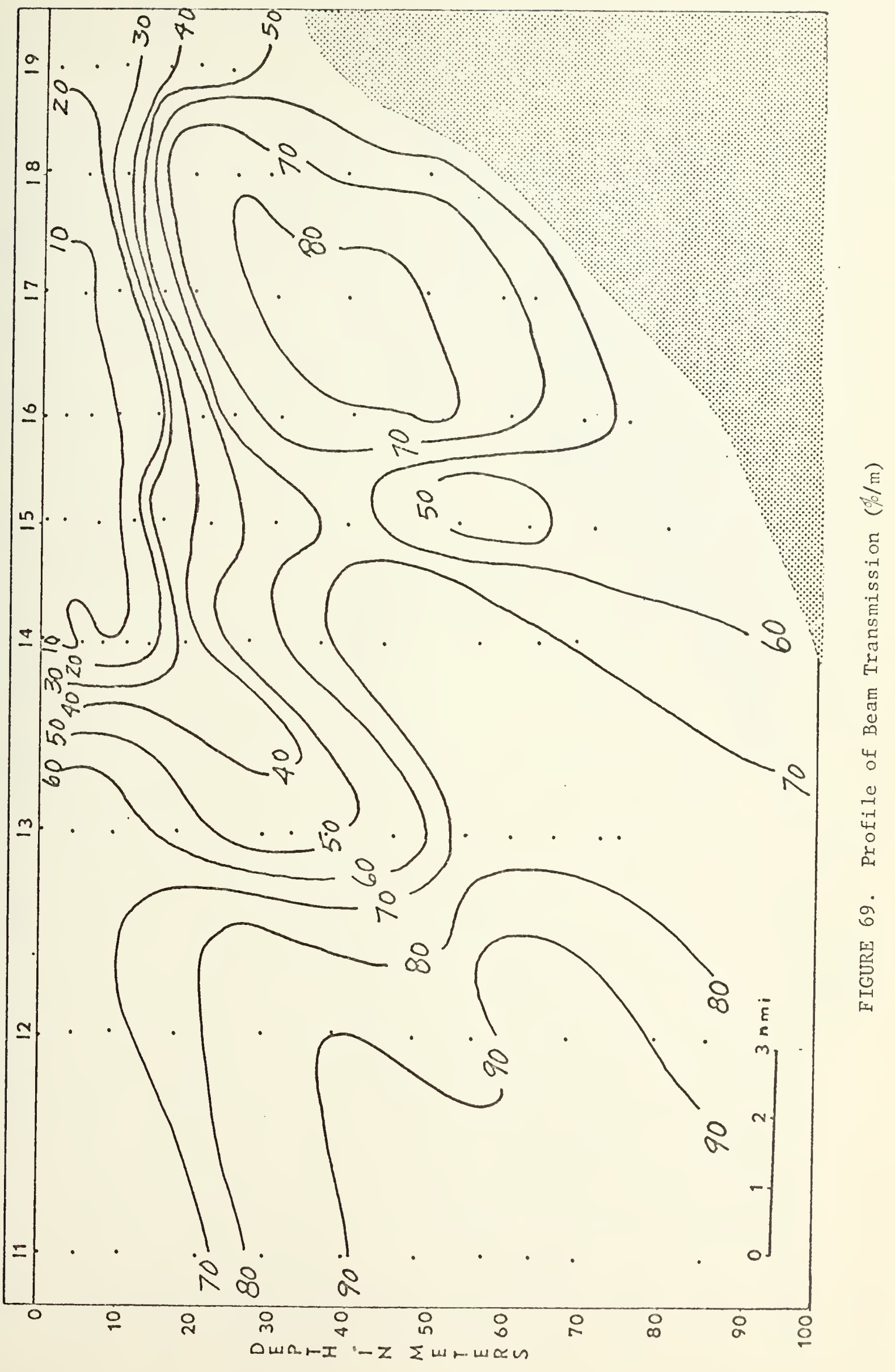





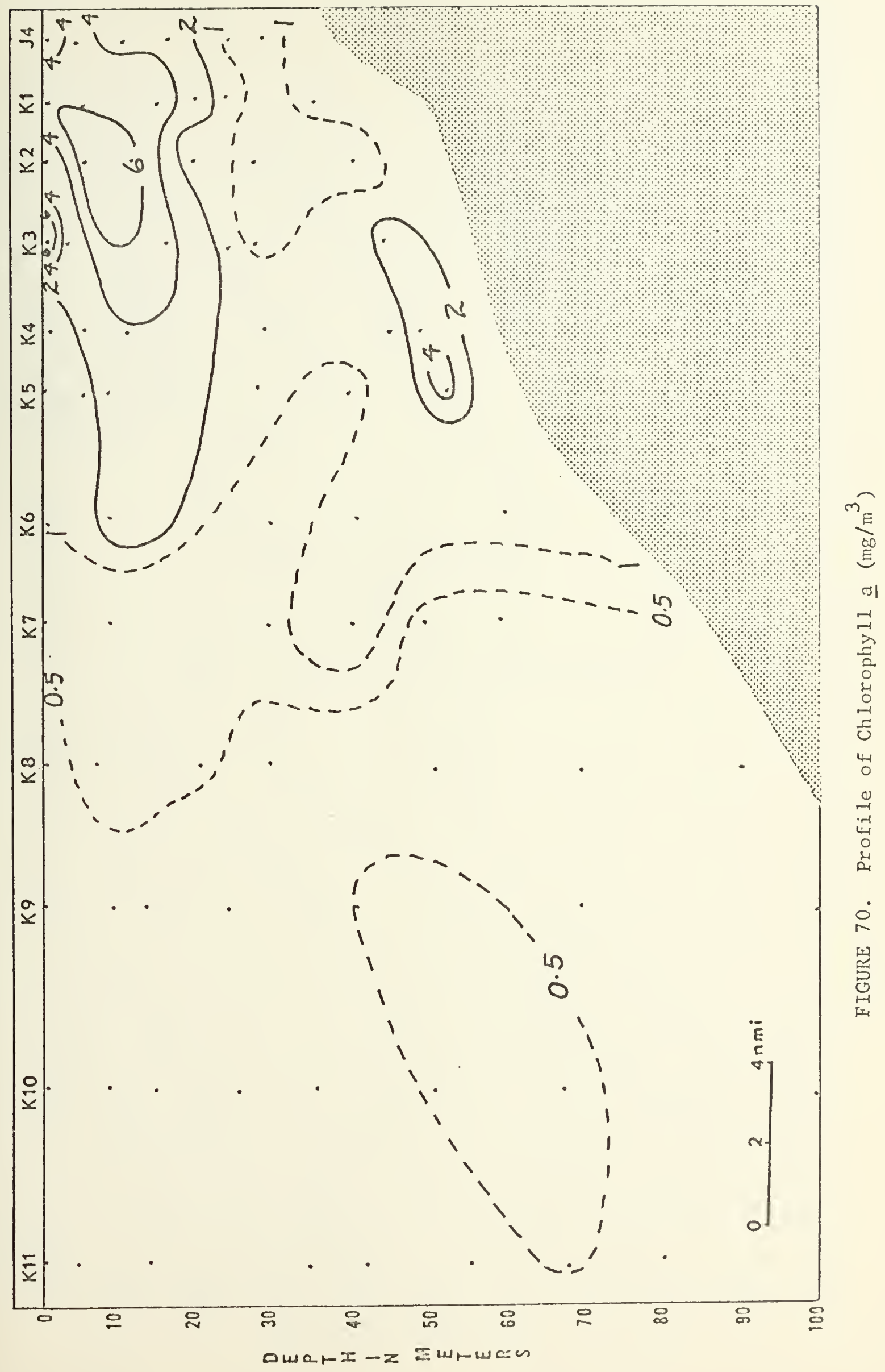





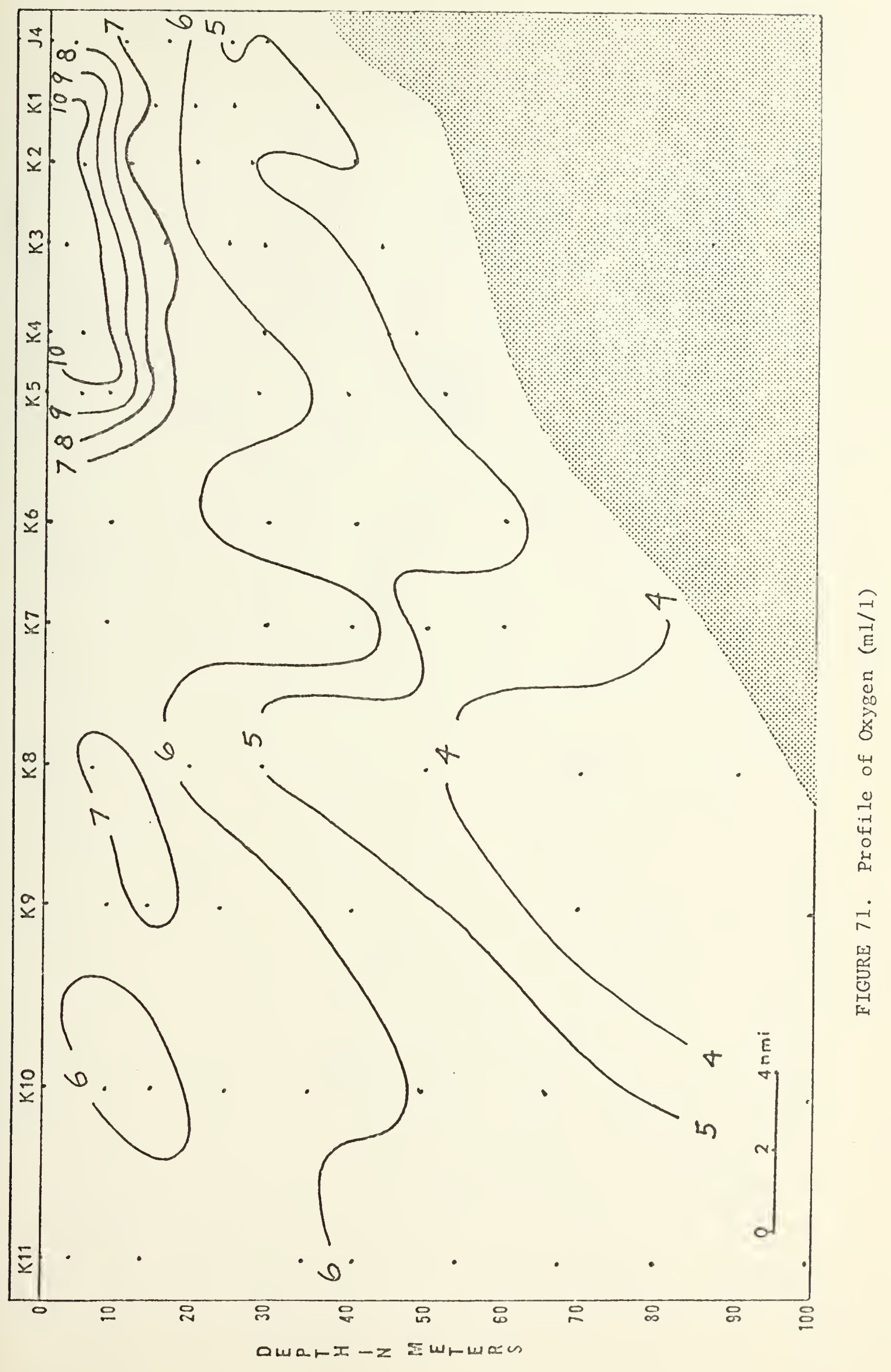





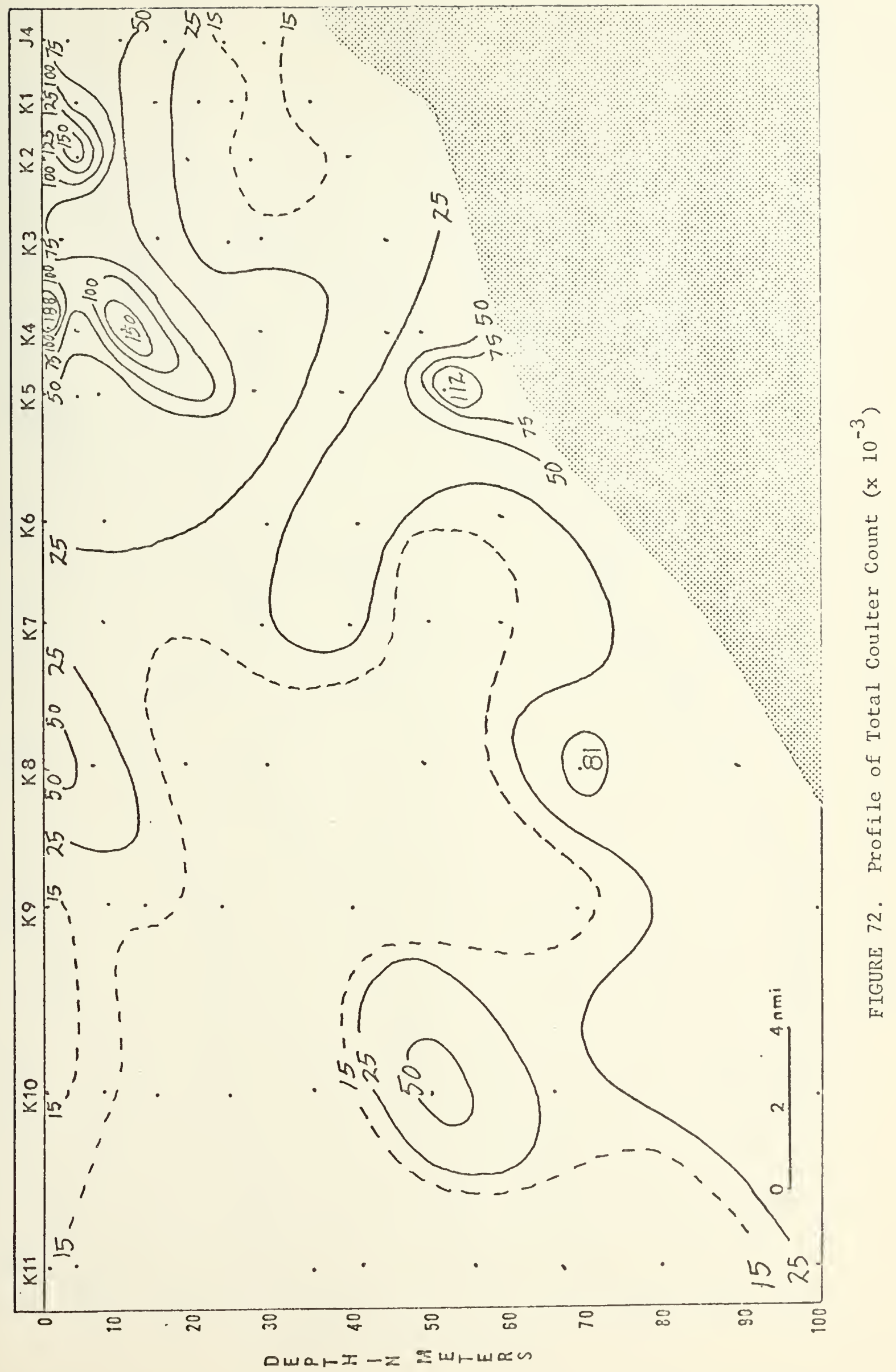





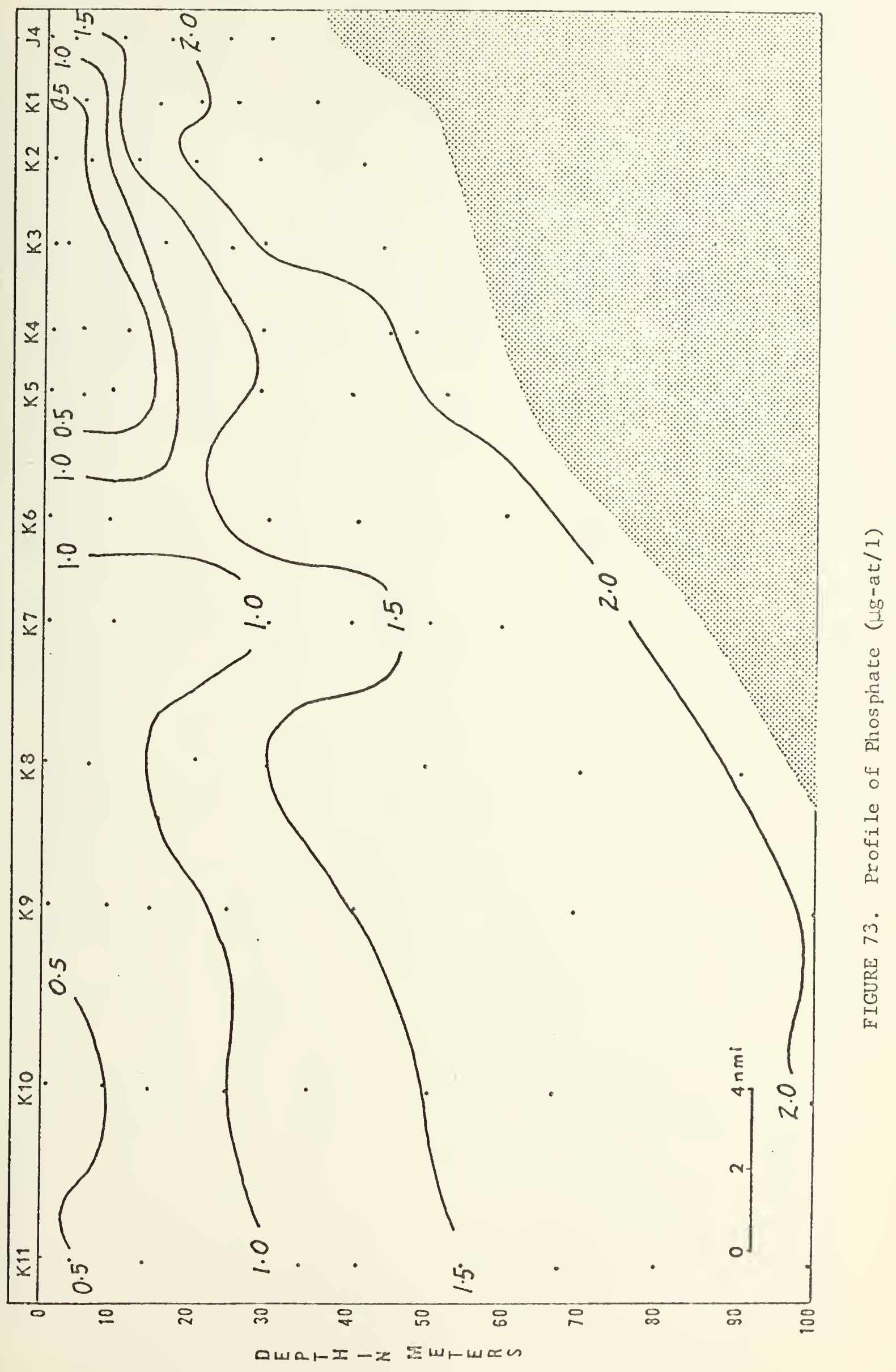





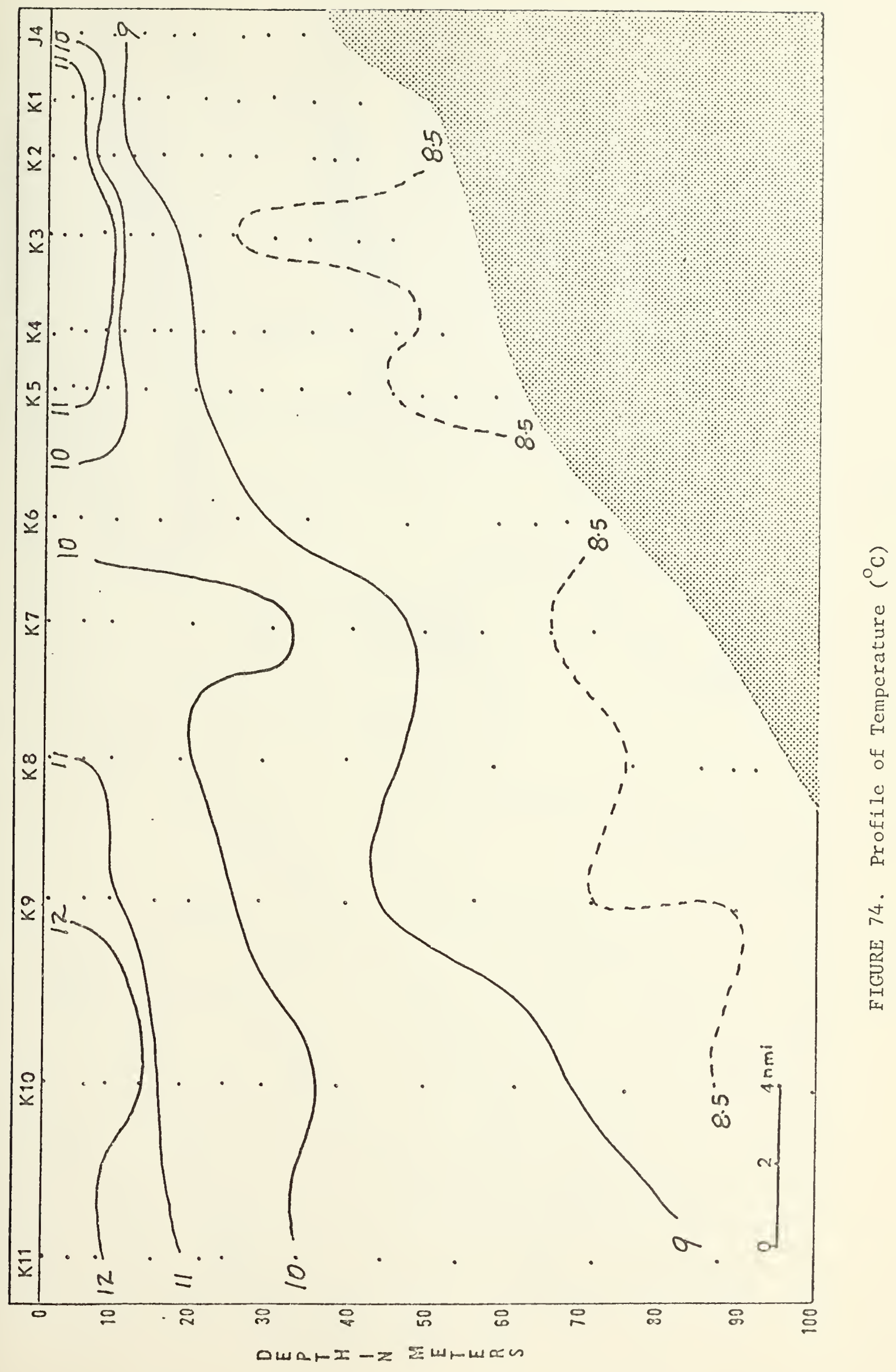





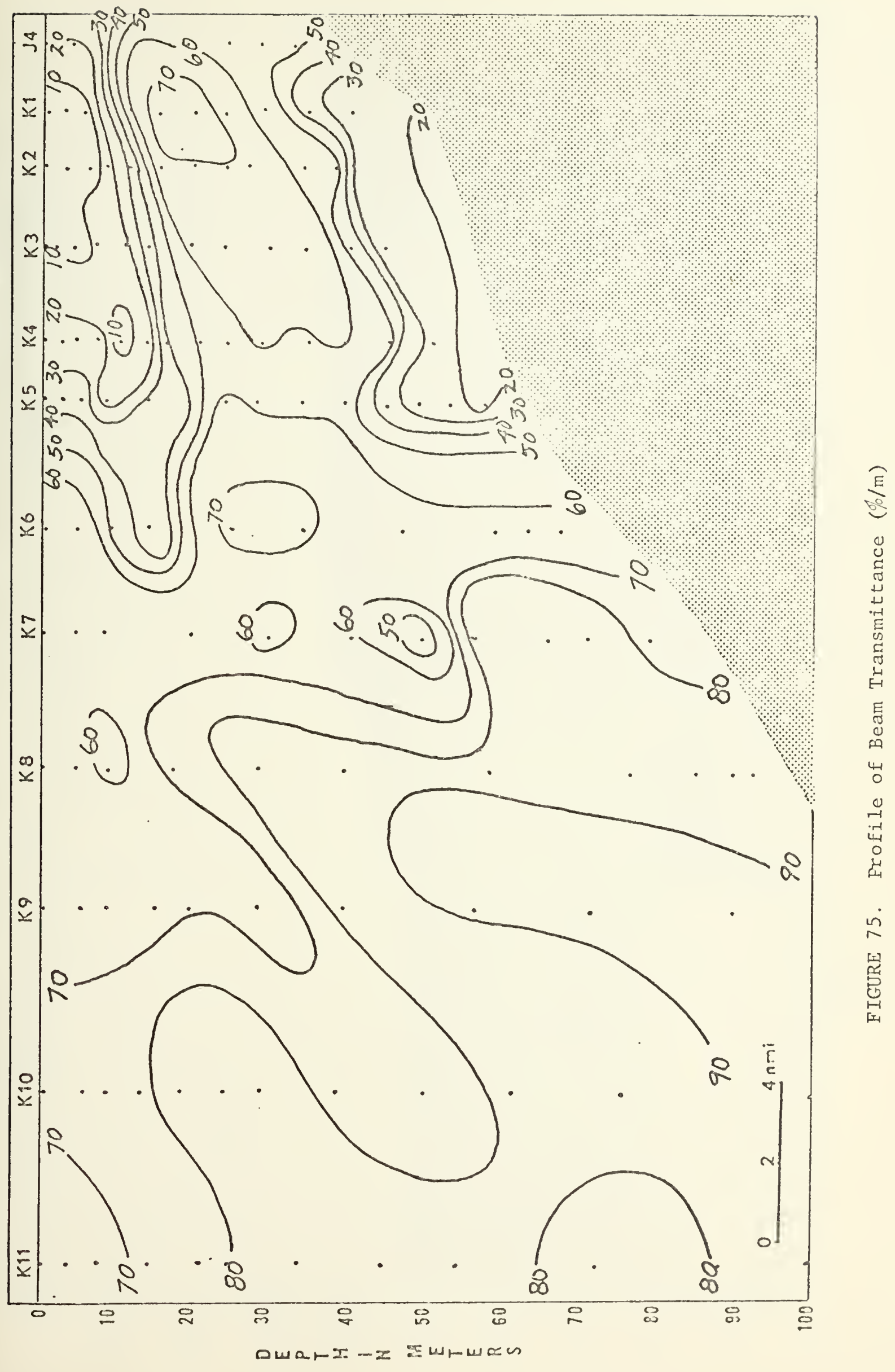





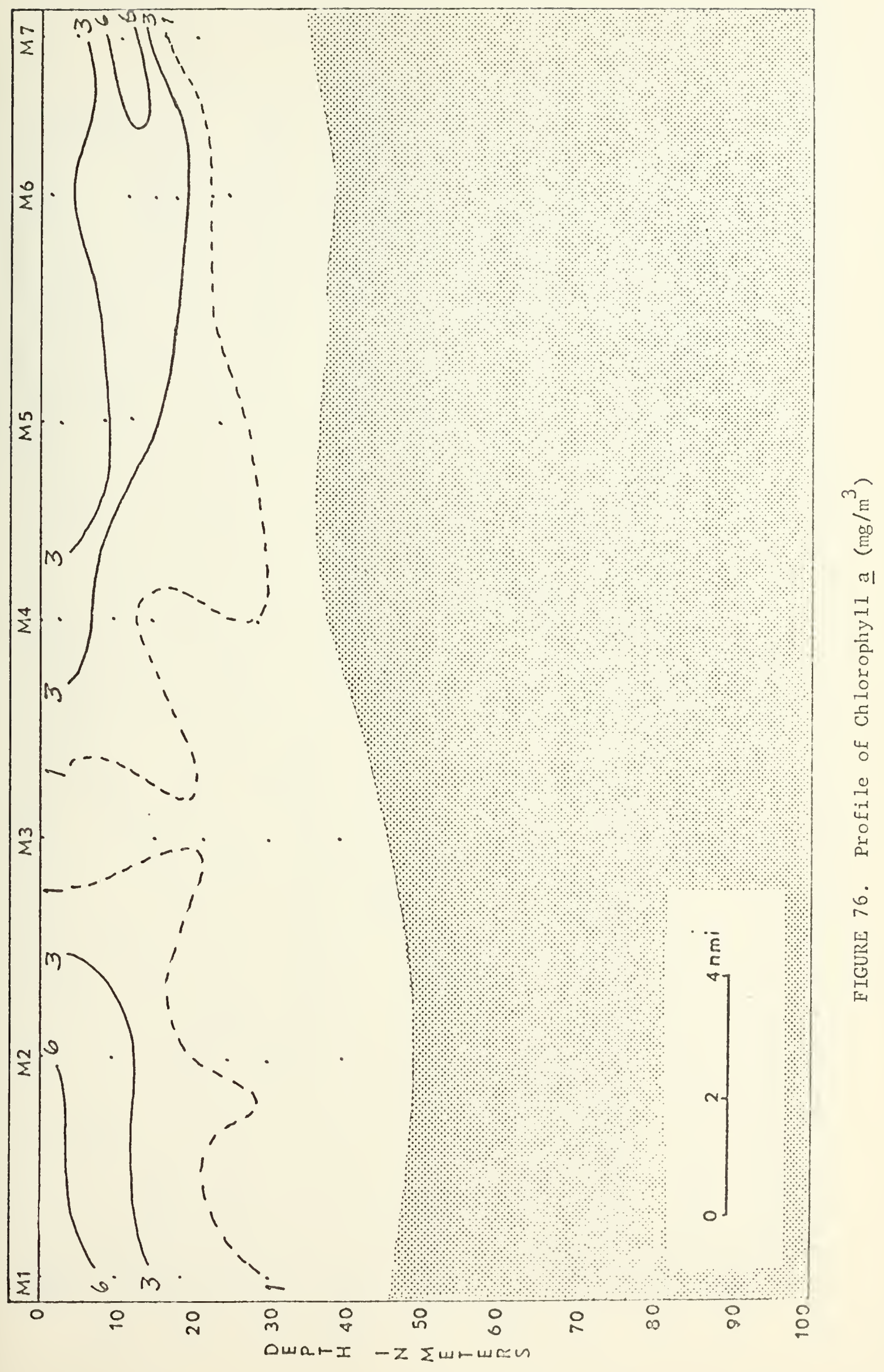





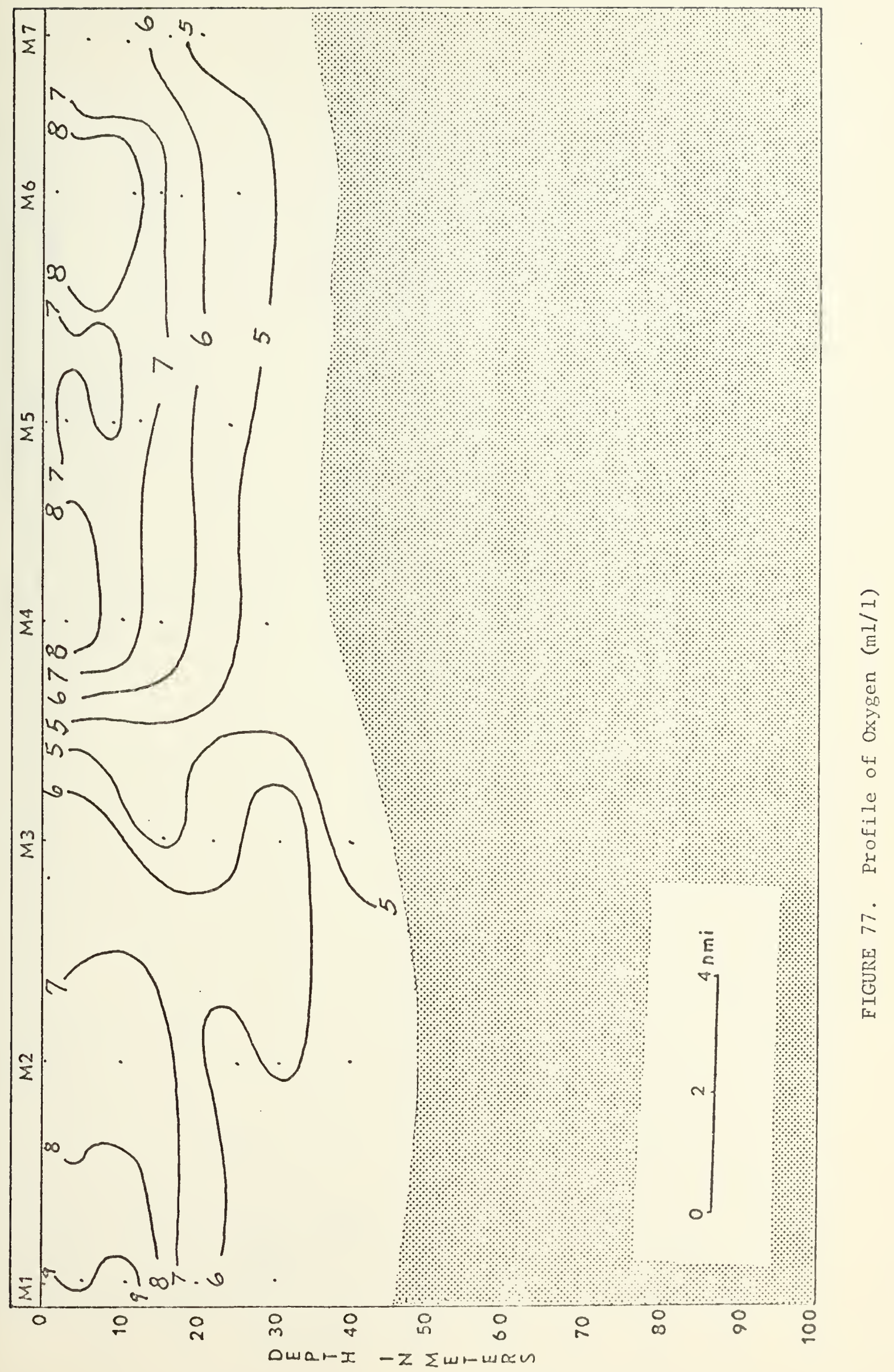





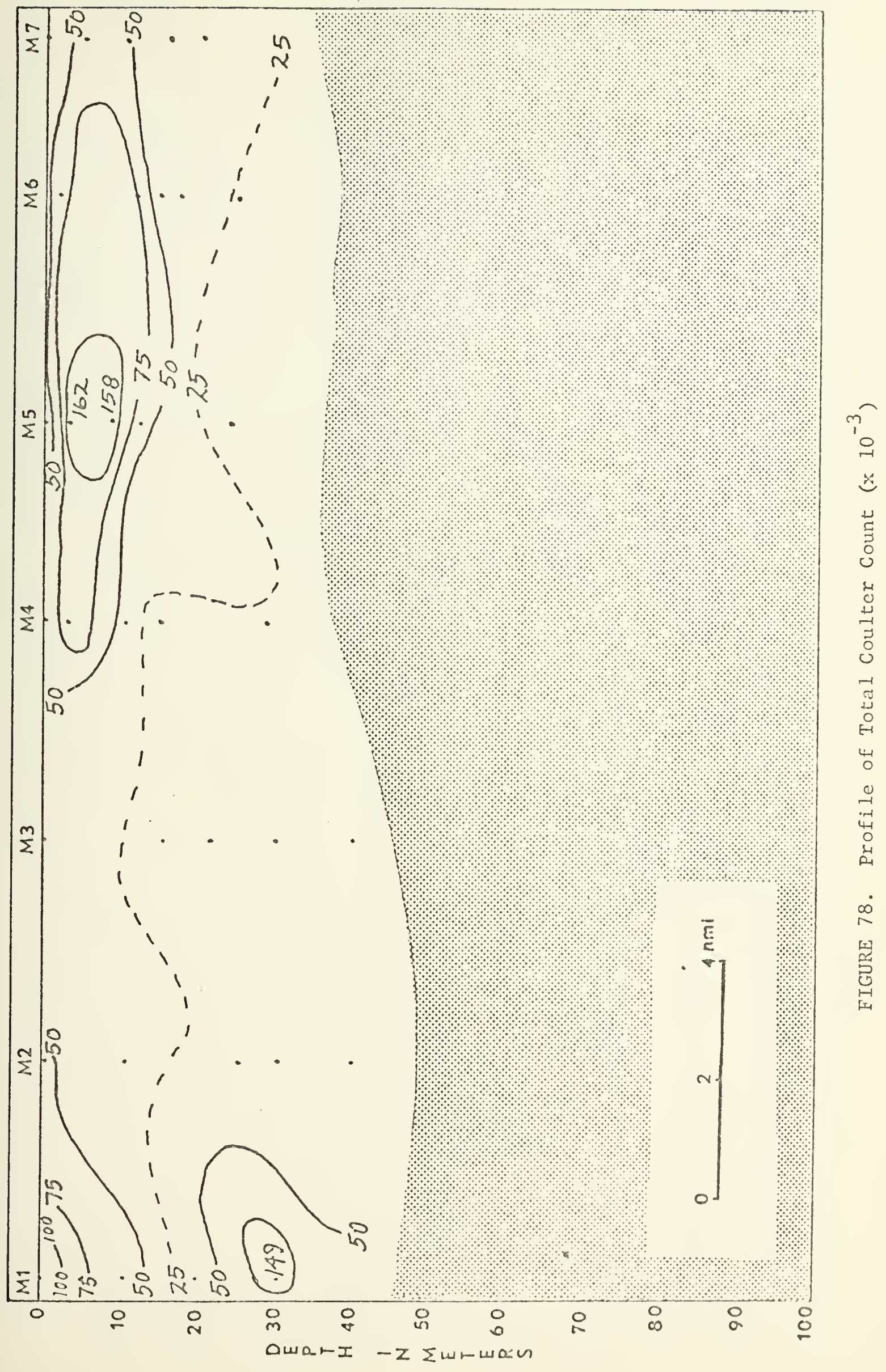





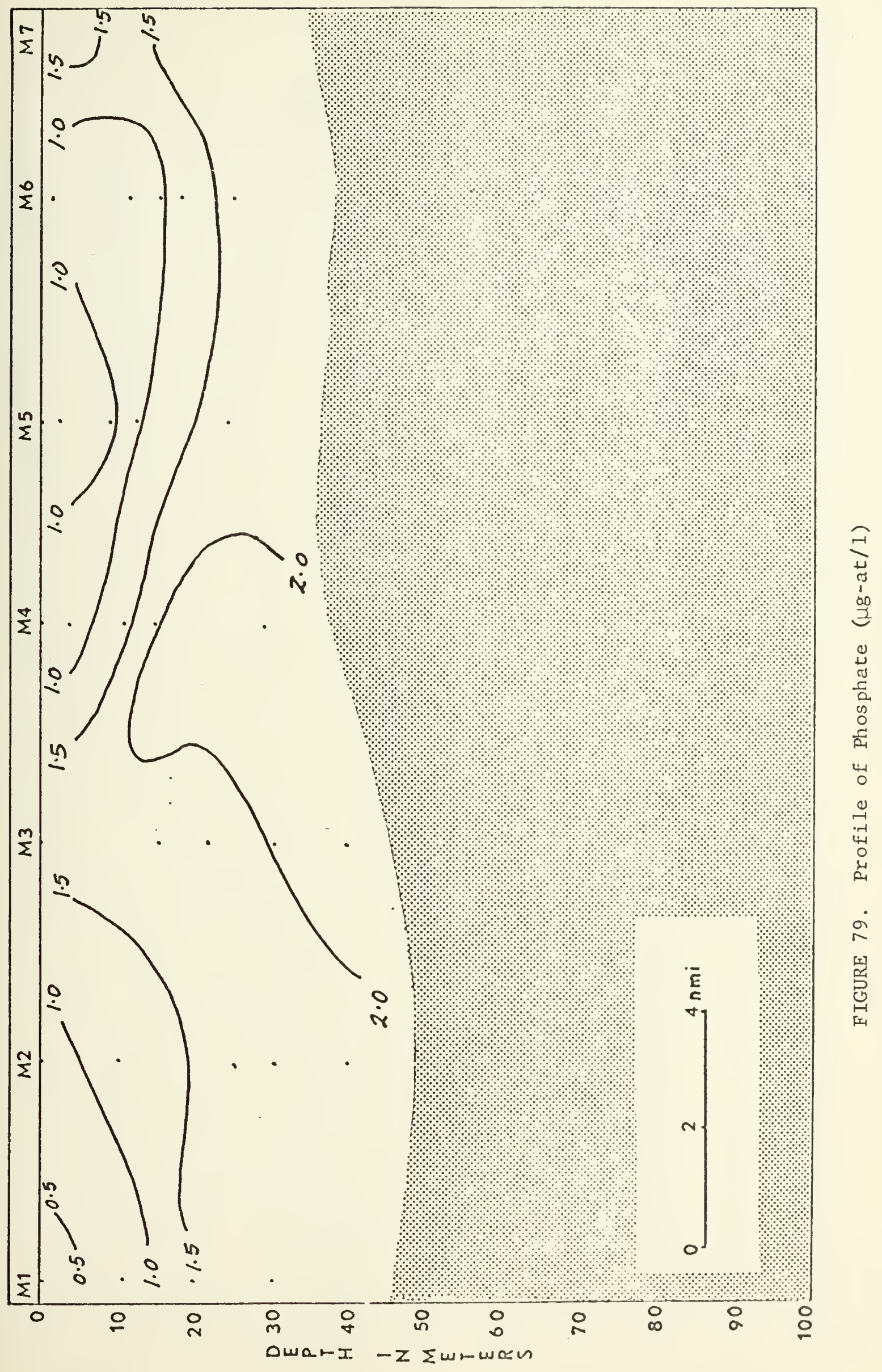





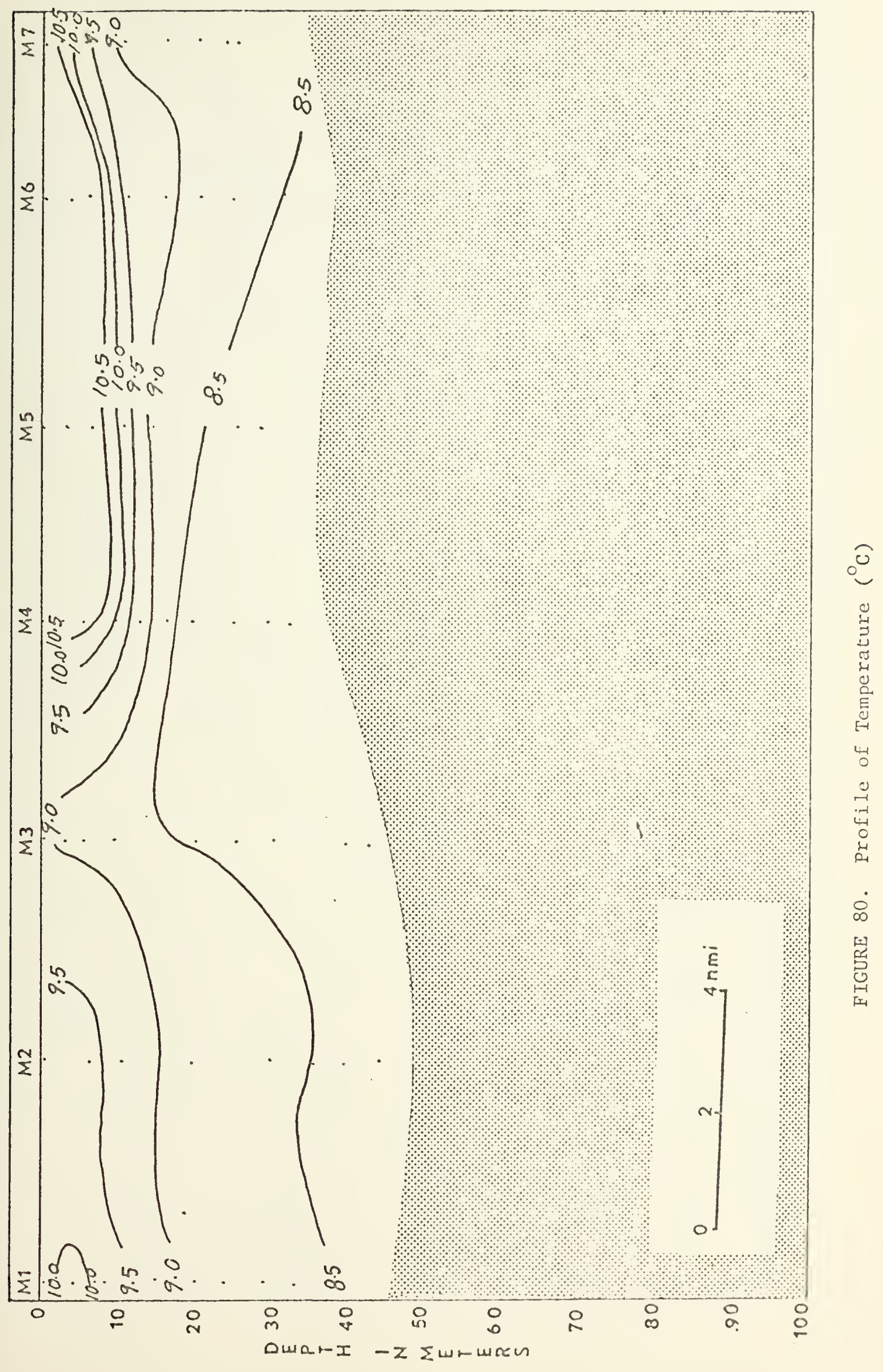





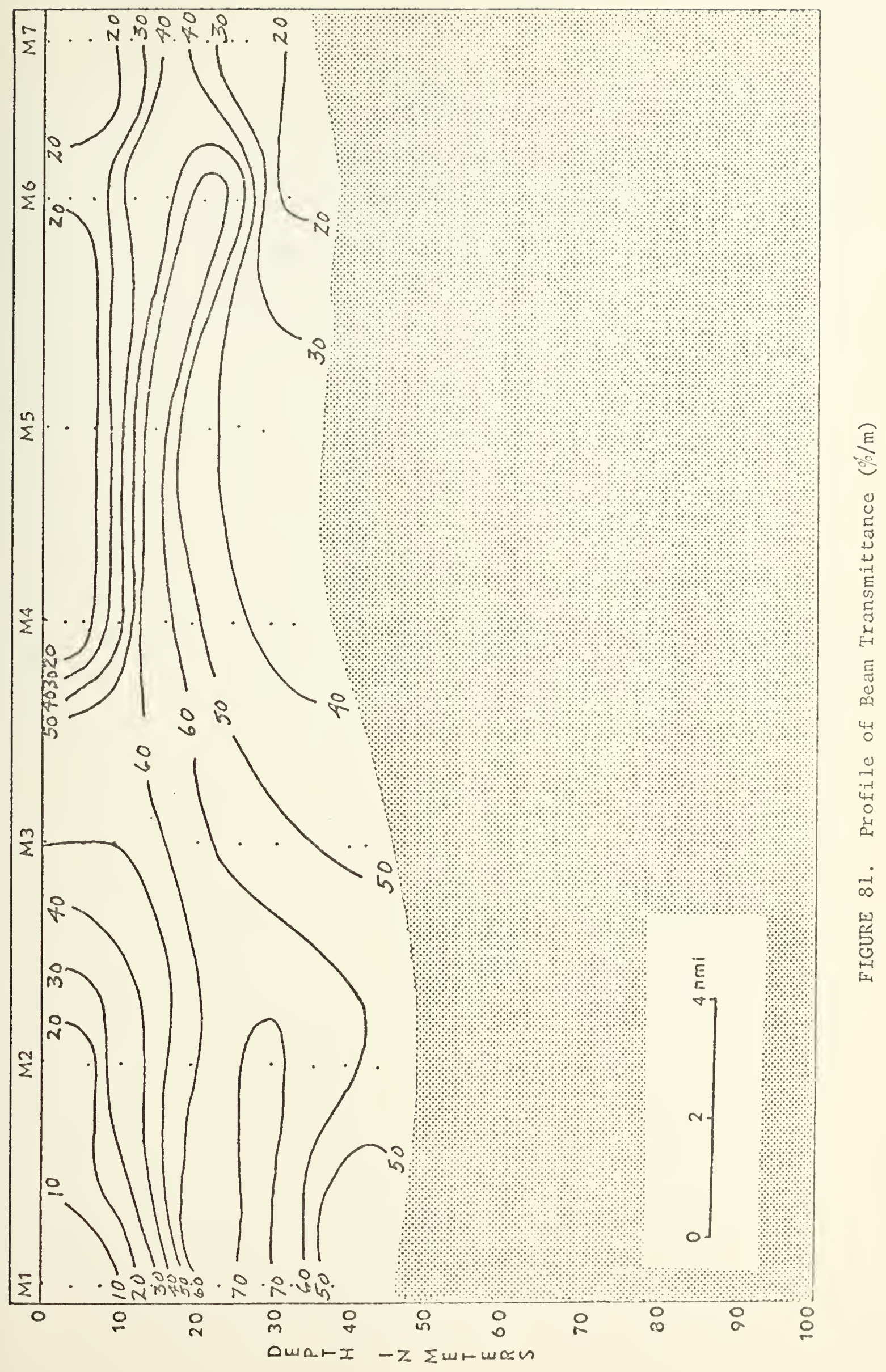





\section{TABLE I}

Station Data: Location, Time, Depth, Weather, Sound Velocity, Temperature, Transmittance, Oxygen Chlorophyl1, and Phos phate 



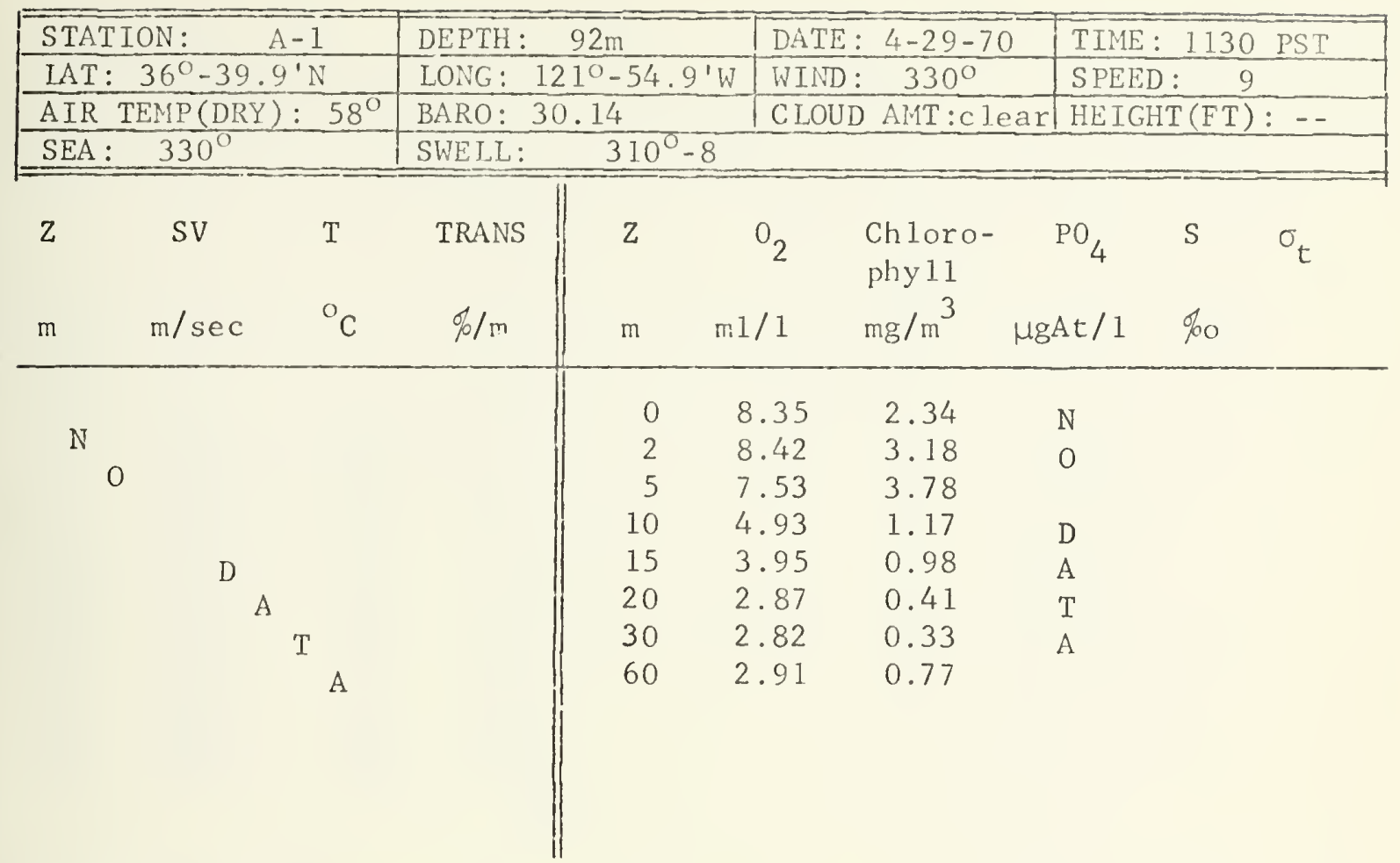

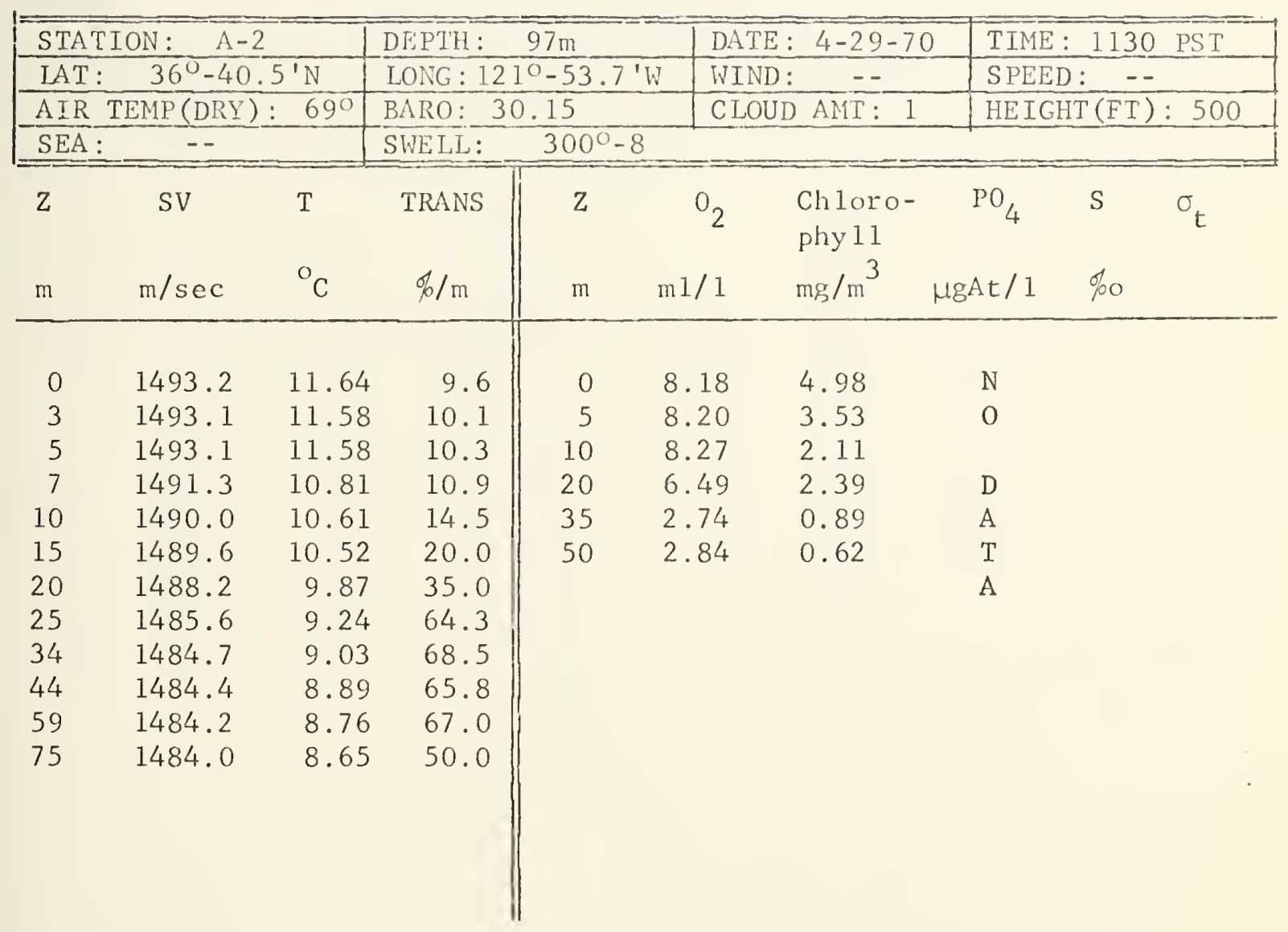





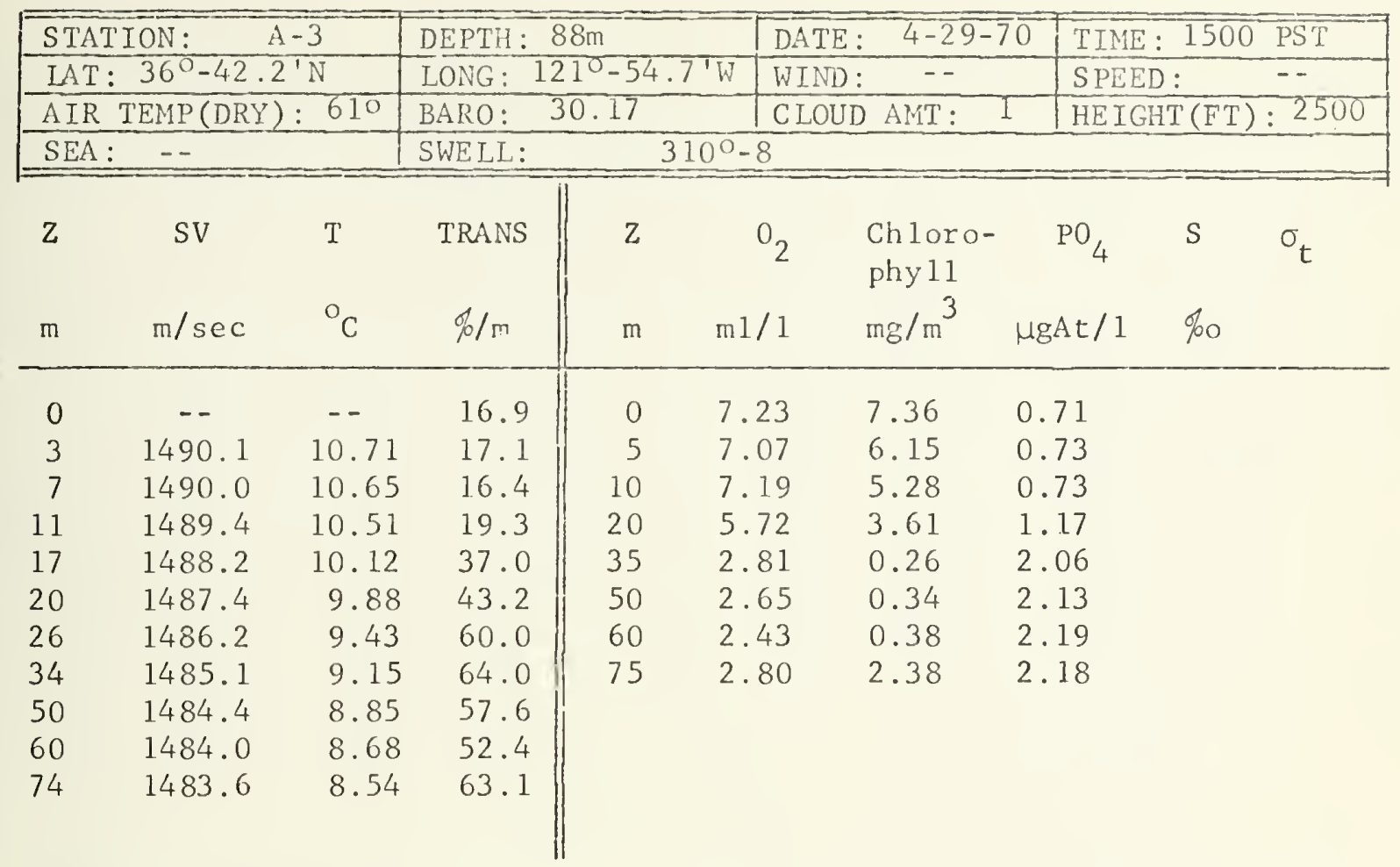

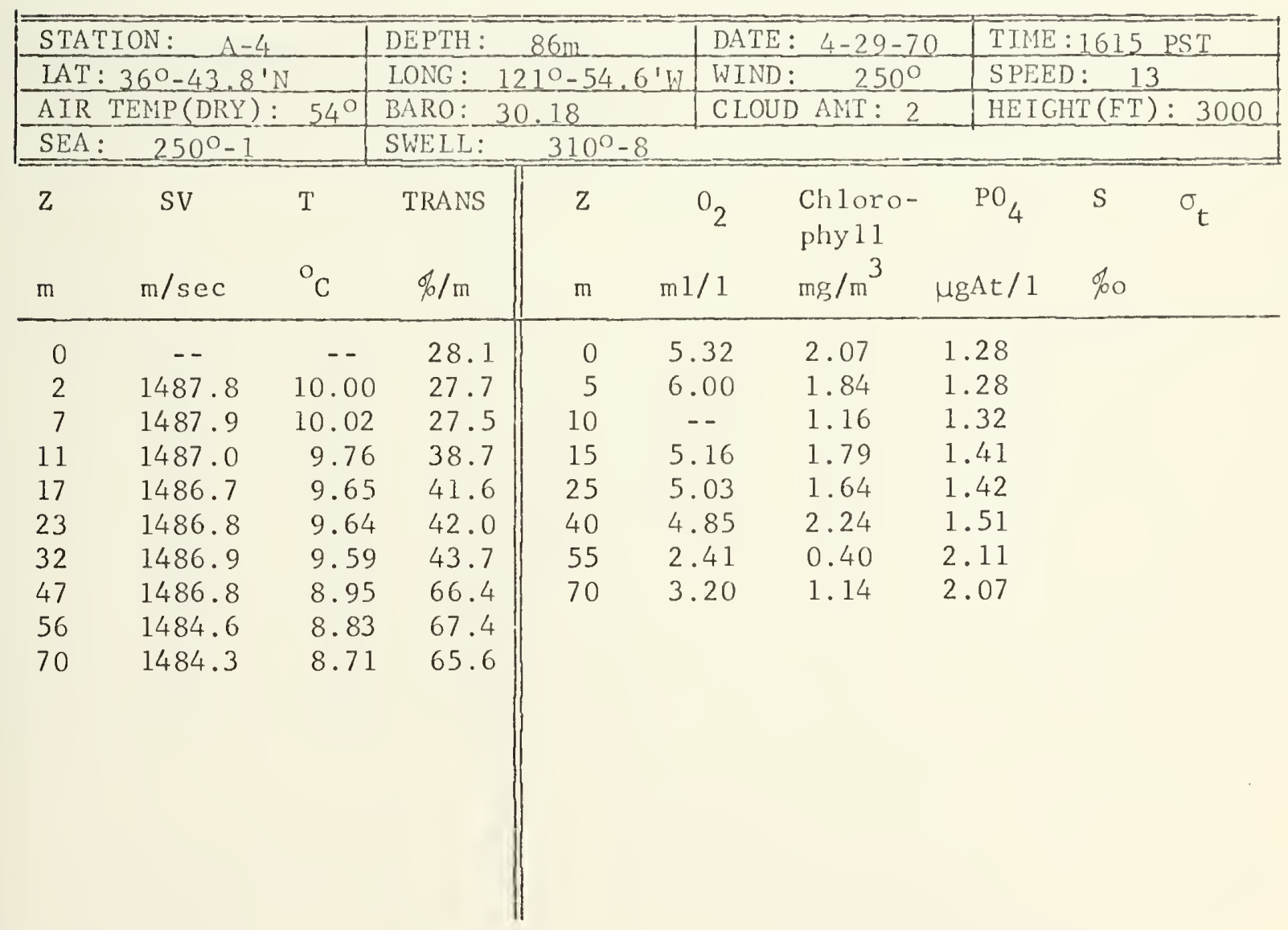





\begin{tabular}{|c|c|c|c|c|c|c|c|c|c|c|}
\hline \multicolumn{3}{|c|}{ STATION: $\quad A-5$} & \multicolumn{3}{|c|}{ DEPTH: $95 \mathrm{~m}$} & \multicolumn{2}{|c|}{ DATE: $4-29-70$} & \multicolumn{3}{|c|}{ TIME : $1800 \mathrm{PST}$} \\
\hline \multicolumn{3}{|c|}{ IAT: $\quad 360^{\circ}-45.0^{\prime} \mathrm{N}$} & \multicolumn{3}{|c|}{ LONG: $121^{\circ}-54.3^{\prime} \mathrm{W}$} & \multicolumn{2}{|c|}{ WIND : $\quad 280^{\circ}$} & \multicolumn{3}{|c|}{ SPEED: 16} \\
\hline \multicolumn{3}{|c|}{ AIR TEMP (DRY): $55^{\circ}$} & \multicolumn{3}{|c|}{ BARO: 30.12} & \multicolumn{2}{|c|}{ CLOUD AMT: 6} & \multicolumn{3}{|c|}{ HEIGHT (FT): 1500} \\
\hline \multicolumn{3}{|c|}{ SEA: $\quad 280^{\circ}-4$} & \multicolumn{8}{|c|}{ SWELL: $\quad 290^{\circ}-8$} \\
\hline 2 & SV & $\mathrm{T}$ & TRANS & $\mathrm{Z}$ & & $\mathrm{O}_{2}$ & $\begin{array}{l}\text { Chloro } \\
\text { phyl1 }\end{array}$ & $\mathrm{PO}_{4}$ & $S$ & $\sigma_{t}$ \\
\hline $\mathrm{m}$ & $\mathrm{m} / \mathrm{sec}$ & ${ }^{\circ} \mathrm{C}$ & $\% / \mathrm{m}$ & $\mathrm{m}$ & $\mathrm{m} 1$ & $/ 1$ & $\mathrm{mg} / \mathrm{m}^{3}$ & $\mu g A t / 1$ & $\% 0$ & \\
\hline 0 & 1489.3 & 10.49 & 13.5 & 0 & & .62 & 3.50 & 1.00 & & \\
\hline 5 & 1489.3 & 10.48 & 14.7 & 5 & & .62 & 2.24 & 1.01 & & \\
\hline 10 & 1488.8 & 10.28 & 16.0 & 10 & & .99 & 1.06 & 1.22 & & \\
\hline 15 & 1487.3 & 9.88 & 33.3 & 20 & & .82 & 1.57 & 1.51 & & \\
\hline 19 & 1486.9 & 9.72 & 41.2 & 30 & & .60 & 0.85 & 1.77 & & \\
\hline 25 & 1486.7 & 9.64 & 43.7 & 35 & & .88 & 0.44 & 1.92 & & \\
\hline 29 & 1486.6 & 9.61 & 45.2 & 50 & & .42 & 0.49 & 2.07 & & \\
\hline 38 & 1485.2 & 9.17 & 65.6 & 70 & & .15 & 0.30 & 2.22 & & \\
\hline 49 & 1484.4 & 8.87 & 55.4 & & & & & & & \\
\hline 68 & 1483.3 & 8.50 & 34.1 & & & & & & & \\
\hline 79 & 1483.2 & 8.40 & 60.5 & & & & & & & \\
\hline
\end{tabular}

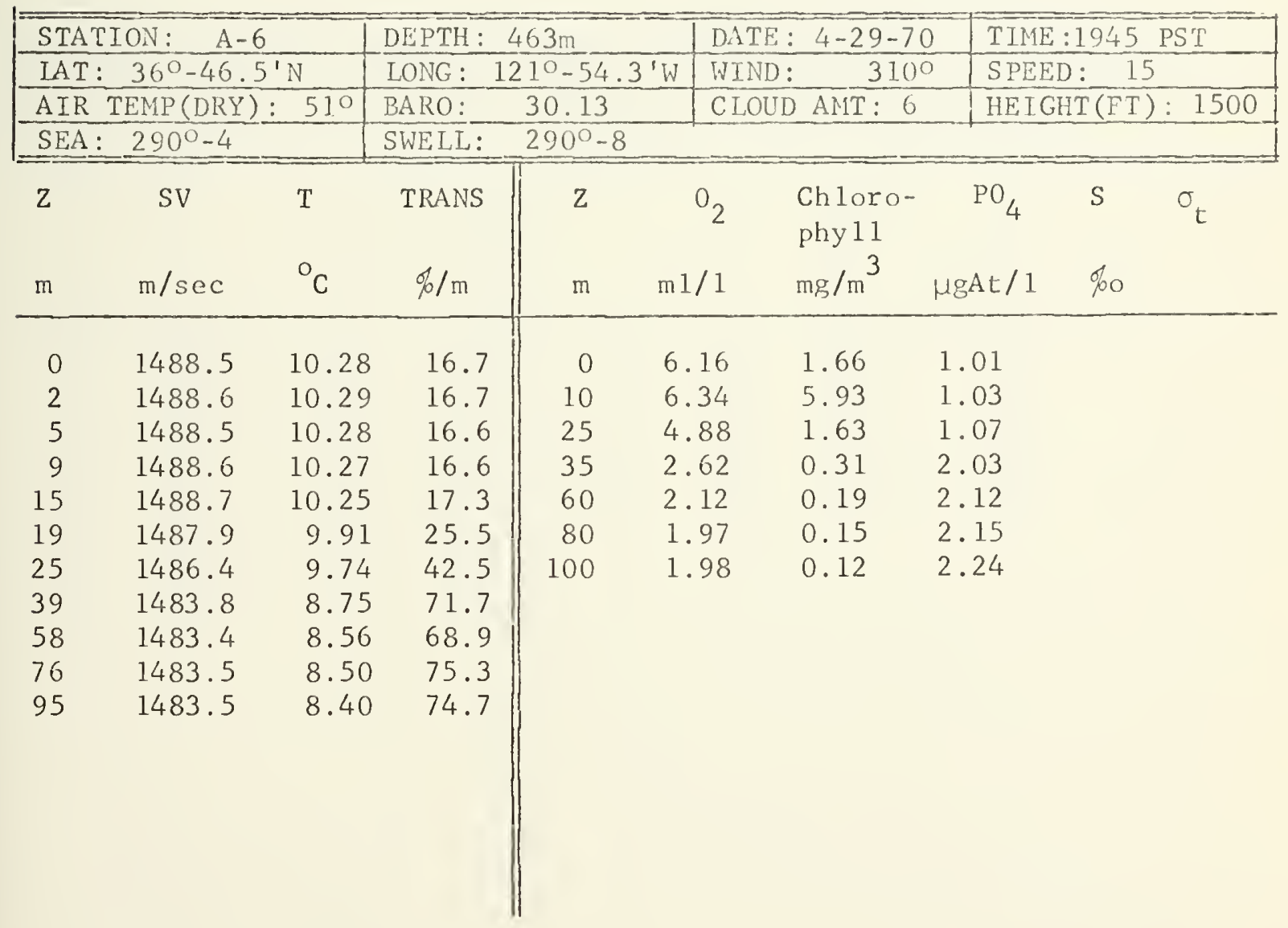





\begin{tabular}{|c|c|c|c|c|c|c|c|c|c|}
\hline & ION: $A-7$ & & DEPTH: & & DATE & $4-29-7$ & TIME & 2200 & \\
\hline & $36^{\circ}-47$ & $5, \mathrm{~N}$ & LONG: & -54 & WIND & $085^{\circ}$ & SPEE & $:$ & 5 \\
\hline & TEMP (DRY & $51^{\circ}$ & BARO: & 17 & CLOUI & $\mathrm{AMT}: \mathrm{c} 1 \mathrm{C}$ & ar $\mathrm{HEI}$ & $\mathrm{T}(\mathrm{FT})$ & $:--$ \\
\hline & $085^{\circ}$ & & SWELL: & $15^{\circ}-$ & & & & & \\
\hline $\mathrm{Z}$ & SV & $\mathrm{T}$ & TRANS & Z & $\mathrm{O}_{2}$ & $\begin{array}{l}\text { Chloro- } \\
\text { phyll }\end{array}$ & $\mathrm{PO}_{4}$ & S & $\sigma_{t}$ \\
\hline $\mathrm{m}$ & $\mathrm{m} / \mathrm{sec}$ & ${ }^{\mathrm{O}} \mathrm{C}$ & $\% / \mathrm{m}$ & $\mathrm{m}$ & $\mathrm{m} 1 / 1$ & $\mathrm{mg} / \mathrm{m}^{3}$ & MgAt / 1 & $\% 0$ & \\
\hline c & 1488.7 & 10.31 & 13.9 & 0 & 6.28 & 4.14 & 0.97 & & \\
\hline 2 & 1488.7 & 10.31 & 14.1 & 5 & 6.30 & 3.30 & 1.02 & & \\
\hline 5 & 1488.8 & 10.32 & 15.0 & 12 & 6.22 & 0.81 & 1.02 & & \\
\hline 11 & 1487.8 & 10.03 & 24.0 & 25 & 4.50 & 3.46 & 1.52 & & \\
\hline 15 & 1487.1 & 9.87 & 23.2 & 35 & 3.49 & 0.58 & 1.48 & & \\
\hline 26 & 1485.9 & 9.44 & 48.9 & 50 & 2.87 & 0.34 & 2.00 & & \\
\hline 35 & 1484.4 & 8.94 & 68.7 & 65 & 2.36 & 0.21 & 2.04 & & \\
\hline 50 & 1483.8 & 8.70 & 81.0 & & & & & & \\
\hline 73 & 1483.4 & 8.48 & 64.0 & & & & & & \\
\hline
\end{tabular}

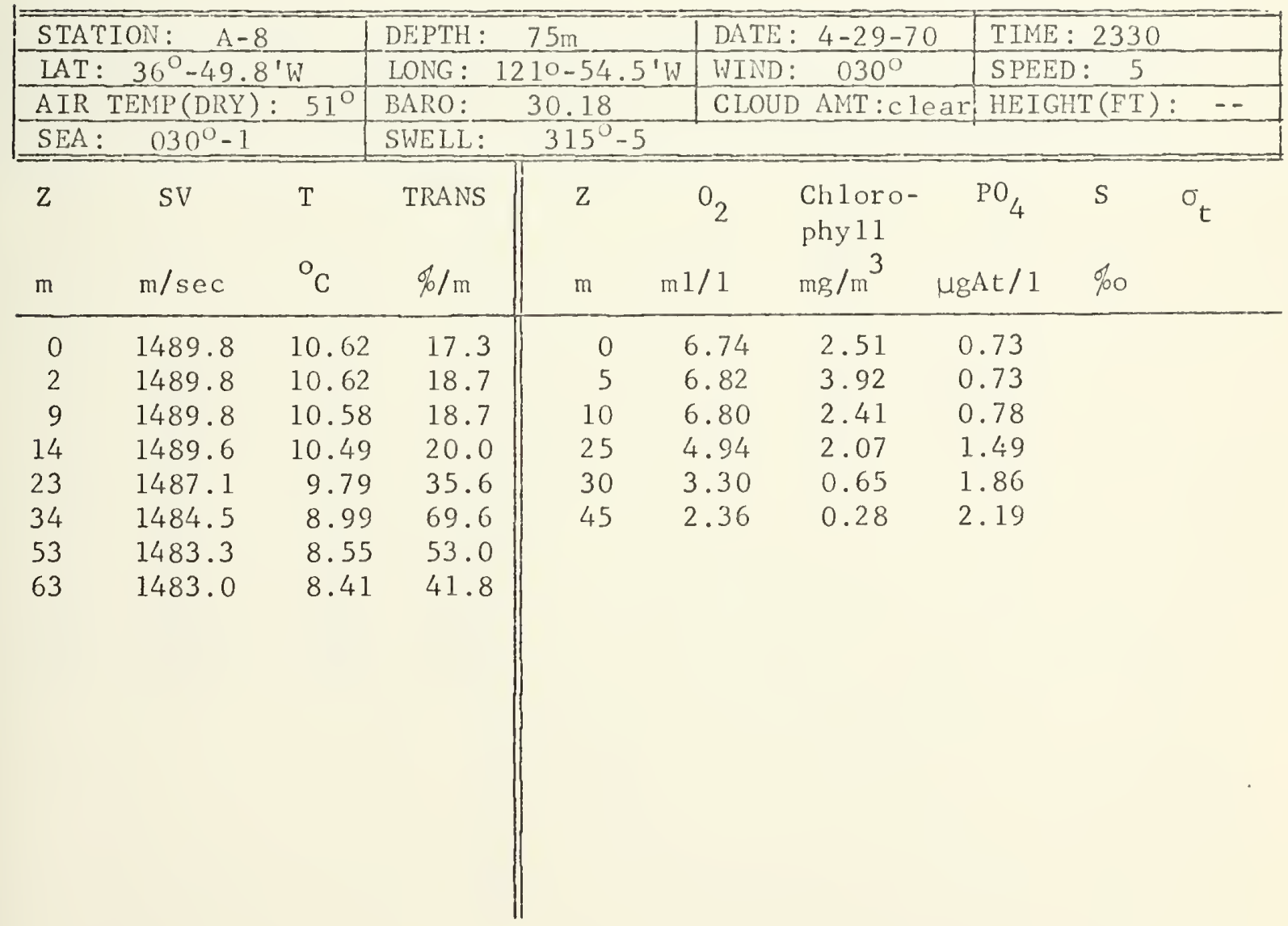





\begin{tabular}{|c|c|c|c|c|c|c|c|c|c|}
\hline STAT & ON: & & \multicolumn{2}{|l|}{ DEPTH : } & \multicolumn{5}{|c|}{ DATE: $4-30-70$ TIME: 0100} \\
\hline $\mathrm{IAT}$ & $36^{\circ}-51.4$ & & $\mathrm{LONG}: 12$ & -54.3 & WIND & $005^{\circ}$ & SPEE & & \\
\hline $\mathrm{AIR}$ & EMP (DRY & $49^{\circ}$ & BARO: & .17 & CLOUI & A AMT: $\mathrm{Cl}$ & ean HEIC & $T(F T):$ & -- \\
\hline SEA & $0050-$ & & SWELL: & $15^{0}-5$ & & & & & \\
\hline $\mathrm{Z}$ & SV & $\mathrm{T}$ & TRANS & Z & $\mathrm{O}_{2}$ & $\begin{array}{l}\text { Chloro- } \\
\text { phy } 11\end{array}$ & $\mathrm{PO}_{4}$ & $S$ & $\sigma_{t}$ \\
\hline $\mathrm{m}$ & $\mathrm{m} / \mathrm{sec}$ & ${ }^{\circ} \mathrm{C}$ & $\% / \mathrm{m}$ & $\mathrm{m}$ & $\mathrm{m} 1 / 1$ & $\mathrm{mg} / \mathrm{m}^{3}$ & $\mu g A t / 1$ & $\%$ & \\
\hline 0 & - & - & 10.0 & 0 & 7.22 & 4.37 & 0.26 & & \\
\hline 2 & 1491.4 & 11.08 & 10.0 & 5 & 6.77 & 6.43 & 0.32 & & \\
\hline 5 & 1491.5 & 11.11 & 10.1 & 10 & 7.13 & 6.68 & 0.45 & & \\
\hline 10 & 1491.3 & 11.03 & 10.9 & 20 & 4.54 & 0.48 & 1.48 & & \\
\hline 16 & 1490.5 & 10.80 & 22.4 & 30 & 2.47 & 0.45 & 2.04 & & \\
\hline 20 & 1488.5 & 10.20 & 31.3 & 40 & 2.26 & 0.35 & 2.10 & & \\
\hline 25 & 1485.2 & 9.29 & 63.8 & & & & & & \\
\hline 31 & 1484.3 & 8.98 & 73.4 & & & & & & \\
\hline 37 & 1483.9 & 8.81 & 69.6 & & & & & & \\
\hline 41 & 1483.6 & 8.70 & 69.7 & & & & & & \\
\hline
\end{tabular}

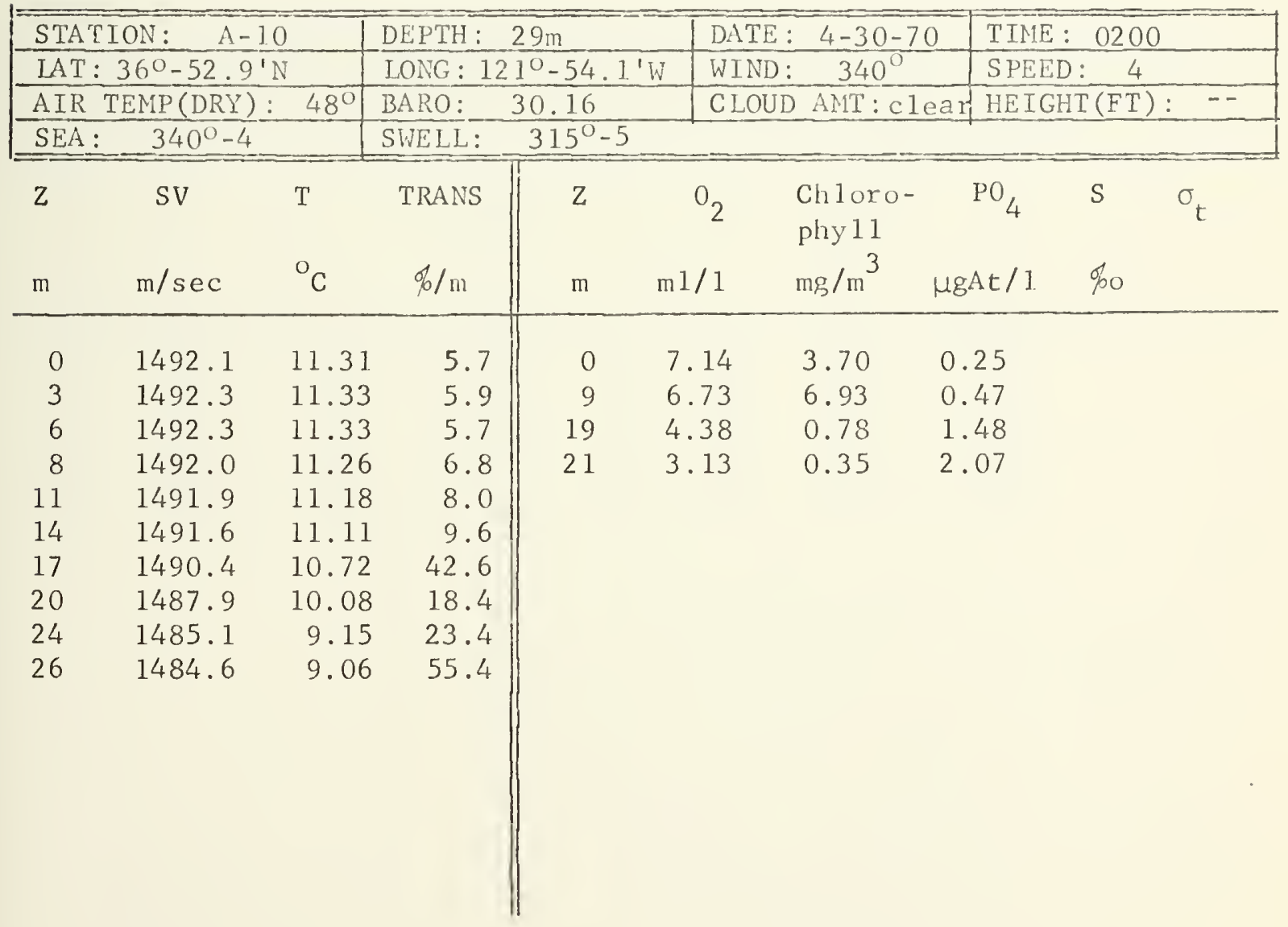





\begin{tabular}{|c|c|c|c|c|}
\hline STATION: $A-11$ & DEPTH : & DATE: $4-30-70$ & TIME: & \\
\hline IAT $: 360-54.1^{\prime} \mathrm{N}$ & LONG: $121^{\circ}-54.4^{\prime} \mathrm{W}$ & WIND: $350^{\circ}$ & SPEED: $\quad 4$ & \\
\hline AIR TEMP(DRY): $49^{\circ}$ & BARO: $\quad 30.15$ & CLOUD AMT:c lear & HEIGHT(FT): & $\ldots$ \\
\hline SEA: $\quad 350^{\circ}-1$ & $315^{0}-5$ & & & \\
\hline
\end{tabular}

\begin{tabular}{lll||lllllll}
$Z$ & $\mathrm{Z} V$ & $0_{2}$ & $\begin{array}{l}\text { Chloro } \\
\text { phyll }\end{array}$ & $\mathrm{PO}_{4}$ & $\mathrm{~S}$ & $\sigma_{t}$
\end{tabular}

\begin{tabular}{|c|c|c|c|c|c|c|c|}
\hline $\mathrm{m}$ & $\mathrm{m} / \mathrm{sec}$ & ${ }^{\mathrm{O}} \mathrm{C}$ & $\% / \mathrm{m}$ & $\mathrm{m}$ & $\mathrm{m} 1 / 1$ & $\mathrm{mg} / \mathrm{m}^{3}$ & $\mu g A t / 1$ \\
\hline 0 & 1491.2 & 11.07 & 8.1 & 0 & 6.51 & 1.83 & 0.31 \\
\hline 5 & 1491.5 & 11.10 & 7.8 & 5 & 7.07 & 8.60 & 0.28 \\
\hline 9 & 1491.5 & 11.08 & 8.9 & 10 & 7.08 & 9.67 & 0.35 \\
\hline 15 & 1490.8 & 10.86 & 13.2 & 15 & 6.79 & 2.20 & 0.51 \\
\hline 17 & 1490.0 & 10.64 & 19.0 & 17 & 6.28 & 2.38 & 0.75 \\
\hline
\end{tabular}

$\begin{array}{llll}19 & 1487.9 & 10.01 & 14.9\end{array}$

$\begin{array}{llll}21 & 1486.3 & 9.57 & 13.2\end{array}$ 



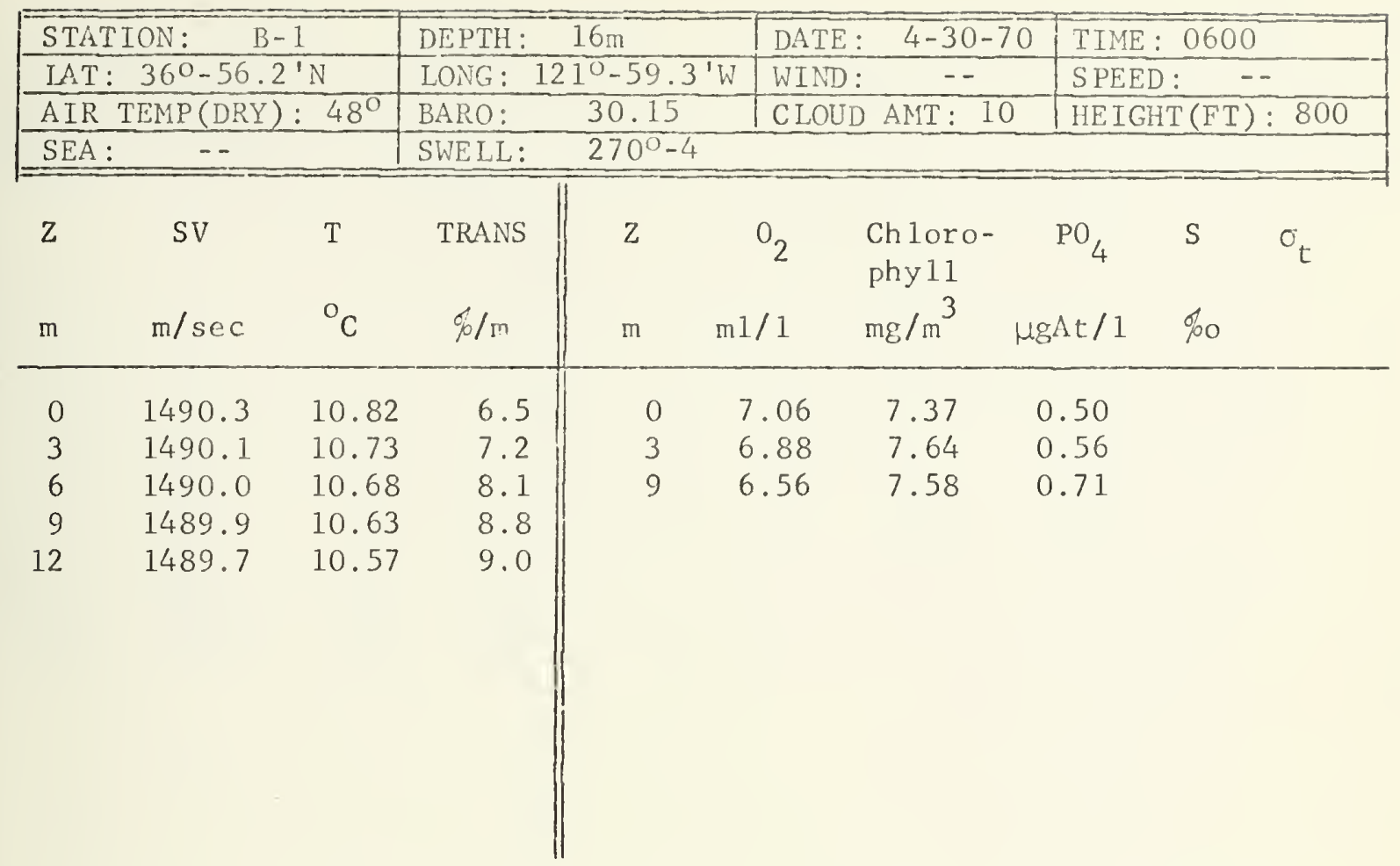

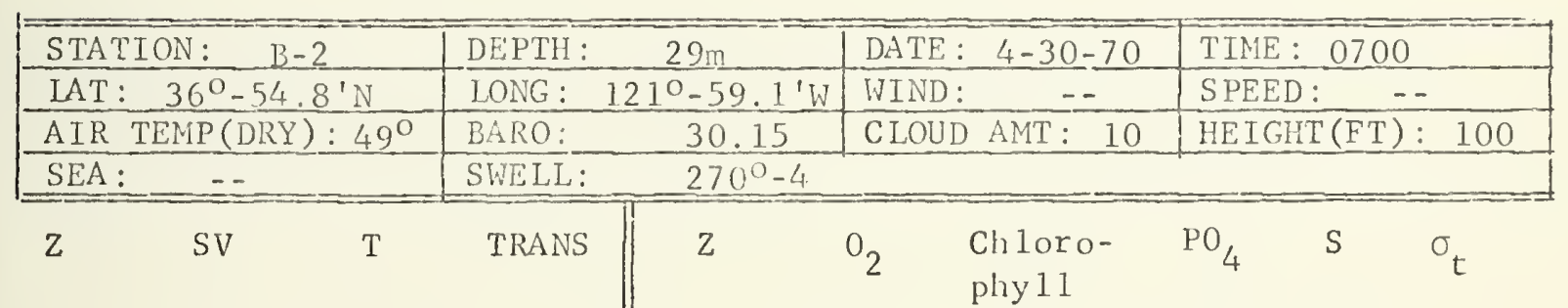

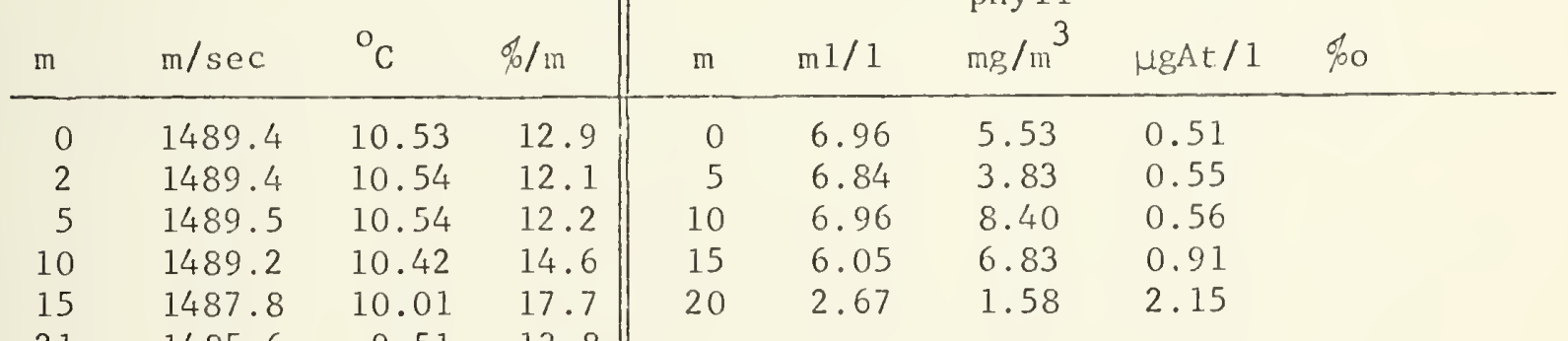

$\begin{array}{rrrr}21 & 1485.6 & 9.51 & 13.8 \\ 24 & 1484.4 & 9.02 & 9.5\end{array}$





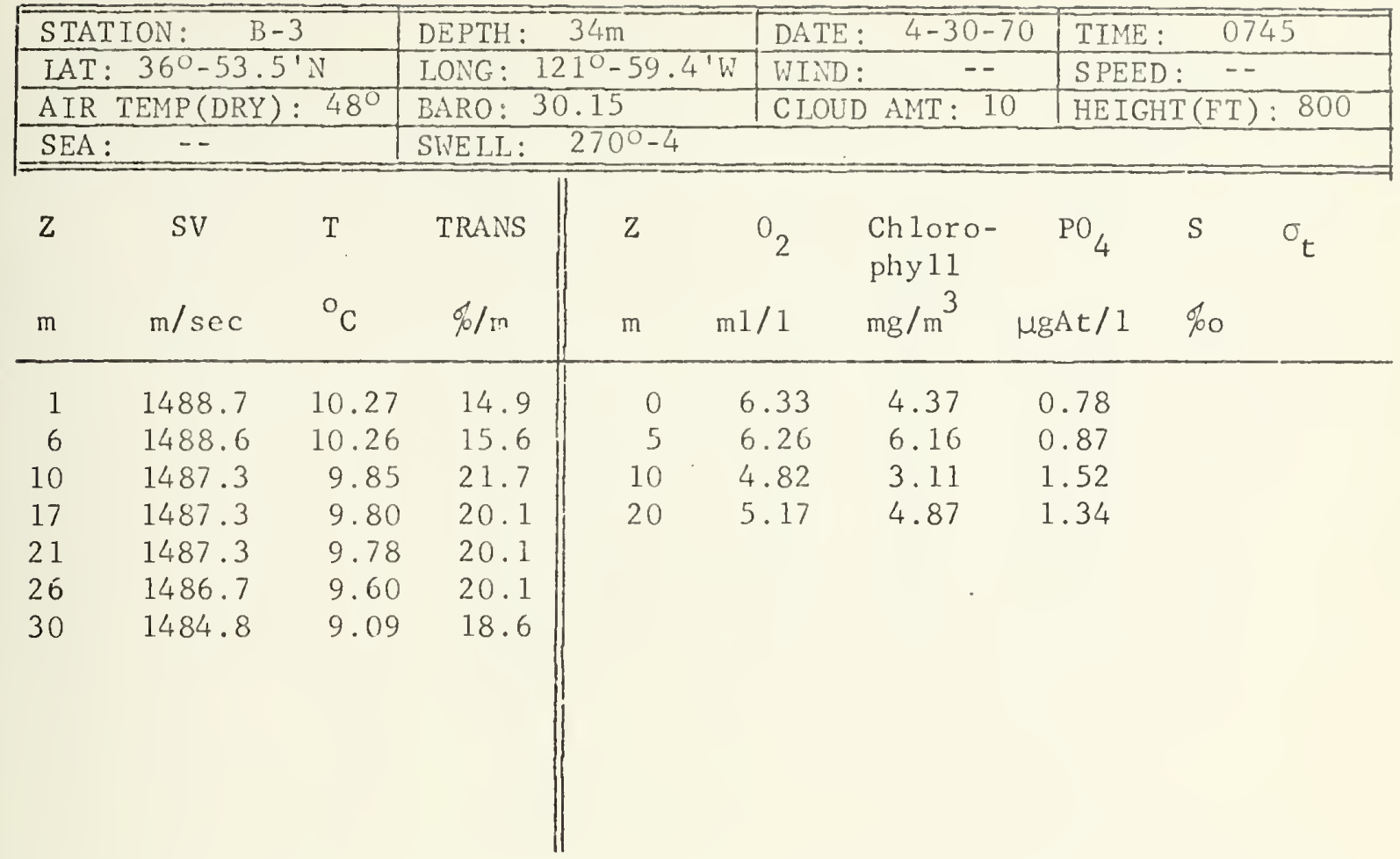

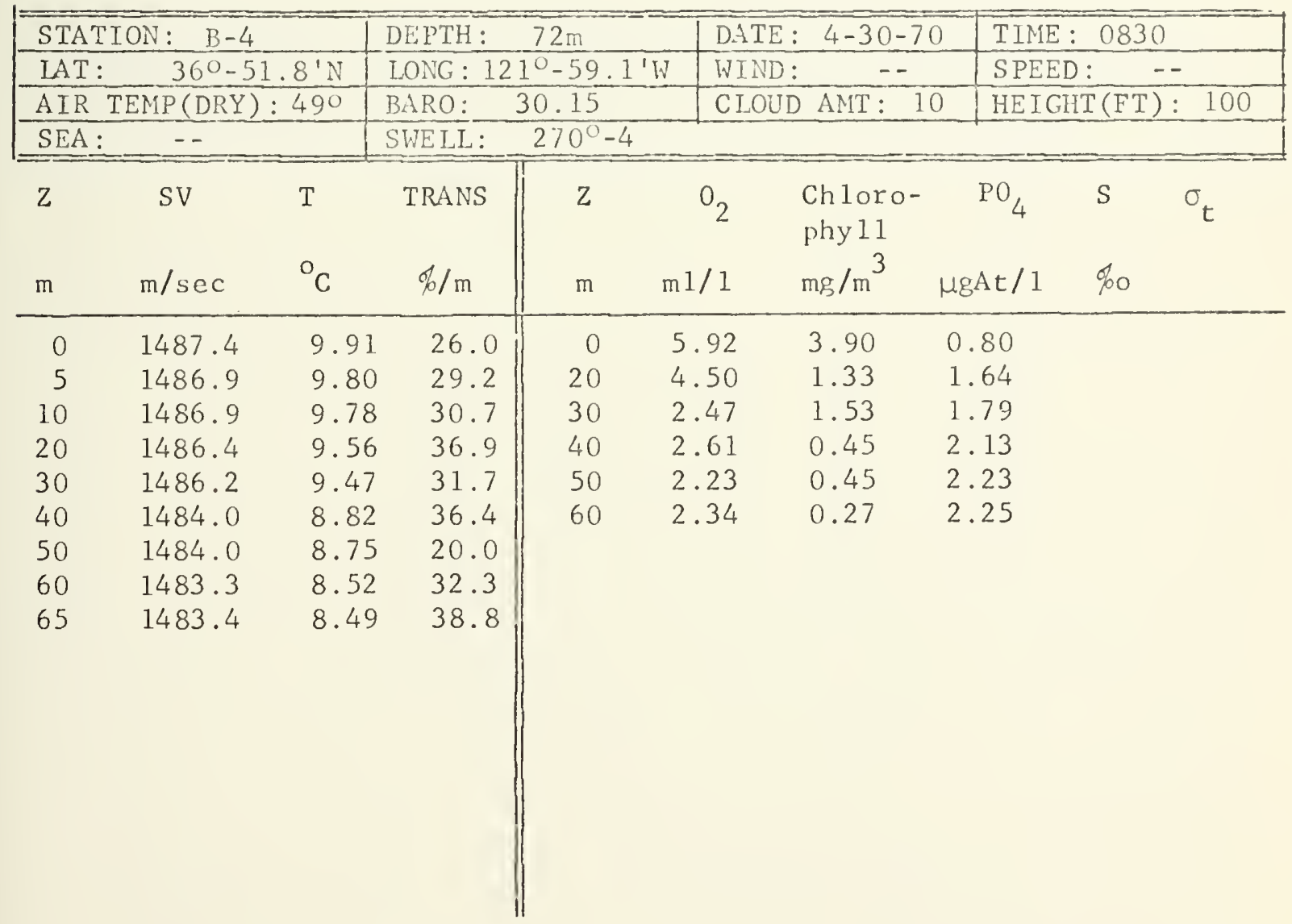





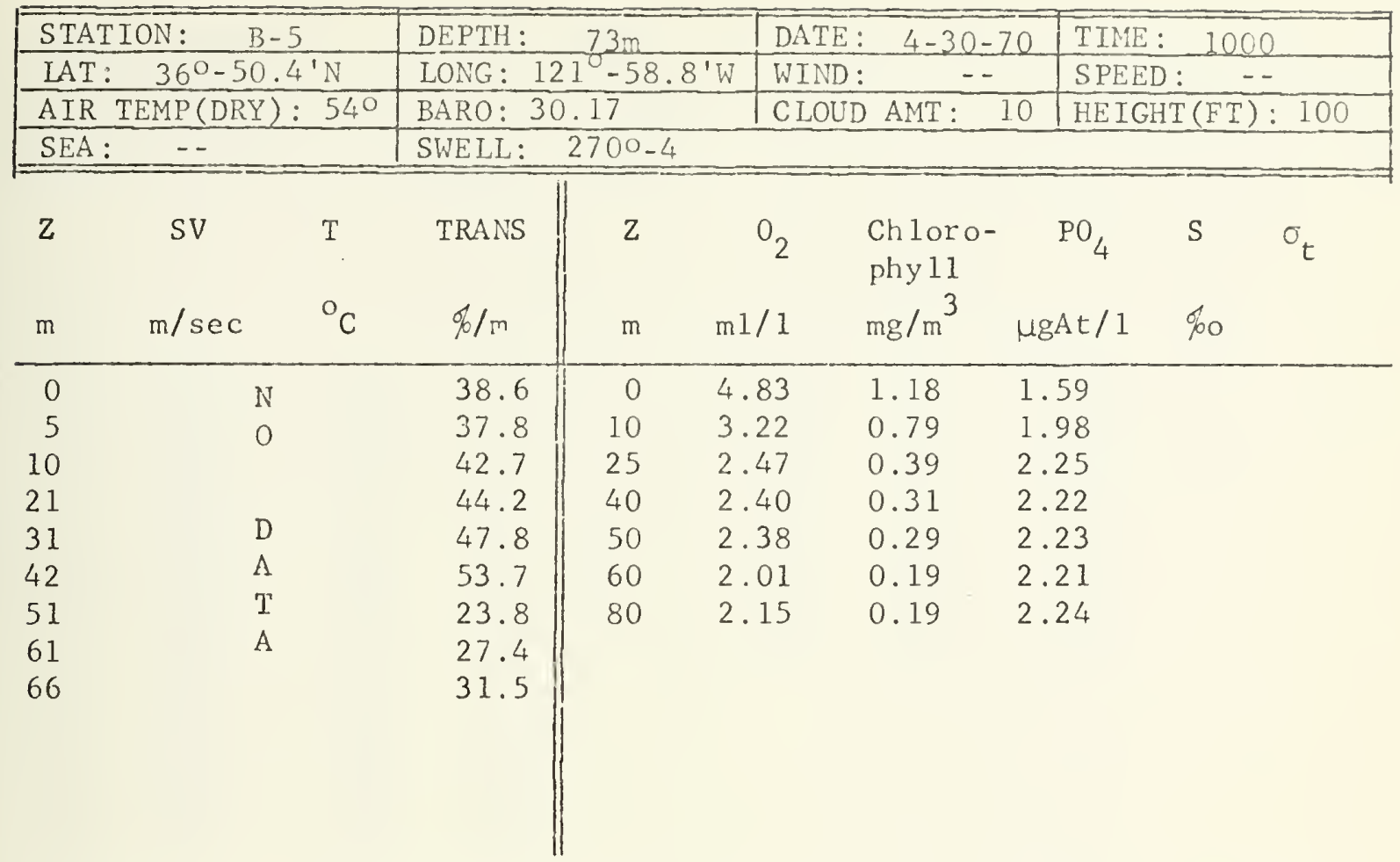

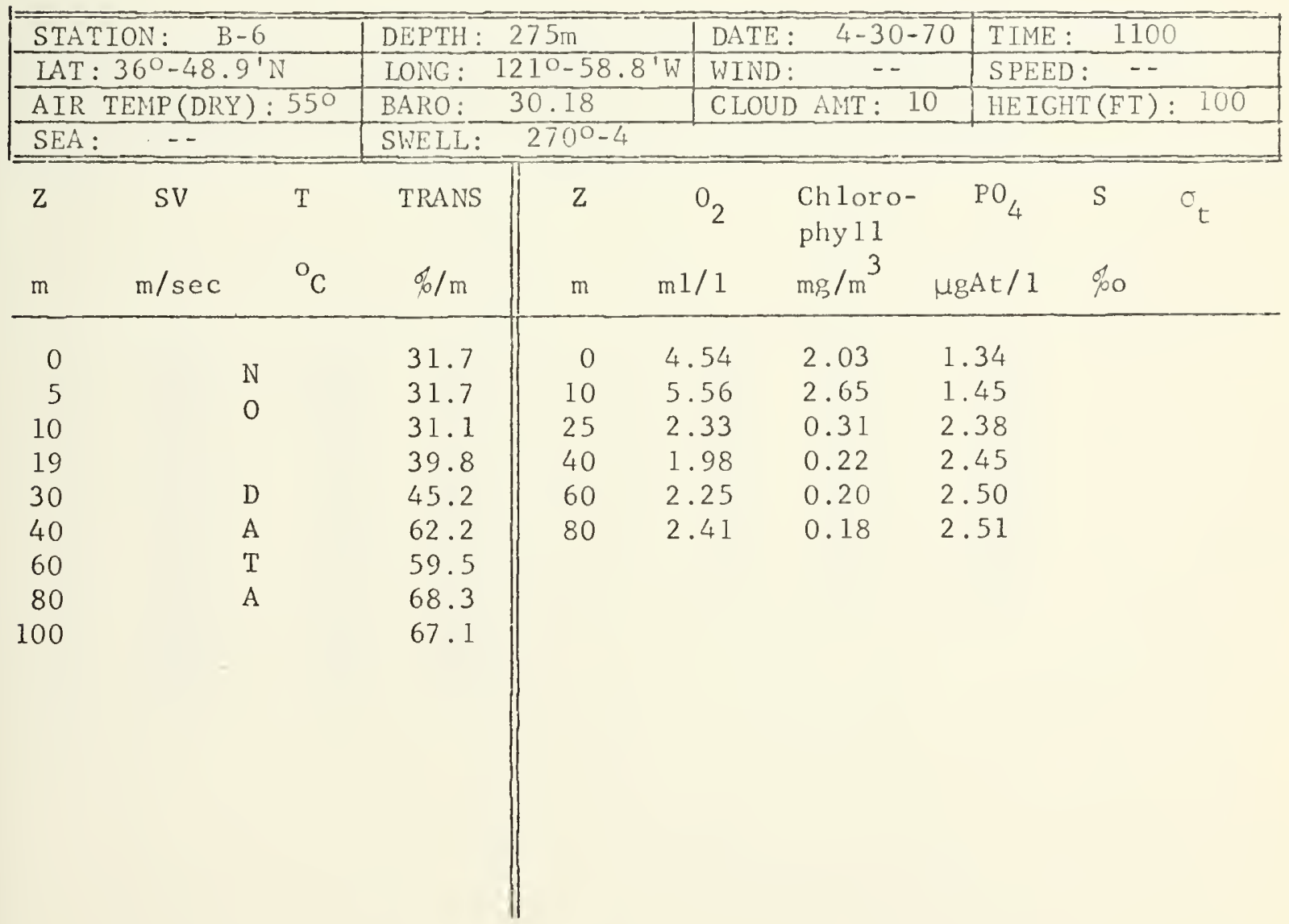





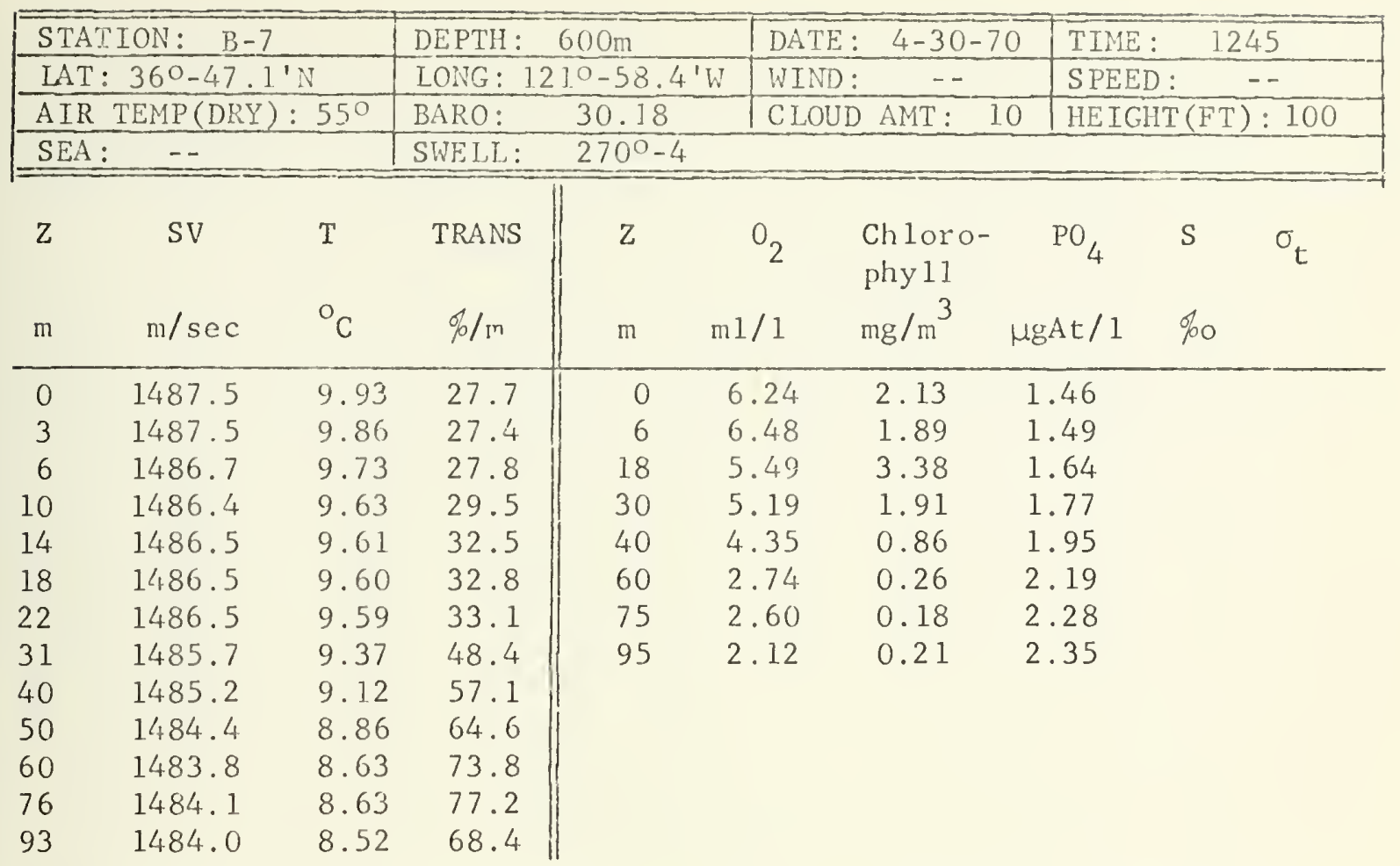

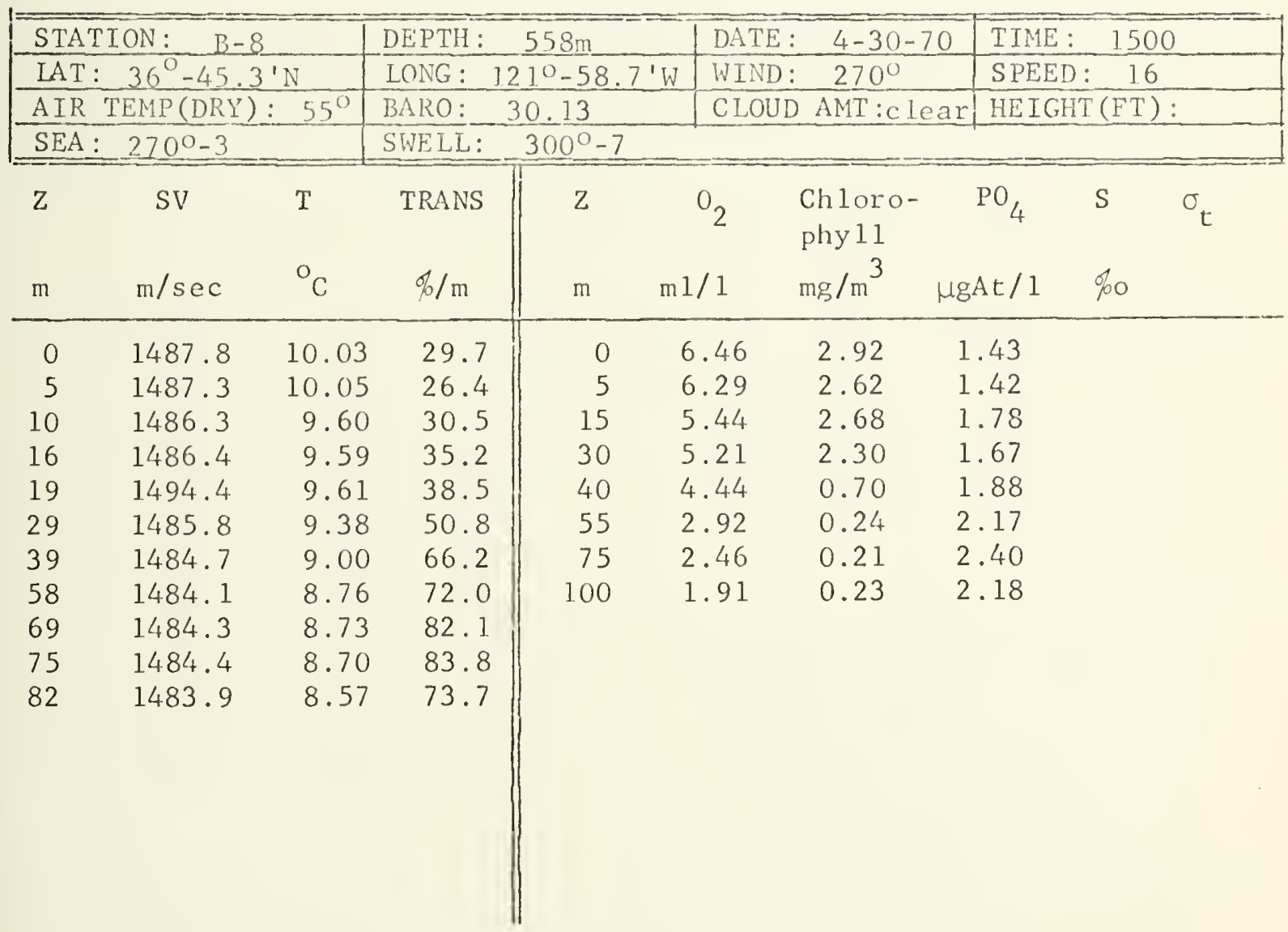





\begin{tabular}{|c|c|c|c|}
\hline STATION: $\mathrm{B}-9$ & DEPTH: $366 \mathrm{~m}$ & DATE : $4-30-70$ & TIME : \\
\hline LAT: $36^{\circ}-44.3^{\prime} \mathrm{N}$ & LONG: $121^{\circ}-59.1^{\prime} \mathrm{W}$ & WIND: $270^{\circ}$ & SPEED: \\
\hline AIR TEMP (DRY): $56^{\circ}$ & BARO: 30.12 & CLOUD AMT c lear & $\operatorname{HEIGHT}(\mathrm{FT}):--$ \\
\hline SEA : $270^{\circ}-4$ & SWELL: $300^{\circ}-8$ & & \\
\hline
\end{tabular}

\begin{tabular}{|c|c|c|c|c|c|c|c|c|c|}
\hline m & $\mathrm{m} / \mathrm{sec}$ & ${ }^{\circ} \mathrm{C}$ & $\phi / m$ & $z$ & $\begin{array}{r}0_{2} \\
\mathrm{ml} / 1\end{array}$ & $\begin{array}{l}\text { Chloro- } \\
\text { phyll } \\
\mathrm{mg} / \mathrm{m}^{3}\end{array}$ & $\begin{array}{c}\mathrm{PO}_{4} \\
\mathrm{mgAt} / 1\end{array}$ & $\begin{array}{l}\text { S } \\
\% 0\end{array}$ & $\sigma_{t}$ \\
\hline 0 & -- & -- & 27.4 & 0 & 6.63 & 2.46 & 1.33 & & \\
\hline 5 & 1487.4 & 9.93 & 27.1 & 5 & 6.61 & 2.57 & 1.38 & & \\
\hline 11 & 1487.2 & 9.87 & 28.3 & 10 & 6.47 & 2.74 & 1.35 & & \\
\hline 14 & 1486.7 & 9.71 & 31.1 & 20 & 6.14 & 2.90 & 1.45 & & \\
\hline 20 & 1486.3 & 9.54 & 40.7 & 30 & 5.46 & 1.98 & 1.53 & & \\
\hline 30 & 1486.3 & 9.48 & 46.9 & 50 & 3.04 & 0.22 & 2.17 & & \\
\hline 40 & 1485.1 & 9.13 & 64.0 & 80 & 2.06 & 0.24 & 2.36 & & \\
\hline 59 & 1484.5 & 8.84 & 70.0 & 100 & 2.25 & 0.16 & 2.41 & & \\
\hline 80 & 1483.9 & 8.58 & 61.8 & & & & & & \\
\hline 96 & 1483.7 & 8.42 & 63.0 & & & & & & \\
\hline
\end{tabular}

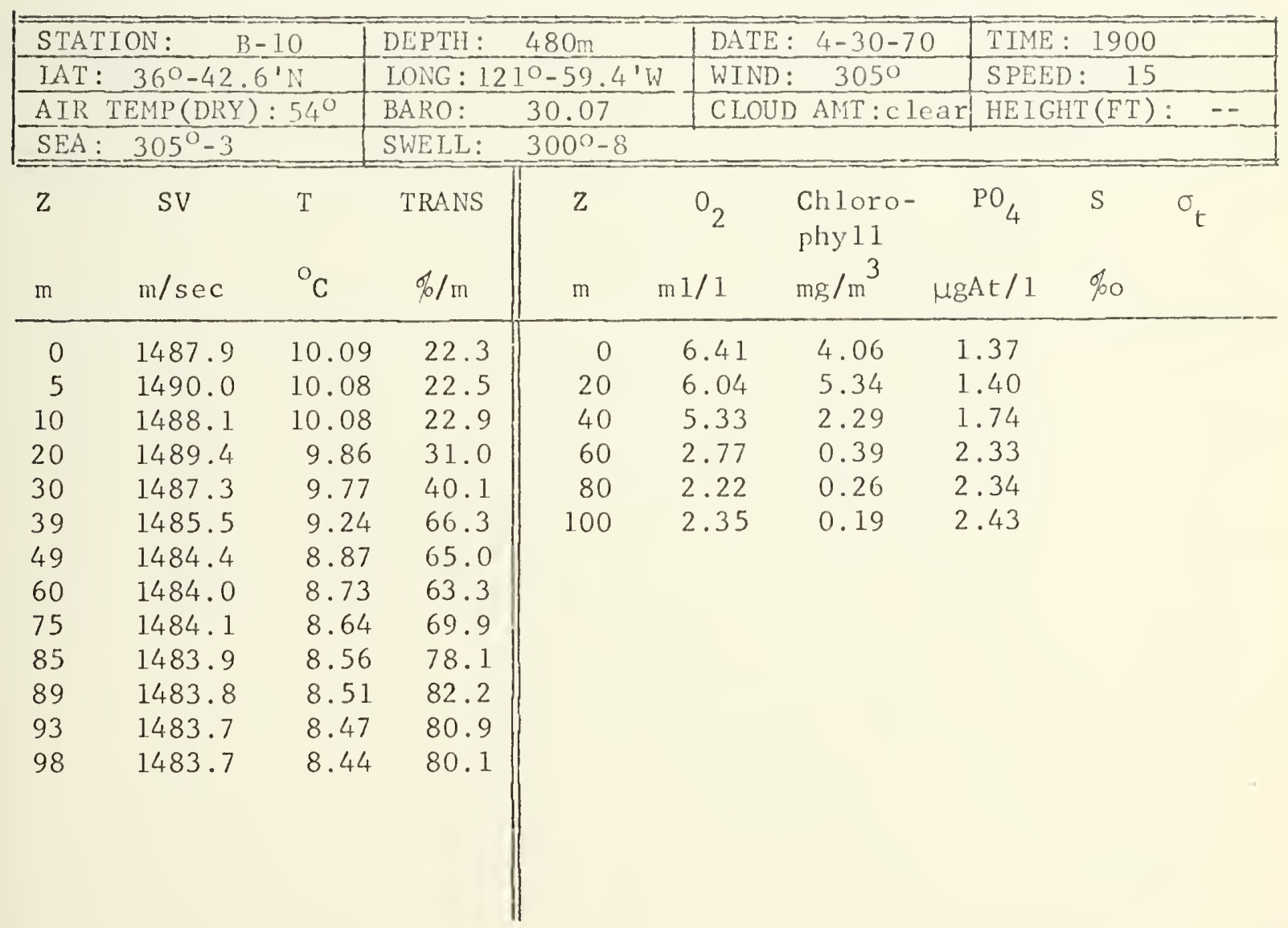





\begin{tabular}{|c|c|c|c|}
\hline STATION: $\quad B-11$ & DEPTH : & DATE : $4-30-70$ & TIME: \\
\hline LAT: $36^{\circ}-41.2^{\prime} \mathrm{N}$ & LONG: $121^{\circ}-59.2^{\prime} \mathrm{W}$ & WIND: $315^{\circ}$ & SPEED \\
\hline AIR TEMP (DRY): $53^{\circ}$ & BARO: $\quad 30.07$ & CLOUD AMT:c lear & $\operatorname{HEIGHT}(\mathrm{FT}):--$ \\
\hline SEA: $315^{\circ}-4$ & $310^{\circ}-9$ & & \\
\hline
\end{tabular}

\begin{tabular}{|c|c|c|c|c|c|c|c|c|c|}
\hline Z & $\mathrm{m} / \mathrm{sec}$ & ${ }^{\circ} \mathrm{C}$ & TRANS & $\mathrm{Z}$ & $\begin{array}{r}\mathrm{O}_{2} \\
\mathrm{~m} 1 / 1\end{array}$ & $\begin{array}{l}\text { Chloro- } \\
\text { phy } 11 \\
\mathrm{mg} / \mathrm{m}^{3}\end{array}$ & $\begin{array}{c}\mathrm{PO}_{4} \\
\mathrm{MgAt} / 1\end{array}$ & $\begin{array}{l}S \\
\% 0\end{array}$ & $o_{t}$ \\
\hline 0 & 1489.1 & 10.43 & 20.2 & 0 & 6.81 & 3.03 & 1.19 & & \\
\hline 11 & 1489.2 & 10.41 & 20.7 & 10 & 6.95 & 2.87 & 1.16 & & \\
\hline 21 & 1488.4 & 10.17 & 26.7 & 30 & 3.54 & 1.96 & 2.03 & & \\
\hline 30 & 1486.4 & 9.61 & 66.1 & 50 & 2.57 & 0.49 & 2.36 & & \\
\hline 41 & 1484.6 & 9.98 & 68.2 & 65 & 2.36 & 0.26 & 2.32 & & \\
\hline 51 & 1484.2 & 8.81 & 69.3 & 90 & 2.10 & 0.32 & 2.42 & & \\
\hline 61 & 1483.9 & 8.70 & 73.3 & & & & & & \\
\hline 71 & 1483.9 & 8.62 & 85.6 & & & & & & \\
\hline 81 & 1484.0 & 8.60 & -- & & & & & & \\
\hline 90 & 1484.0 & 8.55 & 83.6 & & & & & & \\
\hline 100 & 1483.6 & 8.40 & 87.4 & & & & & & \\
\hline
\end{tabular}

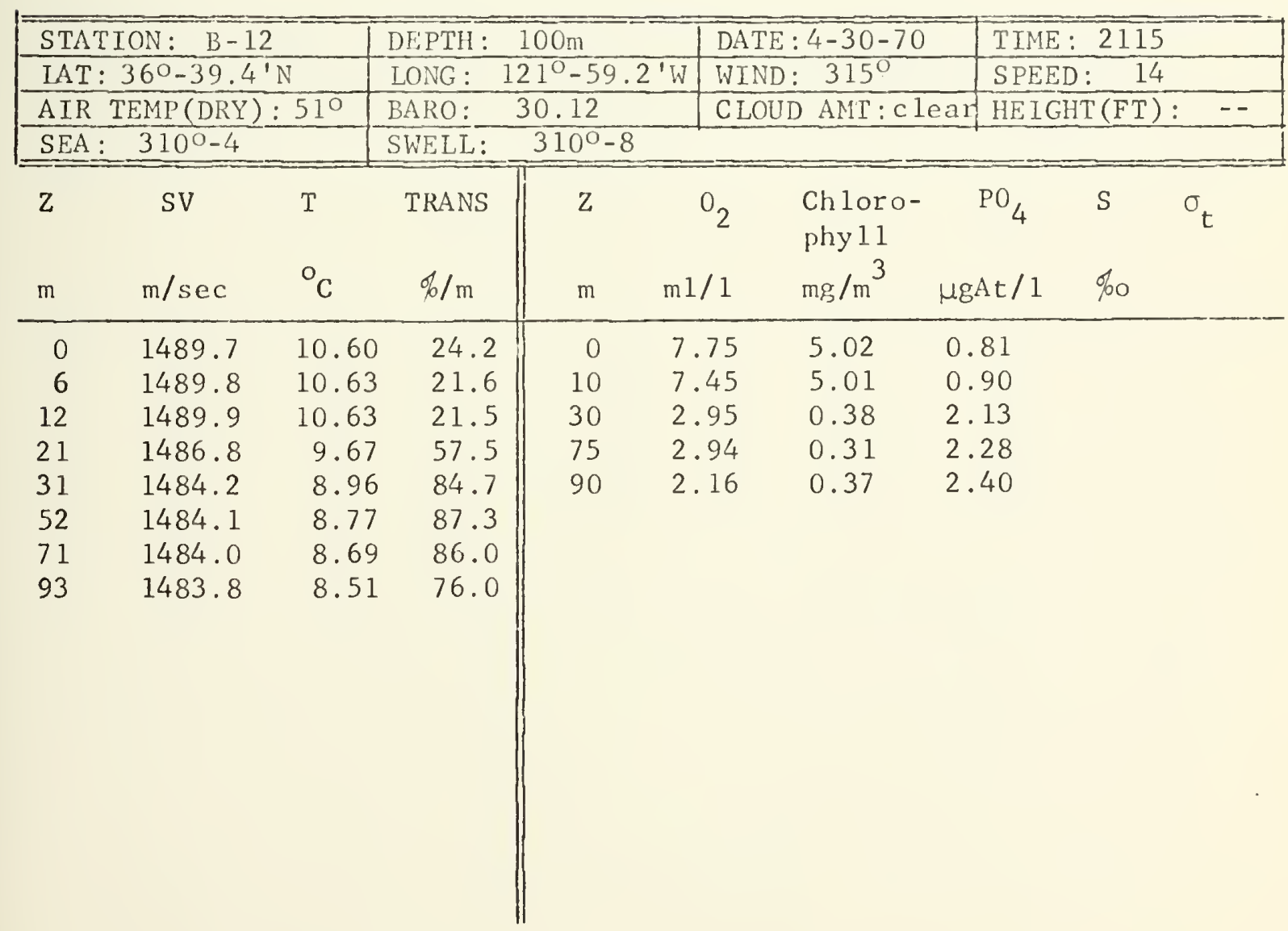





\begin{tabular}{|c|c|c|c|}
\hline STATION: & DEPTH: $82 \mathrm{~m}$ & DATE : $4-30-70$ & TIME: 2215 \\
\hline $\mathrm{LAT}: 36^{\circ}-38.2^{\prime} \mathrm{N}$ & LONG: $121^{\circ}-59.1^{\prime} \mathrm{W}$ & WIND: $315^{\circ}$ & SPEED: 10 \\
\hline AIR TEMP (DRY): $50^{\circ}$ & 30.14 & CLOUD AMT:c lear & HEIGHT(FT): \\
\hline SEA: $315^{\circ}-4$ & SWELL: $315^{\circ}-8$ & & \\
\hline
\end{tabular}

\begin{tabular}{llll|llllll}
$Z$ & $\mathrm{~S} V$ & $\mathrm{~T}$ & $\mathrm{~T}$ & $\mathrm{O}_{2}$ & $\begin{array}{l}\text { Chloro } \\
\text { phyll }\end{array}$ & $\mathrm{PO}_{4}$ & $\mathrm{~S}$ & $\sigma_{t}$
\end{tabular}

\begin{tabular}{|c|c|c|c|c|c|c|c|}
\hline $\mathrm{m}$ & $\mathrm{m} / \mathrm{sec}$ & ${ }^{\circ} \mathrm{C}$ & $\% / \mathrm{m}$ & $\mathrm{m}$ & $\mathrm{ml} / 1$ & $\mathrm{mg} / \mathrm{m}^{3}$ & $\mu g A t / 1$ \\
\hline 0 & 1490.5 & 10.75 & 14.4 & 0 & 7.42 & 6.08 & 0.86 \\
\hline 10 & 1488.6 & 10.51 & 37.0 & 20 & 3.42 & 0.68 & 1.97 \\
\hline 15 & 1485.4 & 9.37 & 68.2 & 40 & 3.18 & 0.47 & 2.19 \\
\hline
\end{tabular}

\begin{tabular}{llll|lll}
15 & 1485.4 & 9.37 & 68.2 & 40 & 3.18 & 0.47
\end{tabular}

$\begin{array}{lll}36 & 1484.3 & 8.89 \\ 39 & 1483.5 & 8.63 \quad 81.4\end{array}$

$\begin{array}{llll}39 & 1483.5 & 8.60 \quad 82.9\end{array}$

$\begin{array}{llll}51 & 1483.4 & 8.50 & 82.9\end{array}$

$\begin{array}{llll}61 & 1483.6 & 8.52 & 83.8\end{array}$

$\begin{array}{llll}66 & 1483.5 & 8.49 & 80.9\end{array}$

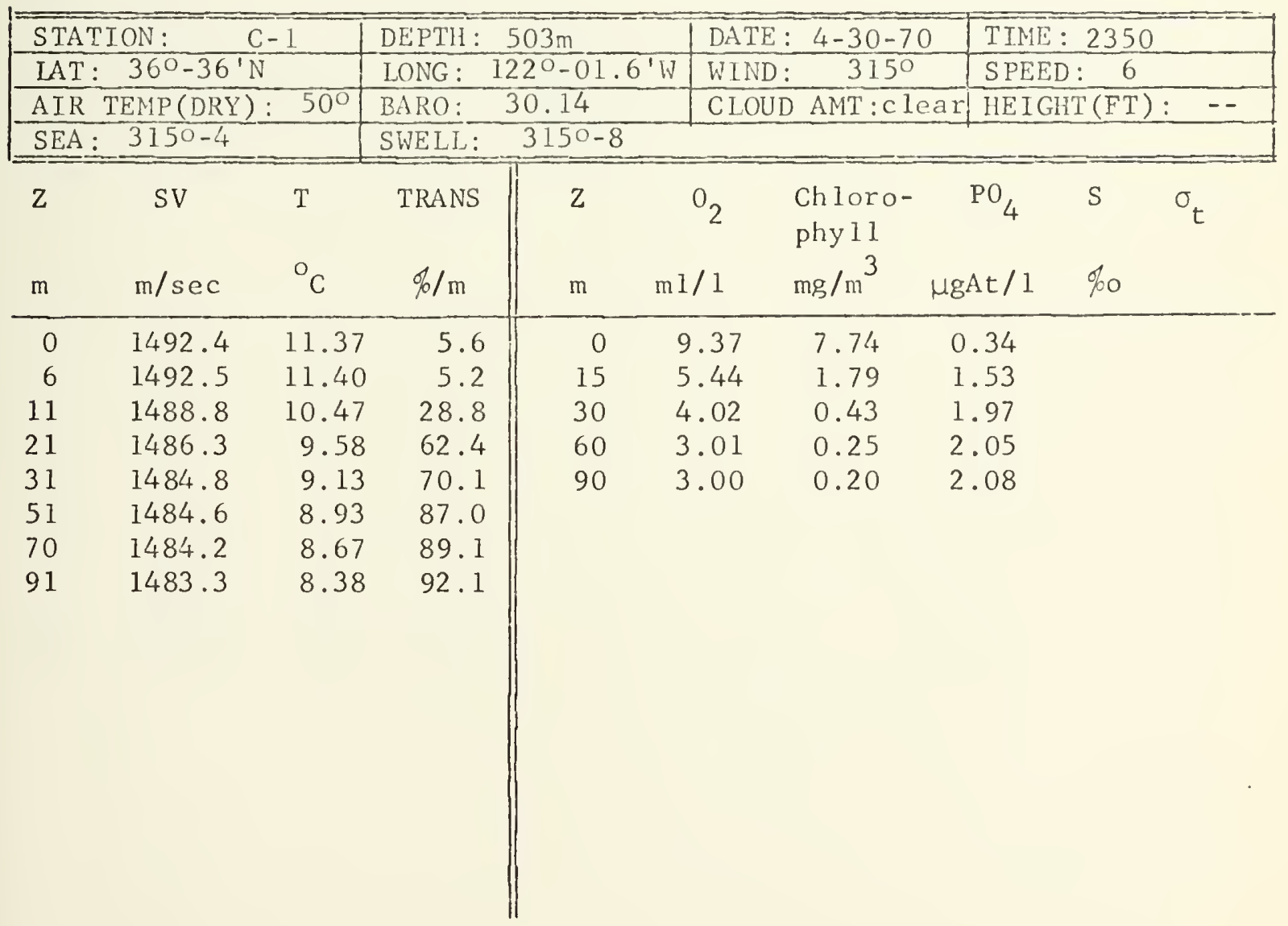





\begin{tabular}{|c|c|c|c|c|c|c|c|c|c|c|}
\hline \multicolumn{3}{|c|}{ STATION: $\mathrm{C}-2$} & \multicolumn{3}{|c|}{ DEPTH $: 1000 \mathrm{~m}$} & \multicolumn{2}{|c|}{ DATE : $5-1-70$} & \multicolumn{3}{|c|}{ TIME: 0145} \\
\hline \multicolumn{3}{|c|}{ LAT $: 36^{\circ}-33.6^{\prime} \mathrm{N}$} & \multicolumn{3}{|c|}{ LONG: $122^{\circ}-04.6^{\prime} \mathrm{W}$} & \multicolumn{2}{|c|}{ WIND: $330^{\circ}$} & \multicolumn{3}{|c|}{ SPEED: 10} \\
\hline \multicolumn{3}{|c|}{ AIR TEMP (DRY): $50^{\circ}$} & \multicolumn{3}{|c|}{ BARO: $\quad 30.12$} & \multicolumn{2}{|c|}{ CLOUD AMT:C lear } & \multicolumn{2}{|c|}{ HEIGHT(FT) } & -- \\
\hline \multicolumn{3}{|c|}{ SEA: $\quad 335^{\circ}-3$} & \multicolumn{8}{|c|}{ SWELL: $320^{\circ}-8$} \\
\hline $\mathrm{Z}$ & SV & $\mathrm{T}$ & TRANS & $\mathrm{Z}$ & & $\mathrm{O}_{2}$ & $\begin{array}{l}\text { Ch1oro- } \\
\text { phy } 11\end{array}$ & $\mathrm{PO}_{4}$ & S & $\sigma_{t}$ \\
\hline $\mathrm{m}$ & $\mathrm{m} / \mathrm{sec}$ & ${ }^{\circ} \mathrm{C}$ & $\% / \mathrm{m}$ & $\mathrm{m}$ & $\mathrm{m} 1$ & & $\mathrm{mg} / \mathrm{m}^{3}$ & $\mu g A t / 1$ & $\%$ & \\
\hline 0 & 1491.2 & 11.04 & 12.6 & 0 & 7. & & 4.78 & 0.46 & & \\
\hline 3 & 1491.4 & 11.07 & 11.0 & 3 & 8. & & 5.85 & 0.47 & & \\
\hline 8 & 1491.4 & 11.07 & 10.7 & 8 & 8. & & 6.24 & 0.49 & & \\
\hline 13 & 1489.2 & 10.43 & 41.0 & 12 & 7. & & 5.06 & 0.62 & & \\
\hline 16 & 1487.5 & 10.00 & 49.6 & 25 & 5 . & & 2.95 & 1.65 & & \\
\hline 20 & 1487.0 & 9.77 & 50.4 & 55 & 4. & & 0.62 & 1.94 & & \\
\hline 26 & 1487.1 & 9.76 & 53.6 & 75 & 3. & & 0.42 & 2.30 & & \\
\hline 37 & 1486.3 & 9.48 & 60.4 & 100 & 2. & & 0.20 & 2.08 & & \\
\hline 46 & 1486.2 & 9.42 & 63.5 & & & & & & & \\
\hline 55 & 1485.4 & 9.15 & 70.4 & & & & & & & \\
\hline 65 & 1484.6 & 8.90 & 74.2 & & & & & & & \\
\hline 77 & 1484.4 & 8.77 & 81.5 & & & & & & & \\
\hline 85 & 1484.5 & 8.74 & 83.5 & & & & & & & \\
\hline 97 & 1484.6 & 8.72 & 81.4 & & & & & & & \\
\hline
\end{tabular}

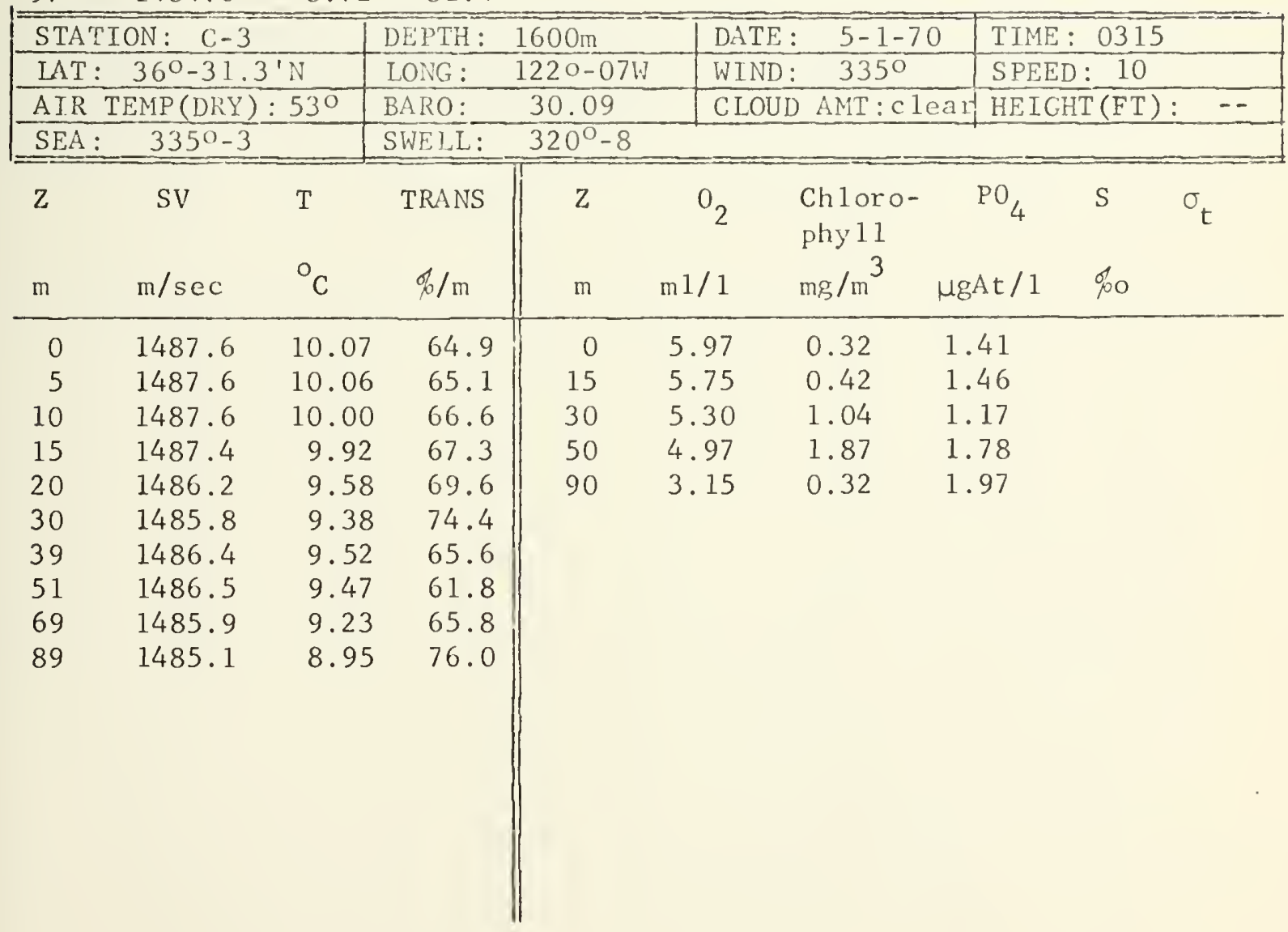





\begin{tabular}{|c|c|c|c|}
\hline STATION: & DEPTH : & $5-1-70$ & TIME: \\
\hline LAT: $36^{\circ}-35.3^{\prime} \mathrm{N}$ & LONG: $122^{\circ}-10.7^{\prime} \mathrm{W}$ & WIND: & SPEED : \\
\hline AIR TEMP (DRY): $50^{\circ}$ & BARO: & CLOUD AMT:c lear & HEIGHT (FT): \\
\hline SEA: & $300^{0}-4$ & & \\
\hline
\end{tabular}

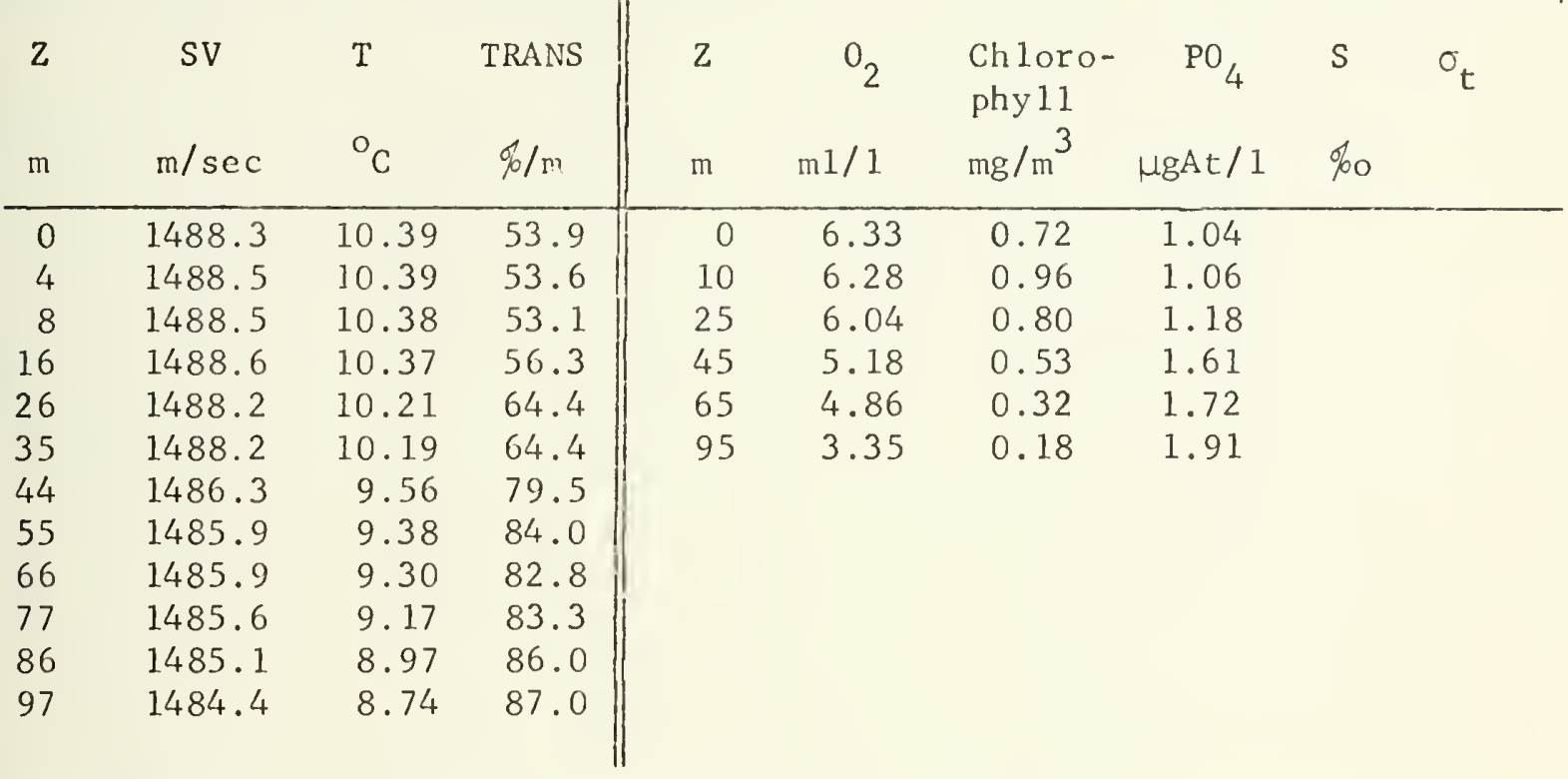

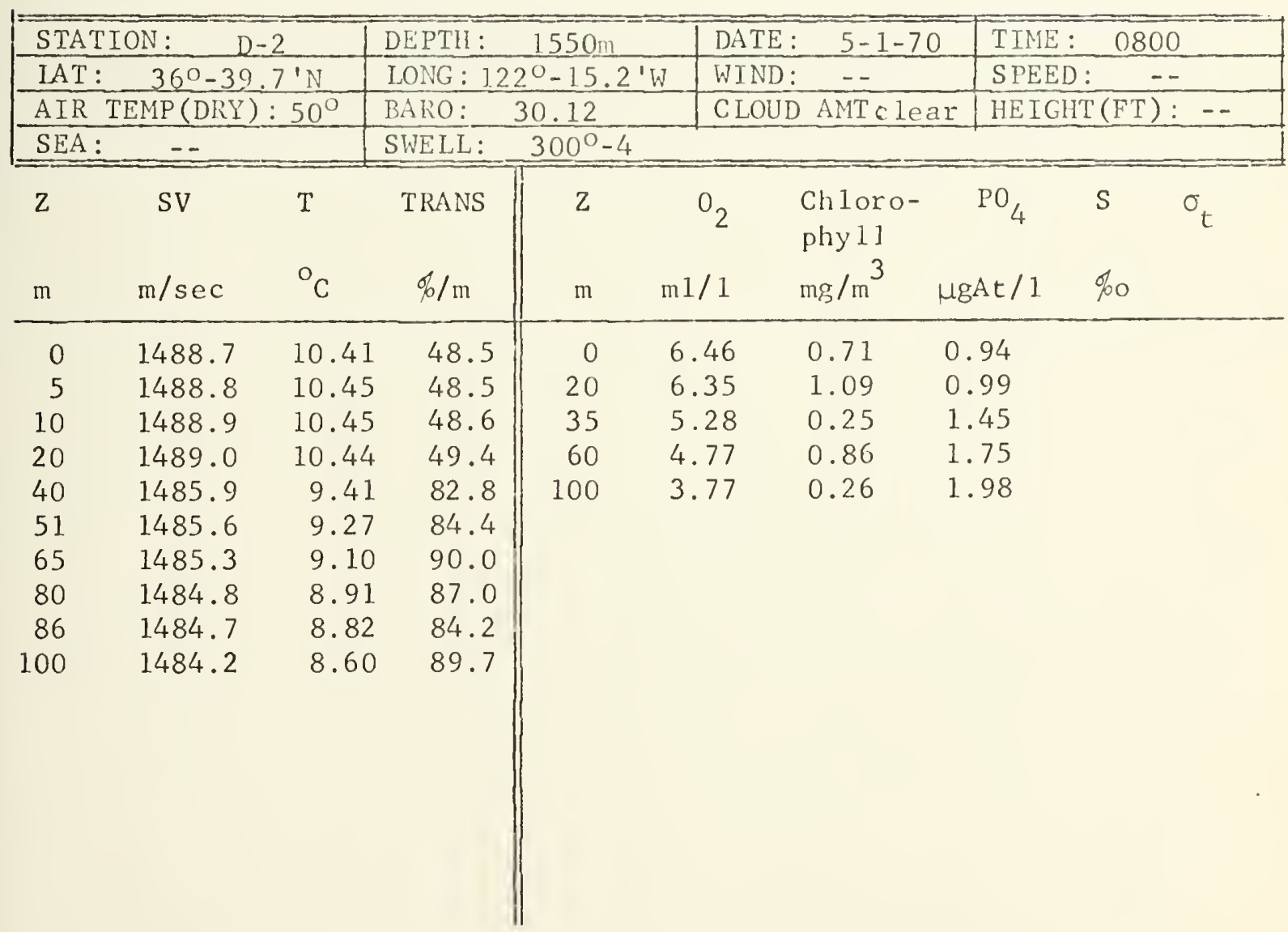





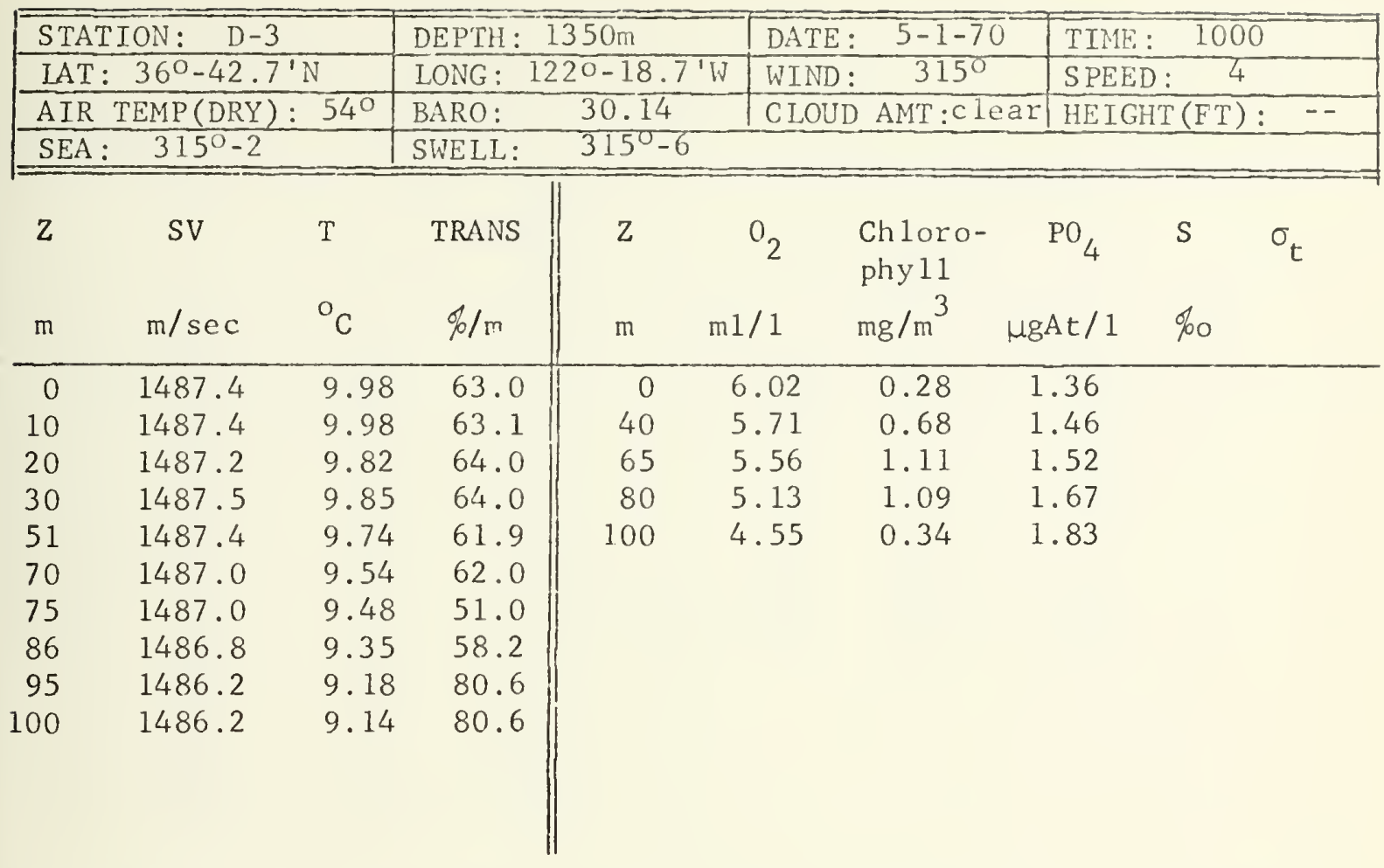

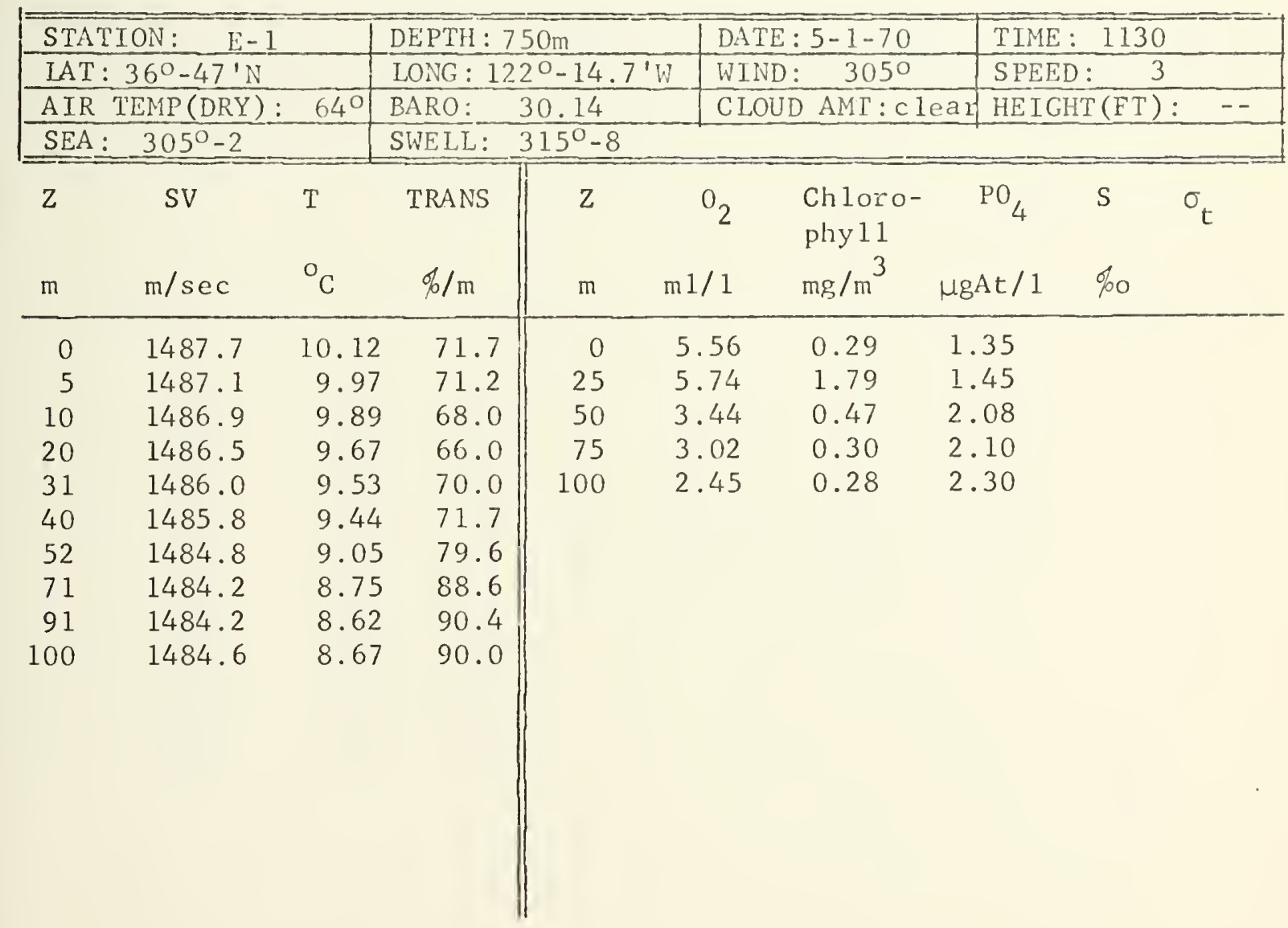





\begin{tabular}{|c|c|c|c|}
\hline STATION: $\mathrm{E}-2$ & DEPTH : $510 \mathrm{~m}$ & $5-1-70$ & TIME : 1330 \\
\hline LAT: $\quad 36^{\circ}-50^{\prime} \mathrm{N}$ & LONG: $122^{\circ}-10.2^{\prime} \mathrm{W}$ & WIND: & SPEED: $\quad 12$ \\
\hline AIR TEMP (DRY): $61^{\circ}$ & BARO: & CLOUD AMT:clear & HEIGHT (FT): -- \\
\hline SEA: $290^{\circ}-3$ & SWELL: & & \\
\hline
\end{tabular}

\begin{tabular}{|c|c|c|c|c|c|c|c|c|c|}
\hline $\mathrm{m}$ & $\mathrm{m} / \mathrm{sec}$ & ${ }^{\circ} \mathrm{C}$ & TRANS & $\mathrm{m}$ & $\mathrm{ml} / 1$ & $\begin{array}{l}\text { Chloro- } \\
\text { phy } 11 \\
\mathrm{mg} / \mathrm{m}^{3}\end{array}$ & $\begin{array}{c}\mathrm{PO}_{4} \\
\mathrm{\mu gAt} / 1\end{array}$ & $\%$ & $\sigma_{t}$ \\
\hline 0 & 1489.4 & 10.53 & 79.1 & 0 & 5.65 & 0.08 & 1.39 & & \\
\hline 3 & 1487.8 & 10.17 & 78.5 & 10 & 5.66 & 0.08 & 1.46 & & \\
\hline 7 & 1486.4 & 9.73 & 66.7 & 15 & 5.96 & 1.68 & 1.41 & & \\
\hline 16 & 1485.8 & 9.48 & 59.0 & 25 & 5.92 & 3.10 & 1.50 & & \\
\hline 25 & 1485.7 & 9.41 & 68.6 & 40 & 4.83 & 1.63 & 1.37 & & \\
\hline 35 & 1485.8 & 9.36 & 45.3 & 60 & 3.95 & 0.58 & -. & & \\
\hline 45 & 1485.6 & 9.27 & 49.0 & 80 & 2.46 & 0.28 & 2.29 & & \\
\hline 54 & 1485.7 & 9.26 & 48.0 & 95 & 5.13 & 1.60 & 2.01 & & \\
\hline 62 & 1485.3 & 9.08 & 55.5 & & & & & & \\
\hline 71 & 1484.9 & 8.91 & 60.8 & & & & & & \\
\hline 78 & 1484.1 & 8.67 & 75.0 & & & & & & \\
\hline 85 & 1483.9 & 8.55 & 93.0 & & & & & & \\
\hline
\end{tabular}

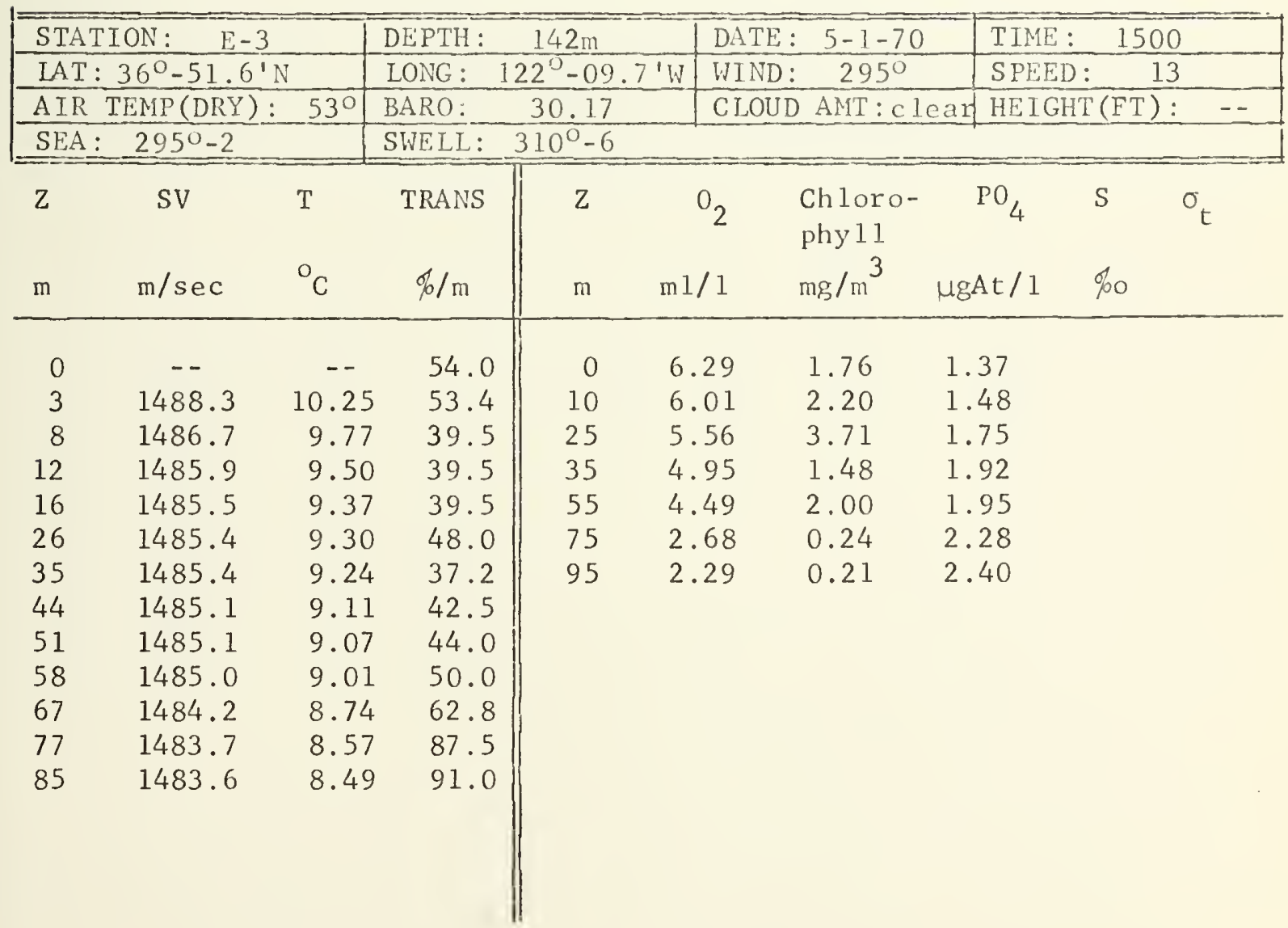





\begin{tabular}{|c|c|c|c|}
\hline STATION: & DEPTH: $95 \mathrm{~m}$ & DATE: $5-1-70$ & TIME : \\
\hline LAT: $36^{\circ}-53.3^{\prime} \mathrm{N}$ & LONG: $122^{\circ}-09.2^{\prime} \mathrm{W}$ & WIND: 2950 & SPEED: \\
\hline AIR TEMP (DRY): $56^{\circ}$ & BARO: $\quad 30.15$ & CLOUD AMT : c lear & $\operatorname{HEIGHT}(\mathrm{FT}):--$ \\
\hline SEA : & $290^{\circ}-4$ & & \\
\hline
\end{tabular}

\begin{tabular}{|c|c|c|c|c|c|c|c|c|c|}
\hline $\mathrm{m}$ & $\mathrm{m} / \mathrm{sec}$ & $\begin{array}{l}\mathrm{T} \\
{ }^{\mathrm{o}} \mathrm{C}\end{array}$ & TRANS & $\mathrm{m}$ & $\begin{array}{r}0_{2} \\
\mathrm{ml} / 1\end{array}$ & $\begin{array}{l}\text { Chloro- } \\
\text { phyl1 } \\
\mathrm{mg} / \mathrm{m}^{3}\end{array}$ & $\begin{array}{r}\mathrm{PO}_{4} \\
\mathrm{MgAt} / \mathrm{l}\end{array}$ & $\begin{array}{l}\text { S } \\
\% 0\end{array}$ & $\sigma_{t}$ \\
\hline 0 & 1489.0 & 10.60 & 26.5 & 0 & 6.20 & 1.83 & 1.48 & & \\
\hline 3 & 1487.5 & 9.92 & 27.8 & 10 & 5.67 & 5.34 & 1.53 & & \\
\hline 9 & 1488.3 & 10.14 & 26.5 & 35 & 3.17 & 0.45 & 2.25 & & \\
\hline 16 & 1485.2 & 9.25 & 32.5 & 55 & 3.20 & 0.48 & 2.32 & & \\
\hline 25 & 1485.2 & 9.19 & 31.3 & 75 & 1.96 & 0.36 & 2.52 & & \\
\hline 35 & 1485.0 & 9.07 & 35.1 & & & & & & \\
\hline 45 & 1484.8 & 8.98 & 41.8 & & & & & & \\
\hline 54 & 1484.4 & 8.86 & 51.0 & & & & & & \\
\hline 64 & 1483.8 & 8.61 & 57.5 & & & & & & \\
\hline 73 & 1483.5 & 8.48 & 78.0 & & & & & & \\
\hline
\end{tabular}

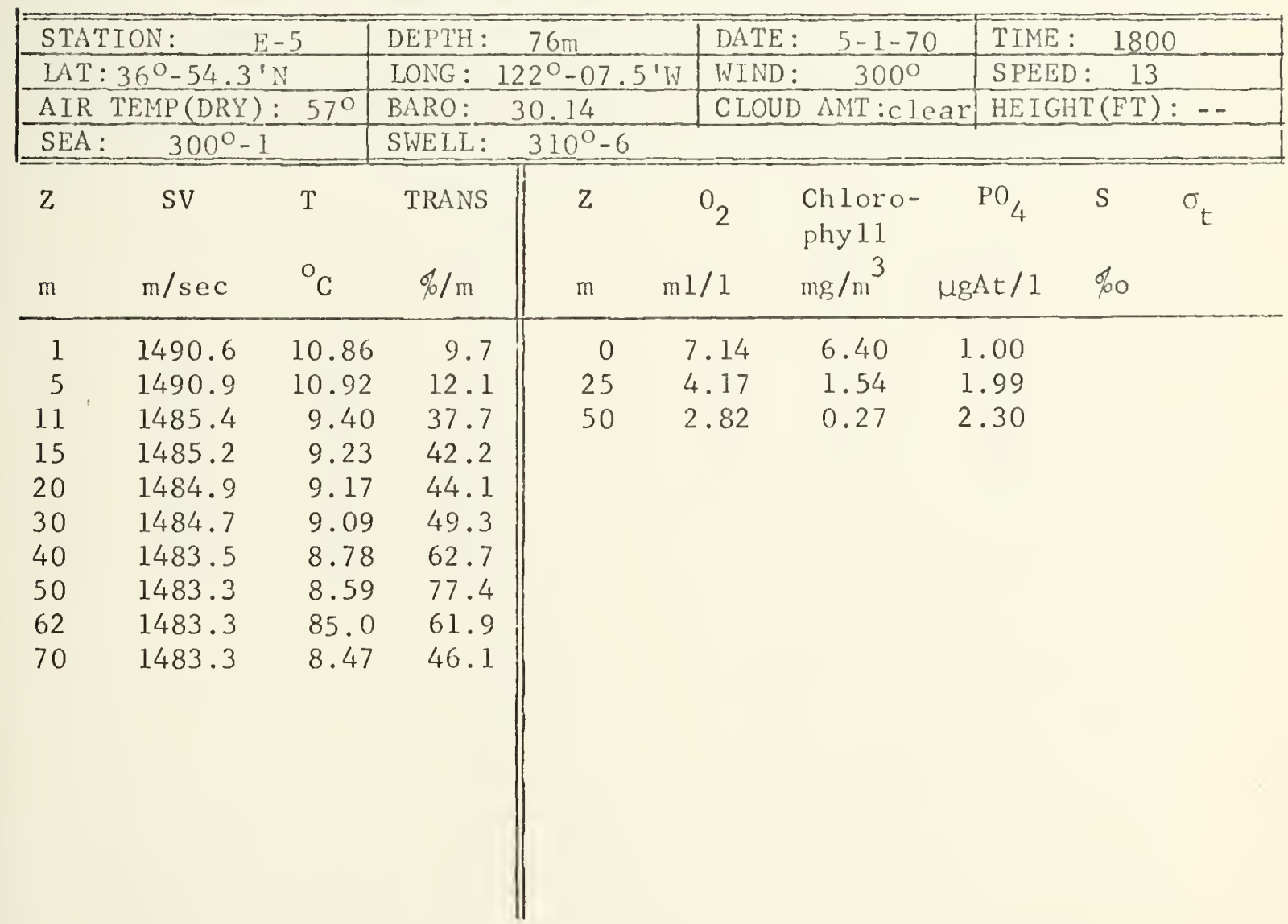





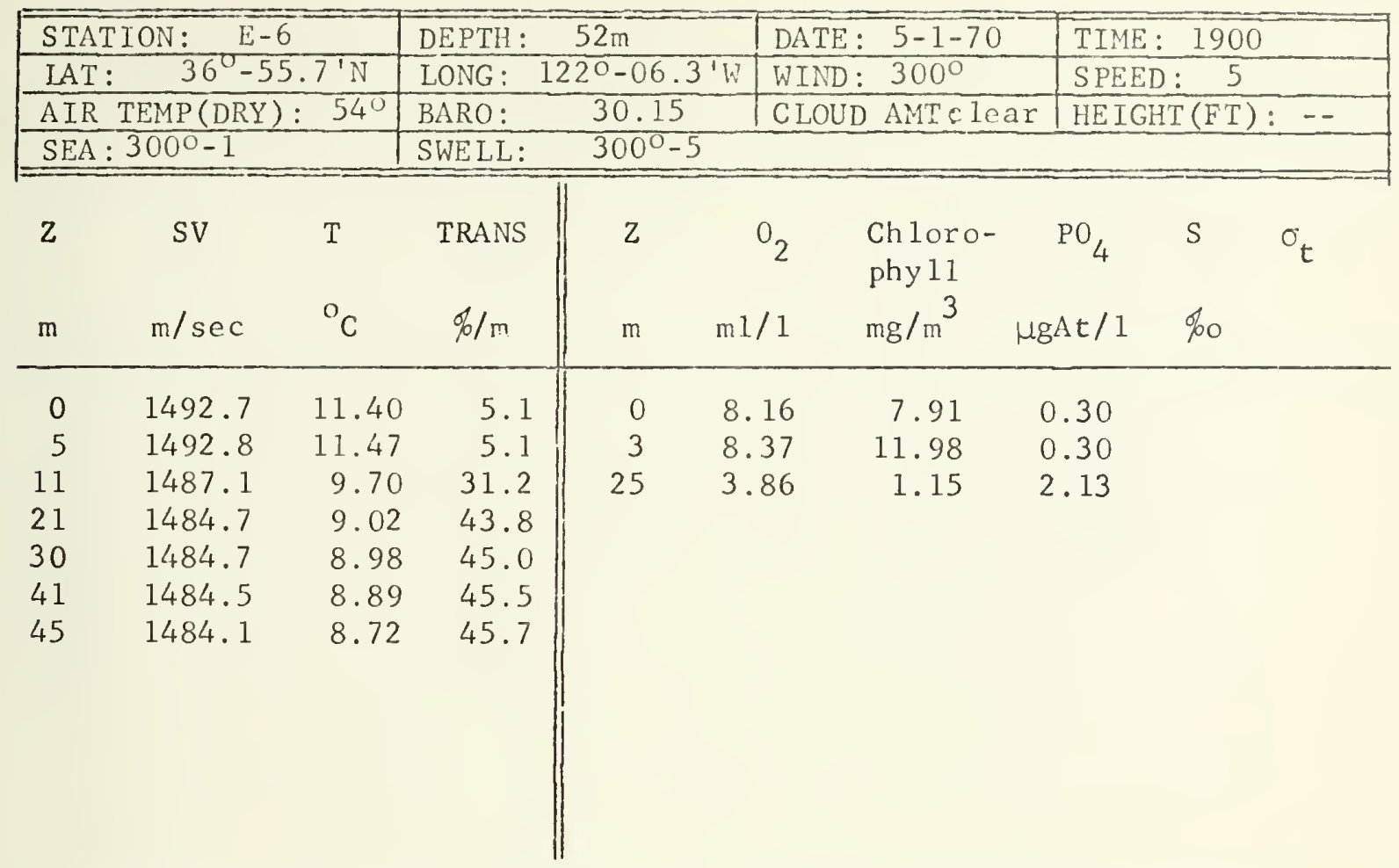

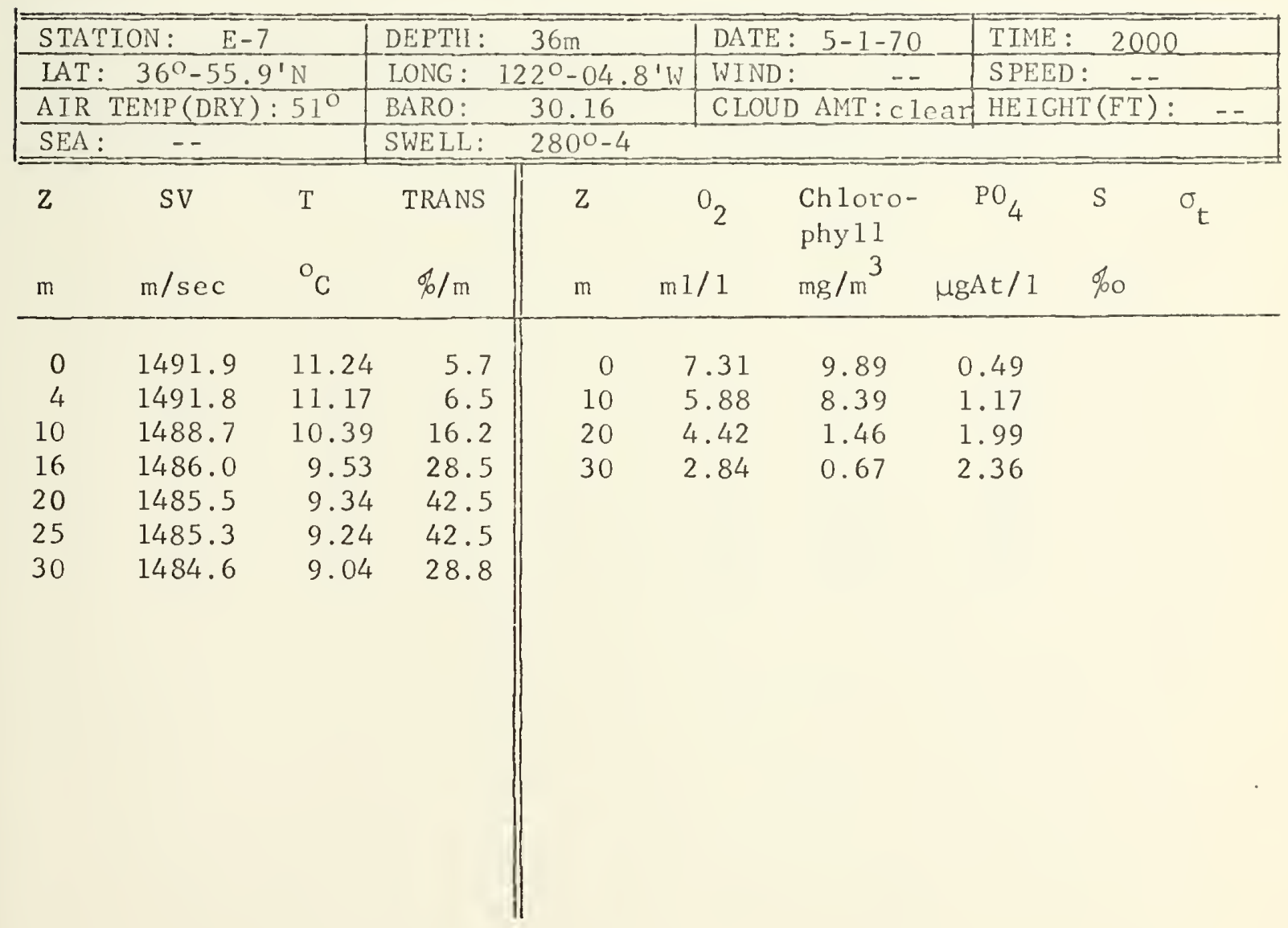





\begin{tabular}{|c|c|c|c|}
\hline STATION: $F-1$ & DEPTH : & DATE: $5-1-70$ & TIME : \\
\hline LAT: $\quad 36^{\circ}-57.4^{\prime} \mathrm{N}$ & LONG: $122^{\circ}-10^{\prime} \mathrm{W}$ & WIND: & SPEED: \\
\hline AIR TEMP (DRY) $: 51^{\circ}$ & BARO: 30.20 & CLOUD AMT: 10 & $\operatorname{HEIGHT}(\mathrm{FT}): 100$ \\
\hline SEA: & SWELL: $290^{\circ}-5$ & & \\
\hline
\end{tabular}

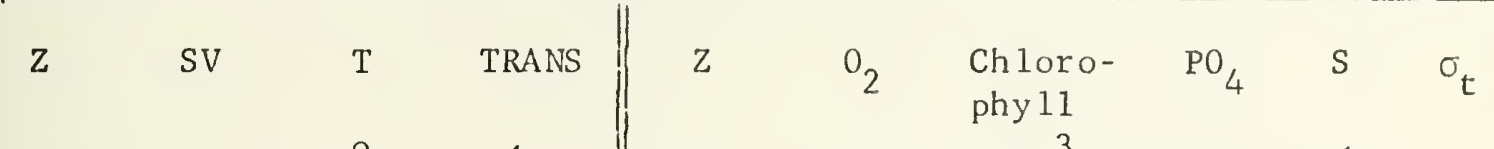

\begin{tabular}{|c|c|c|c|c|c|c|c|}
\hline $\mathrm{m}$ & $\mathrm{m} / \mathrm{sec}$ & ${ }^{\mathrm{O}} \mathrm{C}$ & $\phi / m$ & $\mathrm{~m}$ & $\mathrm{ml} / 1$ & $\mathrm{mg} / \mathrm{m}^{3}$ & $\mu g A t / 1$ \\
\hline 0 & $\mathrm{~N}$ & & 7.6 & 0 & 7.09 & 12.35 & 0.71 \\
\hline 5 & 0 & & 7.6 & 10 & 3.50 & 8.14 & 1.10 \\
\hline 10 & & & 20.2 & 20 & 2.01 & 1.16 & 2.02 \\
\hline 15 & & & 46.0 & 30 & 1.49 & 0.84 & 2.28 \\
\hline 20 & D & & 46.0 & & & & \\
\hline 25 & A & & 35.1 & & & & \\
\hline 30 & $\mathrm{~T}$ & & 30.4 & & & & \\
\hline 35 & A & & 30.0 & & & & \\
\hline
\end{tabular}

\begin{tabular}{|c|c|c|c|c|c|c|c|c|c|}
\hline & ION: & & DEPTH : & $2 m$ & DATE: & $5-2-70$ & TIME & 0130 & \\
\hline & $37^{\circ}-0$ & $+1 \mathrm{~N}$ & LONG : 1 & -14.3 & WIND: & $\quad-$ & SPEE & $: \quad \cdots$ & \\
\hline & TEMP (DRY & $48^{\circ}$ & BARO: & & C LOUD & AMT: & HEIG & $\mathrm{T}(\mathrm{FT}):$ & 100 \\
\hline & $\cdots$ & & SWE LL: & $0^{0}-5$ & & & & & \\
\hline Z & SV & $\mathrm{T}$ & TRANS & Z & $\mathrm{O}_{2}$ & $\begin{array}{l}\text { Chloro- } \\
\text { phyl1 }\end{array}$ & $\mathrm{PO}_{4}$ & S & $\sigma_{t}$ \\
\hline $\mathrm{m}$ & $\mathrm{m} / \mathrm{sec}$ & ${ }^{\mathrm{O}} \mathrm{C}$ & $\% / \mathrm{m}$ & $\mathrm{m}$ & $\mathrm{m} 1 / 1$ & $\mathrm{mg} / \mathrm{m}^{3}$ & $\mu g A t / 1$ & $\% 0$ & \\
\hline 0 & 1487.3 & 9.62 & 21.4 & 0 & 6.79 & 6.58 & 0.87 & & \\
\hline 5 & 1486.7 & 9.42 & 25.5 & 3 & 7.33 & 6.53 & 1.06 & & \\
\hline 10 & 1486.5 & 9.33 & 26.1 & 10 & 6.45 & 6.27 & 1.30 & & \\
\hline 19 & 1485.1 & 8.90 & 28.3 & 14 & 6.11 & 3.60 & 1.44 & & \\
\hline 24 & 1484.5 & 8.74 & 19.6 & 20 & 4.69 & 1.23 & 1.83 & & \\
\hline 30 & 1484.0 & 8.56 & 20.7 & 27 & 4.03 & 1.39 & 2.03 & & \\
\hline 34 & 1483.4 & 8.36 & 25.1 & 35 & 3.80 & 0.87 & 2.22 & & \\
\hline
\end{tabular}





\begin{tabular}{|c|c|c|c|}
\hline STATION: & DEPTH : $36 \mathrm{~m}$ & DATE: $5-2-70$ & TIME : 0300 \\
\hline LAT: $\quad 37^{\circ}-03.8^{\prime} \mathrm{N}$ & LONG: $122^{\circ}-17.9^{\prime} \mathrm{W}$ & WIND : $\quad--$ & SPEED : - - \\
\hline AIR TEMP(DRY): $47^{\circ}$ & BARO: 30.18 & CLOUD AMT: & HEIGHT (FT): 100 \\
\hline SEA : & SWELL: & & \\
\hline
\end{tabular}

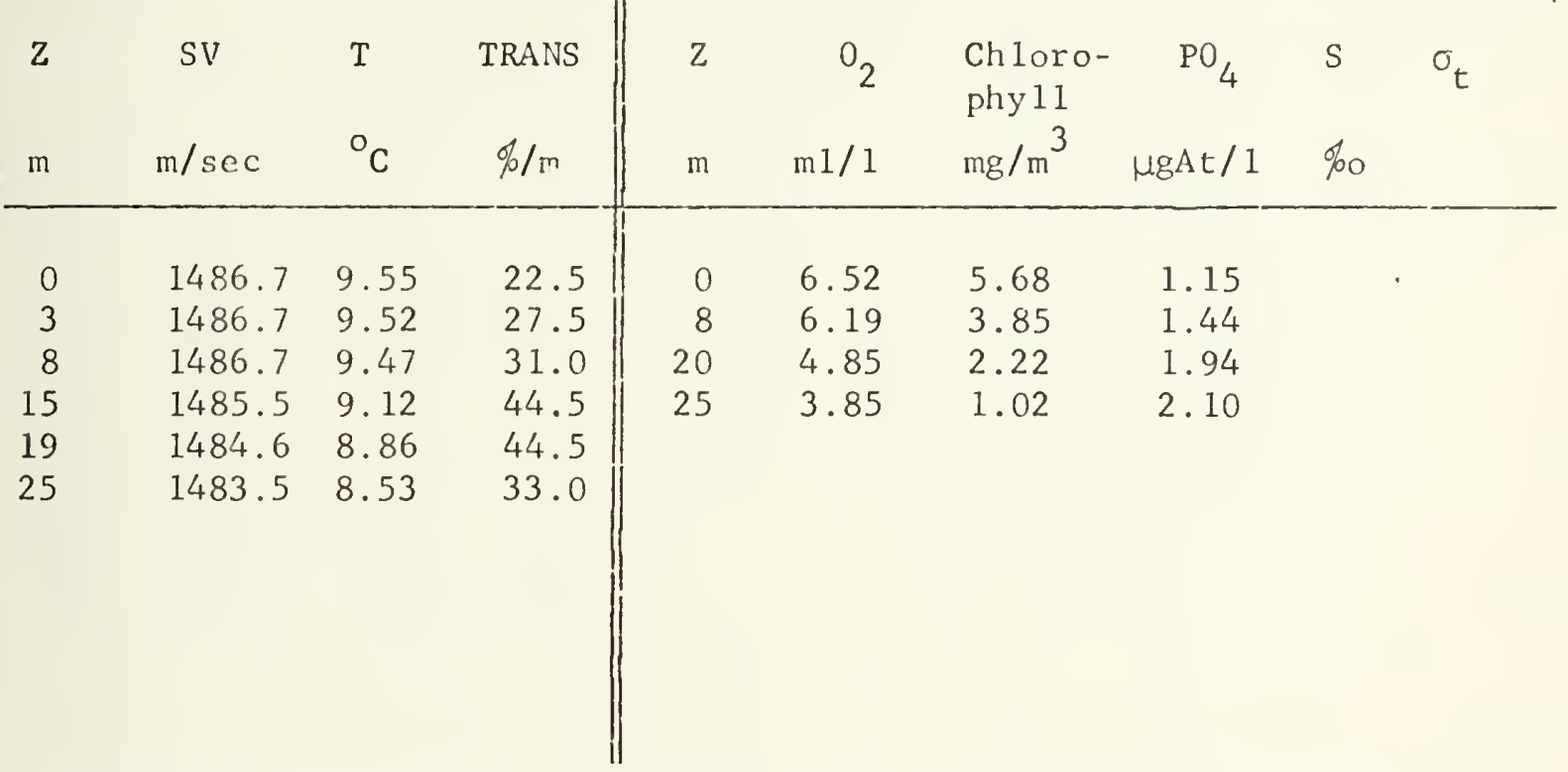

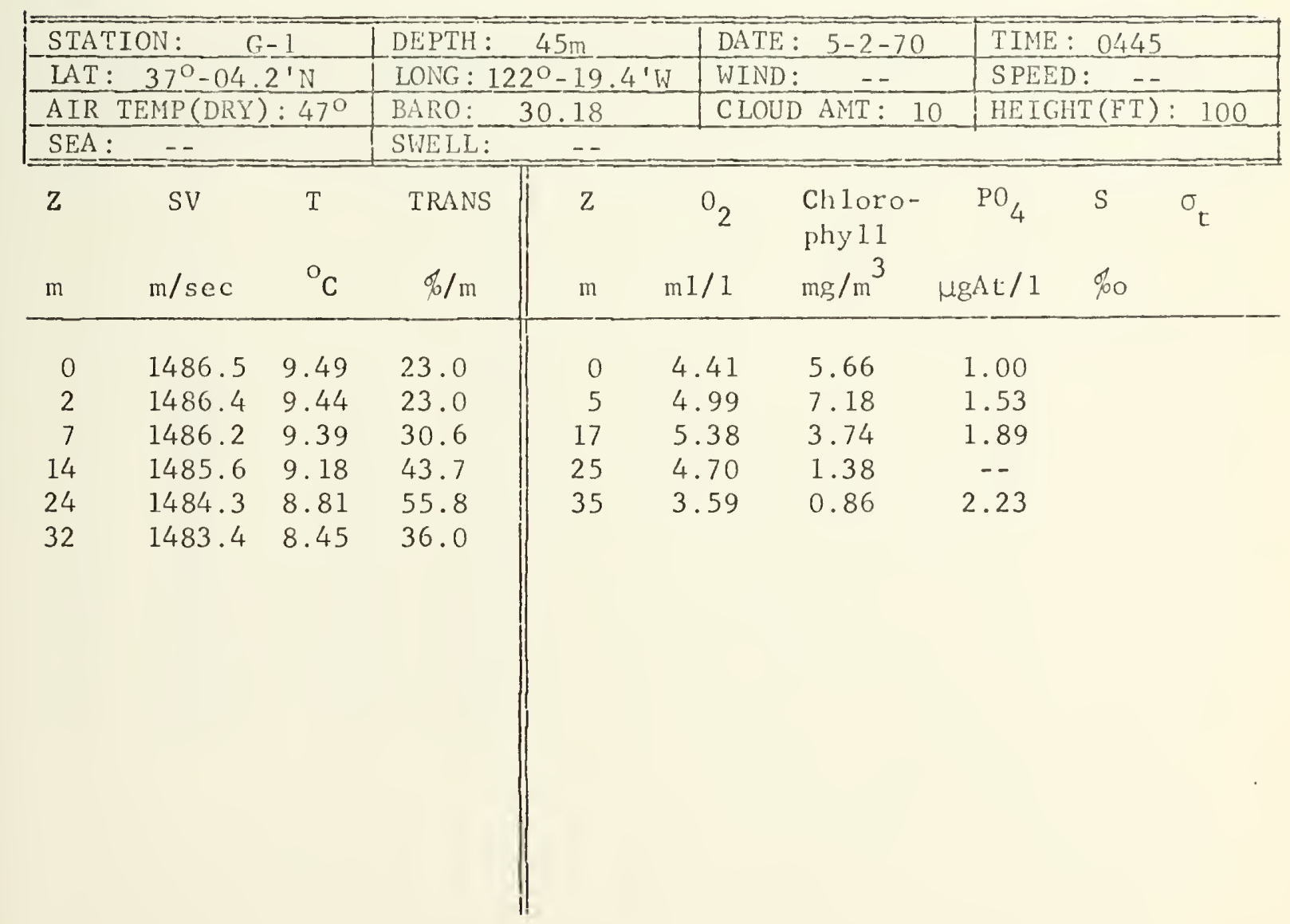





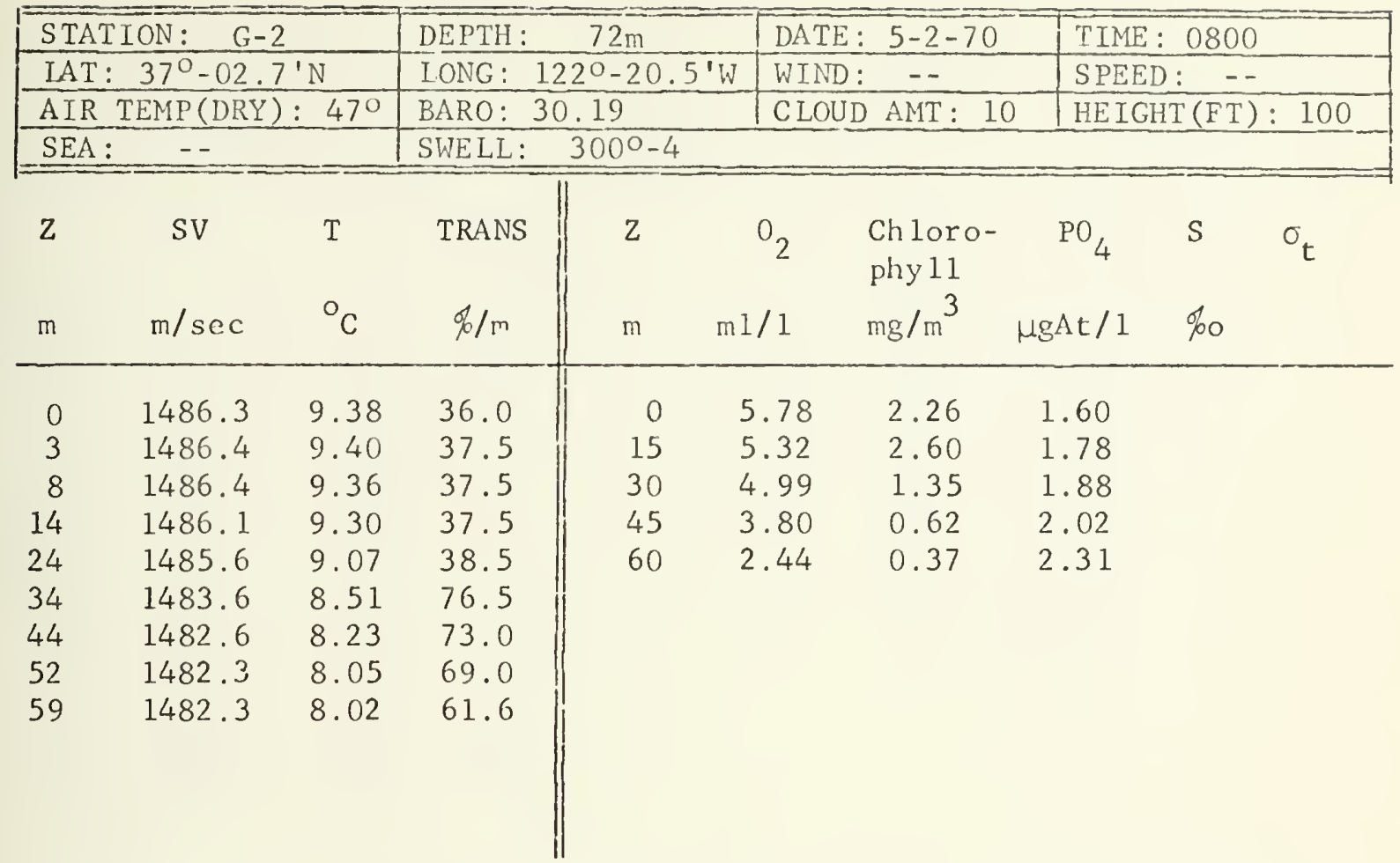

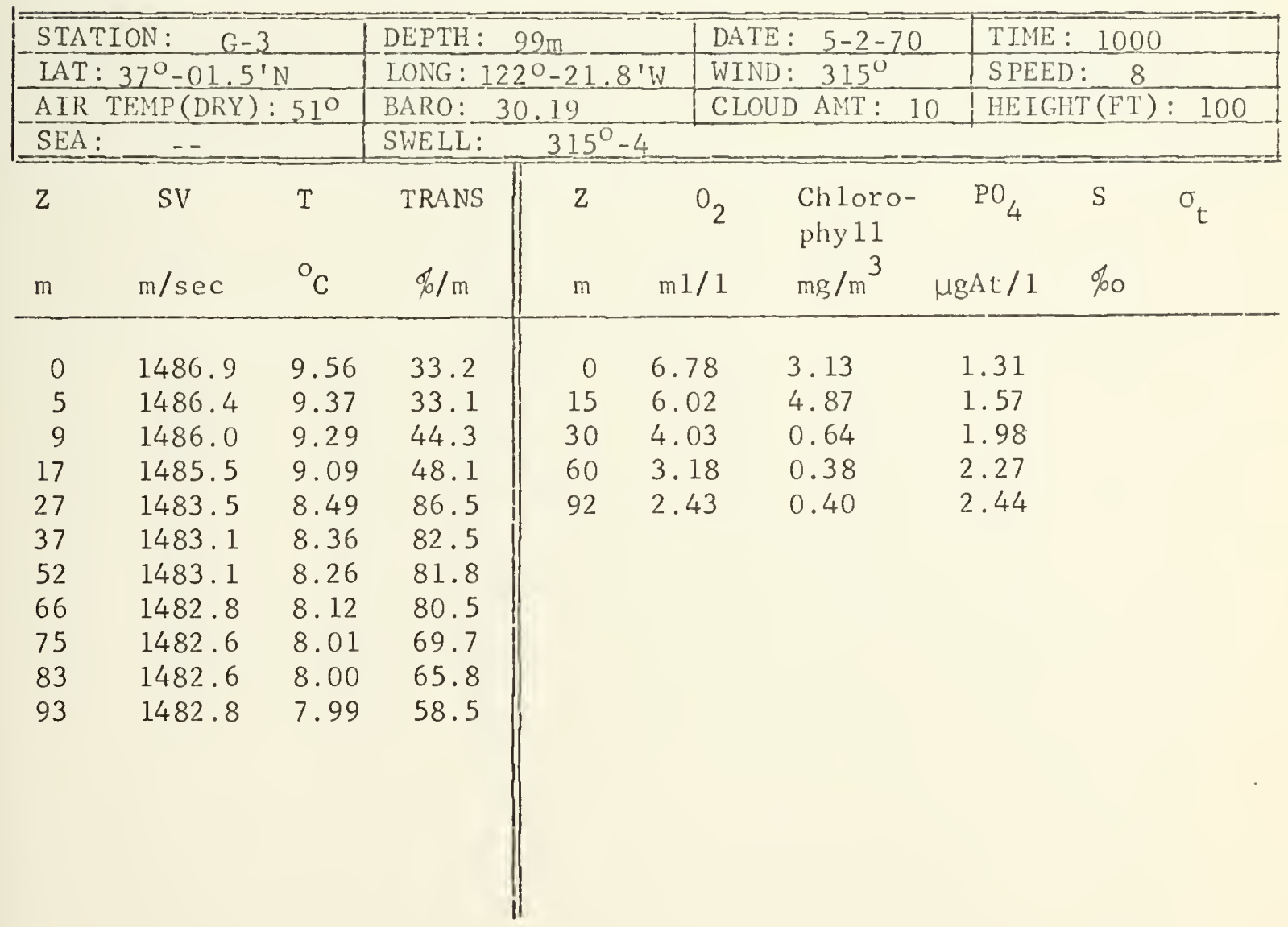





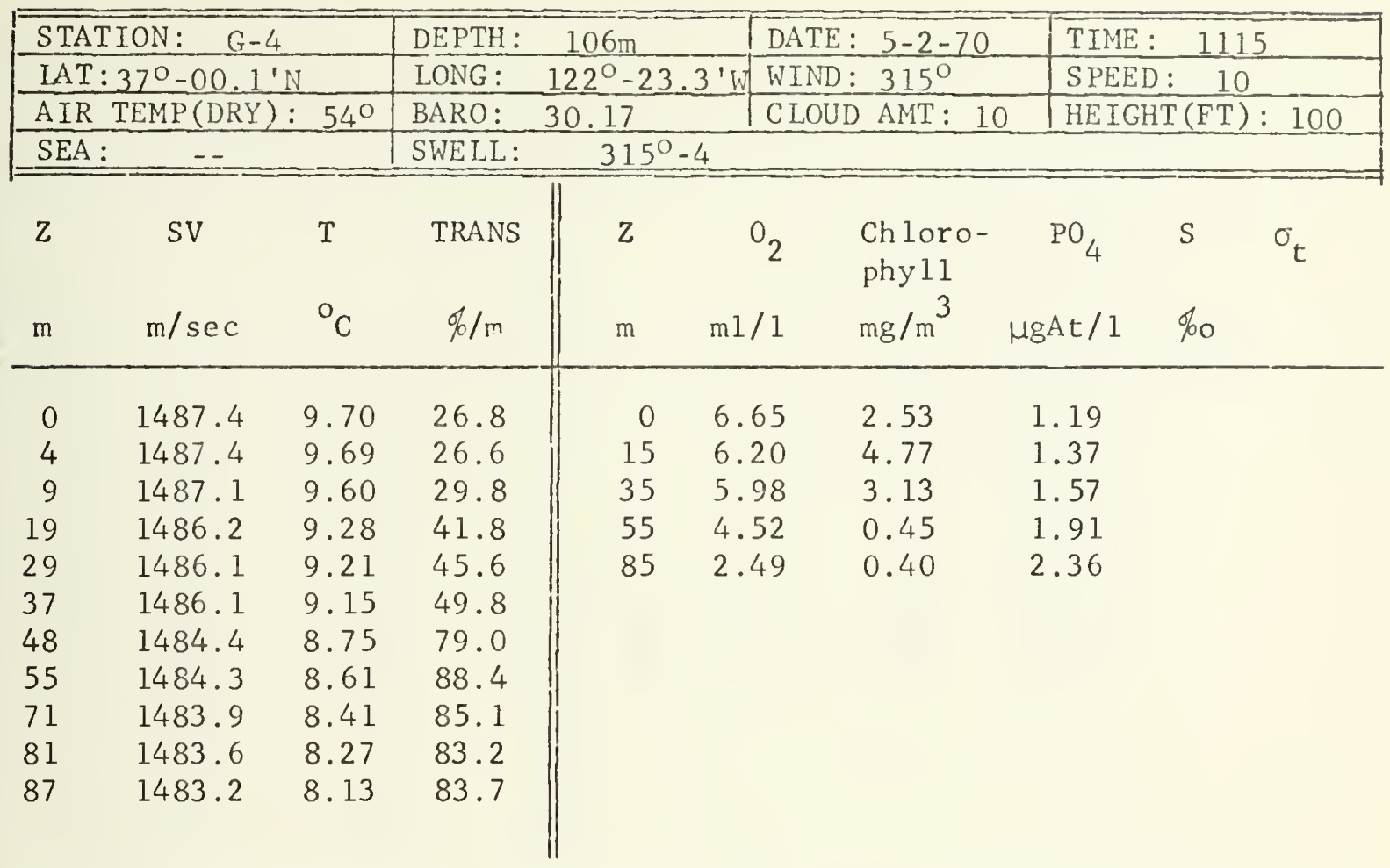

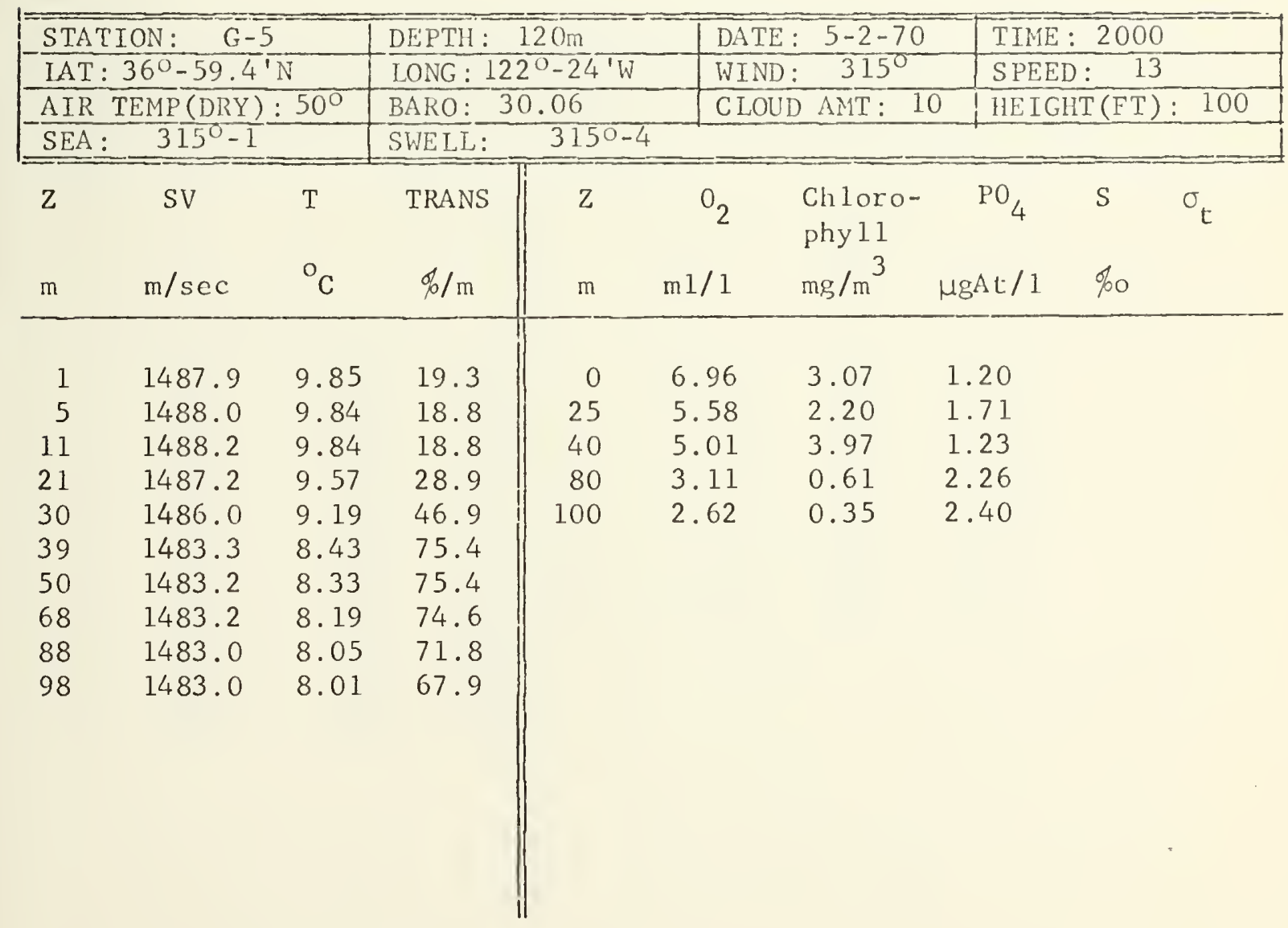





\begin{tabular}{|c|c|c|c|c|c|c|c|c|c|c|}
\hline & $\mathrm{ON}:$ & & DEPTH : & & & $\mathrm{DAT}$ & $5-2-7$ & TIM & 22 & \\
\hline & $36^{\circ}-56$ & 'N & LONG: & -28. & & WIN & $: 315^{\circ}$ & SPE & $:$ & \\
\hline & $\operatorname{EMP}(\mathrm{DR})$ & $50^{\circ}$ & BARO: & & & CLO & AMT: 1 & $\mathrm{HEI}$ & {$[\mathrm{F}]$} & 100 \\
\hline & $315^{\circ}-3$ & & SWE LL: & $315^{\circ}$ & & & & & & \\
\hline Z & SV & $\mathrm{T}$ & TRANS & $z$ & & $0_{2}$ & $\begin{array}{l}\text { Chloro- } \\
\text { phyl1 }\end{array}$ & $\mathrm{PO}_{4}$ & S & $\sigma_{t}$ \\
\hline m & $\mathrm{m} / \mathrm{sec}$ & ${ }^{\mathrm{O}} \mathrm{C}$ & $\% / \mathrm{m}$ & $\mathrm{m}$ & $\mathrm{ml}$ & & $\mathrm{mg} / \mathrm{m}^{3}$ & MgAt / 1 & $\% 0$ & \\
\hline 0 & 1489.6 & 10.41 & $N$ & 0 & 7. & & 4.38 & 0.63 & & \\
\hline 4 & 1489.7 & 10.38 & $\mathrm{O}$ & 5 & 7. & & 3.98 & 0.64 & & \\
\hline 8 & 1489.6 & 10.28 & & 10 & 7. & & 4.27 & 0.62 & & \\
\hline 12 & 1488.0 & 9.68 & $D$ & 15 & 7. & & 5.04 & 0.66 & & \\
\hline 20 & 1487.6 & 9.78 & A & 25 & 6. & & 2.42 & 1.24 & & \\
\hline 30 & 1487.2 & 9.50 & $\mathrm{~T}$ & 35 & 5. & & 0.84 & 1.67 & & \\
\hline 41 & 1486.3 & 9.22 & A & 50 & 3. & & 0.47 & 2.00 & & \\
\hline 52 & 1485.7 & 9.01 & & 75 & 2 . & & 0.19 & 2.26 & & \\
\hline 61 & 1485.3 & 8.86 & & & & & & & & \\
\hline 72 & 1484.9 & 8.70 & & & & & & & & \\
\hline 81 & 1484.3 & 8.45 & & & & & & & & \\
\hline 90 & 1484.4 & 8.45 & & & & & & & & \\
\hline
\end{tabular}

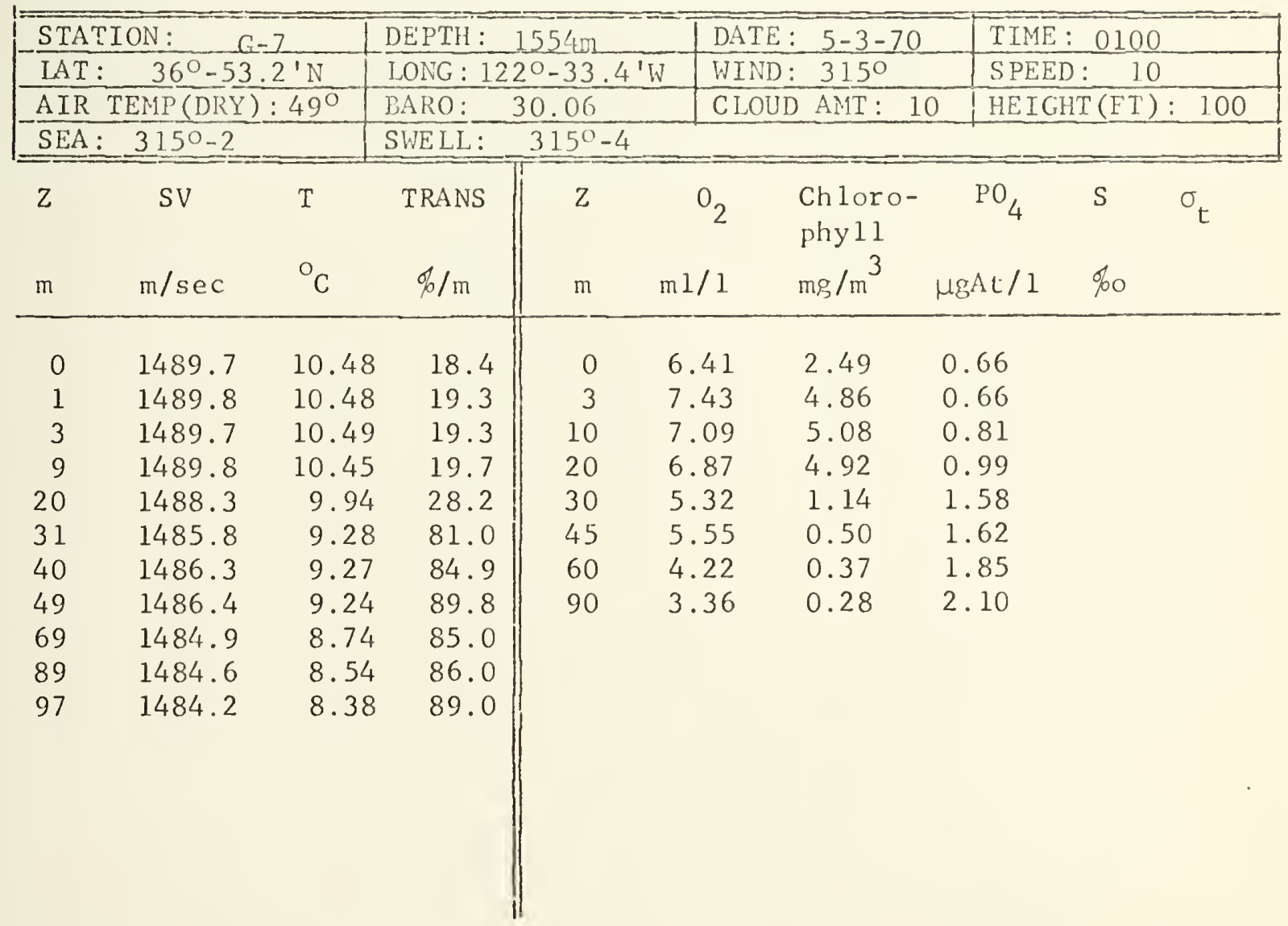





\begin{tabular}{|c|c|c|c|c|c|c|c|c|c|}
\hline & ION : & & DEPTH: & $50 \mathrm{~m}$ & DATE & $5-3-70$ & TIM & 04 & \\
\hline & $36^{\circ}-58$ & $\mathrm{~N}$ & LONG: & $0-40$, & 'W WIND & $: 315^{\circ}$ & $\mathrm{SPE}$ & : & \\
\hline & IEMP (DR) & $48^{\circ}$ & BARO: & .04 & C LOUI & AMT: 10 & $\mathrm{HEI}$ & $\mathrm{T}(\mathrm{F}$ & $: 100$ \\
\hline & $315^{\circ}-2$ & & SWELL: & $315^{\circ}$ & & & & & \\
\hline Z & SV & $\mathrm{T}$ & TRANS & Z & $\mathrm{O}_{2}$ & $\begin{array}{l}\text { Chloro- } \\
\text { phyl1 }\end{array}$ & $\mathrm{PO}_{4}$ & $S$ & $\sigma_{t}$ \\
\hline $\mathrm{m}$ & $\mathrm{m} / \mathrm{sec}$ & ${ }^{\circ} \mathrm{C}$ & $\% / m$ & $\mathrm{~m}$ & $\mathrm{~m} 1 / \mathrm{l}$ & $\mathrm{mg} / \mathrm{m}^{3}$ & $\mu g A t / 1$ & $\%$ & \\
\hline 0 & 1494.4 & 12.04 & 65.9 & 0 & -- & 0.13 & 0.51 & & \\
\hline 3 & 1494.5 & 12.09 & 64.7 & 5 & 6.33 & 0.14 & 0.50 & & \\
\hline 5 & 1494.6 & 12.10 & 65.0 & 10 & 6.26 & 0.21 & 0.73 & & \\
\hline 9 & 1493.2 & 11.57 & 69.6 & 18 & -- & 1.17 & 0.90 & & \\
\hline 18 & 1489.6 & 10.48 & 55.4 & 30 & 6.45 & 1.00 & 1.01 & & \\
\hline 29 & 1488.9 & 10.16 & 62.9 & 50 & 6.11 & 1.20 & 1.30 & & \\
\hline 37 & 1488.3 & 9.91 & 63.0 & 60 & 6.23 & 1.13 & 1.29 & & \\
\hline 57 & 1487.5 & 9.56 & 67.6 & 90 & 5.59 & 1.16 & 1.53 & & \\
\hline 71 & 1486.5 & 9.12 & 61.6 & & & & & & \\
\hline 90 & 1486.2 & 8.96 & 52.0 & & & & & & \\
\hline
\end{tabular}

\begin{tabular}{|c|c|c|c|c|c|c|c|c|c|c|}
\hline \multicolumn{3}{|c|}{ STATION: H-2 } & \multicolumn{3}{|c|}{ DEPTH: $900 \mathrm{~m}$} & \multicolumn{2}{|c|}{ DATE: $5-3-70$} & \multicolumn{3}{|c|}{ TIME: 0800} \\
\hline \multicolumn{3}{|c|}{ LAT: $37^{\circ}-02.6^{\prime} \mathrm{N}$} & \multicolumn{3}{|c|}{ LONG : $122^{\circ}-48.4^{1} \mathrm{~W}$} & \multicolumn{2}{|c|}{ WIND: $330^{\circ}$} & \multicolumn{3}{|c|}{ SPEED : $\quad 13$} \\
\hline \multicolumn{3}{|c|}{ AIR TEMP (DRY): $49^{\circ}$} & \multicolumn{3}{|c|}{ BARO: 29.98} & \multicolumn{2}{|c|}{ CLOUD AMT: 10} & \multicolumn{3}{|c|}{$\operatorname{HEIGHT}(\mathrm{FT}): 100$} \\
\hline \multicolumn{3}{|c|}{ SEA: $330^{\circ}-1$} & \multicolumn{8}{|c|}{ SWE LL: $330^{\circ}-4$} \\
\hline 2 & SV & $\mathrm{T}$ & TRANS & $\mathrm{Z}$ & & $\mathrm{O}_{2}$ & $\begin{array}{l}\text { Chloro- } \\
\text { phyl1 }\end{array}$ & $\mathrm{PO}_{4}$ & $S$ & $\sigma_{t}$ \\
\hline $\mathrm{m}$ & $\mathrm{m} / \mathrm{sec}$ & ${ }^{\mathrm{O}} \mathrm{C}$ & $\not / \mathrm{m}$ & $\mathrm{m}$ & $\mathrm{m} 1$ & $/ 1$ & $\mathrm{mg} / \mathrm{m}^{3}$ & $\mu g A t / 1$ & $\% \circ$ & \\
\hline 0 & - & - & 62.9 & 0 & & 31 & 0.14 & 0.40 & & \\
\hline 5 & 1495.7 & 12.45 & 63.9 & 5 & & 36 & 0.14 & 0.42 & & \\
\hline 10 & 1495.8 & 12.45 & 62.0 & 25 & & 36 & 0.13 & 0.43 & & \\
\hline 19 & 1495.4 & 12.28 & 63.3 & 50 & & 72 & 0.12 & 1.14 & & \\
\hline 29 & 1495.3 & 12.19 & 64.9 & 100 & & 87 & 0.16 & 1.73 & & \\
\hline 38 & 1493.4 & 11.51 & 86.1 & & & & & & & \\
\hline 49 & 1490.9 & 10.84 & 88.5 & & & & & & & \\
\hline 58 & 1487.3 & 9.61 & 94.6 & & & & & & & \\
\hline 67 & 1488.0 & 9.71 & 91.5 & & & & & & & \\
\hline 75 & 1487.8 & 9.64 & 92.0 & & & & & & & \\
\hline 83 & 1487.2 & 9.41 & 92.0 & & & & & & & \\
\hline 92 & 1486.1 & 9.04 & 94.8 & & & & & & & \\
\hline
\end{tabular}





\begin{tabular}{|c|c|c|c|c|c|c|c|c|c|c|}
\hline & ION: $I$ & & DEPTH: & $310 \mathrm{~m}$ & & DATE: & $5-3-7$ & TIMI & 100 & \\
\hline & $37^{\circ}-10$ & & LONG: 1 & $0-45$. & & WIND: & 325 & SPEP & $: 10$ & \\
\hline & TEMP (DR) & $49^{\circ}$ & BARO: & 9.99 & & CLOUI & AMT: I & $\mathrm{HEI}$ & $I(\mathrm{~F})$ & 100 \\
\hline & $325^{\circ}-$ & & SWELL: & $30^{\circ}-4$ & & & & & & \\
\hline$z$ & SV & $\mathrm{T}$ & TRANS & $\mathrm{Z}$ & & $\mathrm{O}_{2}$ & $\begin{array}{l}\text { Ch loro- } \\
\text { phyl1 }\end{array}$ & $\mathrm{PO}_{4}$ & $S$ & $\sigma_{t}$ \\
\hline $\mathrm{m}$ & $\mathrm{m} / \mathrm{sec}$ & ${ }^{\circ} \mathrm{C}$ & $\% / \mathrm{m}$ & $\mathrm{m}$ & $\mathrm{m} 1$ & & $\mathrm{mg} / \mathrm{m}^{3}$ & ugAt / 1 & $\%$ & \\
\hline 0 & 1495.0 & 12.22 & 66.5 & 0 & 6. & 43 & 0.19 & 0.47 & & \\
\hline 5 & 1495.1 & 12.24 & 67.0 & 10 & & 44 & 0.15 & 0.48 & & \\
\hline 10 & 1495.2 & 12.23 & 66.0 & 30 & & 43 & 0.11 & 0.83 & & \\
\hline 20 & 1494.0 & 11.78 & 65.2 & 60 & & 09 & 0.11 & 1.49 & & \\
\hline 29 & 1490.6 & 10.86 & 84.0 & 100 & & 67 & 0.12 & 1.85 & & \\
\hline 39 & 1485.9 & 9.40 & 89.6 & & & & & & & \\
\hline 47 & 1485.1 & 9.10 & 92.9 & & & & & & & \\
\hline 57 & 1485.5 & 9.11 & 94.7 & & & & & & & \\
\hline 63 & 1485.5 & 8.98 & 94.0 & & & & & & & \\
\hline 69 & 1485.5 & 8.94 & 94.2 & & & & & & & \\
\hline 85 & 1485.2 & 8.77 & 94.8 & & & & & & & \\
\hline 89 & 1484.8 & 8.63 & 95.1 & & & & & & & \\
\hline 93 & 1484.4 & 8.48 & 94.1 & & & & & & & \\
\hline
\end{tabular}

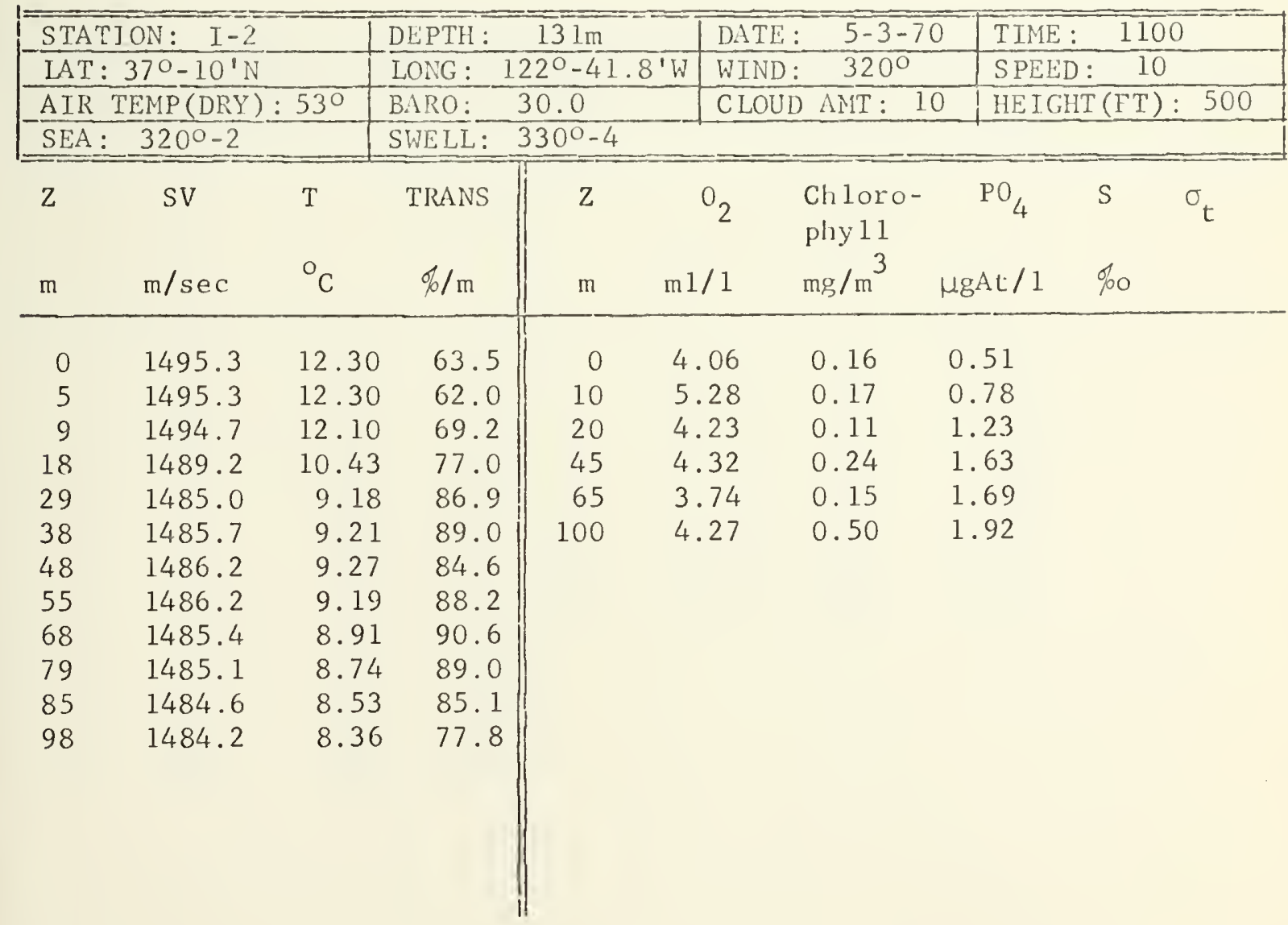





\begin{tabular}{|c|c|c|c|c|c|c|c|c|c|c|}
\hline \multicolumn{3}{|c|}{ STATION: $I-3$} & \multicolumn{3}{|c|}{ DEPTH: $109 \mathrm{~m}$} & \multicolumn{2}{|c|}{ DATE: $5-3-70$} & \multicolumn{3}{|c|}{ TIME : 1200} \\
\hline \multicolumn{3}{|c|}{ IAT: $37^{\circ}-11.0^{\prime} \mathrm{N}$} & \multicolumn{3}{|c|}{ LONG: $122^{\circ}-38.5^{\prime} \mathrm{W}$} & \multicolumn{2}{|c|}{ WIND: $\quad 315^{\circ}$} & \multicolumn{3}{|c|}{ SPEED : 10} \\
\hline \multicolumn{3}{|c|}{ AIR TEMP(DRY): $61^{\circ}$} & \multicolumn{3}{|c|}{ BARO: 30.00} & \multicolumn{2}{|c|}{ CLOUD AMT: 10} & \multicolumn{3}{|c|}{ HEIGHT (FT): 1000} \\
\hline \multicolumn{3}{|c|}{ SEA: $\quad 315^{\circ}-2$} & \multicolumn{8}{|c|}{ SWELL: $\quad 330^{\circ}-4$} \\
\hline $\mathrm{Z}$ & SV & $\mathrm{T}$ & TRANS & Z & & $\mathrm{O}_{2}$ & $\begin{array}{l}\text { Chloro- } \\
\text { phyl1 }\end{array}$ & $\mathrm{PO}_{4}$ & $S$ & $\sigma_{t}$ \\
\hline $\mathrm{m}$ & $\mathrm{m} / \mathrm{sec}$ & ${ }^{\circ} \mathrm{C}$ & $\phi / m$ & $\mathrm{~m}$ & $\mathrm{ml}$ & & $\mathrm{mg} / \mathrm{m}^{3}$ & MgAt/ 1 & $\% 0$ & \\
\hline 0 & 1493.3 & 11.70 & 62.7 & 0 & - & & 0.41 & 0.79 & & \\
\hline 4 & 1493.0 & 11.55 & 64.8 & 10 & 6.8 & & 0.85 & 0.85 & & \\
\hline 9 & 1491.8 & 11.18 & 60.8 & 20 & 6.7 & 74 & 1.18 & 1.10 & & \\
\hline 18 & 1490.3 & 10.69 & 51.2 & 30 & 6. & 50 & 1.18 & 1.33 & & \\
\hline 28 & 1488.3 & 9.94 & 46.0 & 40 & 5. & 59 & 1.43 & 1.57 & & \\
\hline 32 & 1487.8 & 9.72 & 43.3 & 50 & 5. & 01 & 0.73 & 1.73 & & \\
\hline 36 & 1487.9 & 9.75 & 43.1 & 60 & 4. & 98 & 0.74 & 1.77 & & \\
\hline 45 & 1486.7 & 9.34 & 52.2 & 75 & 4. & 53 & 1.61 & 1.93 & & \\
\hline 53 & 1485.6 & 8.94 & 71.5 & & & & & & & \\
\hline 60 & 1485.2 & 8.84 & 76.2 & & & & & & & \\
\hline 66 & 1485.3 & 8.79 & 78.8 & & & & & & & \\
\hline 73 & 1485.1 & 8.73 & 78.6 & & & & & & & \\
\hline
\end{tabular}

\begin{tabular}{|c|c|c|c|c|c|c|c|c|c|c|}
\hline \multicolumn{3}{|c|}{ STATION: I -4} & \multicolumn{3}{|c|}{ DEPTH: $95 \mathrm{~m}$} & \multicolumn{2}{|c|}{ DATE: $5-3-70$} & \multicolumn{3}{|c|}{ TIME: 1400} \\
\hline \multicolumn{3}{|c|}{ IAT: $37^{\circ}-10.9^{\prime} \mathrm{N}$} & \multicolumn{3}{|c|}{ LONG: $122^{\circ}-35.2^{\prime} \mathrm{W}$} & \multicolumn{2}{|c|}{ WIND: $320^{\circ}$} & \multicolumn{3}{|c|}{ SPEED : $\quad 12$} \\
\hline \multicolumn{3}{|c|}{ AIR TEMP (DRY):56 } & \multicolumn{3}{|c|}{ BARO: $\frac{29.95}{2}$} & \multicolumn{2}{|c|}{ CLOUD AMT: 10} & \multicolumn{3}{|c|}{ HEIGHT (FT): 1000} \\
\hline \multicolumn{3}{|c|}{ SEA: $320^{\circ}-3$} & \multicolumn{8}{|c|}{ SWELL: $330^{\circ}-5$} \\
\hline $\mathrm{Z}$ & SV & $\mathrm{T}$ & TRANS & $\mathrm{Z}$ & & $0_{2}$ & $\begin{array}{l}\text { Chloro- } \\
\text { phyll }\end{array}$ & $\mathrm{PO}_{4}$ & $S$ & $\sigma_{t}$ \\
\hline $\mathrm{m}$ & $\mathrm{m} / \mathrm{sec}$ & ${ }^{\circ} \mathrm{C}$ & $\% / \mathrm{m}$ & $\mathrm{m}$ & $\mathrm{m} 1$ & & $\mathrm{mg} / \mathrm{m}^{3}$ & $\mu g A t / 1$ & \%o & \\
\hline 0 & 1492.6 & 11.21 & 9.5 & 0 & 9. & 10 & 2.14 & 0.31 & & \\
\hline 2 & 1492.6 & 11.25 & 9.5 & 3 & 9. & 51 & 3.23 & 0.36 & & \\
\hline 5 & 1492.5 & 11.18 & 13.0 & 12 & & 78 & 4.07 & 0.44 & & \\
\hline 7 & 1491.2 & 10.88 & 10.0 & 20 & & 75 & 2.59 & 1.33 & & \\
\hline 10 & 1489.3 & 10.27 & 14.0 & 30 & & 95 & 0.82 & 1.65 & & \\
\hline 13 & 1487.7 & 9.76 & 15.8 & 45 & & 59 & 0.93 & 1.92 & & \\
\hline 18 & 1485.9 & 9.20 & 39.1 & 60 & & 48 & 0.72 & 2.03 & & \\
\hline 27 & 1484.6 & 8.76 & 57.3 & 80 & & 51 & 0.93 & 2.05 & & \\
\hline 36 & 1483.5 & 8.45 & 68.8 & & & & & & & \\
\hline 44 & 1483.5 & 8.42 & 70.6 & & & & & & & \\
\hline 56 & 1483.6 & 8.35 & 72.8 & & & & & & & \\
\hline 63 & 1483.8 & 8.38 & 71.8 & & & & & & & \\
\hline 70 & 1483.6 & 8.33 & 66.3 & & & & & & & \\
\hline
\end{tabular}





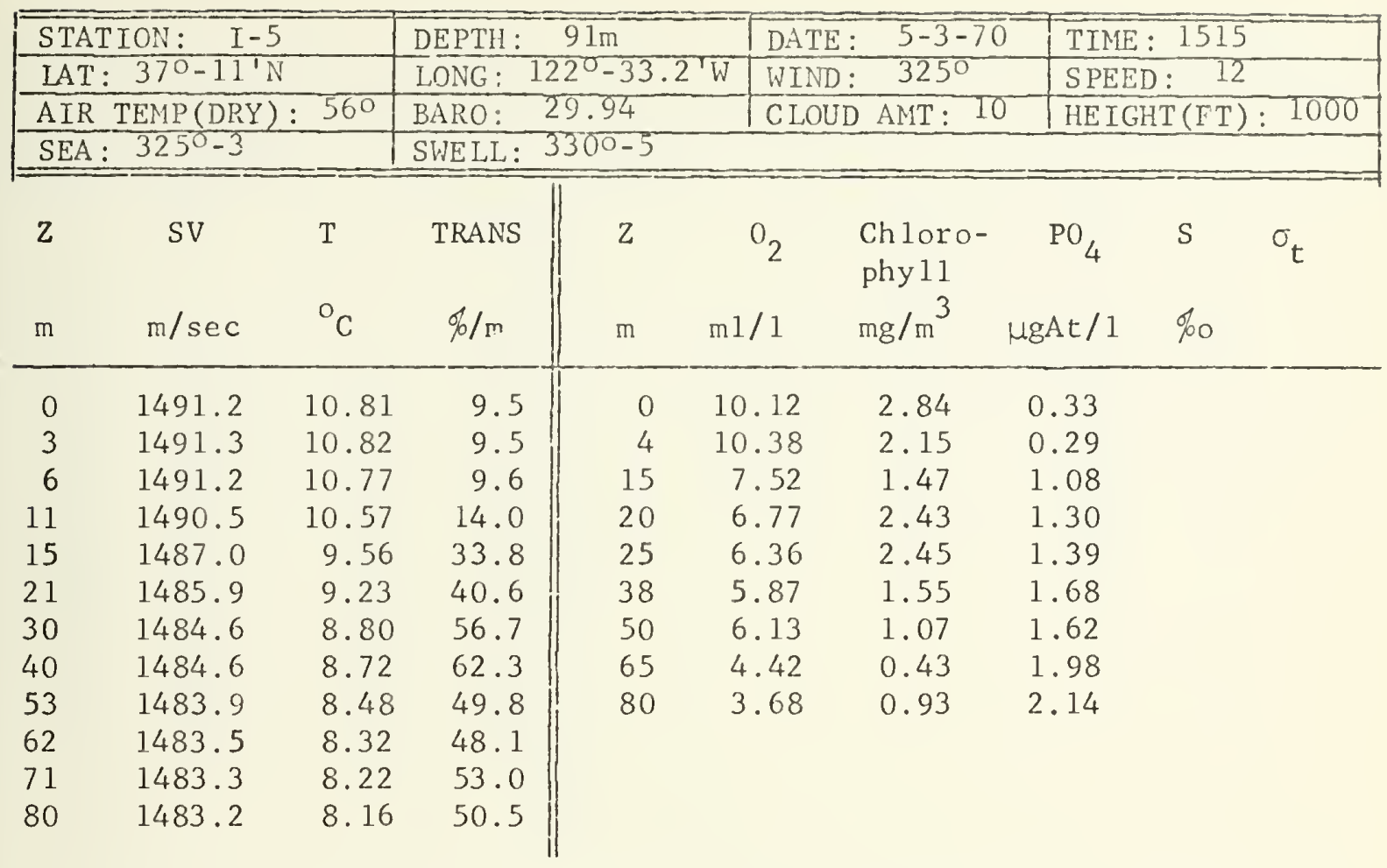

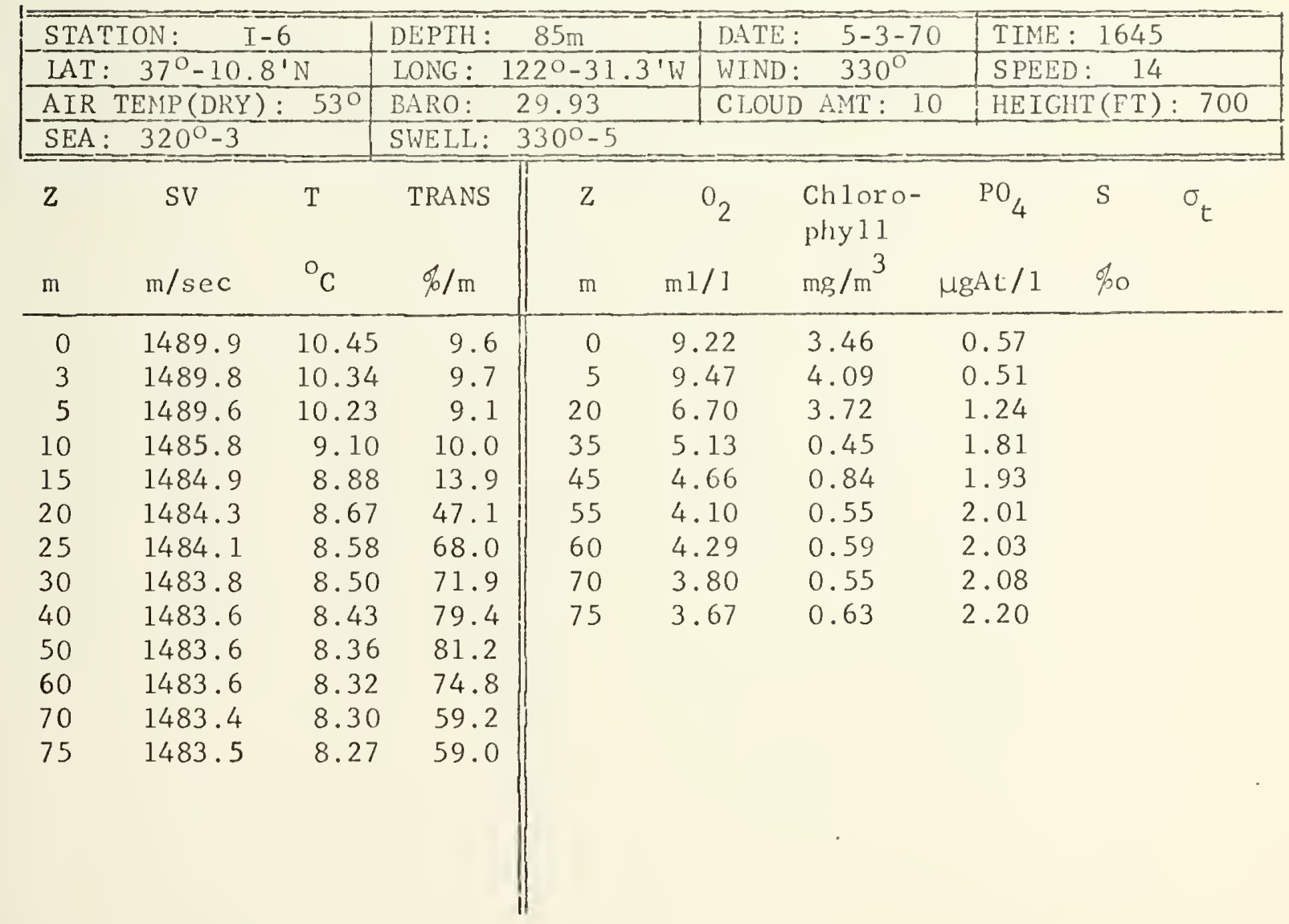





\begin{tabular}{|c|c|c|c|c|c|c|c|c|c|c|}
\hline \multicolumn{3}{|c|}{ STATION: } & \multicolumn{3}{|c|}{ DEPTH: $73 \mathrm{~m}$} & \multicolumn{2}{|c|}{ DATE: $\quad 5-3-70$} & \multicolumn{3}{|c|}{ TIME : 1800} \\
\hline \multicolumn{3}{|c|}{ LAT: $\quad 37^{\circ}-11^{\prime} \mathrm{N}$} & \multicolumn{3}{|c|}{ LONG: $122^{\circ}-29.1^{\prime} \mathrm{W}$} & \multicolumn{2}{|c|}{ WIND: $\quad 340^{\circ}$} & \multicolumn{3}{|c|}{ SPEED : $\quad 15$} \\
\hline \multicolumn{3}{|c|}{ AIR TEMP (DRY): $50^{\circ}$} & \multicolumn{3}{|c|}{ BARO: 29.91} & CLOUD & D AMT: & \multicolumn{3}{|c|}{ HEIGHT(FT): 500} \\
\hline \multicolumn{3}{|c|}{ SEA: $320^{\circ}-4$} & \multicolumn{8}{|c|}{ SWELL: $\quad 320^{\circ}-8$} \\
\hline $\mathrm{z}$ & SV & $\mathrm{T}$ & TRANS & Z & & $\mathrm{O}_{2}$ & $\begin{array}{l}\text { Chloro- } \\
\text { phy } 11\end{array}$ & $\mathrm{PO}_{4}$ & $S$ & $\sigma_{t}$ \\
\hline $\mathrm{m}$ & $\mathrm{m} / \mathrm{sec}$ & ${ }^{\mathrm{O}} \mathrm{C}$ & $\% / m$ & $\mathrm{~m}$ & $\mathrm{~m} 1$ & & $\mathrm{mg} / \mathrm{m}^{3}$ & $\mu g A t / 1$ & $\%$ & \\
\hline 0 & 1489.2 & 10.21 & 10.2 & 0 & 8 . & 27 & 5.59 & 0.70 & & \\
\hline 5 & 1489.3 & 10.17 & 10.6 & 5 & & 50 & 5.39 & 0.77 & & \\
\hline 9 & 1488.9 & 10.09 & 13.2 & 15 & & 01 & 4.11 & 1.13 & & \\
\hline 15 & 1485.9 & 9.24 & 52.5 & 25 & & 17 & 2.15 & 1.73 & & \\
\hline 19 & 1484.9 & 9.02 & 73.0 & 50 & & 26 & 0.41 & 2.02 & & \\
\hline 30 & 1484.1 & 8.70 & 81.9 & & & & & & & \\
\hline 40 & 1484.0 & 8.59 & 81.4 & & & & & & & \\
\hline 49 & 1483.9 & 8.51 & 79.5 & & & & & & & \\
\hline 59 & 1483.4 & 8.35 & 76.4 & & & & & & & \\
\hline 63 & 1483.2 & 8.28 & 60.5 & & & & & & & \\
\hline
\end{tabular}

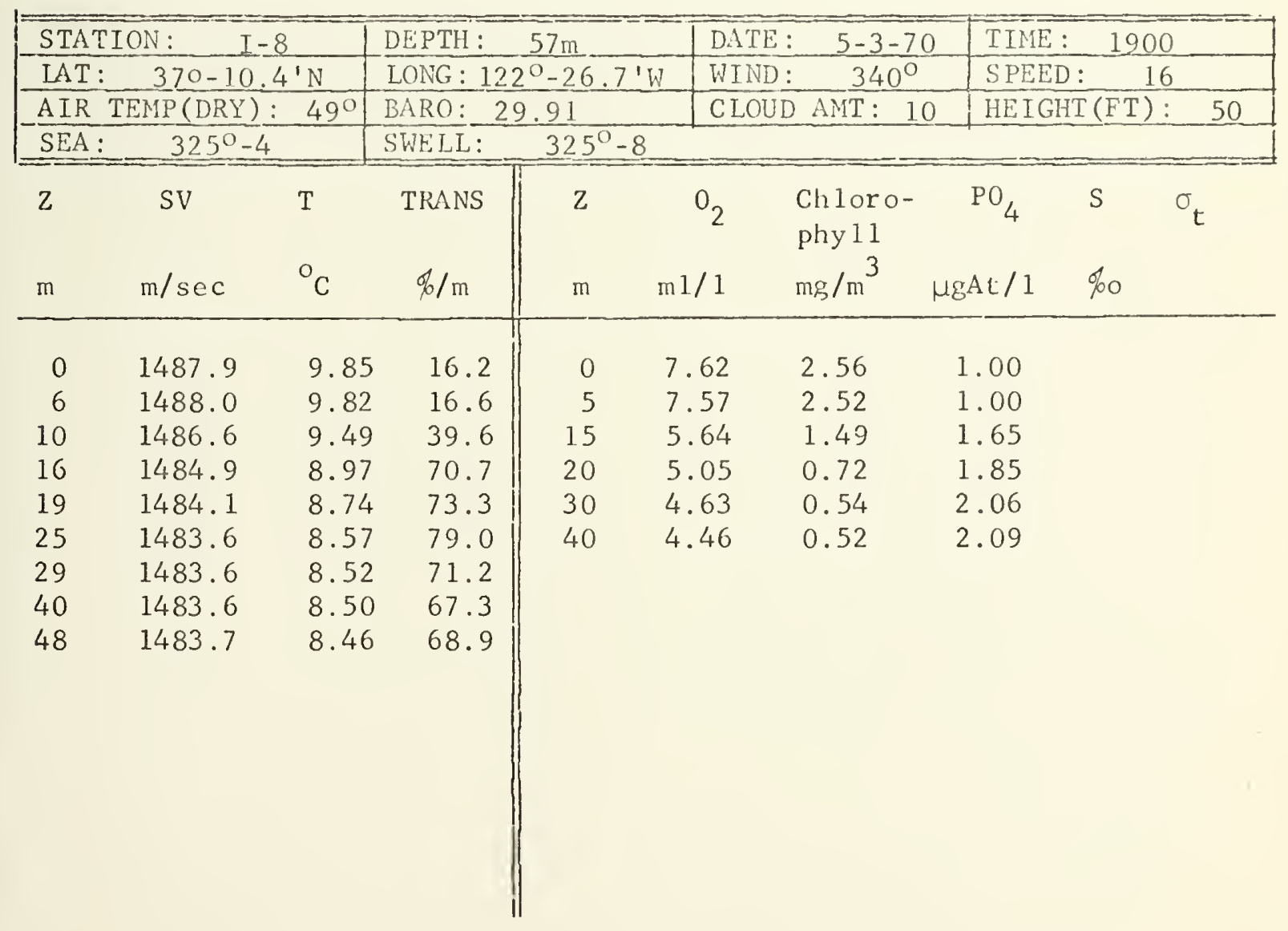





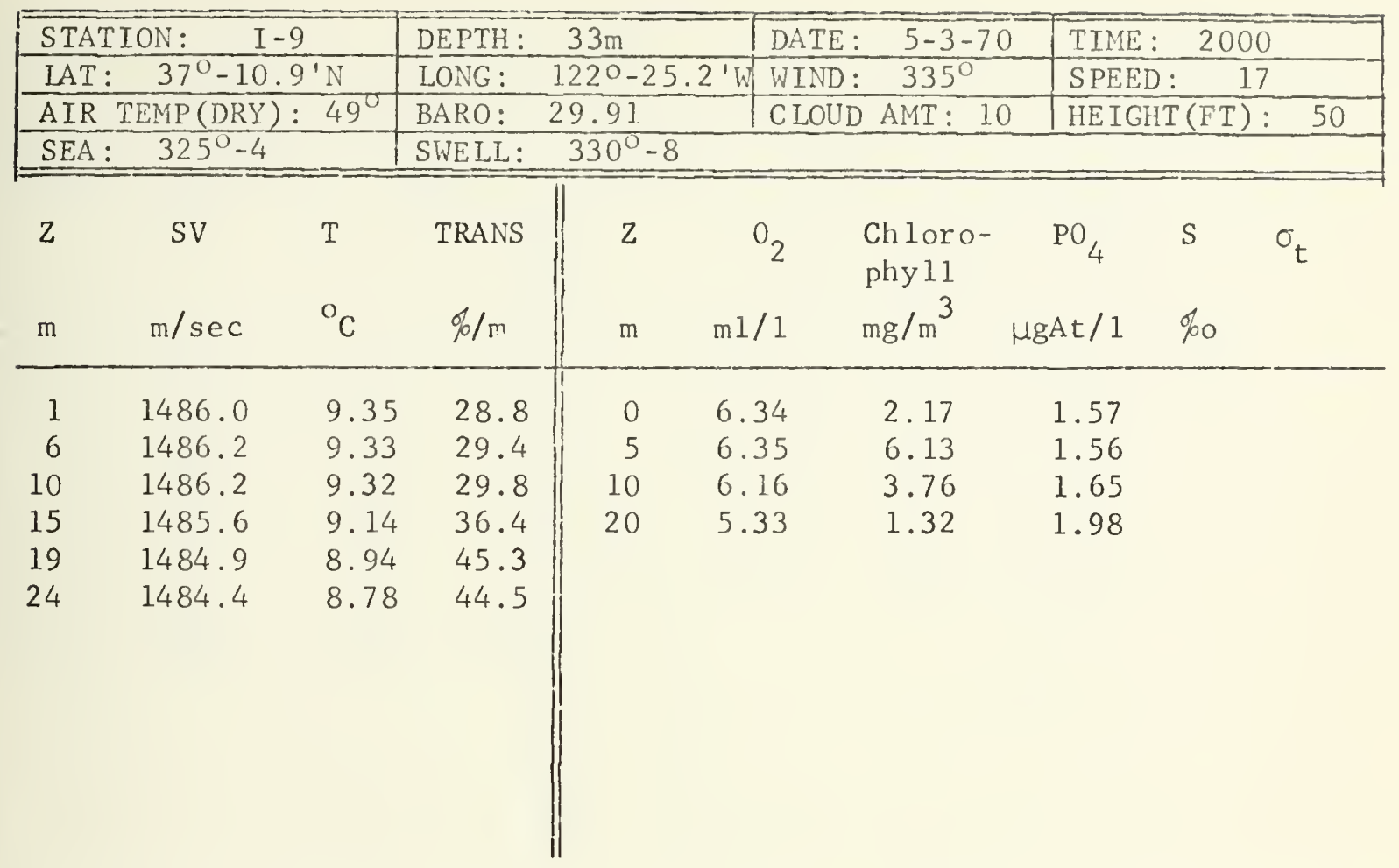

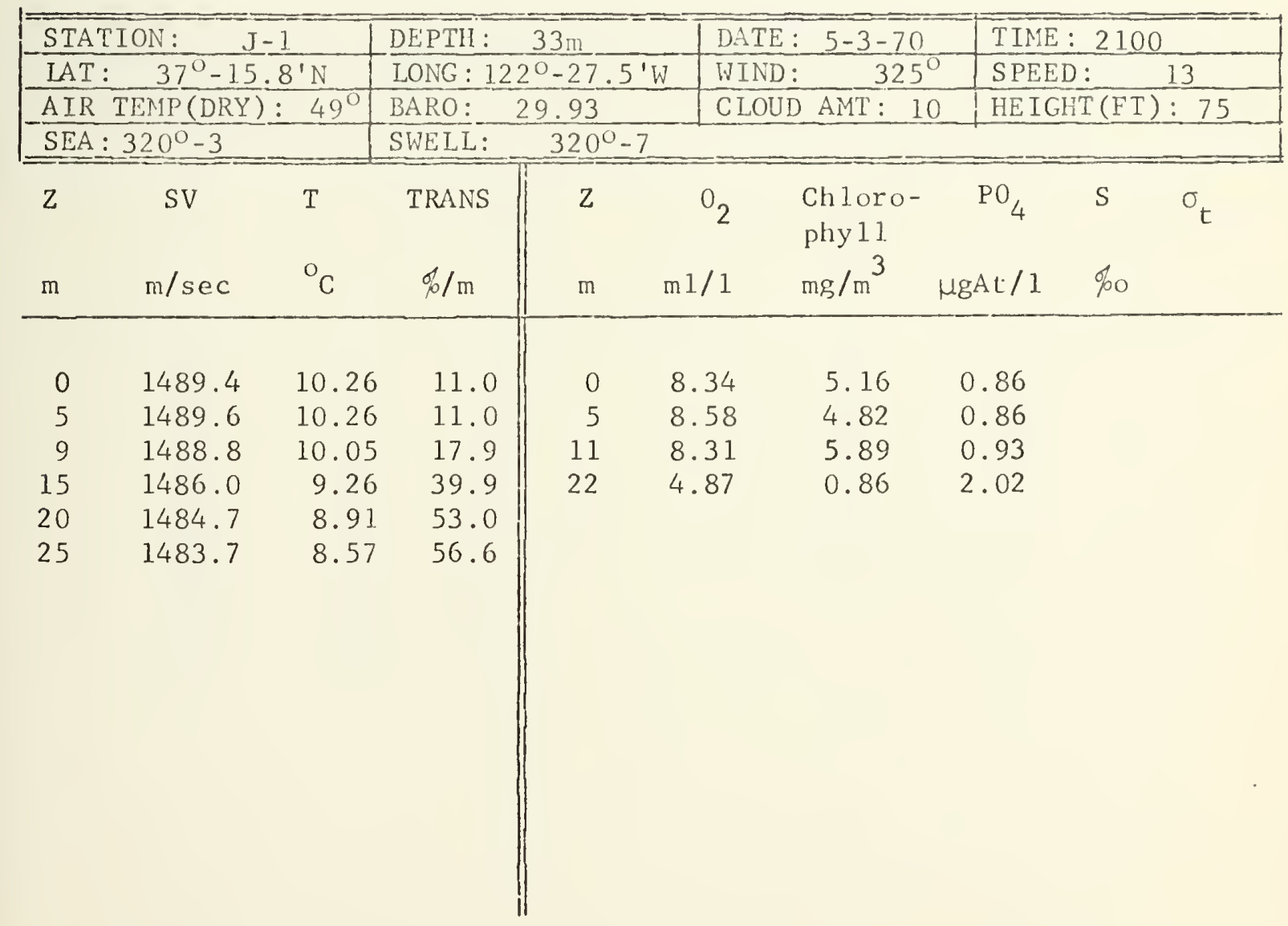





\begin{tabular}{|c|c|c|c|}
\hline STATION: $\quad \mathrm{J}-2$ & DEPTH: & DATE: $5-3-70$ & TIME: 2200 \\
\hline $37^{0}-21.6^{\prime} \mathrm{N}$ & LONG: $122^{\circ}-29.6^{\prime} \mathrm{W}$ & WIND: & SPEED : 10 \\
\hline AIR TEMP (DRY): $49^{\circ}$ & BARO: 29.94 & CLOUD AMT : 10 & $\operatorname{HEIGHT}(\mathrm{FT}):$ \\
\hline $315^{\circ}-2$ & SWELL: & & \\
\hline
\end{tabular}

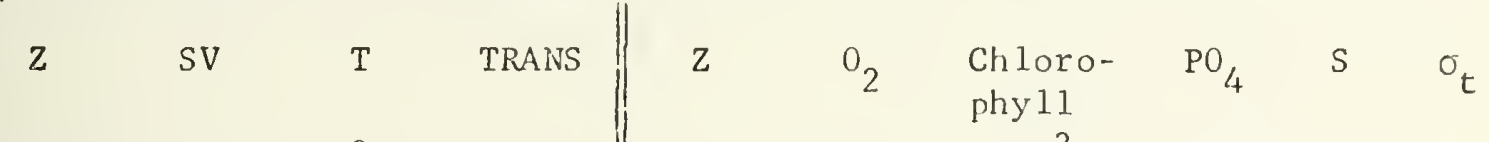

\begin{tabular}{cccc|ccccc}
$\mathrm{m}$ & $\mathrm{m} / \mathrm{sec}$ & ${ }^{\circ} \mathrm{C}$ & $\% / \mathrm{m}$ & $\mathrm{m}$ & $\mathrm{ml} / 1$ & $\mathrm{mg} / \mathrm{m}^{3}$ & $\mu g A t / 1$ & $\% 0$ \\
\hline 0 & 1488.2 & 9.93 & 19.0 & 0 & 7.95 & 3.86 & 1.07
\end{tabular}

$\begin{array}{llllllll}6 & 1488.2 & 9.93 & 19.4 & 5 & 8.15 & 2.89 & 1.10\end{array}$

\begin{tabular}{llll|llll}
9 & 1488.1 & 9.87 & 21.4 & 15 & 6.05 & 2.49 & 1.68
\end{tabular}

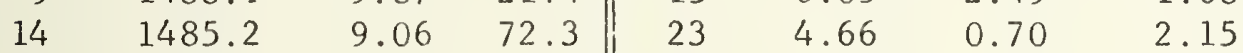

\begin{tabular}{llll|llll}
20 & 1484.3 & 8.74 & 63.2 & 30 & 3.82 & 1.48 & 2.45
\end{tabular}

$24 \quad 1483.9 \quad 8.64 \quad 54.9$

$28 \quad 1484.0 \quad 8.62 \quad 39.8$ 



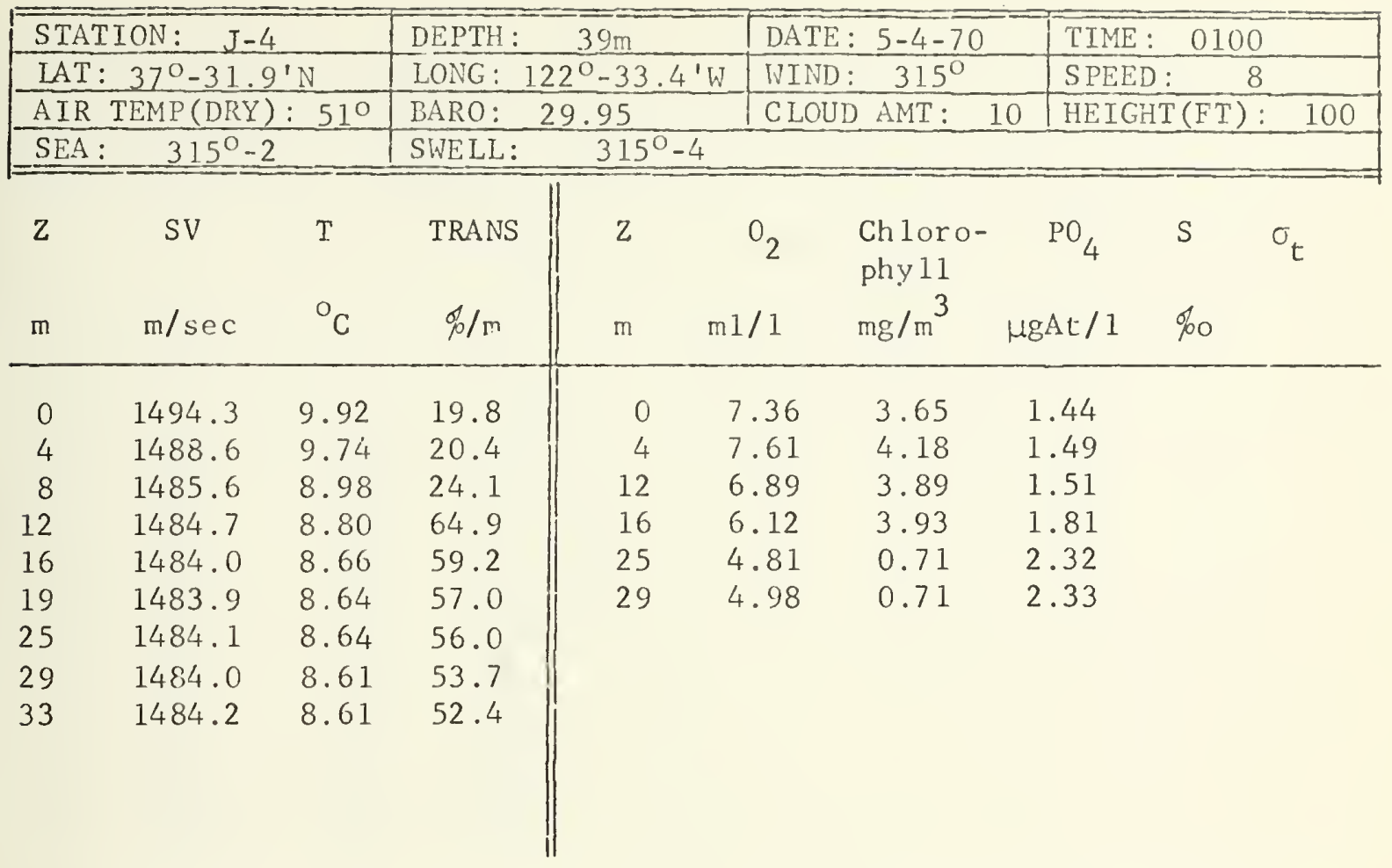

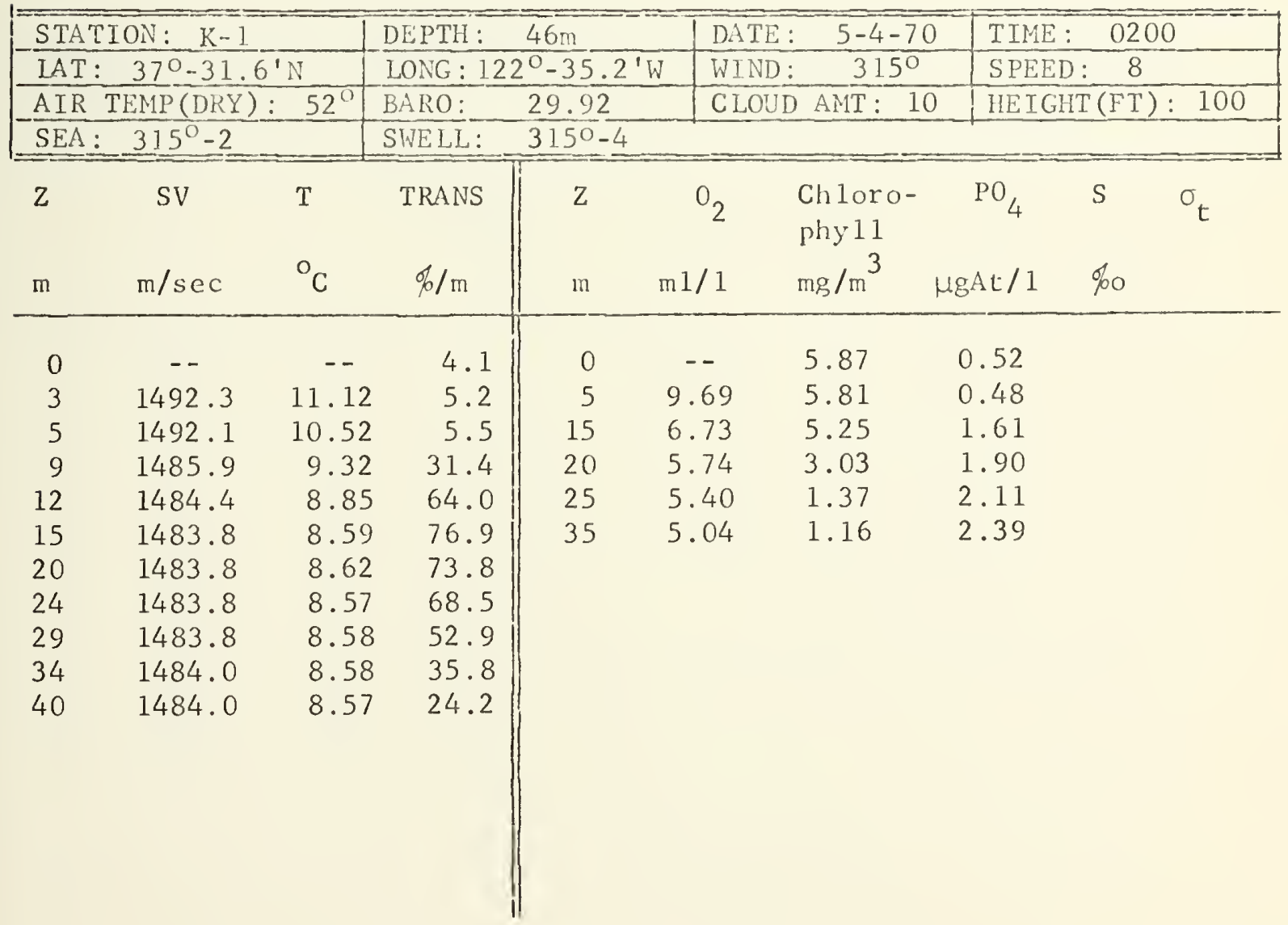





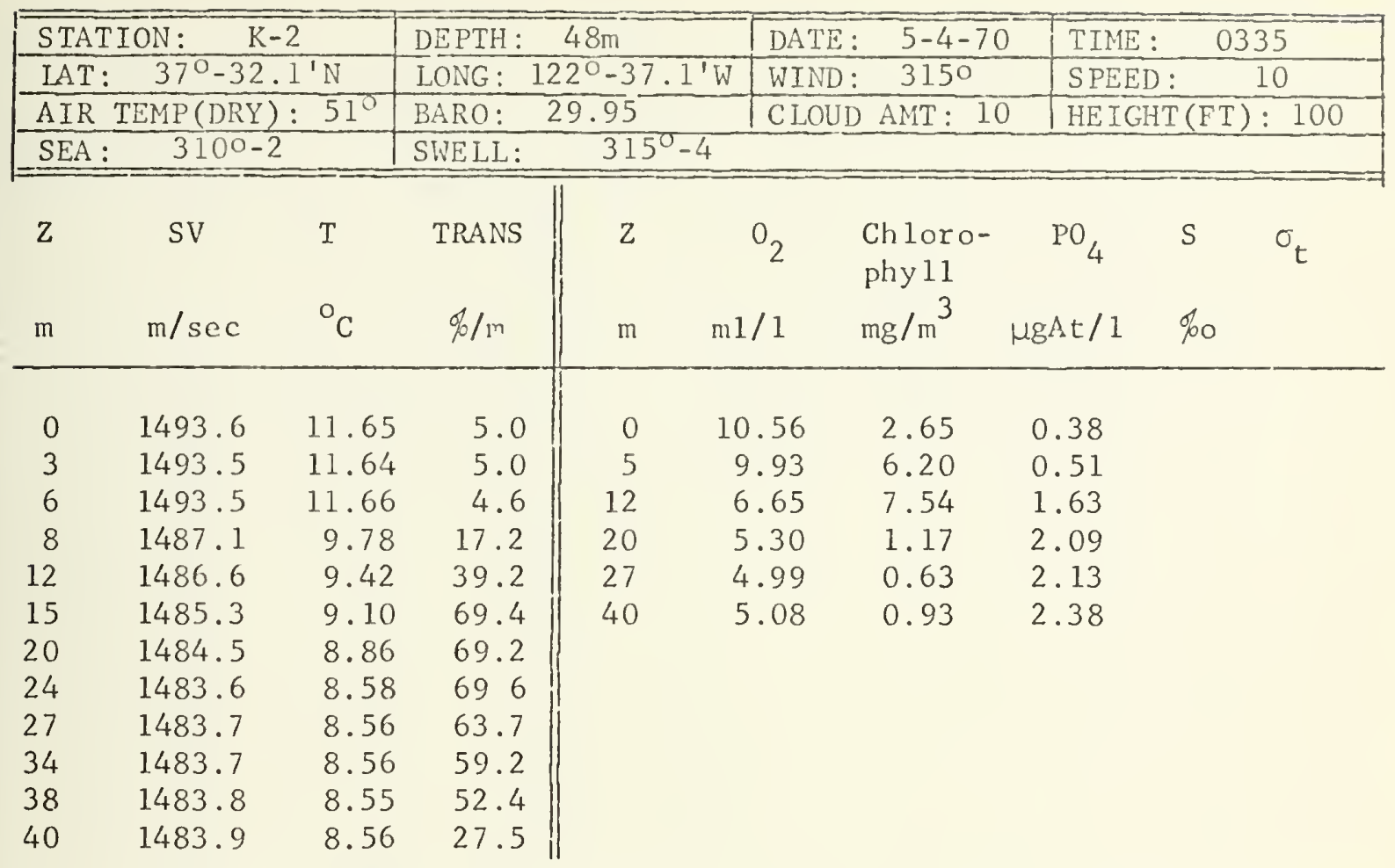

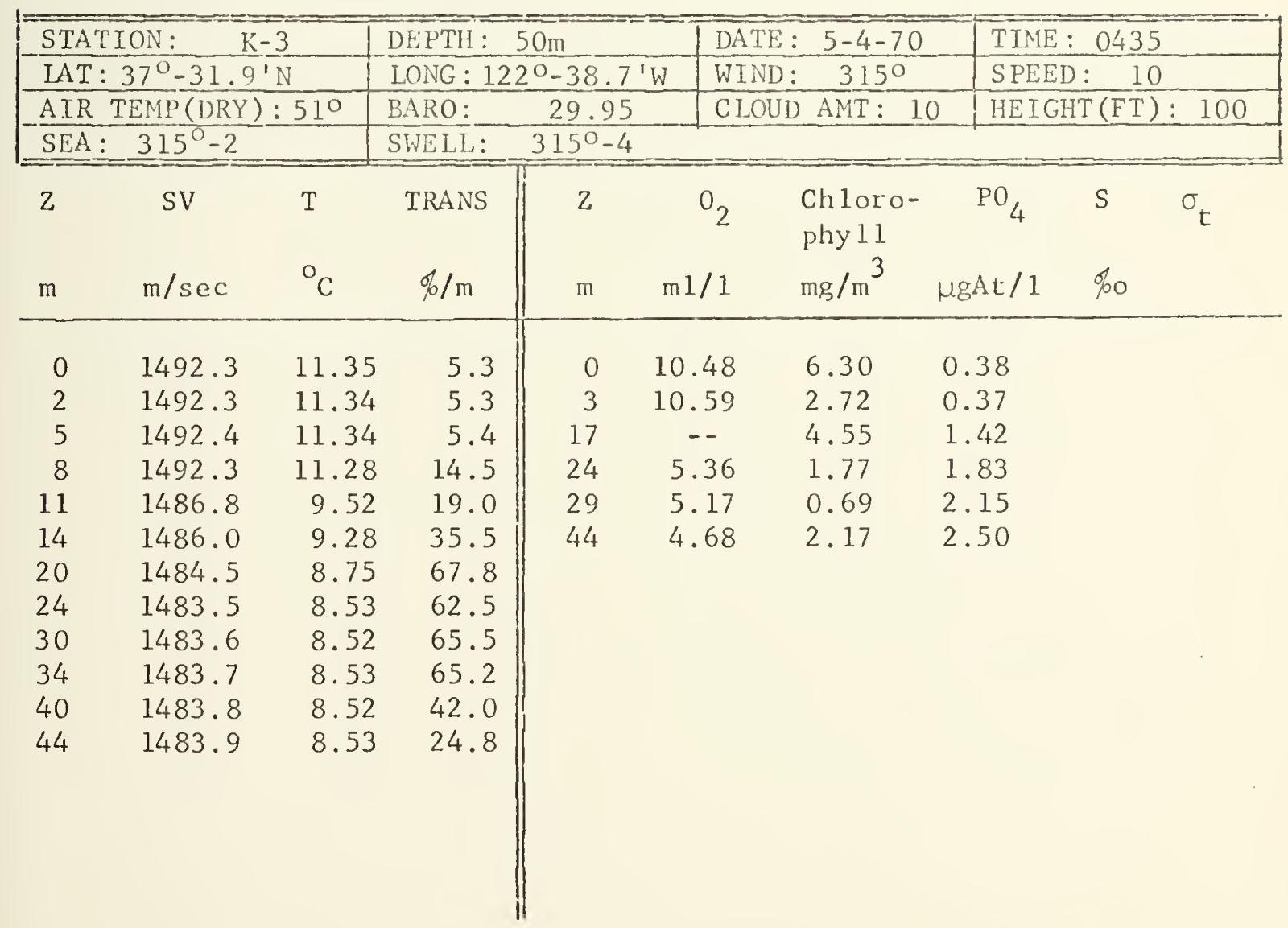





\begin{tabular}{|c|c|c|c|c|c|c|c|c|c|c|}
\hline \multicolumn{3}{|c|}{ STATION: $\mathrm{K}-4$} & DEPTH: & \multicolumn{2}{|l|}{$57 \mathrm{~m}$} & DATE: & $5-4-70$ & \multicolumn{3}{|c|}{ TIME : 0530} \\
\hline \multicolumn{3}{|c|}{ LAT: $37^{\circ}-32.2^{\prime} \mathrm{N}$} & \multicolumn{3}{|c|}{ LONG: $122^{0-4} 1.3^{\prime} \mathrm{W}$} & WIND: & $310^{\circ}$ & \\
\hline \multicolumn{3}{|c|}{ AIR TEMP (DRY): $50^{\circ}$} & BARO: & \multicolumn{2}{|l|}{29.96} & CLOUD & AMT: & \begin{tabular}{l|l}
10 & $\mathrm{HEIG}$ \\
\end{tabular} & SPEED : 9 & 700 \\
\hline \multicolumn{3}{|c|}{ SEA: $310^{\circ}-2$} & SWELL: & \multicolumn{7}{|c|}{$300^{\circ}-6$} \\
\hline $\mathrm{Z}$ & SV & $\mathrm{T}$ & TRANS & 2 & & $\mathrm{O}_{2}$ & $\begin{array}{l}\text { Chloro- } \\
\text { phy } 11\end{array}$ & $\mathrm{PO}_{4}$ & S & $\sigma_{t}$ \\
\hline $\mathrm{m}$ & $\mathrm{m} / \mathrm{sec}$ & ${ }^{\circ} \mathrm{C}$ & $\% / \mathrm{m}$ & m & $\mathrm{ml}$ & $/ 1$ & $\mathrm{mg} / \mathrm{m}^{3}$ & $\mu g A t / 1$ & $\%$ & \\
\hline 0 & 1492.6 & 11.41 & 22.1 & 0 & & .72 & 0.57 & 0.34 & & \\
\hline 3 & 1492.7 & 11.40 & 22.2 & 5 & & .61 & 2.20 & 0.29 & & \\
\hline 5 & 1492.8 & 11.44 & 22.2 & 12 & & .04 & 3.85 & 0.40 & & \\
\hline 8 & 1492.8 & 11.42 & 21.2 & 29 & & .03 & 1.08 & 1.64 & & \\
\hline 11 & 1487.4 & 9.73 & 8.9 & 44 & & .28 & 1.53 & 1.92 & & \\
\hline 14 & 1486.3 & 9.36 & 19.0 & 47 & & .85 & 1.98 & 2.11 & & \\
\hline 17 & 1485.7 & 9.15 & 43.7 & & & & & & & \\
\hline 21 & 1484.8 & 8.90 & 54.6 & & & & & & & \\
\hline 24 & 1484.6 & 8.82 & 56.1 & & & & & & & \\
\hline 29 & 1484.3 & 8.70 & 62.2 & & & & & & & \\
\hline 35 & 1484.1 & 8.65 & 58.4 & & & & & & & \\
\hline 39 & 1484.1 & 8.59 & 59.7 & & & & & & & \\
\hline 44 & 1484.1 & 8.57 & 54.3 & & & & & & & \\
\hline 50 & 1483.4 & 8.38 & 29.8 & & & & & & & \\
\hline
\end{tabular}

\begin{tabular}{|c|c|c|c|}
\hline STATION: $K-5$ & DEPTH : & DATE $: 5-4-70$ & TIME: \\
\hline IAT: $37^{\circ}-31.9^{\prime} \mathrm{N}$ & LONG : $122^{\circ}-43.1^{\prime} \mathrm{W}$ & WIND: & SPEED: \\
\hline AIR TEMP (DRY): $50^{\circ}$ & BARO: 29.96 & CLOUD AMT: 10 & HEIGHT (FT): 800 \\
\hline SEA: $\quad 310^{\circ}-2$ & SWELL: $\quad 300^{\circ}-6$ & & \\
\hline SV & TRANS & $\begin{array}{l}\text { Chloro- } \\
\text { phyll }\end{array}$ & $\mathrm{PO}_{4}$ \\
\hline
\end{tabular}

\begin{tabular}{|c|c|c|c|c|c|c|c|}
\hline$m$ & $\mathrm{~m} / \mathrm{sec}$ & ${ }^{\circ} \mathrm{C}$ & $\% / m$ & $\mathrm{~m}$ & $\mathrm{~m} 1 / 1$ & $\mathrm{mg} / \mathrm{m}^{3}$ & $\mu g A t / 1$ \\
\hline 0 & 1492.5 & 11.18 & 31.8 & 0 & 9.32 & 1.44 & 0.15 \\
\hline 3 & 1492.6 & 11.26 & 31.7 & 5 & 9.79 & 1.52 & 0.11 \\
\hline 5 & 1492.6 & 11.24 & 32.9 & 10 & 9.87 & 2.26 & 0.18 \\
\hline 9 & 1490.6 & 10.59 & 16.7 & 29 & 6.35 & 1.54 & 1.54 \\
\hline 14 & 1485.6 & 9.29 & 32.9 & 39 & 5.44 & 0.71 & 1.85 \\
\hline 20 & 1485.0 & 8.96 & 39.0 & 52 & 4.63 & 4.14 & 2.32 \\
\hline
\end{tabular}

$\begin{array}{llll}24 & 1484.1 & 8.69 & 60.9\end{array}$

$\begin{array}{llll}29 & 1484.1 & 8.66 & 58.0\end{array}$

$\begin{array}{llll}34 & 1484.2 & 8.66 & 58.7\end{array}$

$\begin{array}{llll}39 & 1484.1 & 8.62 & 59.3\end{array}$

$\begin{array}{llll}44 & 1483.9 & 8.54 & 33.1\end{array}$

$\begin{array}{llll}48 & 1483.7 & 8.44 & 22.2\end{array}$

$\begin{array}{llll}52 & 1483.6 & 8.40 & 20.5\end{array}$

$\begin{array}{llll}57 & 1483.7 & 8.39 & 14.9\end{array}$ 



\begin{tabular}{|c|c|c|c|c|c|c|c|c|c|c|}
\hline \multicolumn{3}{|c|}{ STATION: $\quad \mathrm{K}-6$} & DEPTH : & \multicolumn{2}{|l|}{$77 \mathrm{~m}$} & \multicolumn{2}{|c|}{ DATE: $5-4-70$} & \multicolumn{3}{|c|}{ TIME : $\quad 0800$} \\
\hline \multicolumn{3}{|c|}{$\mathrm{LAT}: 37^{\circ}-31.6^{\prime} \mathrm{N}$} & \multicolumn{3}{|c|}{ LONG: $122^{\circ}-46.9^{\prime} \mathrm{W}$} & \multicolumn{2}{|c|}{ WIND: $320^{\circ}$} & \multicolumn{3}{|c|}{ SPEED: 9} \\
\hline \multicolumn{3}{|c|}{ AIR TEMP (DRY): $50^{\circ}$} & BARO: & \multicolumn{2}{|c|}{29.94} & CLOUD & AMT: 10 & \multicolumn{3}{|c|}{ HEIGHT (FT): 900} \\
\hline \multicolumn{3}{|c|}{ SEA: $\quad 320^{\circ}-1$} & \multicolumn{8}{|l|}{ SWELL: } \\
\hline $\mathrm{Z}$ & SV & $\mathrm{T}$ & TRANS & $\mathrm{Z}$ & & $0_{2}$ & $\begin{array}{l}\text { Chloro- } \\
\text { phy } 11\end{array}$ & $\mathrm{PO}_{4}$ & S & $\sigma_{t}$ \\
\hline $\mathrm{m}$ & $\mathrm{m} / \mathrm{sec}$ & ${ }^{\mathrm{O}} \mathrm{C}$ & $\% / m$ & $\mathrm{~m}$ & $\mathrm{~m} 1$ & & $\mathrm{mg} / \mathrm{m}^{3}$ & $\mu g A t / 1$ & $\%$ & \\
\hline 0 & 1486.2 & 9.76 & 62.3 & 0 & 6. & 16 & 1.04 & 1.20 & & \\
\hline 5 & 1487.3 & 9.76 & 62.3 & 10 & 6. & 44 & 2.18 & 1.13 & & \\
\hline 10 & 1487.4 & 9.75 & 45.9 & 30 & 5. & 18 & 0.89 & 1.70 & & \\
\hline 15 & 1487.5 & 9.72 & 33.4 & 40 & 5 . & 06 & 1.06 & 1.77 & & \\
\hline 25 & 1485.5 & 9.14 & 78.5 & 60 & 5. & 17 & 1.29 & 1.86 & & \\
\hline 34 & 1485.5 & 8.78 & 70.8 & & & & & & & \\
\hline 47 & 1484.4 & 8.64 & 65.7 & & & & & & & \\
\hline 58 & 1484.4 & 8.63 & 62.2 & & & & & & & \\
\hline 62 & 1484.5 & 8.59 & 61.6 & & & & & & & \\
\hline 66 & 1484.4 & 8.58 & 63.3 & & & & & & & \\
\hline
\end{tabular}

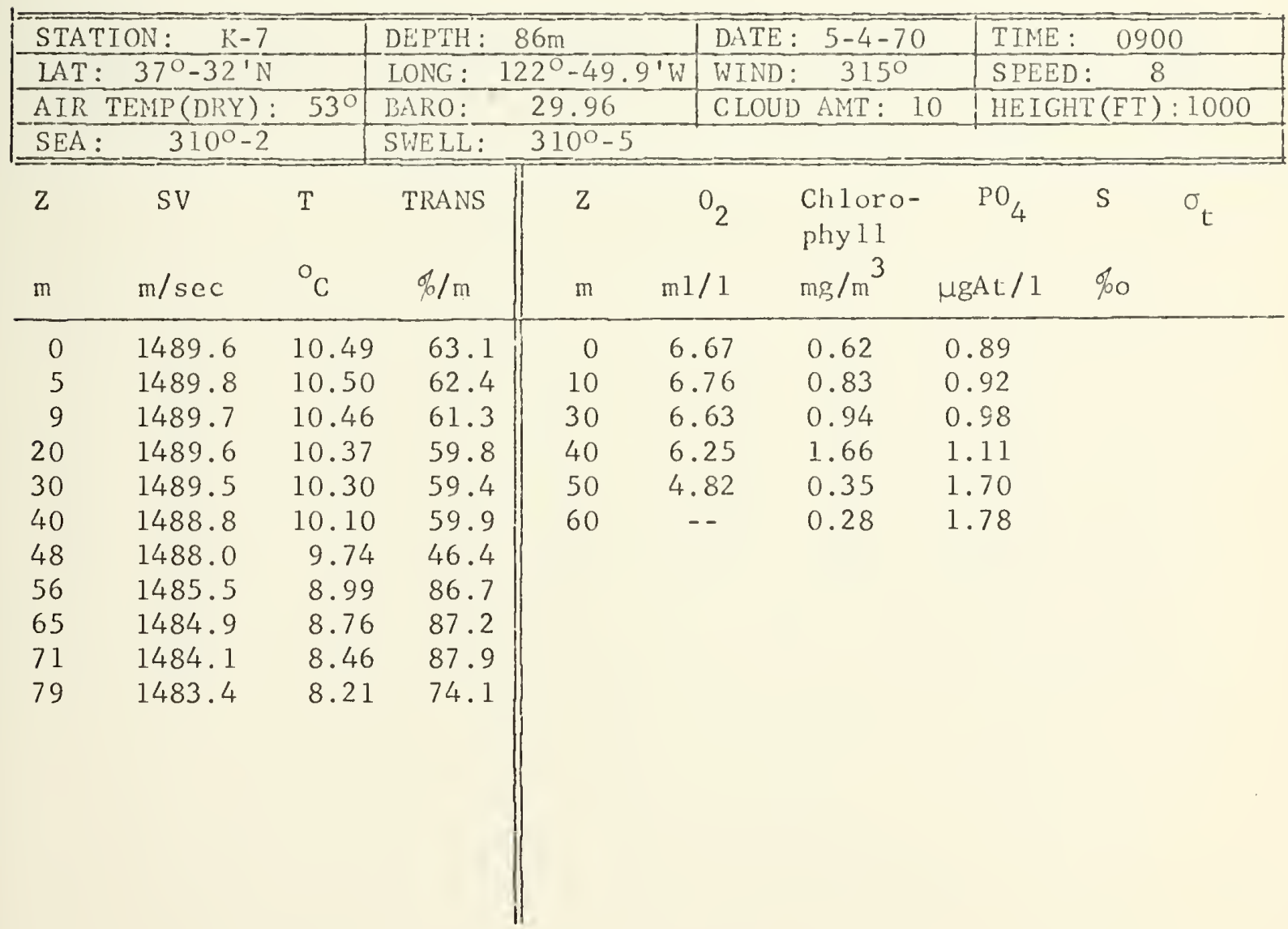





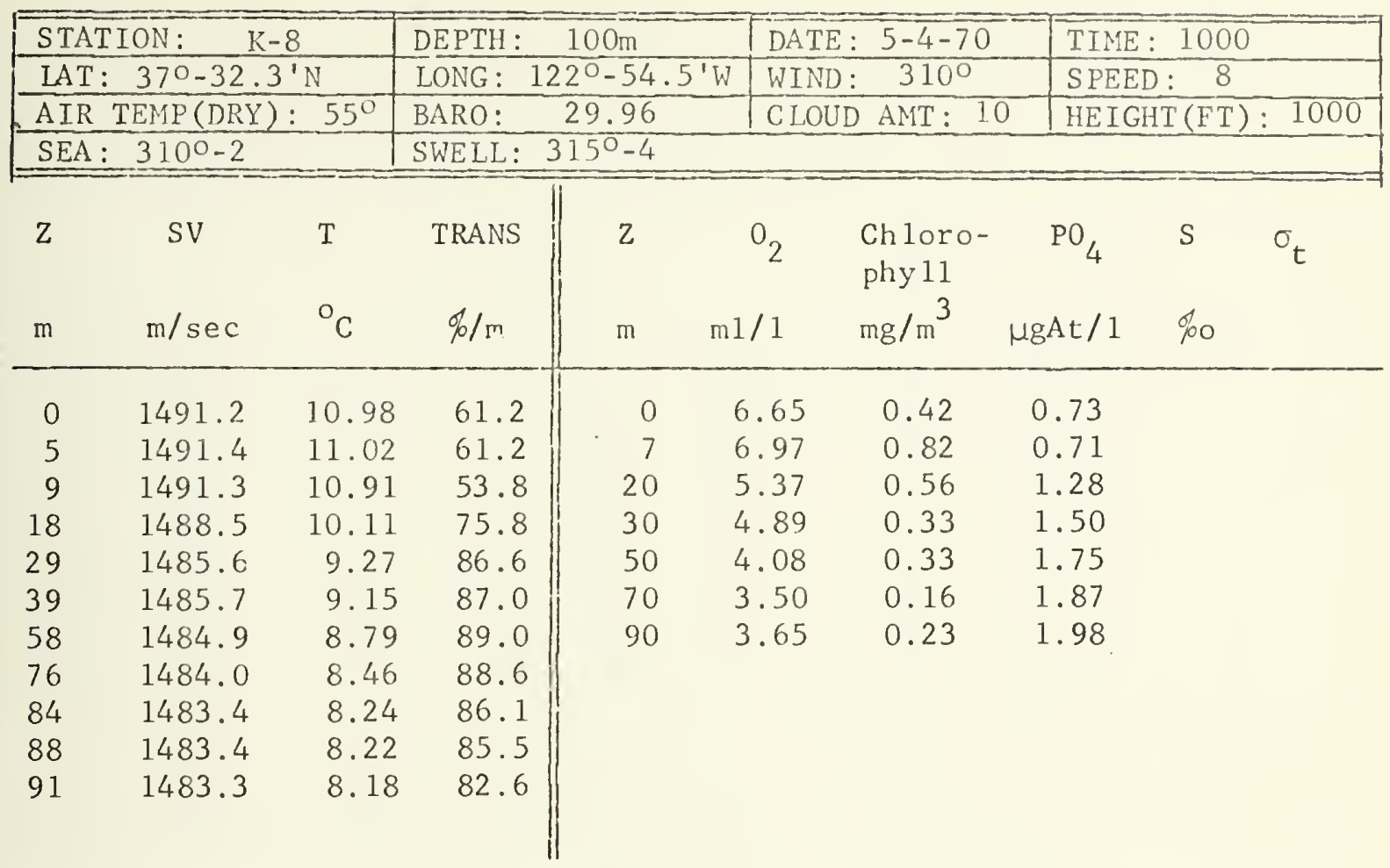

\begin{tabular}{|c|c|c|c|}
\hline STATION: & DEPTH : & $5-4-70$ & TIME : \\
\hline $\mathrm{LAT}: 37^{\circ}-31.2^{\mathrm{N}} \mathrm{N}$ & LONG: $122^{\circ}-58^{\prime} \mathrm{W}$ & WIND: & SPEED: \\
\hline AIR TEMP (DRY): $59^{\circ}$ & BARO: 30.02 & CLOUD AMT: 10 & HEIGHT (FT): 1000 \\
\hline SEA: $\quad 315^{\circ}-2$ & $315^{\circ}-4$ & & \\
\hline SV & TRANS & $\begin{array}{l}\text { Chloro- } \\
\text { phy } 11\end{array}$ & $\mathrm{PO}_{4}$ \\
\hline
\end{tabular}

\begin{tabular}{|c|c|c|c|c|c|c|c|c|}
\hline $\mathrm{m}$ & $\mathrm{m} / \mathrm{sec}$ & ${ }^{\circ} \mathrm{C}$ & $\% / \mathrm{m}$ & $\mathrm{m}$ & $\mathrm{m} 1 / 1$ & $\mathrm{mg} / \mathrm{m}^{3}$ & $\mu g A t / 1$ & $\% 0$ \\
\hline 0 & 1493.9 & 11.88 & 68.2 & 0 & 6.56 & 0.15 & 0.61 & \\
\hline 6 & 1493.9 & 11.87 & 68.8 & 10 & 6.46 & 0.28 & 0.76 & \\
\hline 9 & 1491.4 & 11.04 & 63.5 & 15 & 7.72 & 0.35 & 0.85 & \\
\hline 15 & 1490.3 & 10.62 & 67.9 & 25 & 6.53 & 0.41 & 1.10 & \\
\hline 19 & 1489.4 & 10.37 & 70.0 & 40 & 5.38 & 0.49 & 1.50 & \\
\hline 28 & 1487.7 & 9.75 & 65.6 & 70 & 3.73 & 0.11 & 1.86 & \\
\hline 39 & 1485.4 & 9.13 & 83.6 & 100 & 3.84 & 0.09 & 1.97 & \\
\hline 56 & 1484.8 & 8.75 & 90.2 & & & & & \\
\hline 71 & 1484.3 & 8.54 & 90.2 & & & & & \\
\hline 89 & 1484.2 & 8.46 & 90.6 & & & & & \\
\hline
\end{tabular}





\begin{tabular}{|c|c|c|c|c|c|c|c|c|c|c|}
\hline \multicolumn{3}{|c|}{ STATION: $\mathrm{K}-10$} & \multicolumn{3}{|c|}{ DEPTH: $755 \mathrm{~m}$} & \multicolumn{2}{|c|}{ DATE: $5-4-70$} & \multicolumn{3}{|c|}{ TIME: 1330} \\
\hline \multicolumn{3}{|c|}{ LAT $: 37^{\circ}-32.3^{\prime} \mathrm{N}$} & \multicolumn{3}{|c|}{ LONG: $123^{\circ}-03.8^{\prime} \mathrm{W}$} & \multicolumn{2}{|c|}{ WIND : $\quad 315^{\circ}$} & \multicolumn{3}{|c|}{ SPEED : 14} \\
\hline \multicolumn{3}{|c|}{ AIR TEMP (DRY): $58^{\circ}$} & \multicolumn{3}{|c|}{ BARO: 30.00} & C LOUD & AMT: & \multicolumn{3}{|c|}{ HEIGHT (FT): 4000} \\
\hline \multicolumn{3}{|c|}{ SEA: $315^{\circ}-2$} & \multicolumn{8}{|c|}{ SWELL: $\quad 315^{\circ}-4$} \\
\hline 2 & SV & $\mathrm{T}$ & TRANS & Z & & $0_{2}$ & $\begin{array}{l}\text { Chloro- } \\
\text { phy } 11\end{array}$ & $\mathrm{PO}_{4}$ & S & $\sigma_{t}$ \\
\hline $\mathrm{m}$ & $\mathrm{m} / \mathrm{sec}$ & ${ }^{\circ} \mathrm{C}$ & $\% / \mathrm{m}$ & $\mathrm{m}$ & $\mathrm{m} 1$ & & $\mathrm{mg} / \mathrm{m}^{3}$ & $\mu g A t / 1$ & $\%$ & \\
\hline 0 & 1495.1 & 12.27 & 72.6 & 0 & 6. & & 0.11 & 0.46 & & \\
\hline 6 & 1495.3 & 12.28 & 72.6 & 10 & 6. & & 0.14 & 0.48 & & \\
\hline 9 & 1495.3 & 12.25 & 73.1 & 15 & 5 . & & 0.10 & 0.74 & & \\
\hline 14 & 1495.2 & 12.20 & 76.5 & 25 & 6. & & 0.13 & 0.99 & & \\
\hline 19 & 1488.7 & 10.27 & 90.8 & 36 & 6. & & 0.18 & 1.15 & & \\
\hline 24 & 1489.8 & 10.48 & 87.7 & 50 & 5. & & 0.69 & 1.45 & & \\
\hline 29 & 1489.8 & 10.45 & 88.4 & 67 & 5. & & 0.89 & 1.56 & & \\
\hline 38 & 1488.2 & 9.93 & 78.7 & 100 & 3. & 85 & 0.22 & 1.95 & & \\
\hline 47 & 1487.1 & 9.47 & 75.4 & & & & & & & \\
\hline 61 & 1486.2 & 9.13 & 81.8 & & & & & & & \\
\hline 75 & 1485.5 & 8.86 & 80.6 & & & & & & & \\
\hline 93 & 1484.1 & 8.39 & 96.0 & & & & & & & \\
\hline 100 & 1484.1 & 8.34 & 96.0 & & & & & & & \\
\hline
\end{tabular}

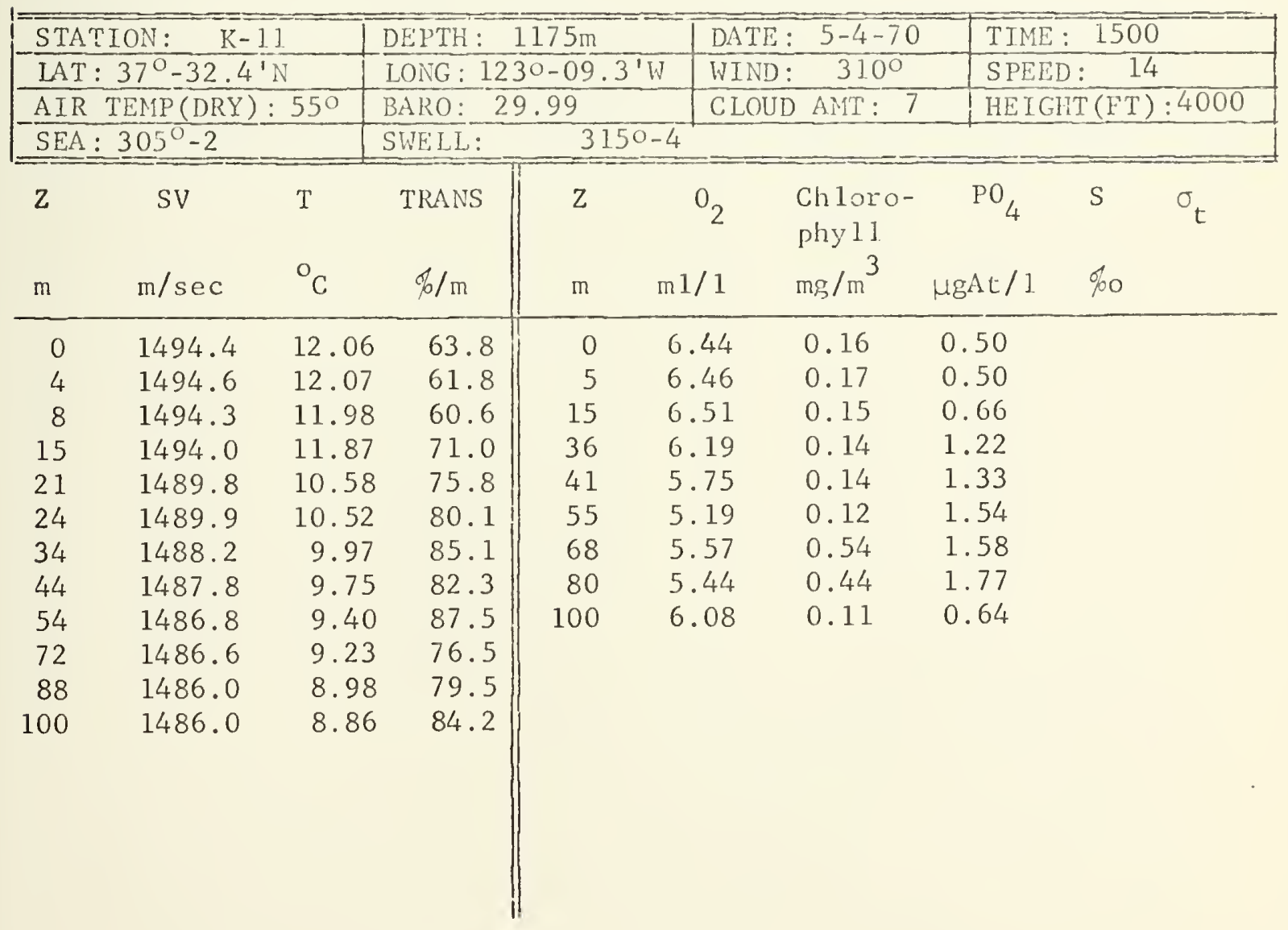





\begin{tabular}{|c|c|c|c|c|c|c|c|c|c|c|}
\hline \multicolumn{3}{|c|}{ STATION: $\quad L-1$} & \multicolumn{3}{|c|}{ DEPTH : $1463 \mathrm{~m}$} & \multicolumn{2}{|c|}{ DATE : $5-4-70$} & \multicolumn{3}{|c|}{ TIME : 1645} \\
\hline \multicolumn{3}{|c|}{ LAT: $37^{\circ}-36.8^{\prime} \mathrm{N}$} & \multicolumn{3}{|c|}{ LONG: $123^{\circ}-15.4^{\prime} \mathrm{W}$} & \multicolumn{2}{|c|}{ WIND: $300^{\circ}$} & \multicolumn{3}{|c|}{ SPEED: 14} \\
\hline \multicolumn{3}{|c|}{ AIR TEMP (DRY): $52^{\circ}$} & \multicolumn{3}{|c|}{ BARO: $\quad 30.00$} & \multicolumn{2}{|c|}{ CLOUD AMT: 5} & \multicolumn{3}{|c|}{ HEIGHT (FT): 3700} \\
\hline \multicolumn{3}{|c|}{ SEA: $305^{\circ}-2$} & \multicolumn{8}{|c|}{ SWELL: $\quad 310^{\circ}-4$} \\
\hline 2 & SV & $\mathrm{T}$ & TRANS & $Z$ & & $0_{2}$ & $\begin{array}{l}\text { Chloro- } \\
\text { phy } 11\end{array}$ & $\mathrm{PO}_{4}$ & $S$ & $\sigma_{t}$ \\
\hline $\mathrm{m}$ & $\mathrm{m} / \mathrm{sec}$ & ${ }^{\circ} \mathrm{C}$ & $\% / \mathrm{n}$ & $\mathrm{m}$ & $\mathrm{m} 1$ & & $\mathrm{mg} / \mathrm{m}^{3}$ & MgAt/ 1 & $\%$ & \\
\hline 0 & 1491.6 & 11.07 & 64.7 & 0 & 7. & & 0.25 & 0.89 & & \\
\hline 5 & 1491.8 & 11.09 & 66.4 & 5 & 6. & 90 & 0.25 & 0.86 & & \\
\hline 10 & 1490.3 & 10.61 & 68.5 & 10 & 6. & 94 & 0.22 & 0.89 & & \\
\hline 14 & 1487.9 & 9.91 & 61.2 & 15 & 6. & 81 & 0.40 & 1.09 & & \\
\hline 19 & 1487.1 & 9.64 & 55.8 & 30 & 6. & 04 & 1.43 & 1.39 & & \\
\hline 24 & 1486.8 & 9.52 & 58.2 & 50 & 5 . & 09 & 0.72 & 1.75 & & \\
\hline 34 & 1486.3 & 9.32 & 70.4 & 75 & 4. & 92 & 0.22 & 1.88 & & \\
\hline 44 & 1485.5 & 9.05 & 83.3 & 100 & 5. & 17 & 0.26 & 1.88 & & \\
\hline 55 & 1485.2 & 8.90 & 89.3 & 150 & & 22 & 0.12 & 2.09 & & \\
\hline 64 & 1485.0 & 8.79 & 90.1 & 200 & 3 . & 89 & 0.21 & 2.06 & & \\
\hline 75 & 1485. & 8.72 & 88.4 & & & & & & & \\
\hline 84 & 1484.6 & 8.57 & 88.0 & & & & & & & \\
\hline 100 & 1484.9 & 8.55 & 87.0 & & & & & & & \\
\hline
\end{tabular}

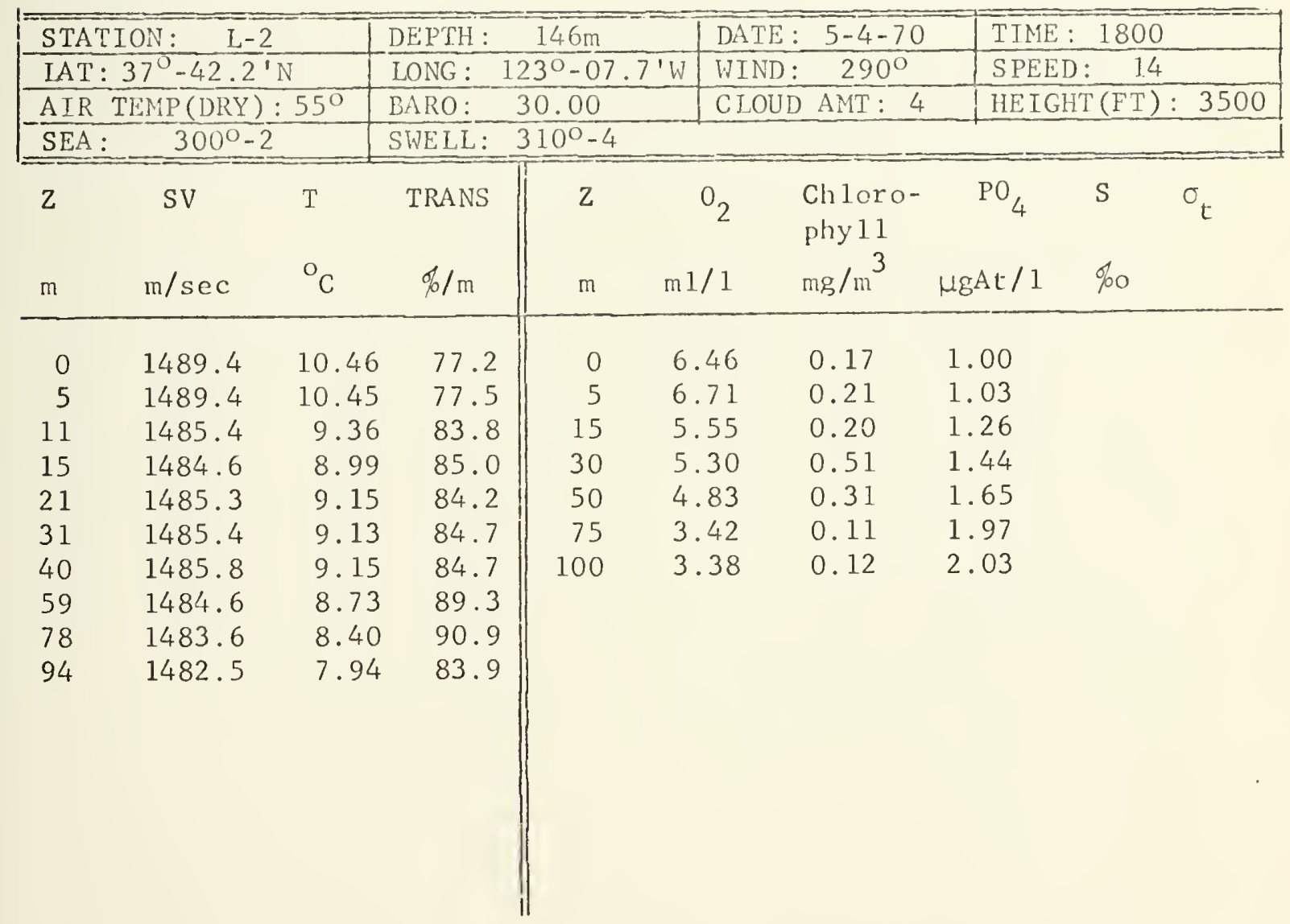





\begin{tabular}{|c|c|c|c|}
\hline STATION: $\quad$ L-3 & DEPTH: & DATE: $5-4-70$ & TIME : \\
\hline LAT: $37^{\circ}-47^{\prime} 7^{\prime} \mathrm{N}$ & LONG: $122^{\circ}-59.7^{\prime} \mathrm{W}$ & WIND: $290^{\circ}$ & SPEED: \\
\hline AIR TEMP (DRY): $53^{\circ}$ & BARO: & CLOUD AMT: & HEIGHT (FT): \\
\hline SEA: $280^{\circ}-2$ & SWELL: & & \\
\hline
\end{tabular}

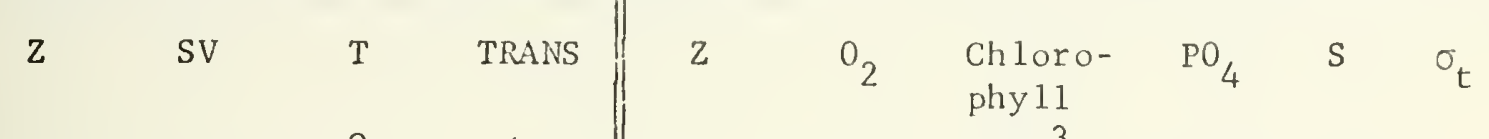

$\mathrm{m} \mathrm{m} / \mathrm{sec} \quad{ }^{\circ} \mathrm{C} \quad \% / \mathrm{m} \quad \mathrm{m} \quad \mathrm{ml} / 1 \quad \mathrm{mg} / \mathrm{m}^{3} \mathrm{\mu gAt} / 1$ \%

\begin{tabular}{rrrr||rrrr}
\hline 0 & 1489.2 & 10.19 & 6.1 & 0 & 9.06 & 2.62 & 0.67 \\
6 & 1489.2 & 10.17 & 6.1 & 5 & 9.28 & 3.23 & 0.42 \\
10 & 1487.3 & 9.65 & 10.9 & 20 & 5.89 & 0.76 & 1.58 \\
20 & 1485.1 & 8.95 & 32.1 & 30 & 4.81 & 1.37 & 1.86 \\
31 & 1483.9 & 8.60 & 52.2 & 45 & 4.40 & 1.95 & 1.96 \\
39 & 1483.5 & 8.43 & 70.8 & 60 & 4.20 & 1.16 & 2.08 \\
49 & 1483.3 & 8.36 & 68.2 & & & & \\
59 & 1482.8 & 8.16 & 61.5 & & & &
\end{tabular}

\begin{tabular}{|c|c|c|c|}
\hline STATION: $\quad$ L-4 & DEPTH: $55 \mathrm{~m}$ & DATE: $5-4-70$ & TIME: 2130 \\
\hline LAT: $37^{\circ}-52.6^{\prime} \mathrm{N}$ & LONG: $1220-52.5^{\prime} \mathrm{W}$ & WIND: $295^{\circ}$ & SPEED : 19 \\
\hline AIR TEMP (DRY): $54^{\circ}$ & 30.04 & CLOUD AMT: 10 & $\operatorname{HEIGHT}(\mathrm{FT}): 1500$ \\
\hline SEA : $295^{\circ}-4$ & SWE LL: $290^{\circ}-4$ & & \\
\hline
\end{tabular}

\begin{tabular}{|c|c|c|c|c|c|c|c|}
\hline $\mathrm{m}$ & $\mathrm{m} / \mathrm{sec}$ & ${ }^{\circ} \mathrm{C}$ & $\% / \mathrm{m}$ & $\mathrm{m}$ & $\mathrm{m} 1 / 1$ & $\mathrm{mg} / \mathrm{m}^{3}$ & $\mu g A t / 1$ \\
\hline 0 & 1488.3 & 9.94 & 12.0 & 0 & 8.36 & 2.67 & 0.69 \\
\hline 5 & 1488.4 & 9.94 & 11.7 & 10 & 8.37 & 4.06 & 0.72 \\
\hline 10 & 1488.4 & 9.95 & 11.7 & 25 & 5.79 & 1.07 & 1.69 \\
\hline 15 & 1486.4 & 9.42 & 28.7 & 45 & 4.74 & 0.94 & 1.98 \\
\hline
\end{tabular}

$29 \quad 1484.1 \quad 8.65-72.7$

$\begin{array}{llll}39 & 1483.6 & 8.49 & 78.1\end{array}$

$\begin{array}{llll}44 & 1483.6 & 8.44 & 63.5\end{array}$

$\begin{array}{llll}49 & 1483.6 & 8.44 & 52.9\end{array}$ 



\begin{tabular}{|l|l|l|l|}
\hline \hline STATION: M-1 & DEPTH: $47 \mathrm{~m}$ & DATE: $5-4-70$ & TIME: 2200 \\
\hline LAT: $37^{\circ}-53.2^{\prime} \mathrm{N}$ & LONG: $122^{\circ}-49.2^{\prime} \mathrm{W}$ & WIND: $295^{\circ}$ & SPEED : 20 \\
\hline AIR TEMP (DRY): 540 & BARO: 30.05 & CLOUD AMT: 10 & HEIGHT(FT) : 1500 \\
\hline SEA: $295^{\circ}-4$ & SWELL: $290^{\circ}-4$ & \\
\hline
\end{tabular}

\begin{tabular}{|c|c|c|c|c|c|c|c|c|c|}
\hline $\mathrm{m}$ & $\begin{array}{l}\text { SV } \\
\mathrm{m} / \mathrm{sec}\end{array}$ & ${ }^{\circ} \mathrm{C}$ & $\begin{array}{l}\text { TRANS } \\
\% / \mathrm{m}\end{array}$ & $\mathrm{m}$ & $\begin{array}{r}{ }_{2} \\
\mathrm{~m} 1 / 1\end{array}$ & $\begin{array}{l}\text { Chloro- } \\
\text { phyl1 } \\
\mathrm{mg} / \mathrm{m}^{3}\end{array}$ & $\begin{array}{c}\mathrm{PO}_{4} \\
\mathrm{MgAt} / 1\end{array}$ & $\begin{array}{l}\text { S } \\
\% 0\end{array}$ & $\sigma_{t}$ \\
\hline 0 & 1488.3 & 9.94 & 9.8 & 0 & 9.04 & 2.41 & 0.51 & & \\
\hline 4 & 1488.4 & 9.96 & 9.8 & 5 & 8.74 & 6.33 & 0.53 & & \\
\hline 8 & 1488.4 & 9.92 & 10.4 & 10 & 9.12 & 4.82 & 0.60 & & \\
\hline 14 & 1486.2 & 9.32 & 29.7 & 20 & 6.38 & 1.52 & 1.49 & & \\
\hline 19 & 1484.8 & 8.91 & 64.1 & 30 & 5.63 & 1.00 & 1.69 & & \\
\hline 23 & 1484.6 & 8.83 & 67.0 & & & & & & \\
\hline 28 & 1484.3 & 8.71 & 69.6 & & & & & & \\
\hline 32 & 1484.1 & 8.65 & 69.0 & & & & & & \\
\hline 38 & 1483.7 & 8.51 & 46.1 & & & & & & \\
\hline
\end{tabular}

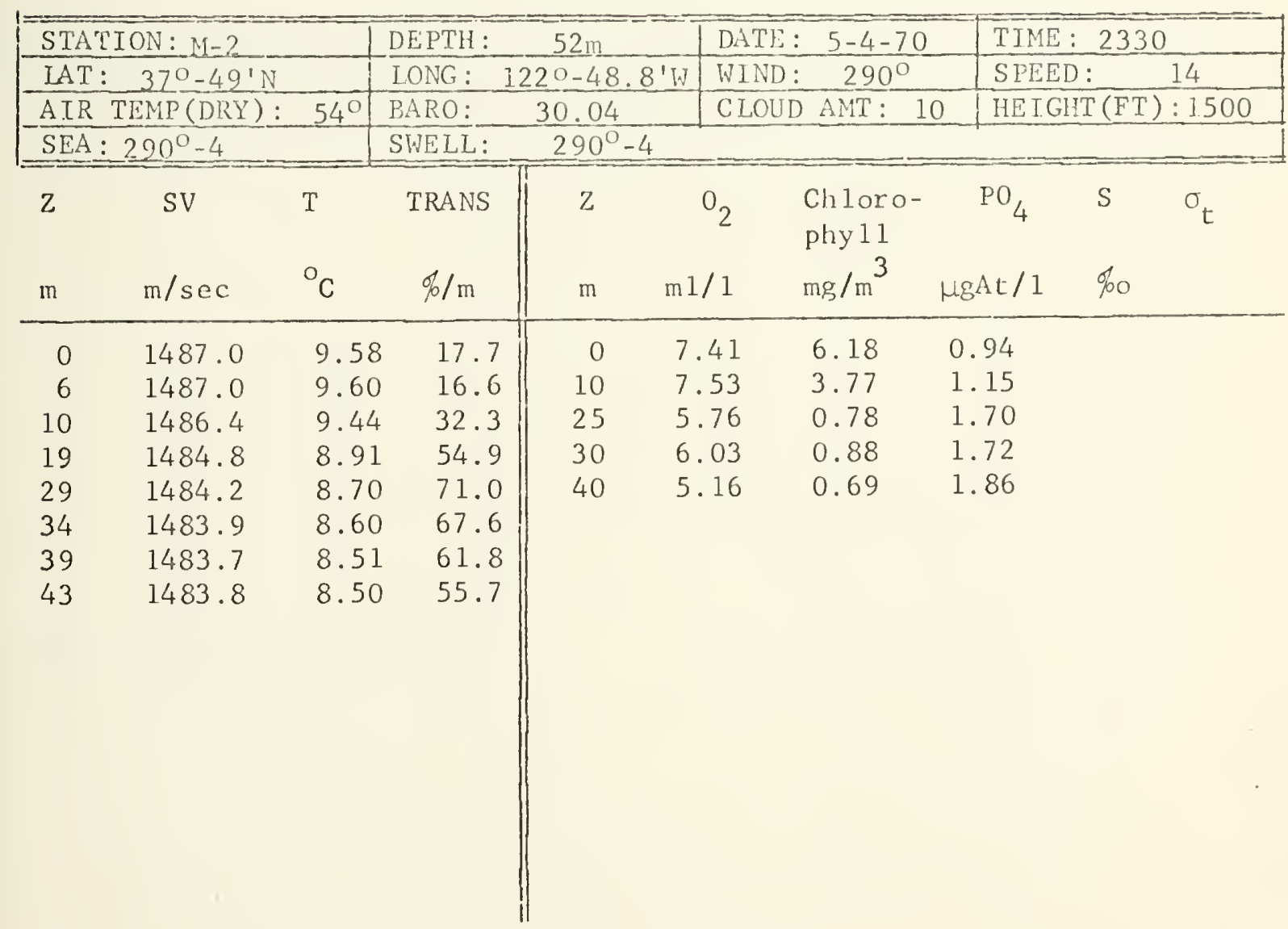





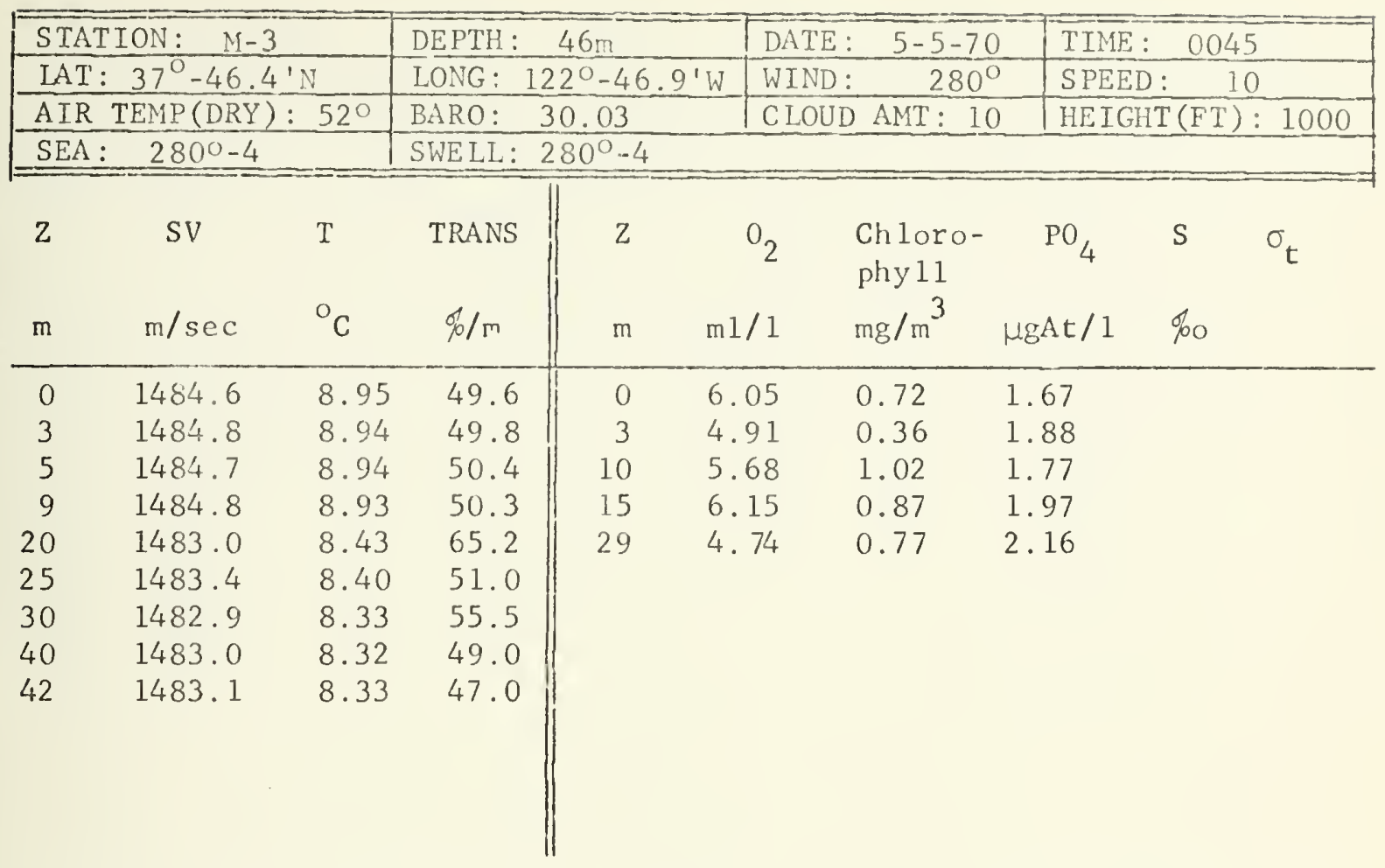

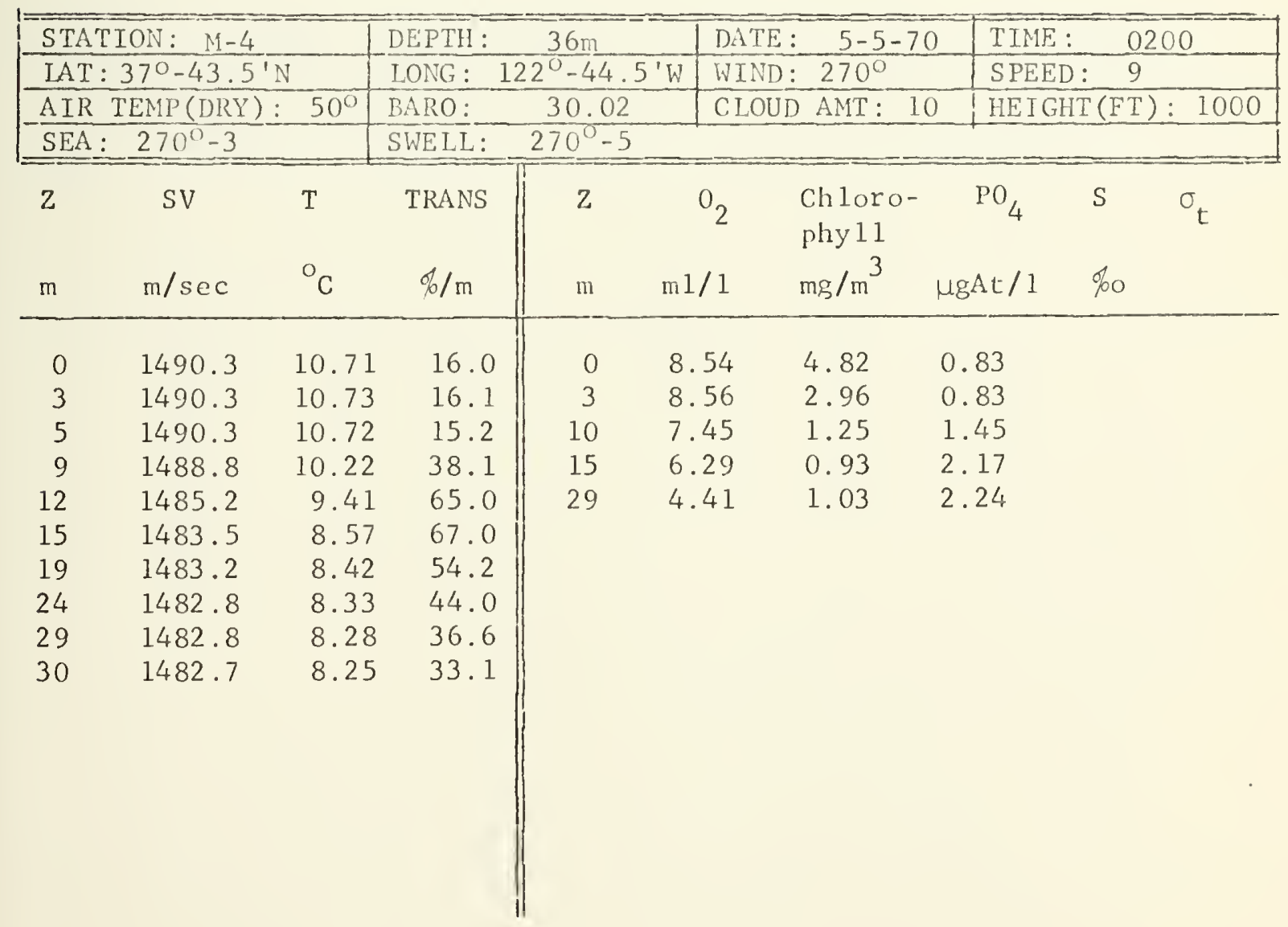





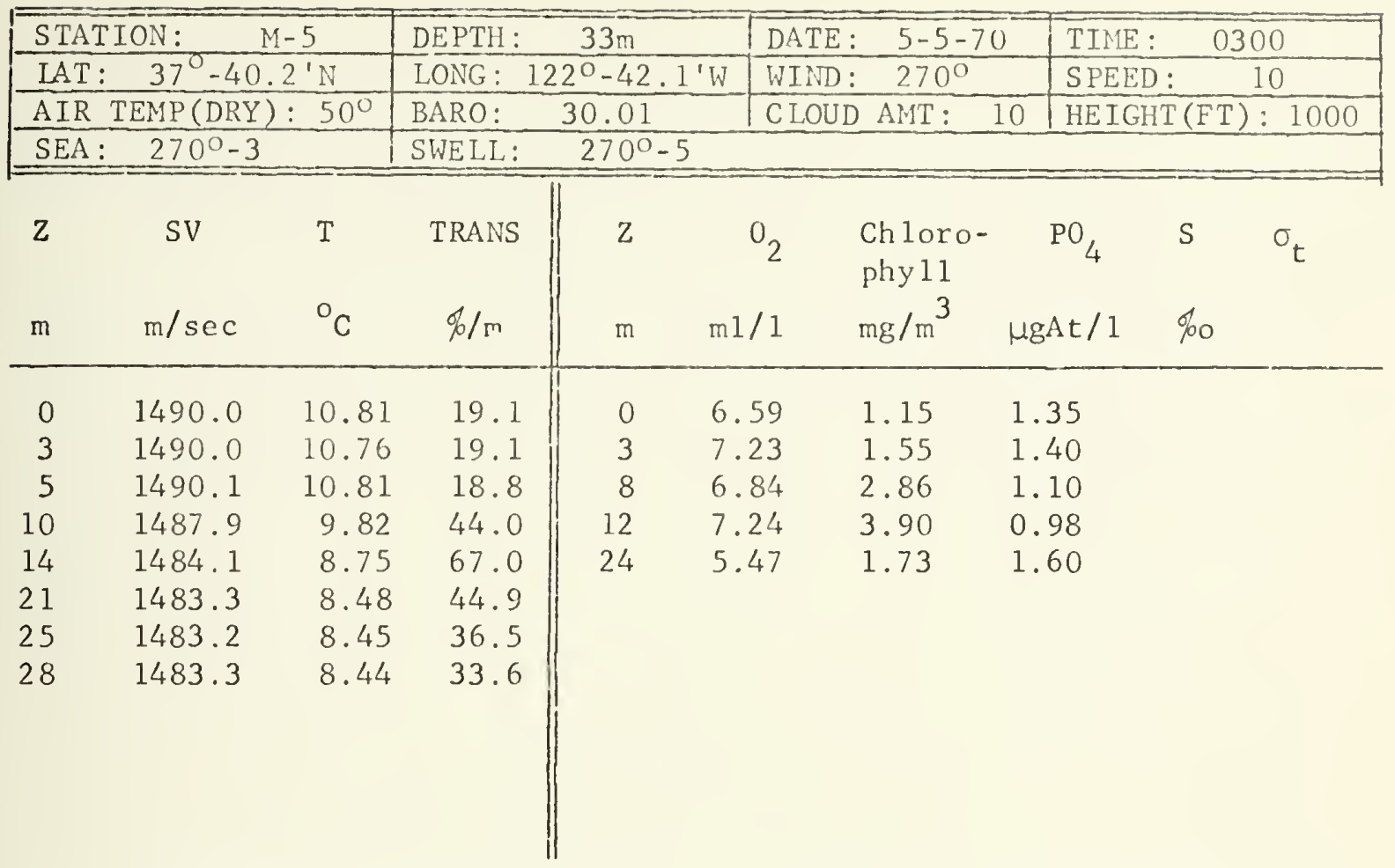

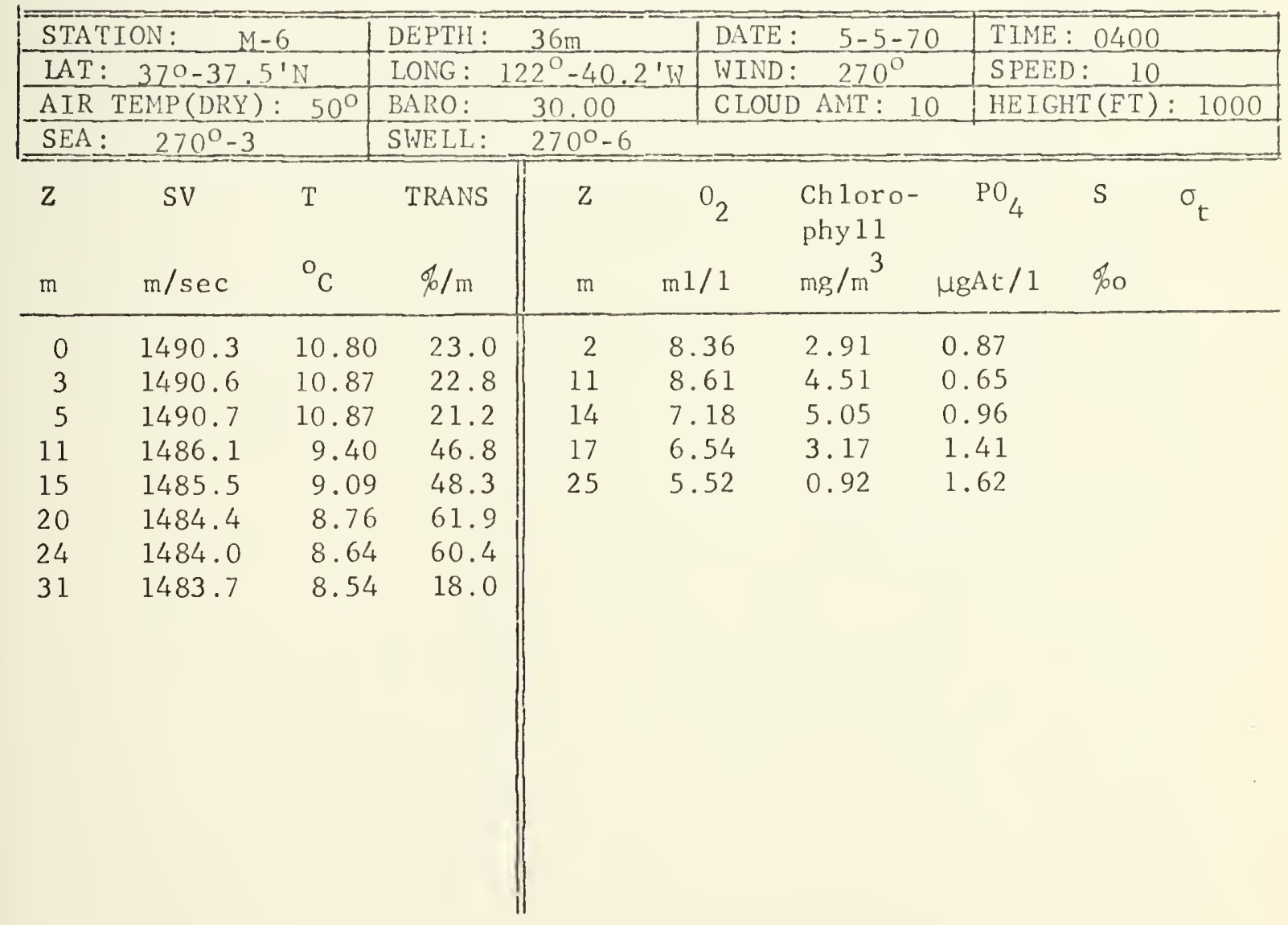





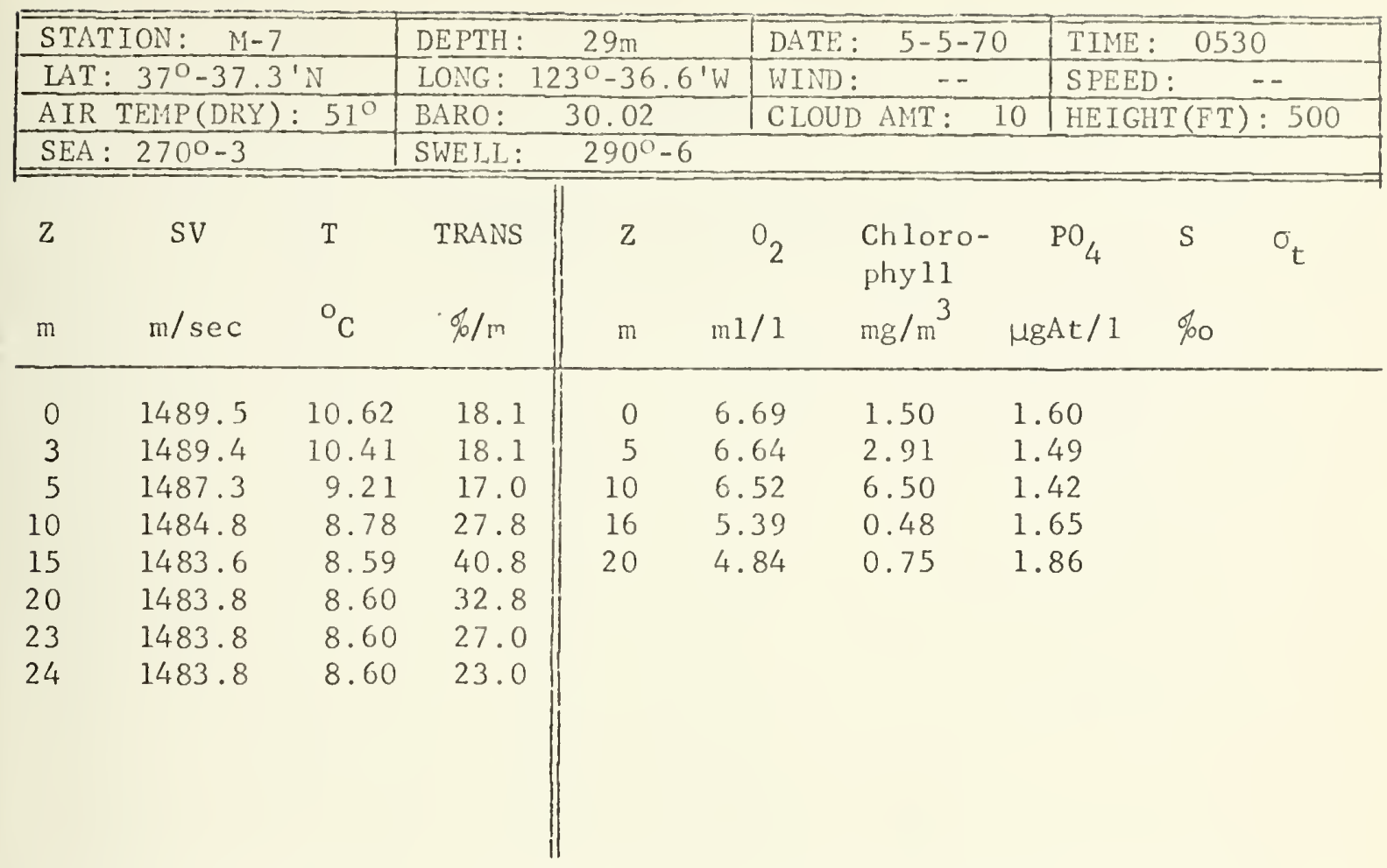

\begin{tabular}{|c|c|c|c|c|c|c|c|c|c|}
\hline \multicolumn{3}{|c|}{ STATION: } & \multicolumn{2}{|l|}{ DEPTH : } & \multicolumn{2}{|c|}{ DATE: } & \multicolumn{3}{|c|}{ TIME : } \\
\hline \multicolumn{3}{|c|}{ LAT: } & \multicolumn{2}{|l|}{ LONG : } & \multicolumn{2}{|c|}{ WIND: } & \multicolumn{3}{|c|}{ SPEED : } \\
\hline \multicolumn{3}{|c|}{ AIR TEMP (DRY): } & \multicolumn{2}{|l|}{ BARO: } & \multicolumn{2}{|c|}{ CLOUD AMT: } & \multicolumn{3}{|c|}{ HEIGHT (FT): } \\
\hline \multicolumn{3}{|c|}{ SEA: } & \multicolumn{7}{|l|}{ SWELL: } \\
\hline $\mathrm{Z}$ & SV & $T$ & TRANS & $\mathrm{Z}$ & $\mathrm{O}_{2}$ & $\begin{array}{l}\text { Chloro- } \\
\text { phyll }\end{array}$ & $\mathrm{PO}_{4}$ & S & $\sigma_{t}$ \\
\hline $\mathrm{m}$ & $\mathrm{m} / \mathrm{sec}$ & ${ }^{\circ} \mathrm{C}$ & $\% / \mathrm{m}$ & $\mathrm{m}$ & $\mathrm{ml} / \mathrm{l}$ & $\mathrm{mg} / \mathrm{m}^{3}$ & $\mu g A t / 1$ & $\% 0$ & \\
\hline
\end{tabular}



TABIE II

Particle Size Distributions 



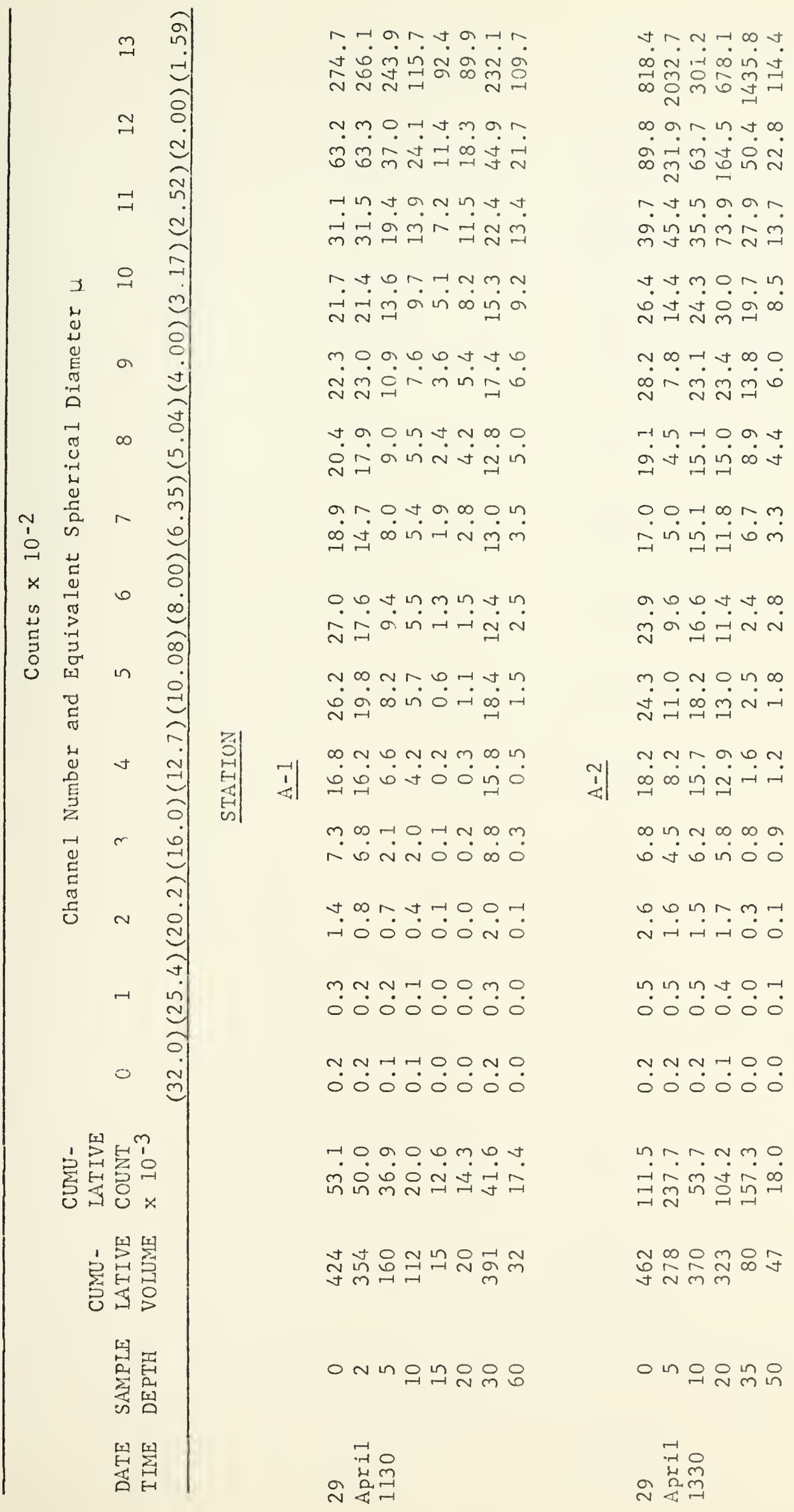





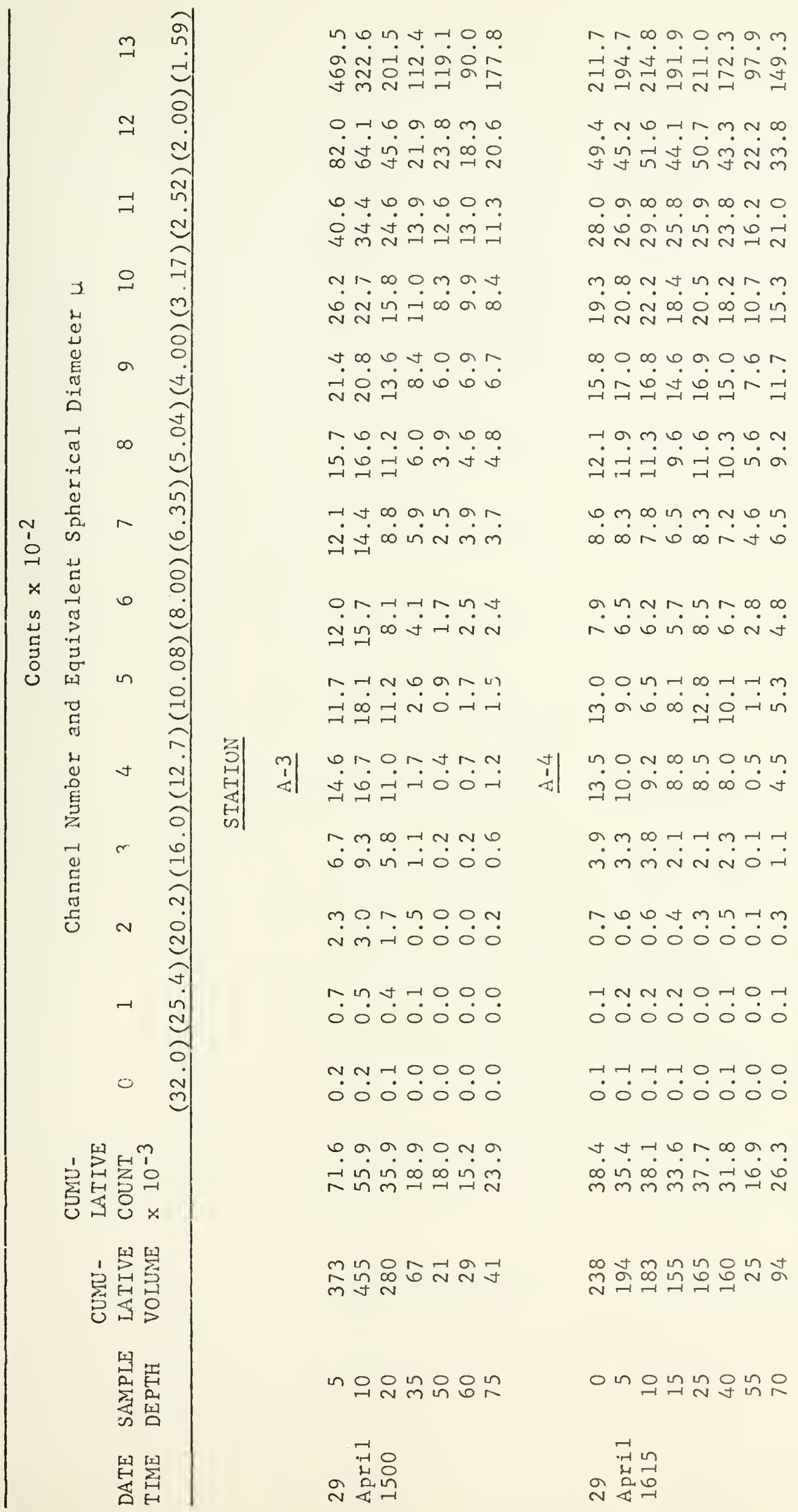





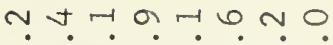
in $6000 \sim+\infty$

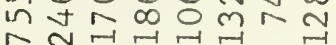

A. Thu ลู่

$0 \infty \infty$ o $\infty$ N 0

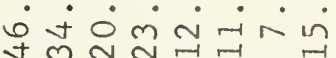

annamand $\infty \dot{i} \infty \dot{0}^{\circ} \dot{0}$ menctm n

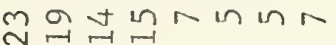

กดン $\therefore \dot{j} 0 \dot{0}$ in $\dot{0}$

monthntw $\sim 0 \infty \infty$ iो ${ }^{-1}$ in

og th m 0 ta

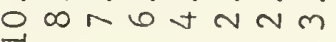

Nomenttin moरेंmini

写 in
$\vdots$
4

ดก- の

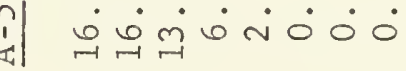
o ontmitim

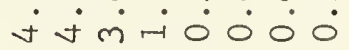
nก. m H h n O०்:0்:0

N N N N O H H O0 0 O0:

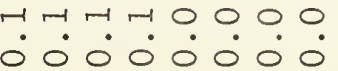
$\infty \wedge r$ in in $N a$ in

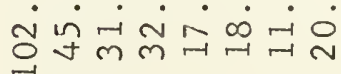
ํํํㅇํㄱำำ

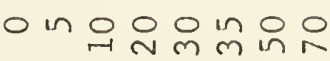

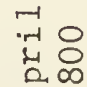
요 त \& in in $y, 0,2$ in

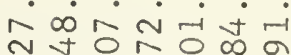
กำ

nNmetin वं०

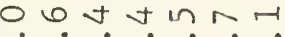

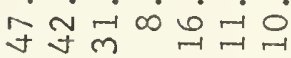
* 90.90

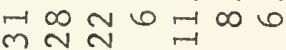
man inं o m $\infty$ in $\dot{m}$ in $\dot{m} \dot{m}$ ‥ $0.0 \% 01$ mं०

$\infty$ tonOn

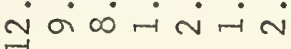

m $\operatorname{con}$ a लंñ 希

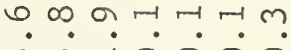
लिं กำง Hก ก $\therefore 00 \dot{0} 0 \dot{0}$ …ㅇ․ㅇ․ㅇ․․ A nh nmand

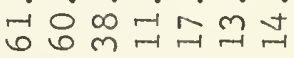

mํำ

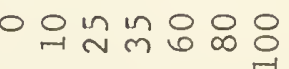

:-1 in 군 



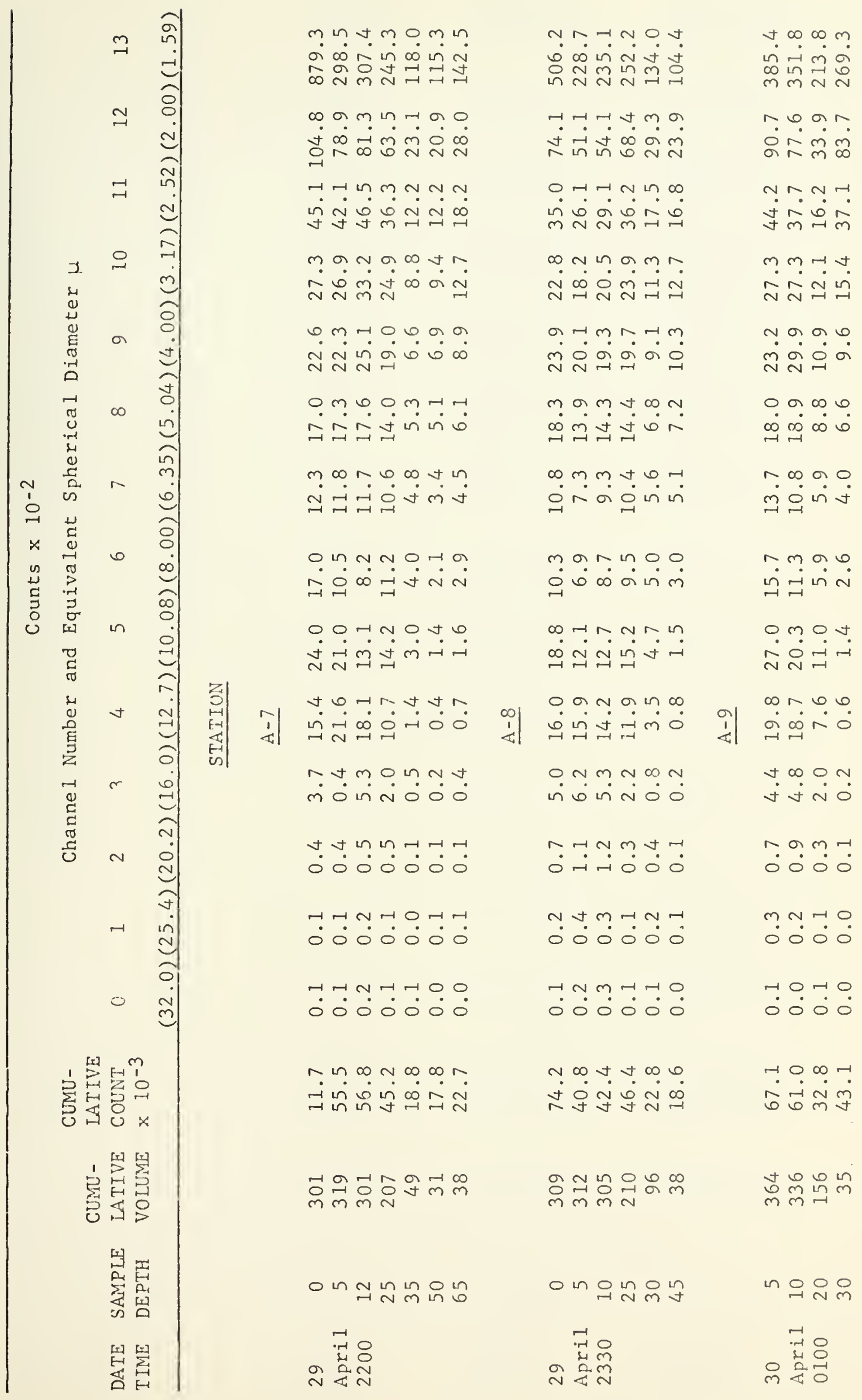





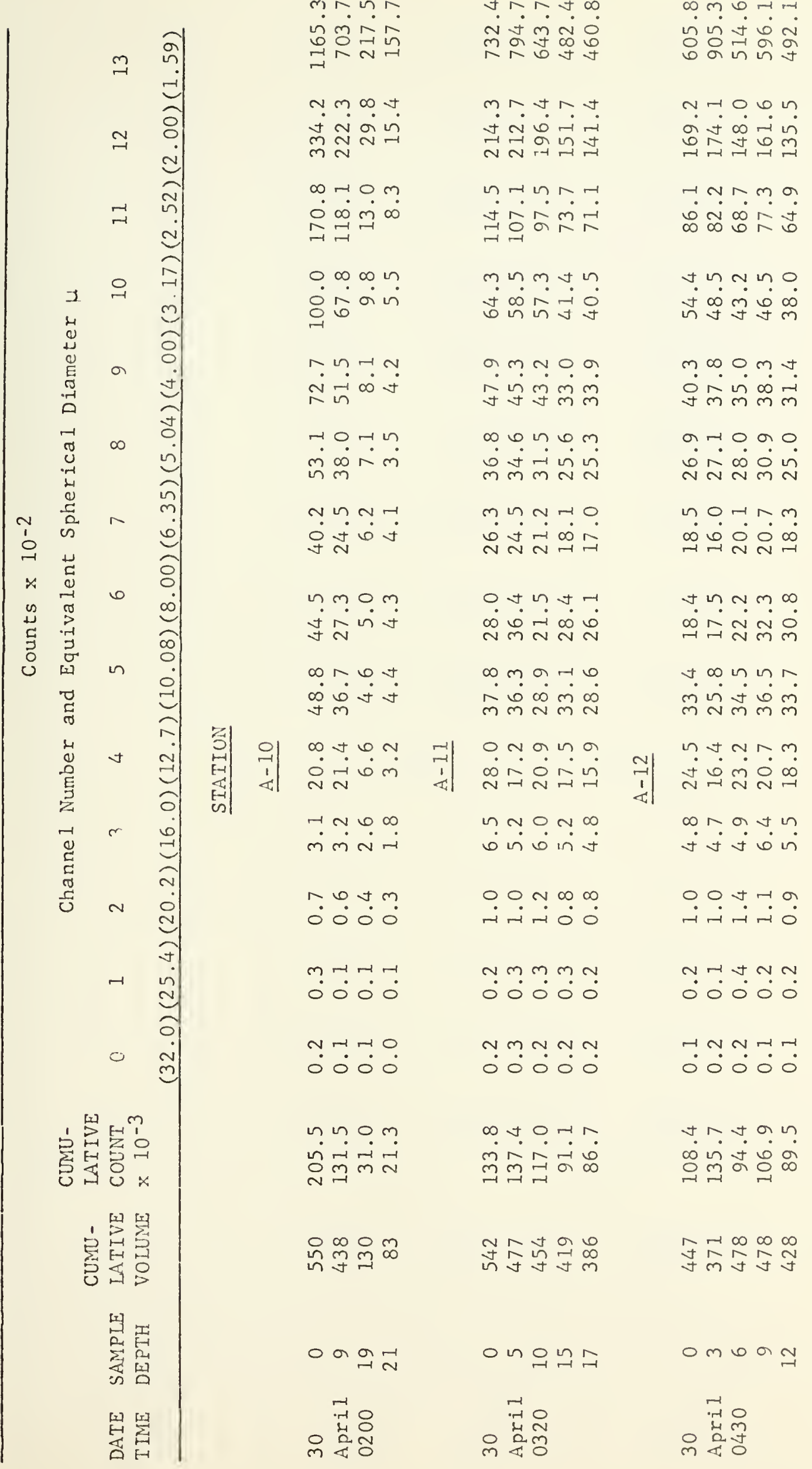





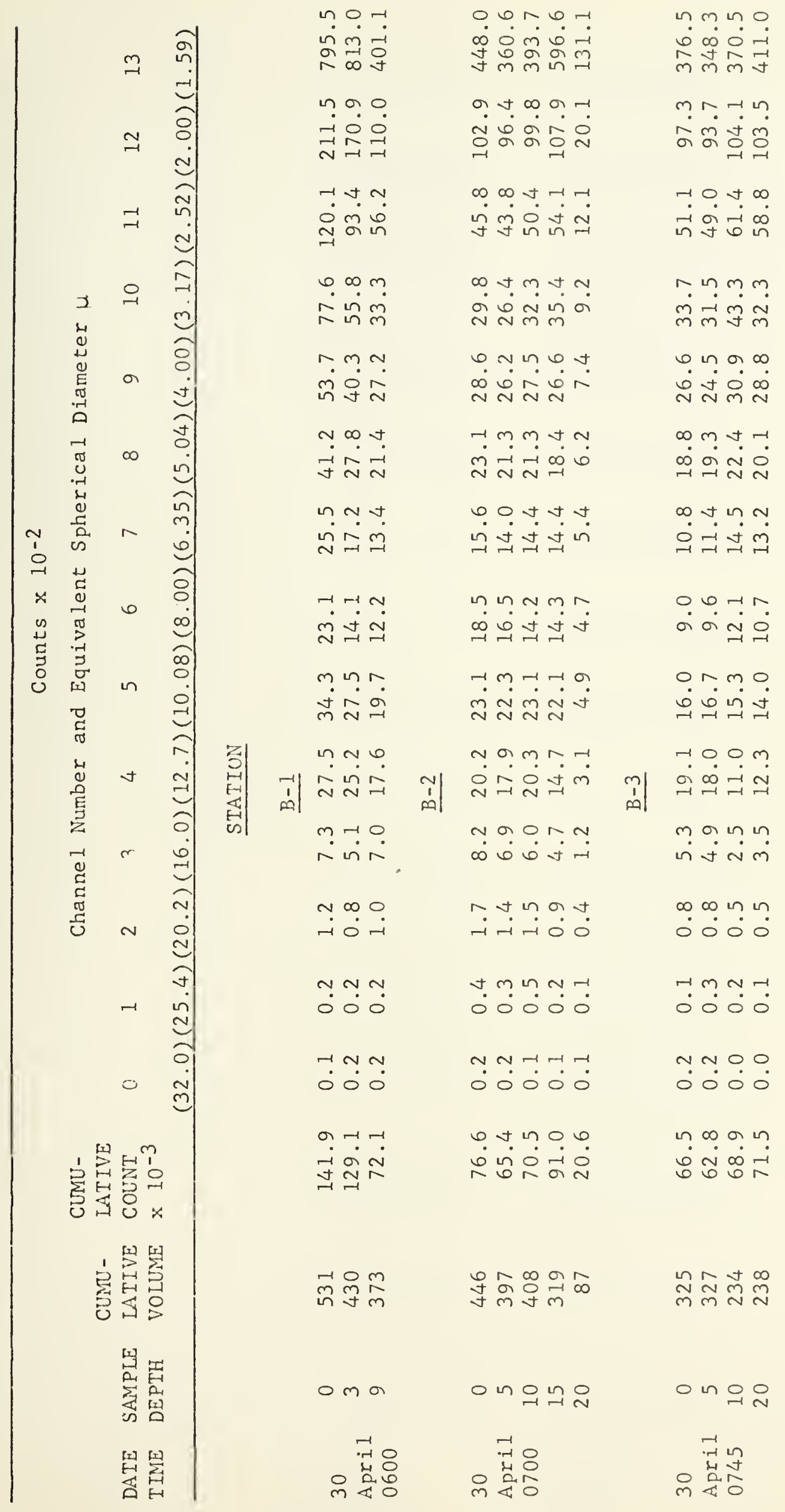





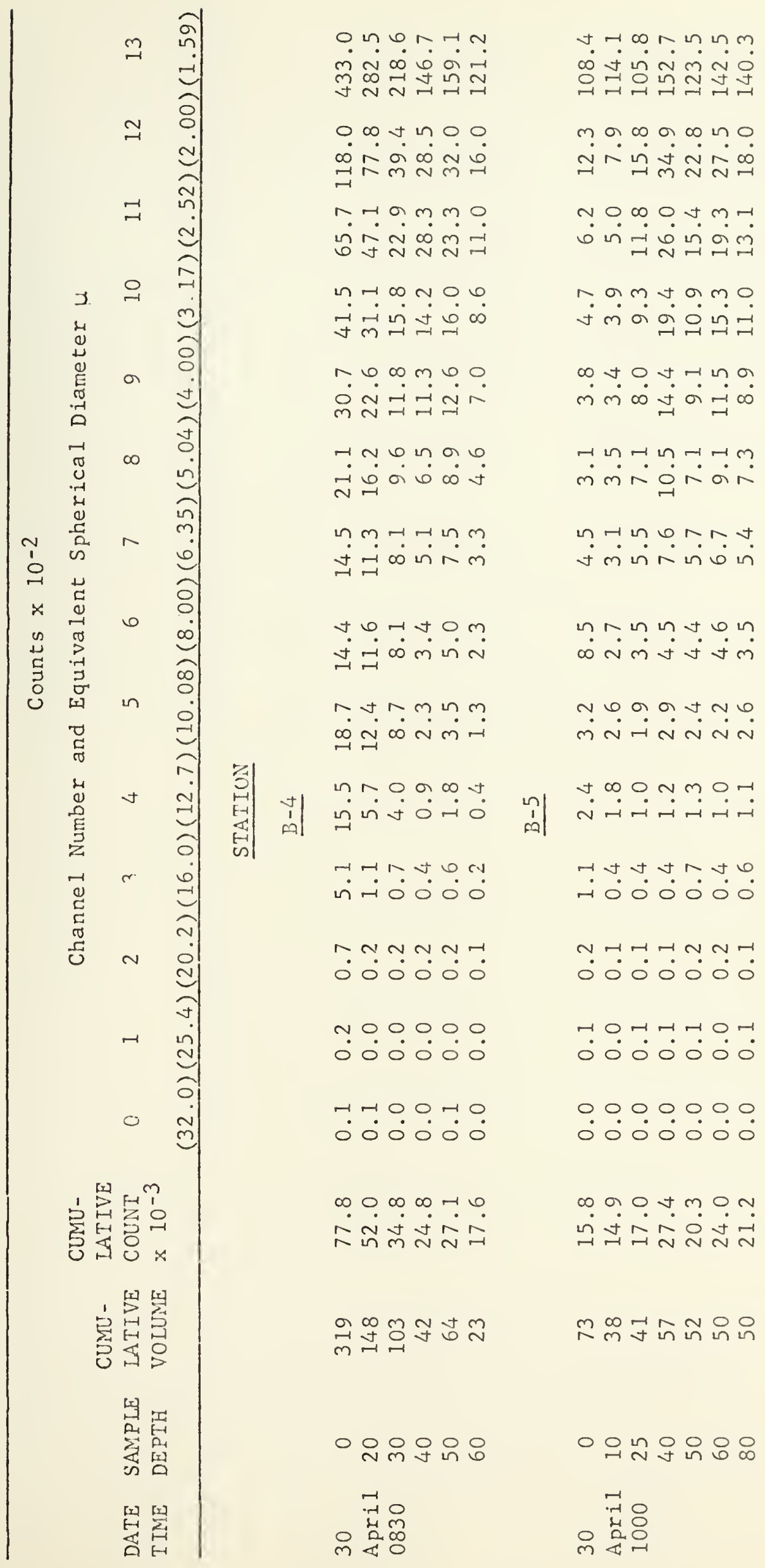





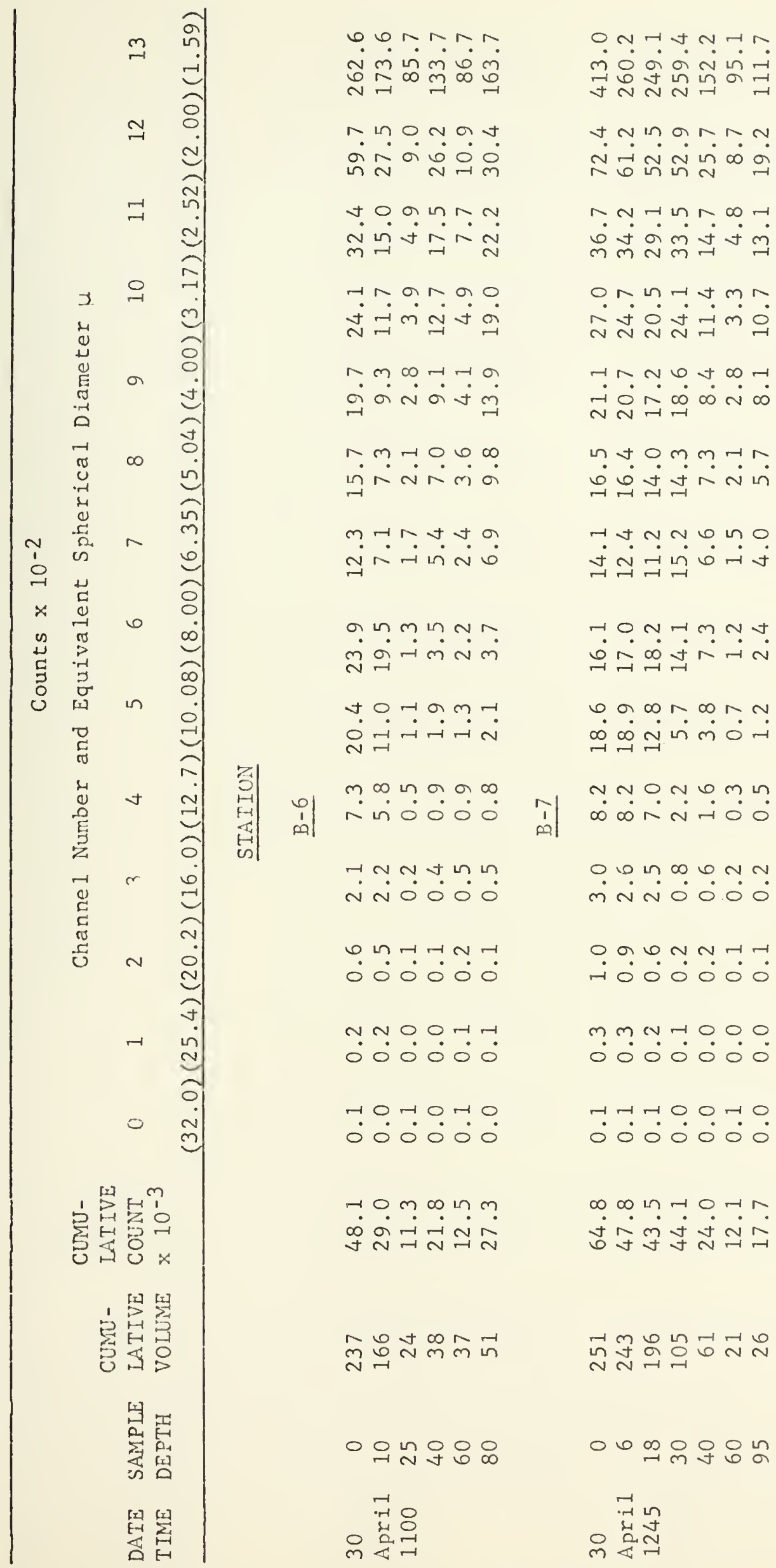





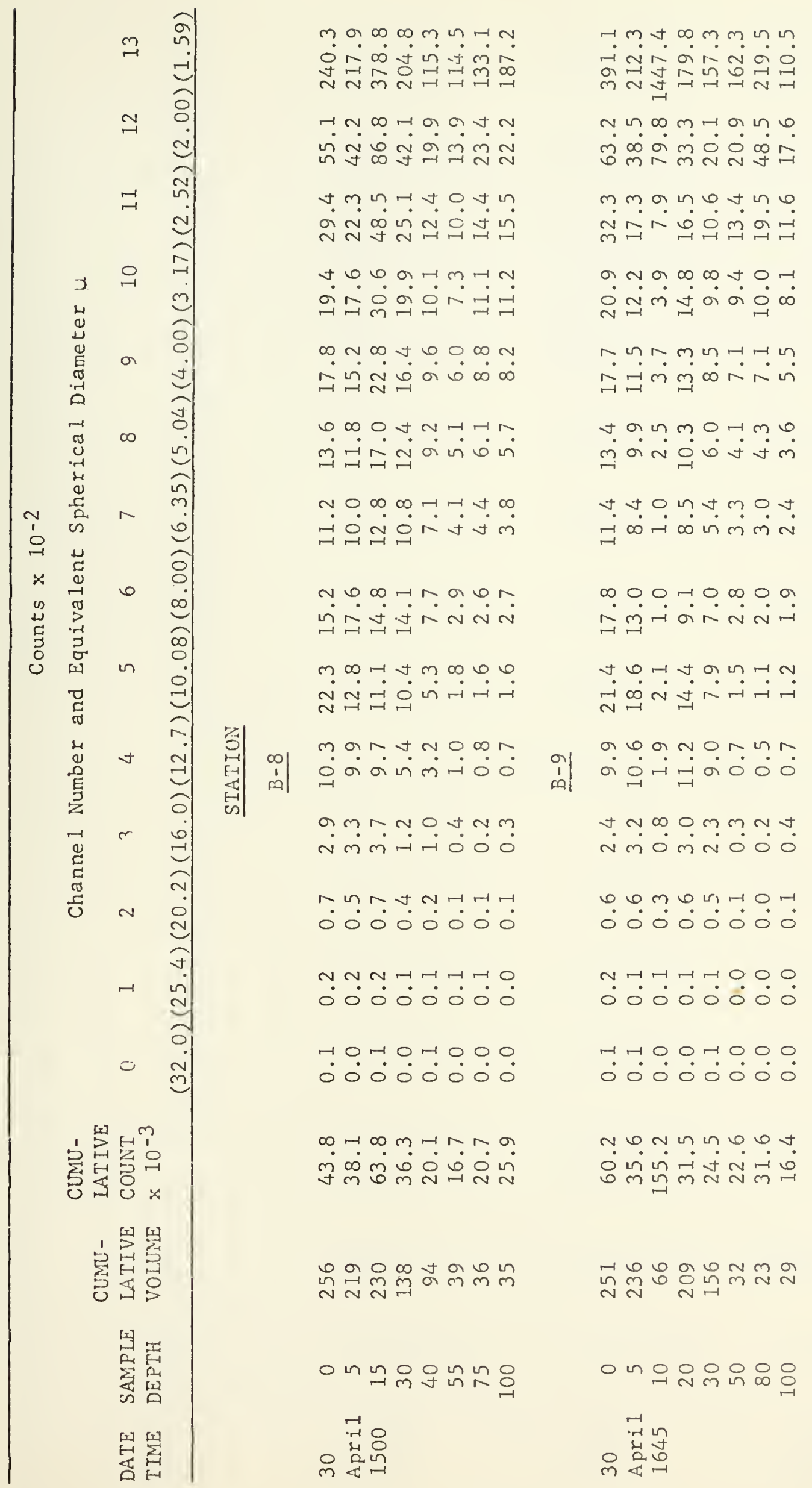





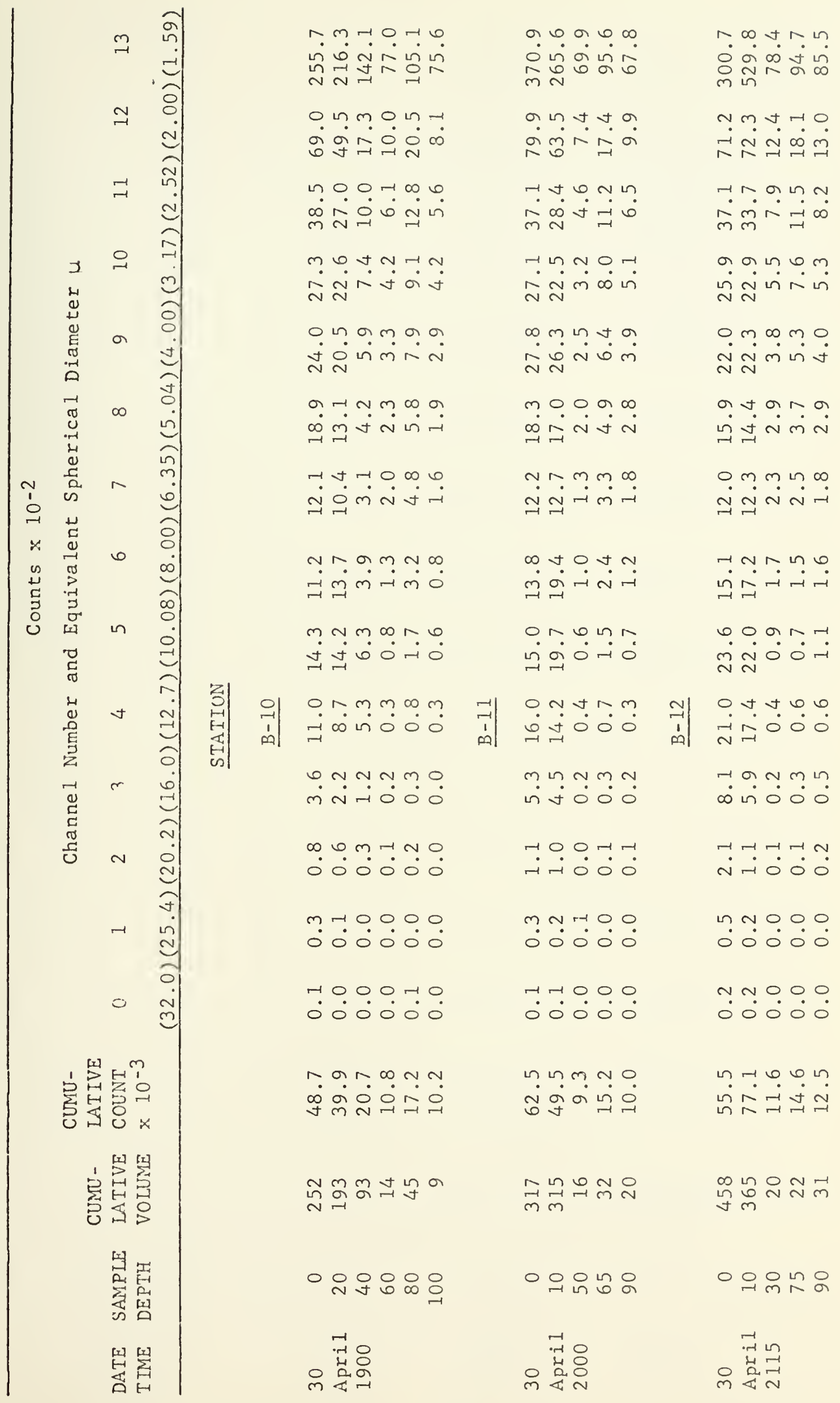





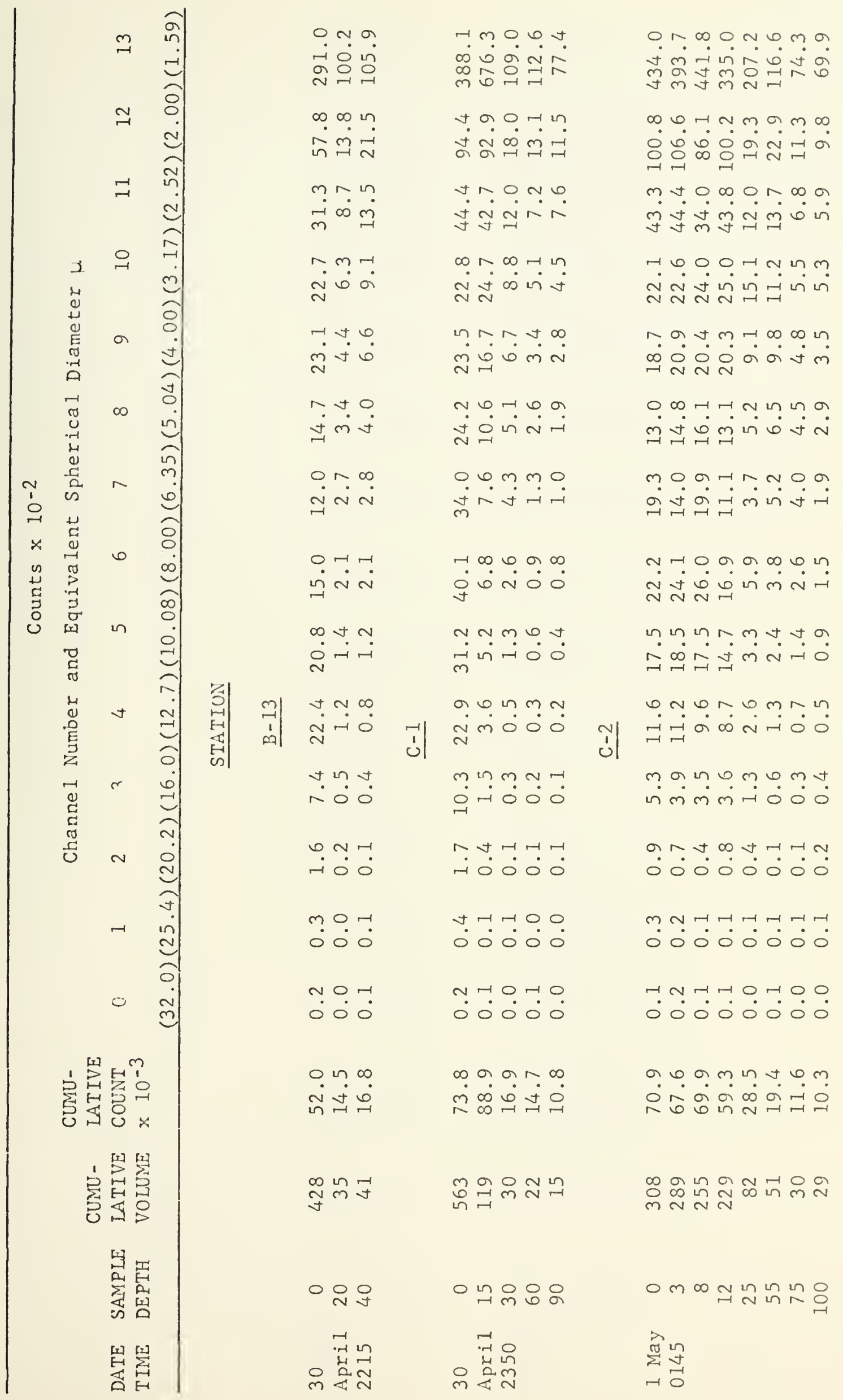





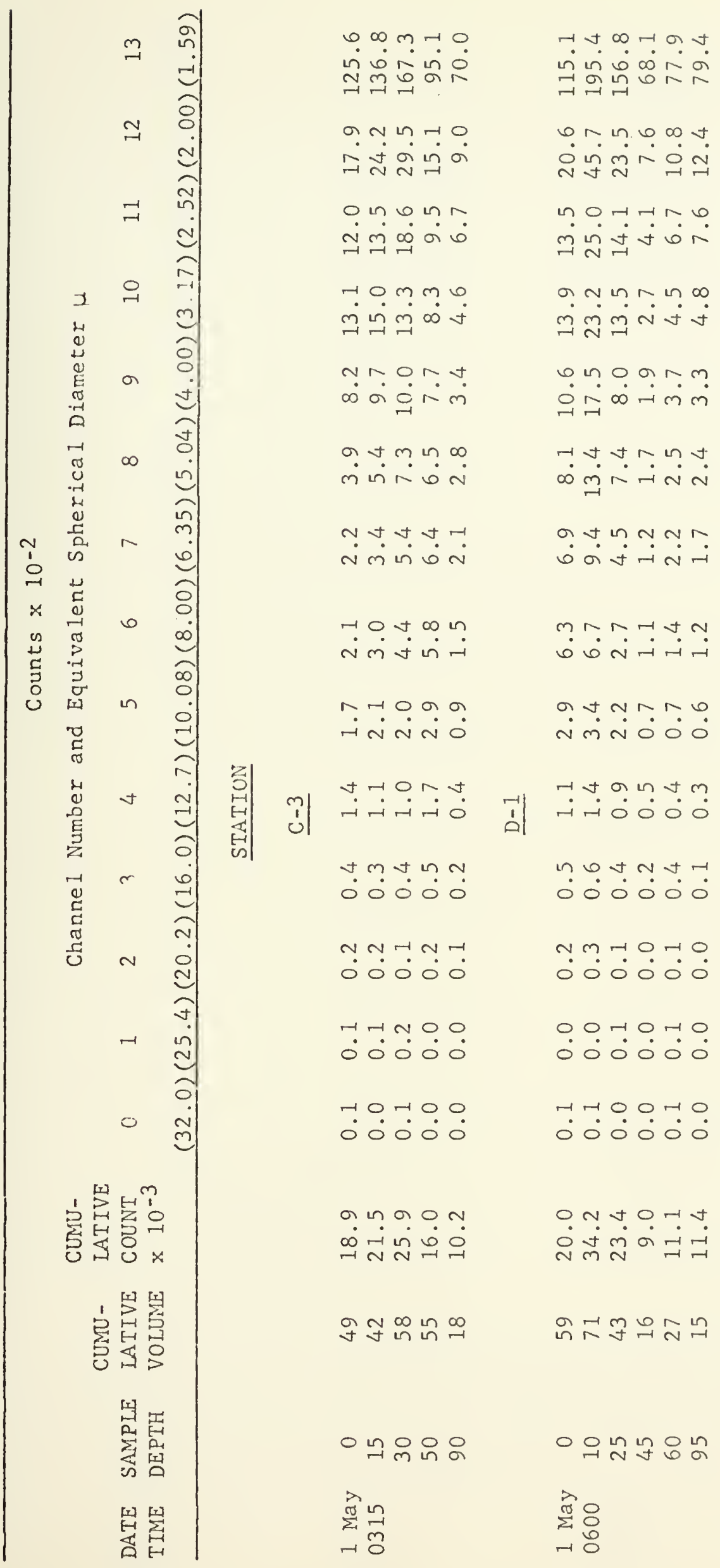





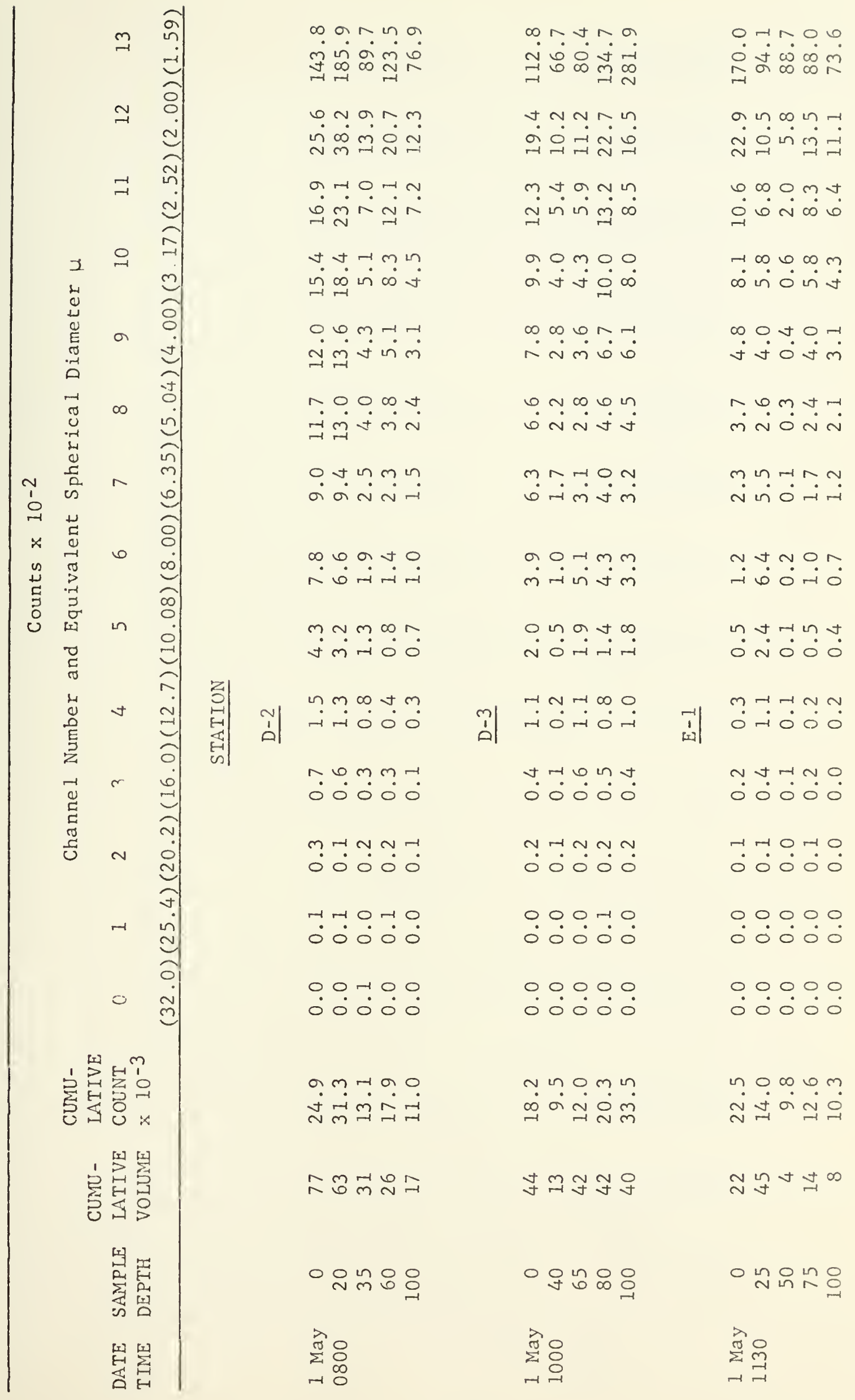





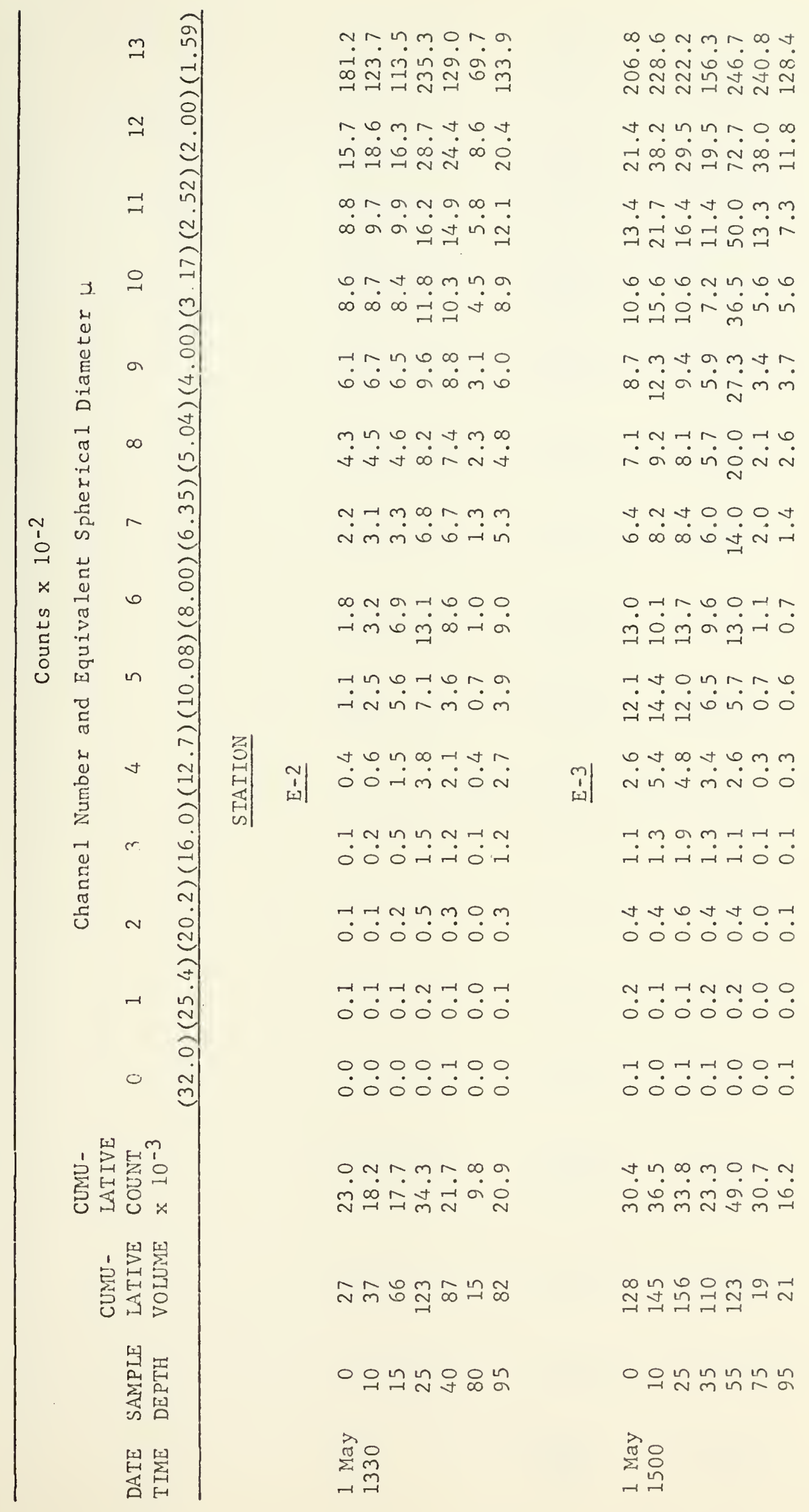





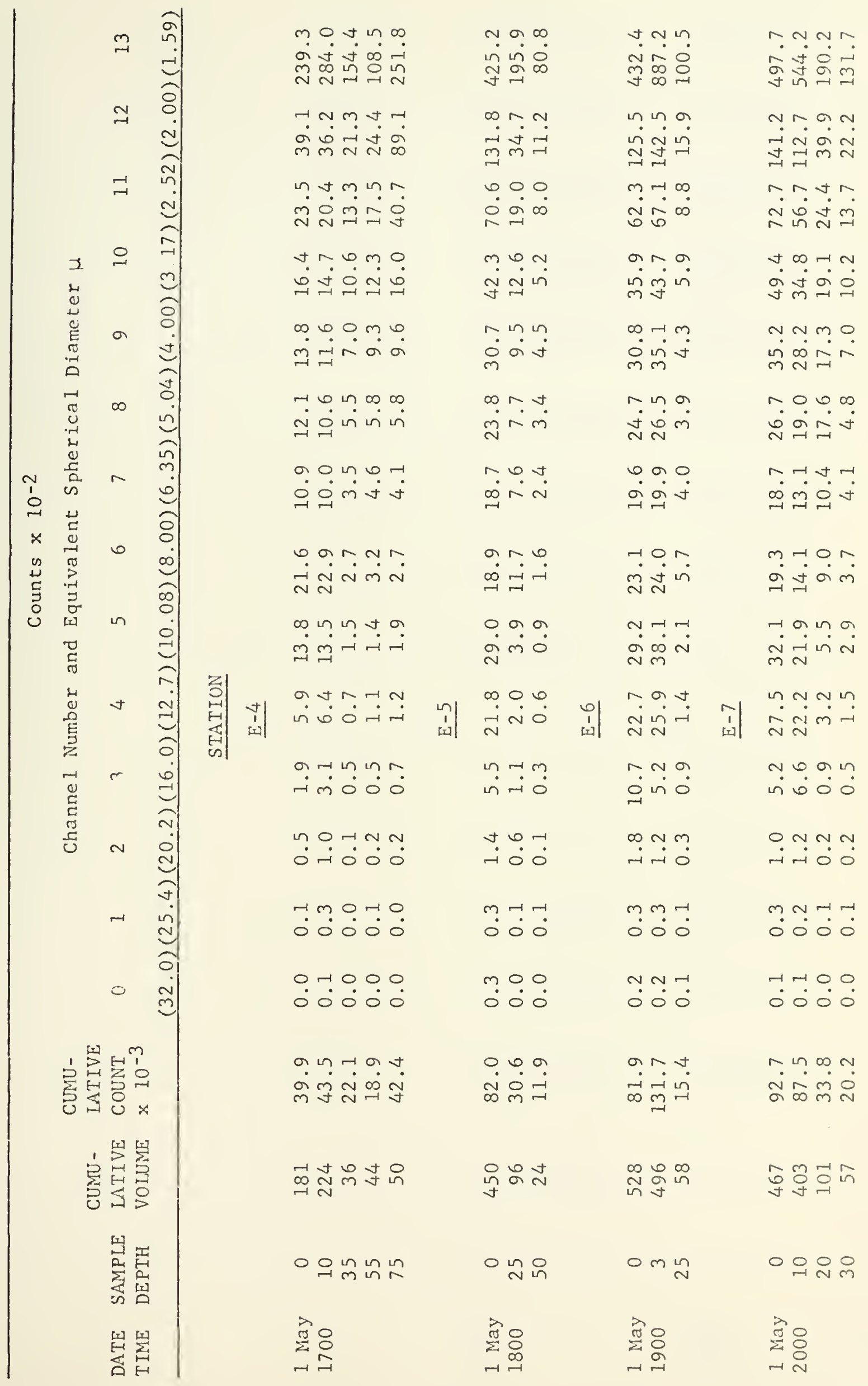





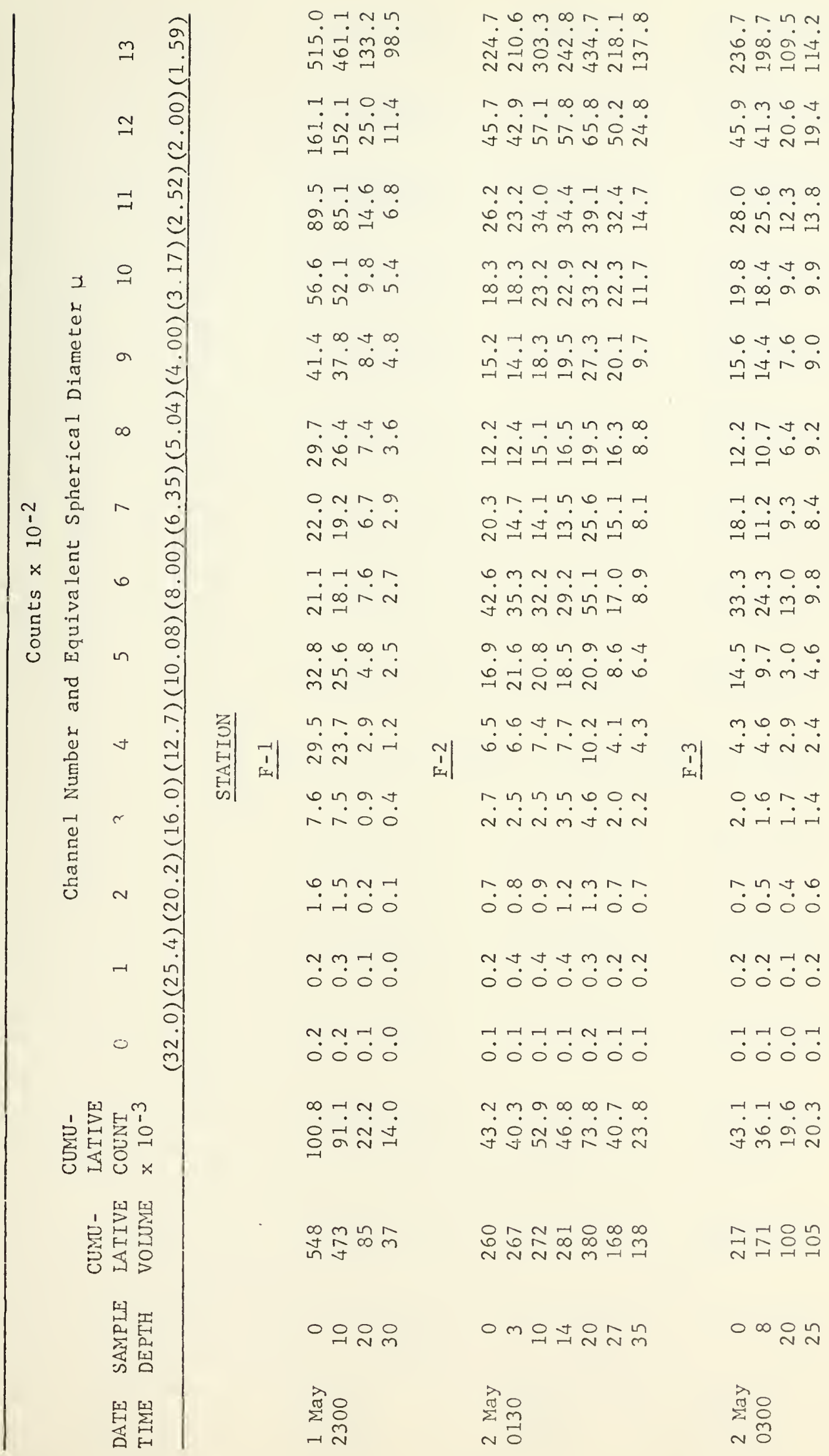





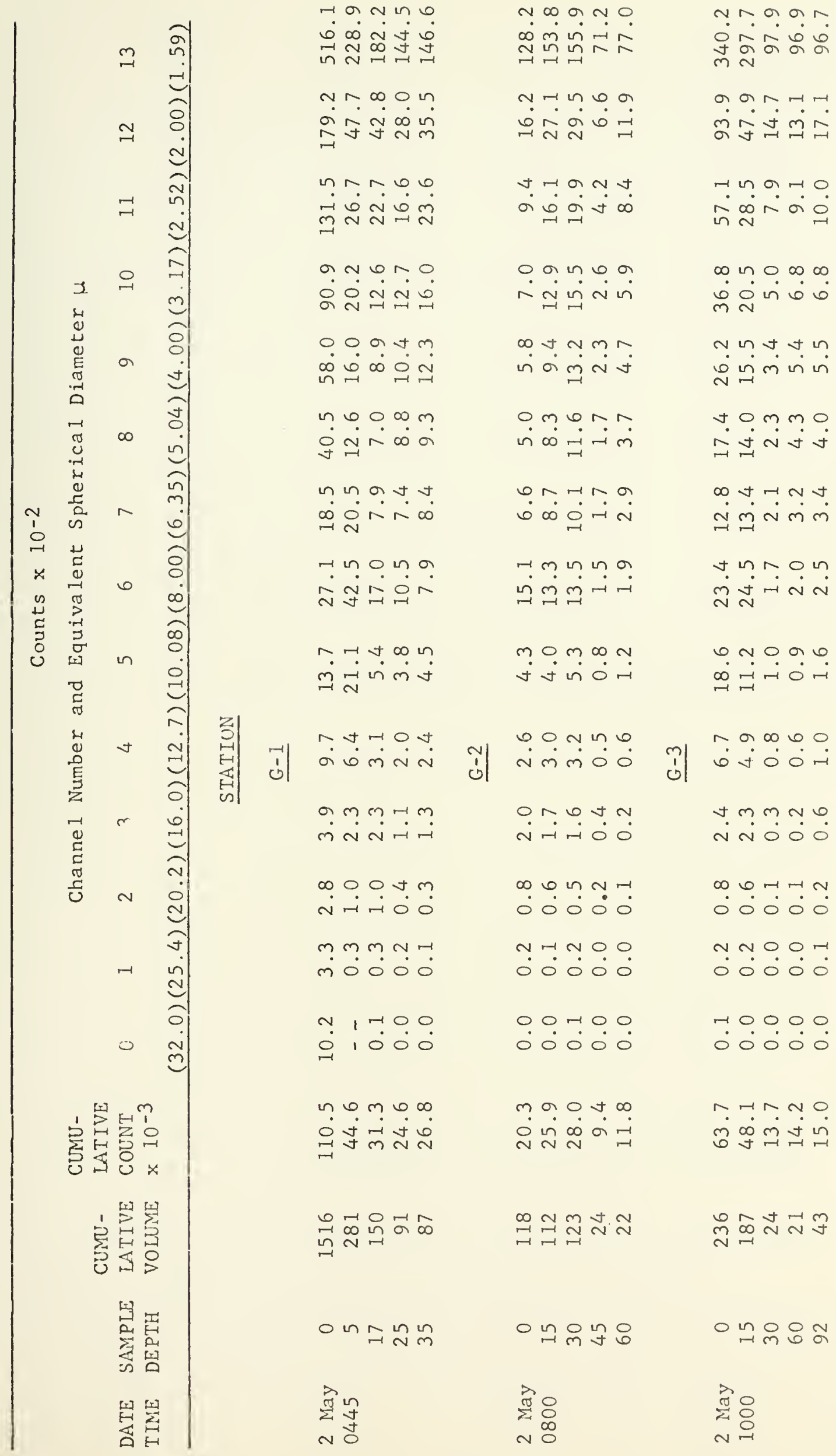





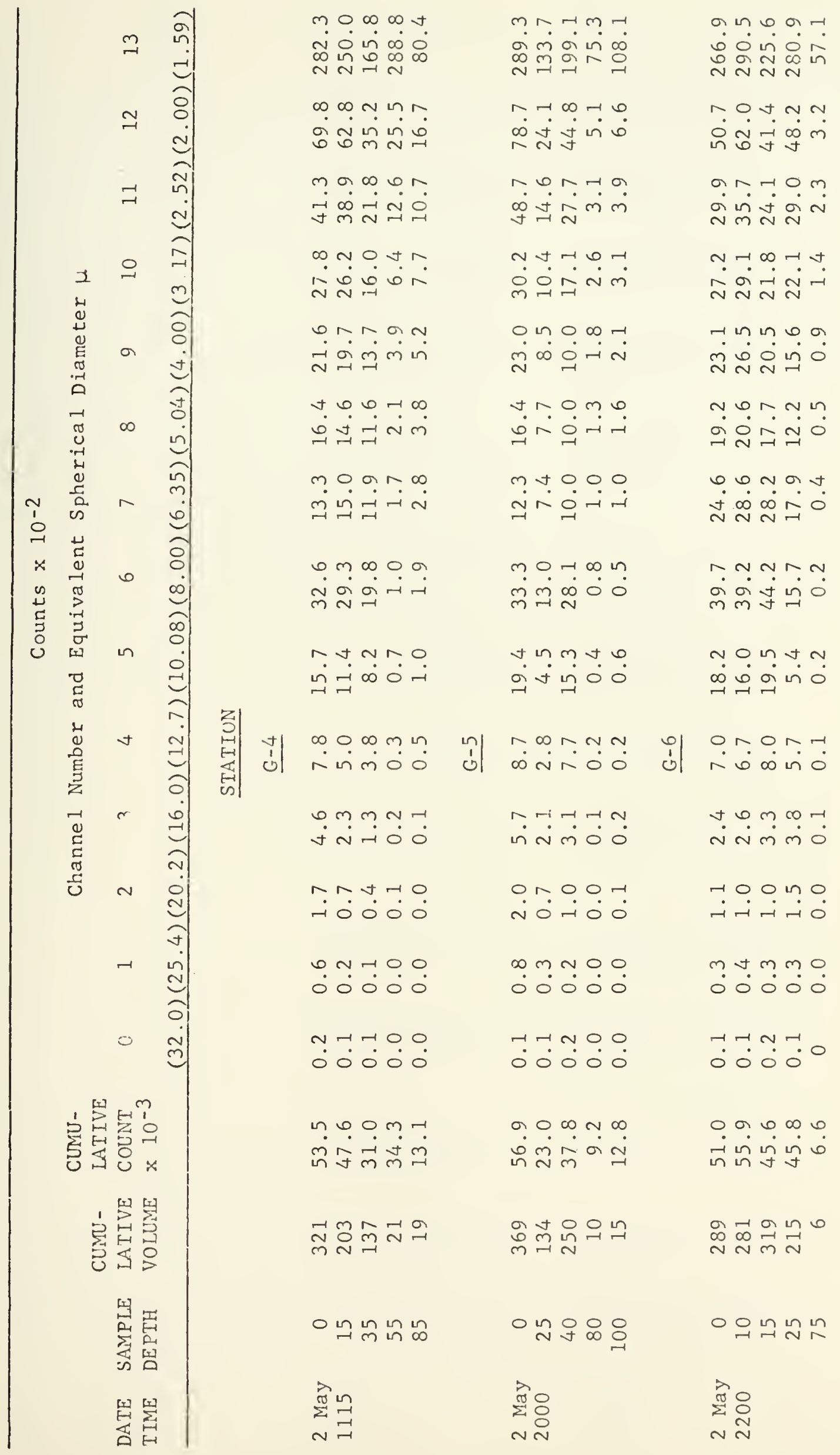





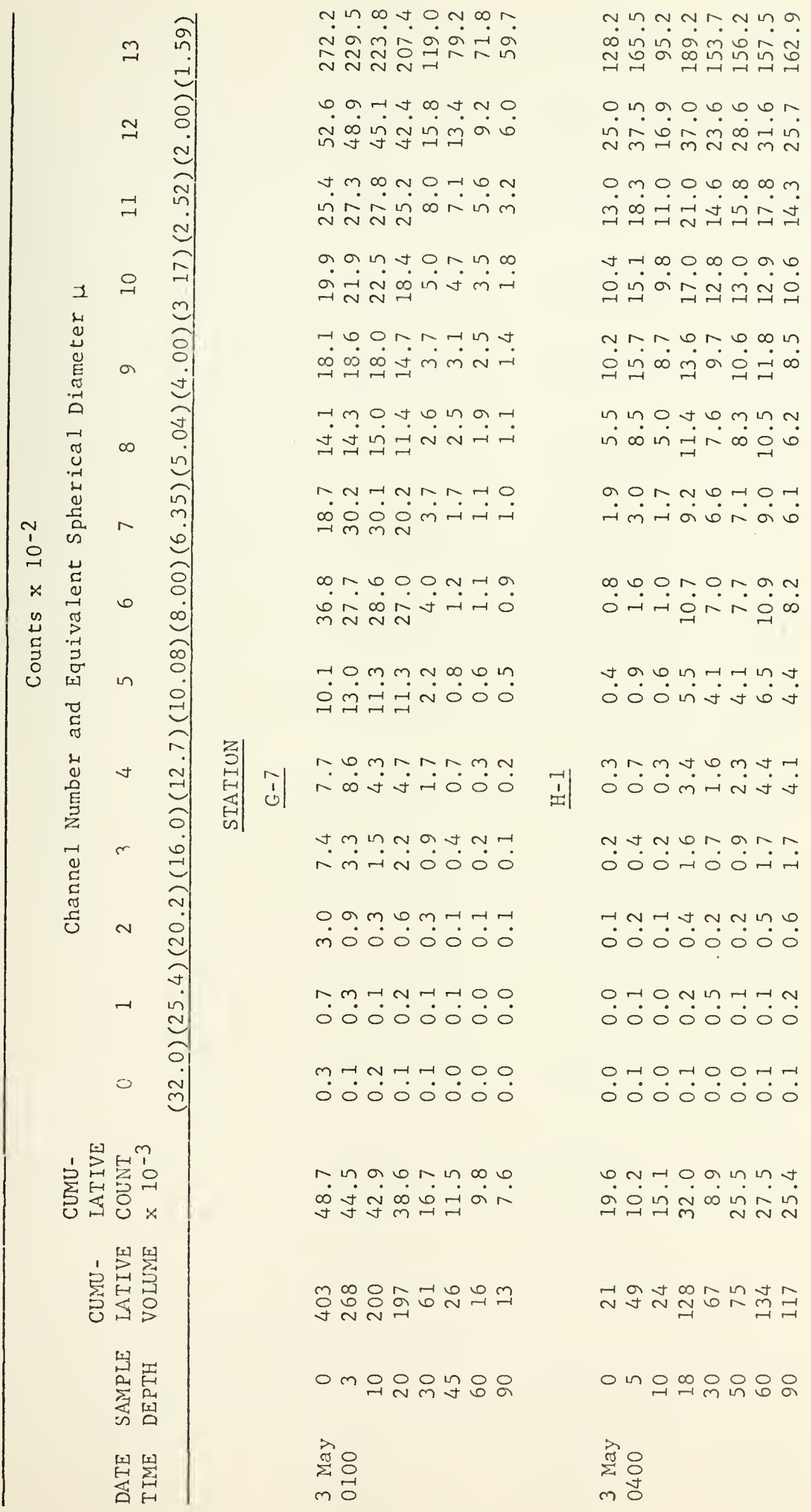





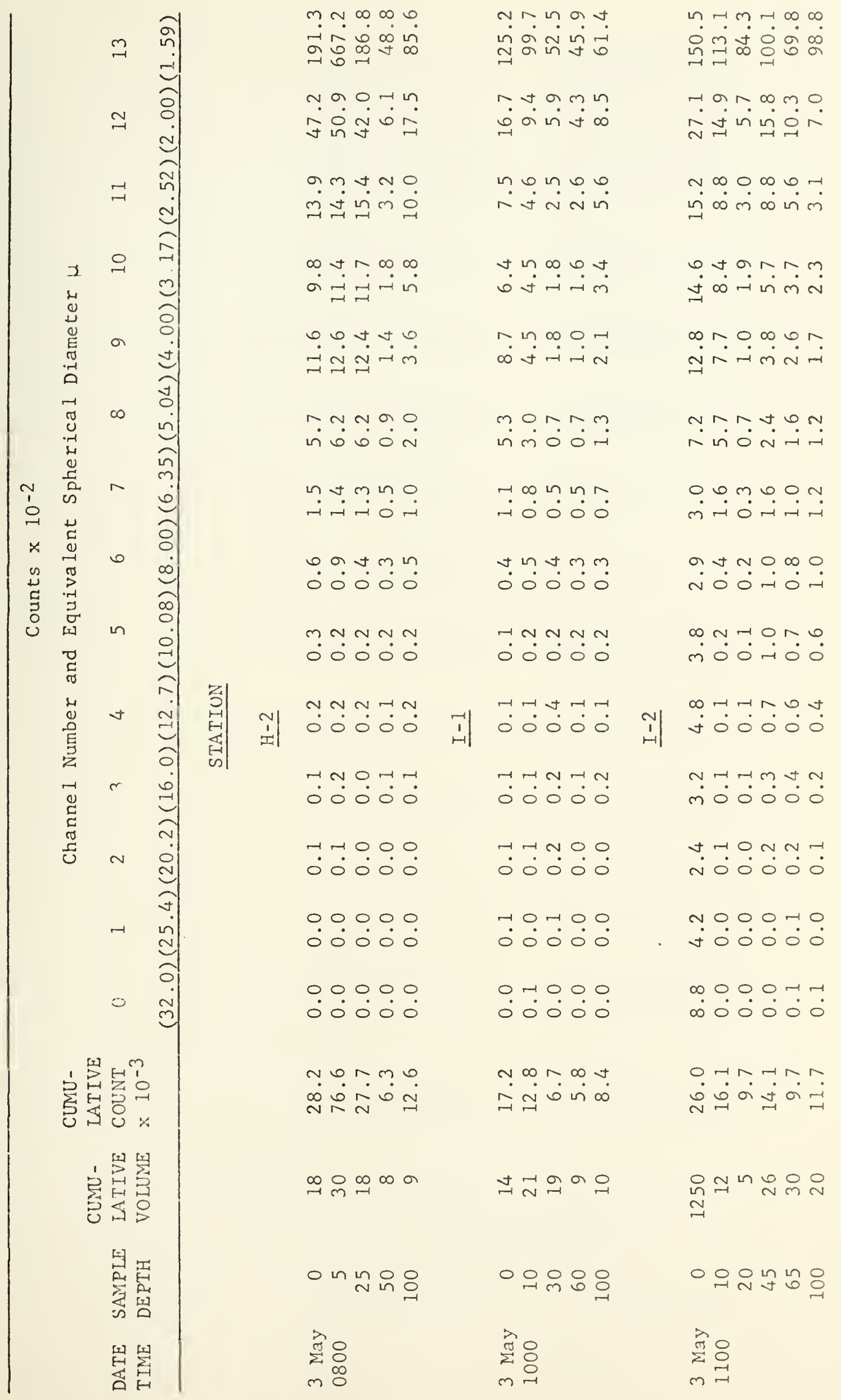





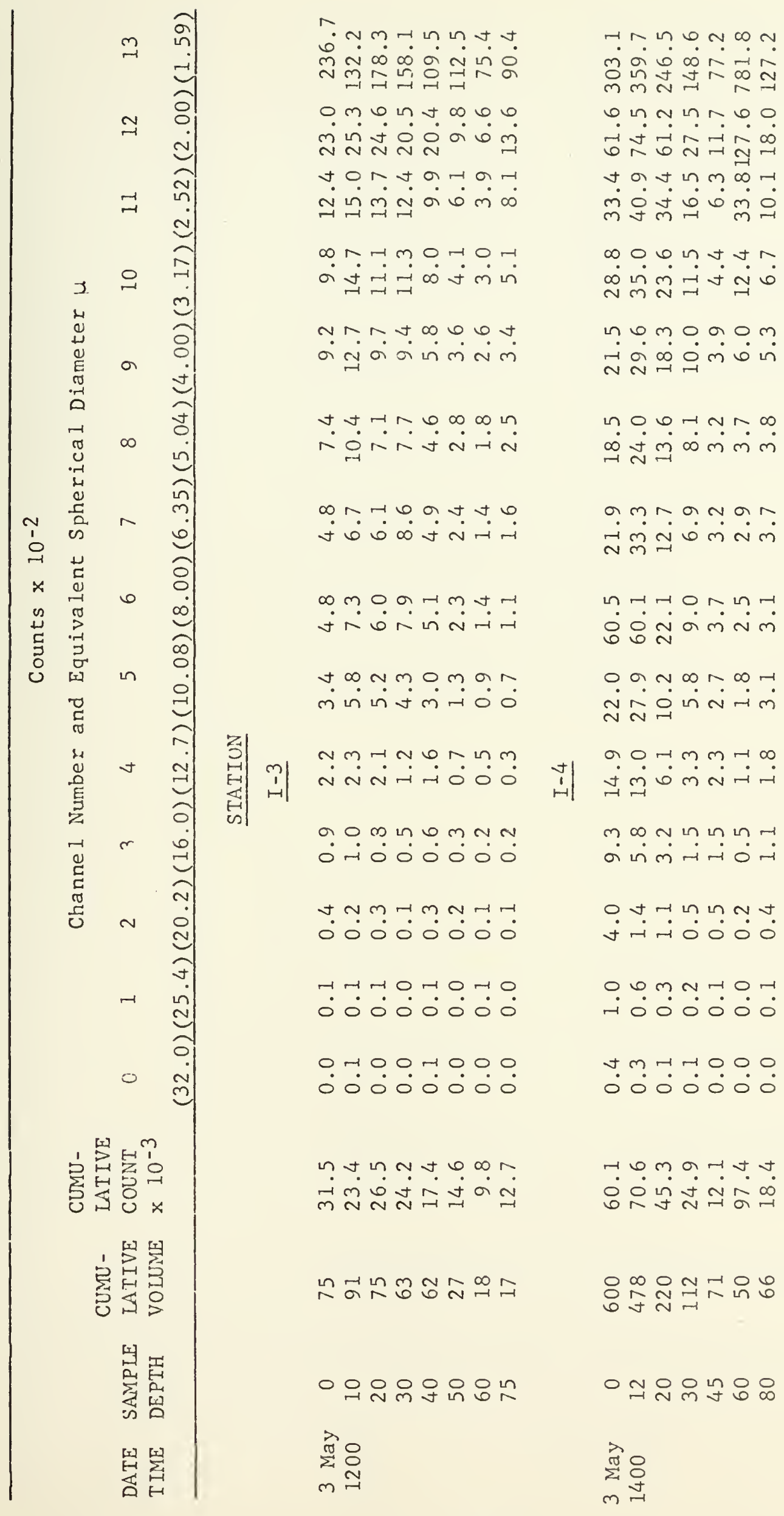





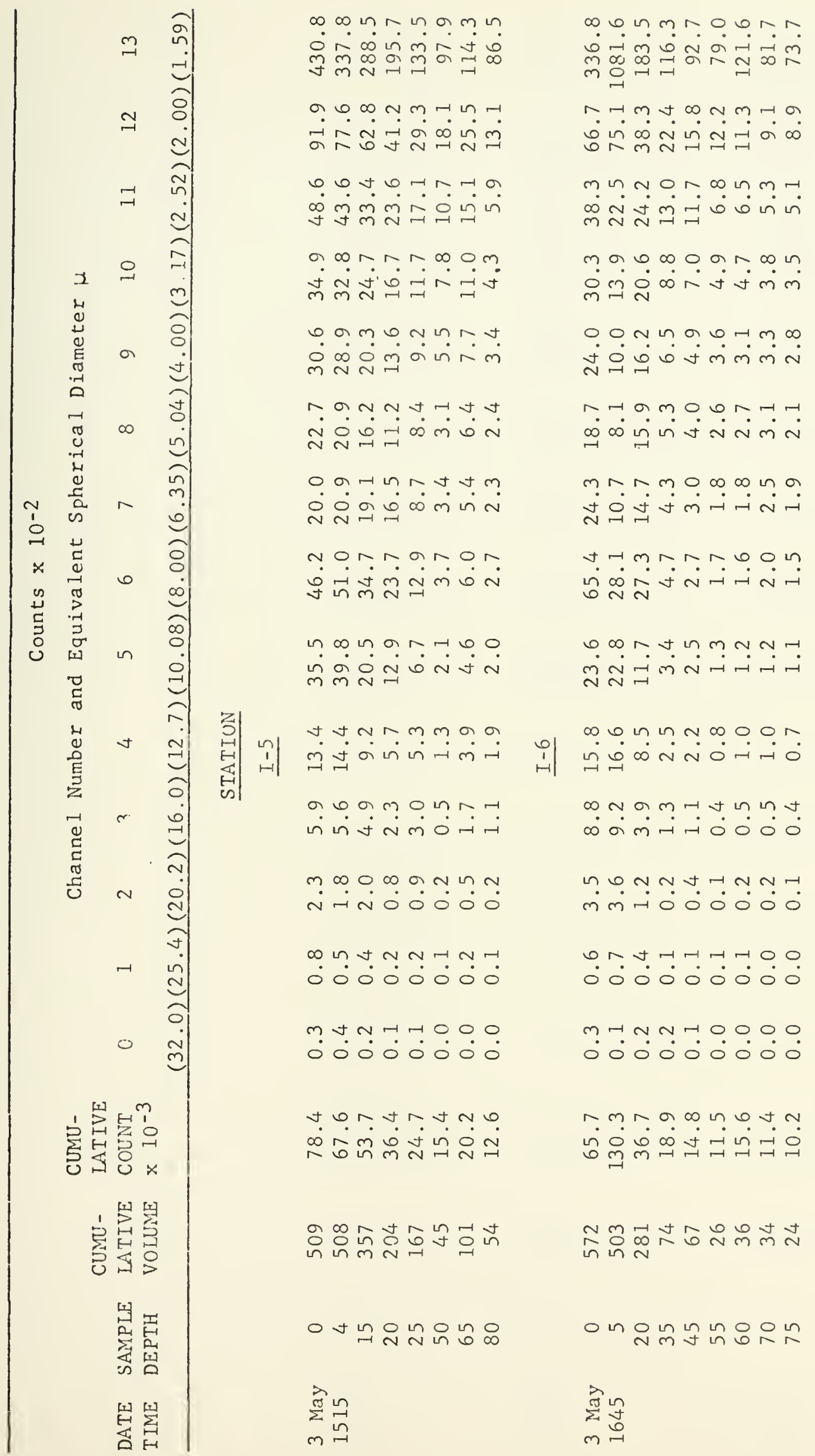





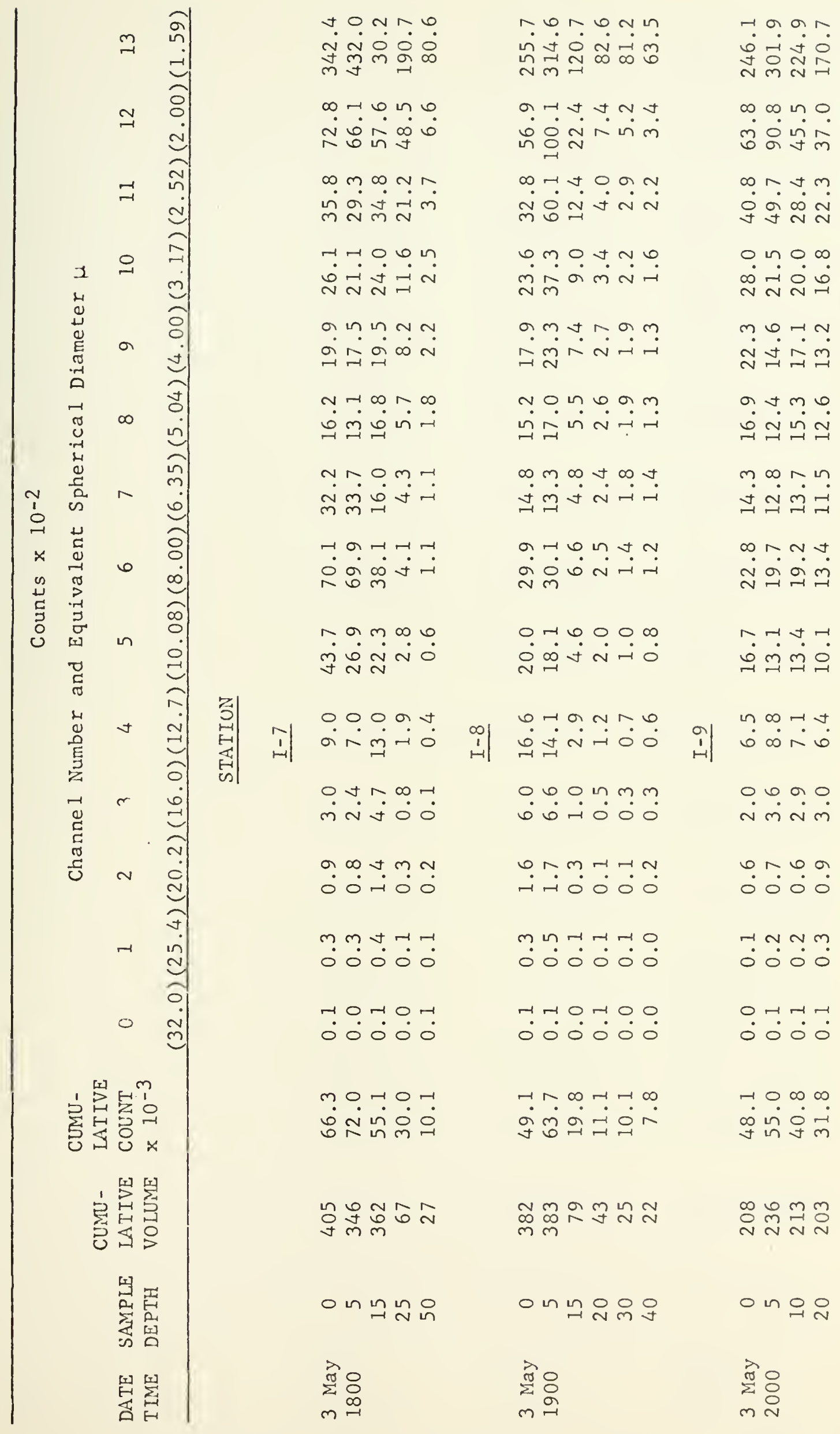





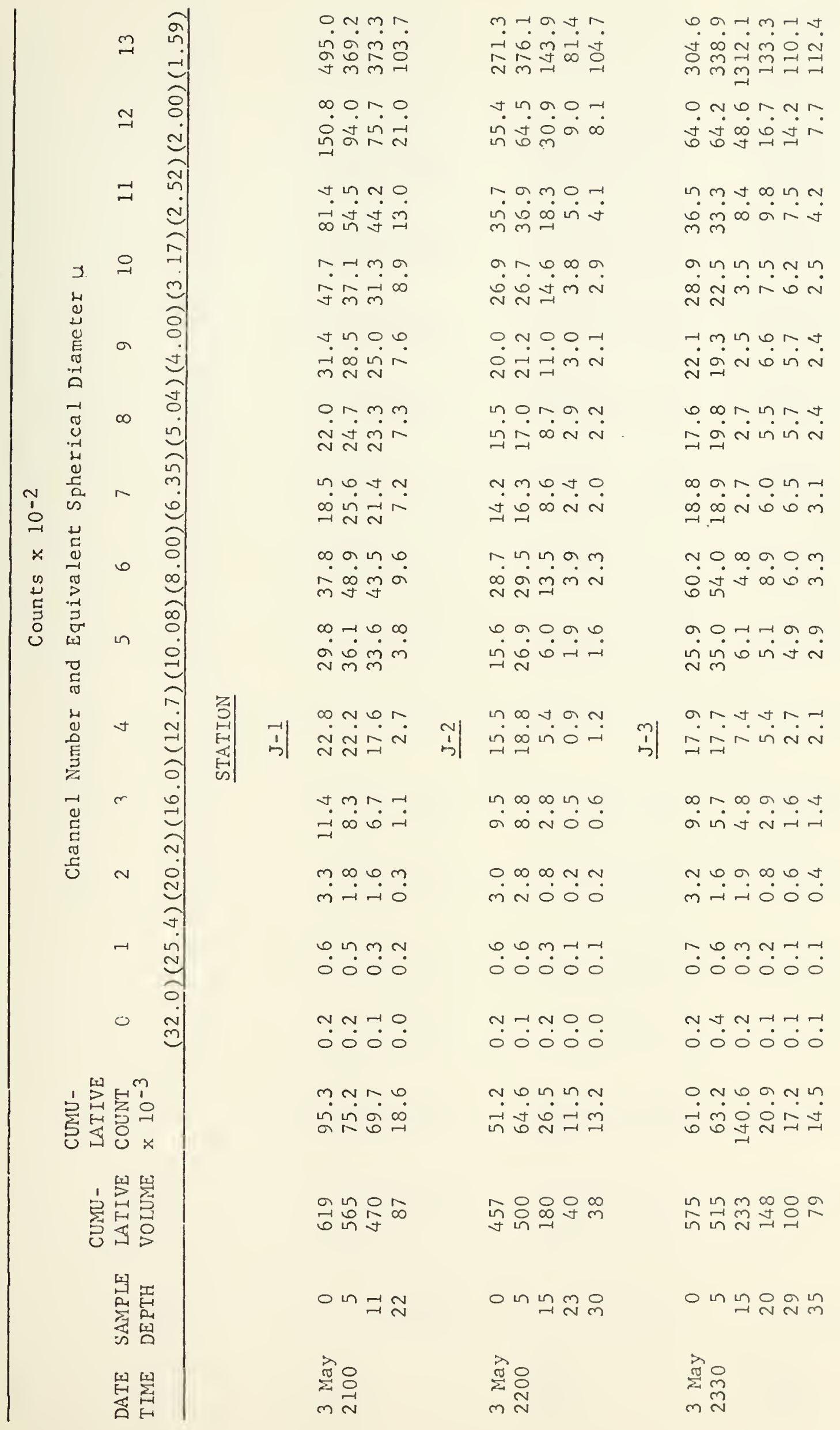





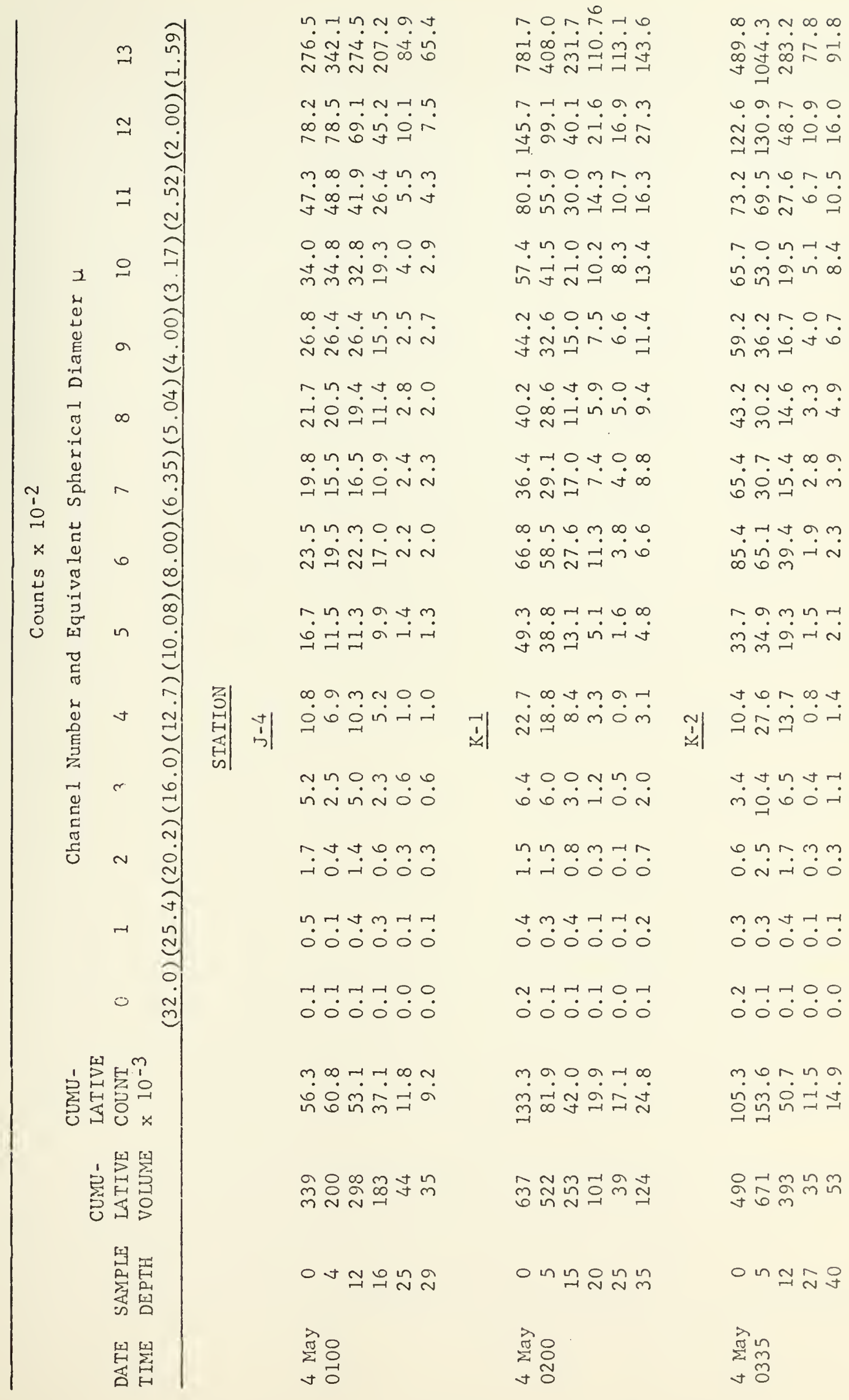



๑.

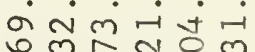
m $\mathrm{m}-\mathrm{f}$ 음

tom 0 on மำ $\dot{\sim} \dot{\sim}$

$\sim$ เn $\ln N \in$ in ษ $\dot{m} \ddot{\sim} \sim \dot{\sim} \dot{\sim}$

o a v in ma

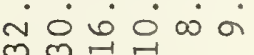

$\infty \infty \infty \forall-1$ vi $\underset{\sim}{\sim} \infty \dot{0}$ no oon inon mm 00 in

$\neg \infty \infty \wedge$ تن

a $t \infty \infty n+$ ம்

a on ont m) ข a 00000 บबN

nกa ma लंNO000

$\infty$ 는 0ं0் mற0

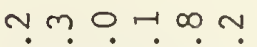

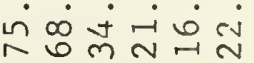

에ำำำ om 沓 am $\infty \circ m$ o बंत्रं० on $\mathrm{m} N \sim \infty$

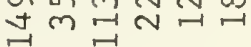

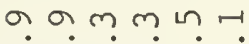
जिंलें में ㅇำ on $⿻$ t ஸें ๓

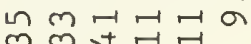

ก ก $\dot{0} \dot{\sim} \dot{m} \dot{\infty}$

$\infty$ am iं $n \infty m m$ J i $\dot{0} 0$ in m ด $N$ แn $\infty$ in

n $1 \mathrm{~N} N \mathrm{~m}$ ते

n, t 1
$\vdots$
$\vdots$ $\dot{\sim} \dot{\sim} \dot{\sim} \dot{\sim}$

namn ○ं

N 17 N ○ 10000

- 1 m. $\circ 10000$

N na ONn $\infty \tilde{\omega}$

mกษ mก ำ

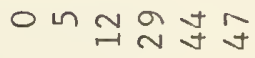

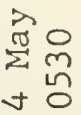

. . . . . . in $m \sim \mathscr{I}+\infty$

90,00 in

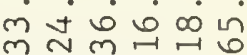

m $t$ r 0 in m 윔 $\infty \mathrm{Nm}$ a $\mathrm{n} m$

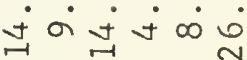
ษ $\infty \cup 6$,

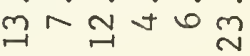
om $\mathrm{mon}$ चN

$\pi$ แก $น$ แ 슴

Tオ ๗슴

ก $า$ แก $m$ เก 음ำ

nomana

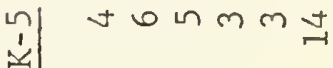

ง $\sim m \sim \sim \infty$

ot $0 \mathrm{n}$ un $\infty$ मिम

กงกคน $\dot{\circ} \dot{0} \dot{0} \dot{0} 0$

พขนดน ○ं 0000

mon $\infty \circ \mathrm{N}$

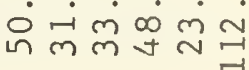

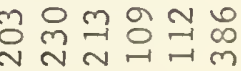

เ

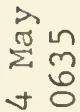





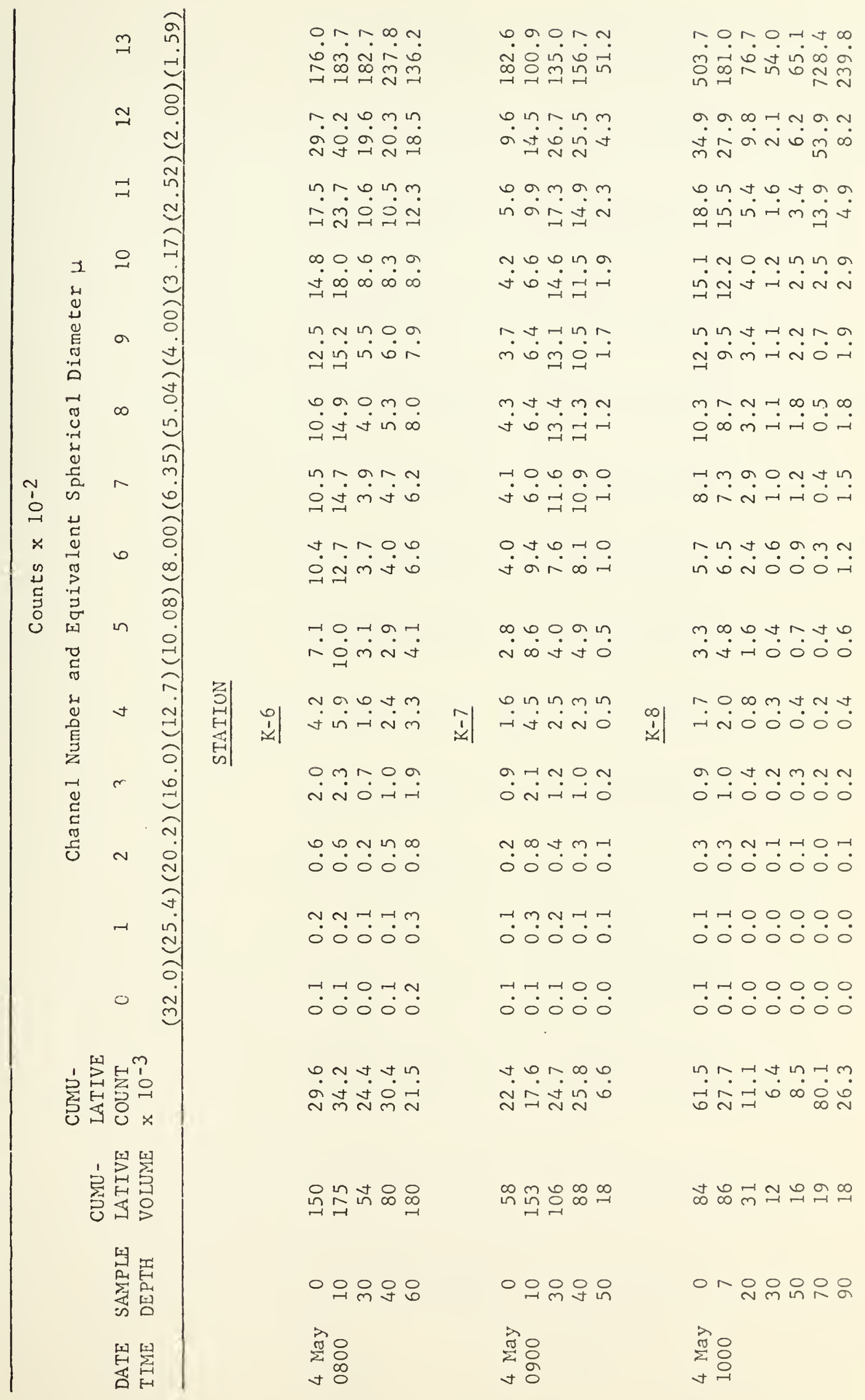





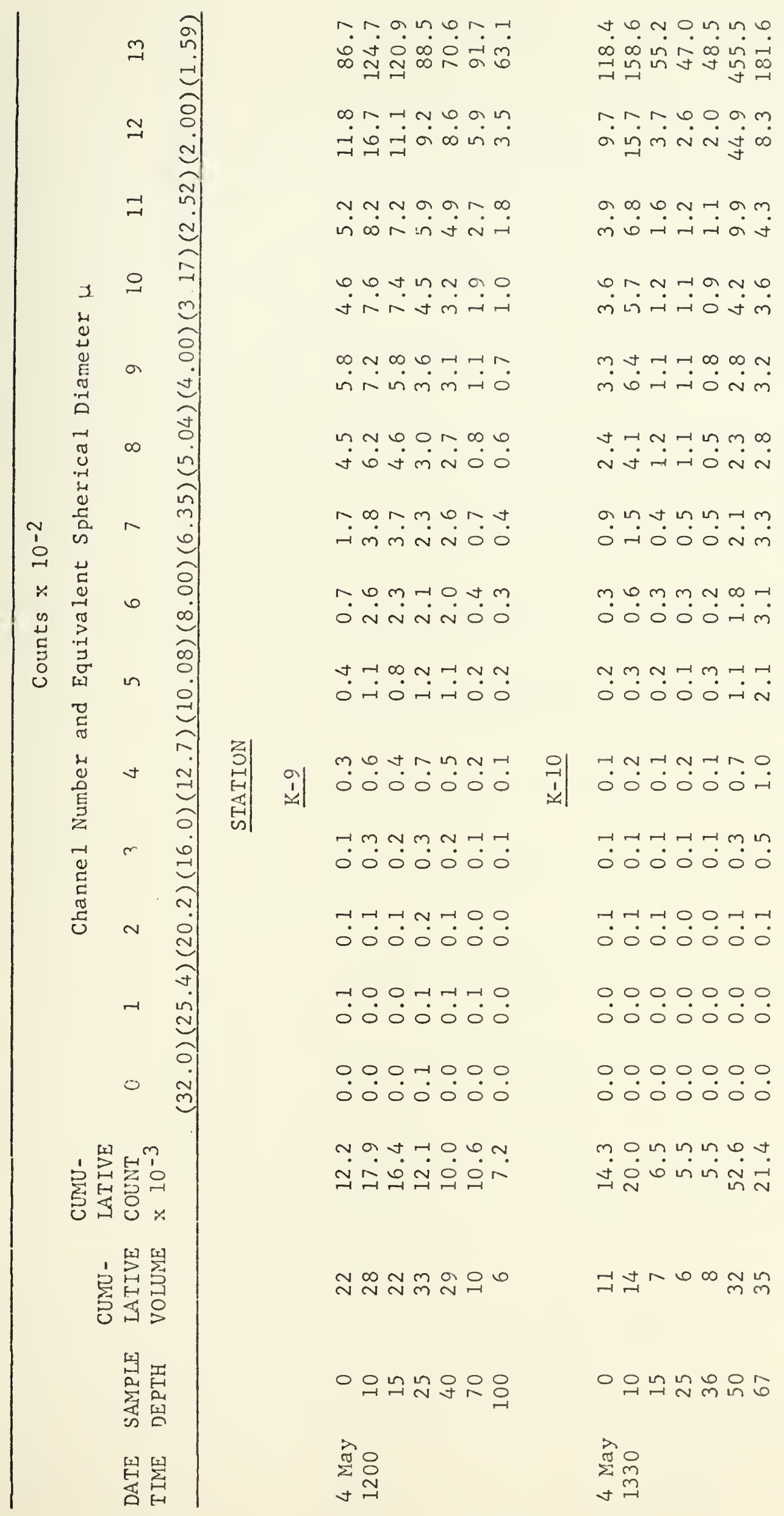





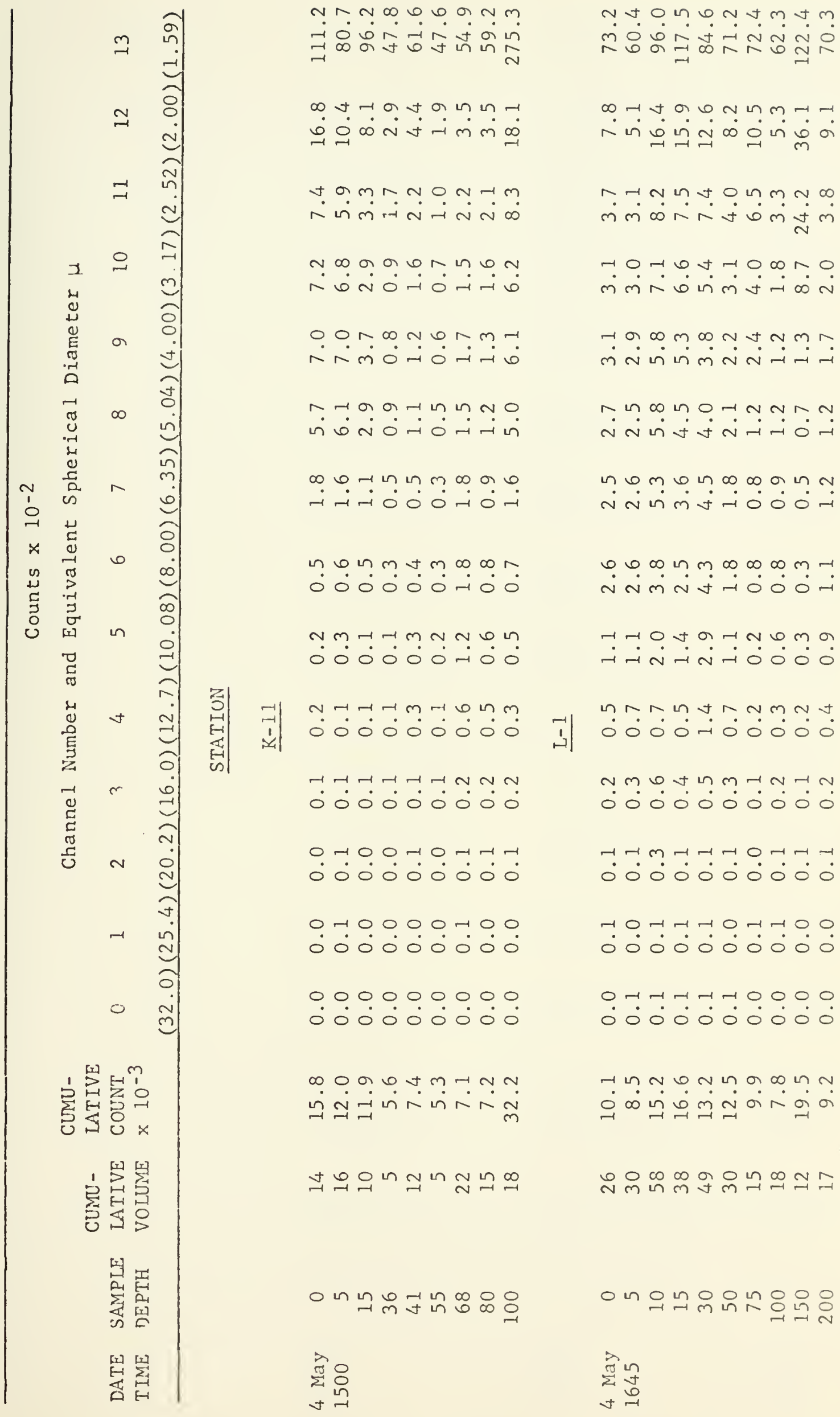





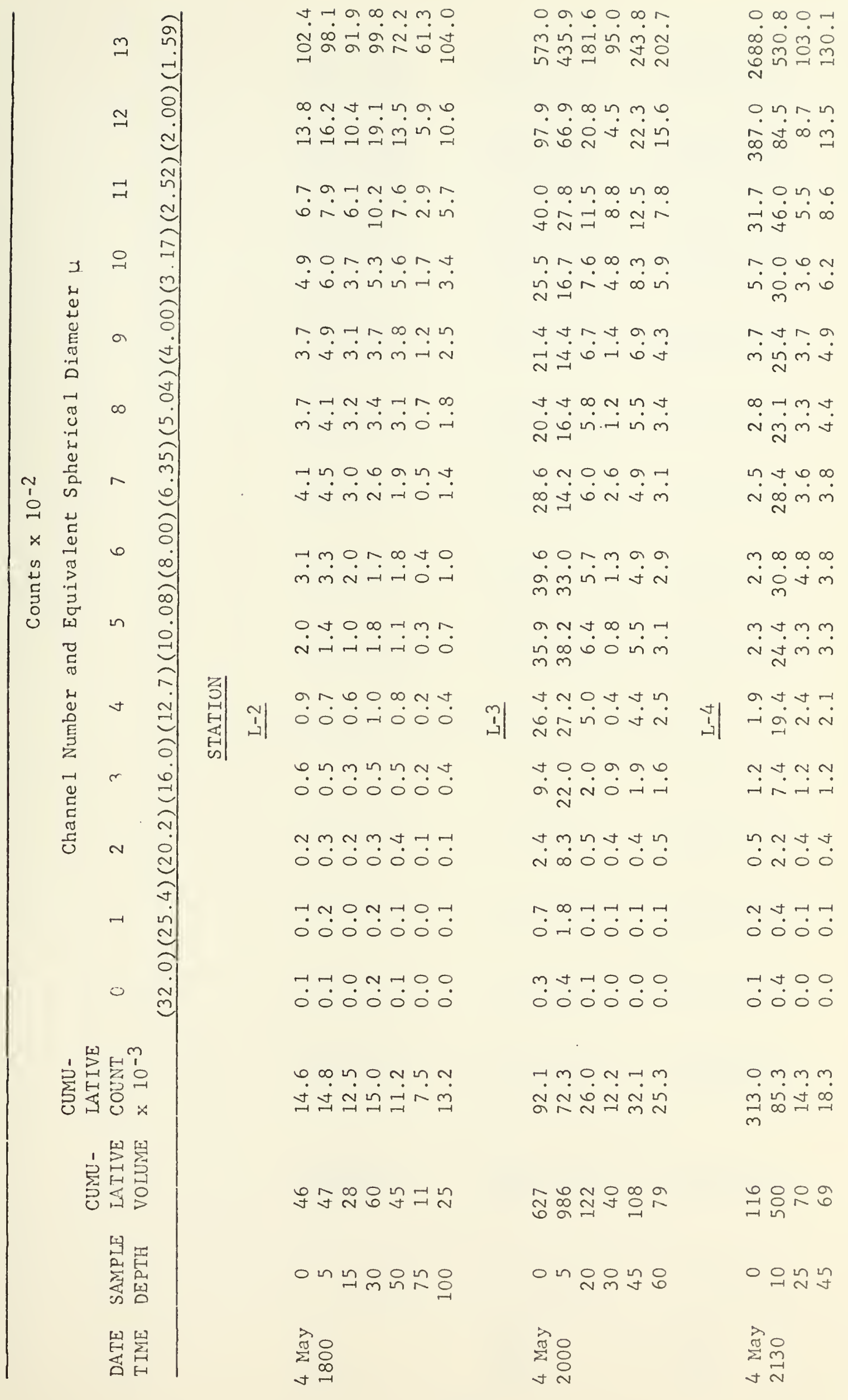





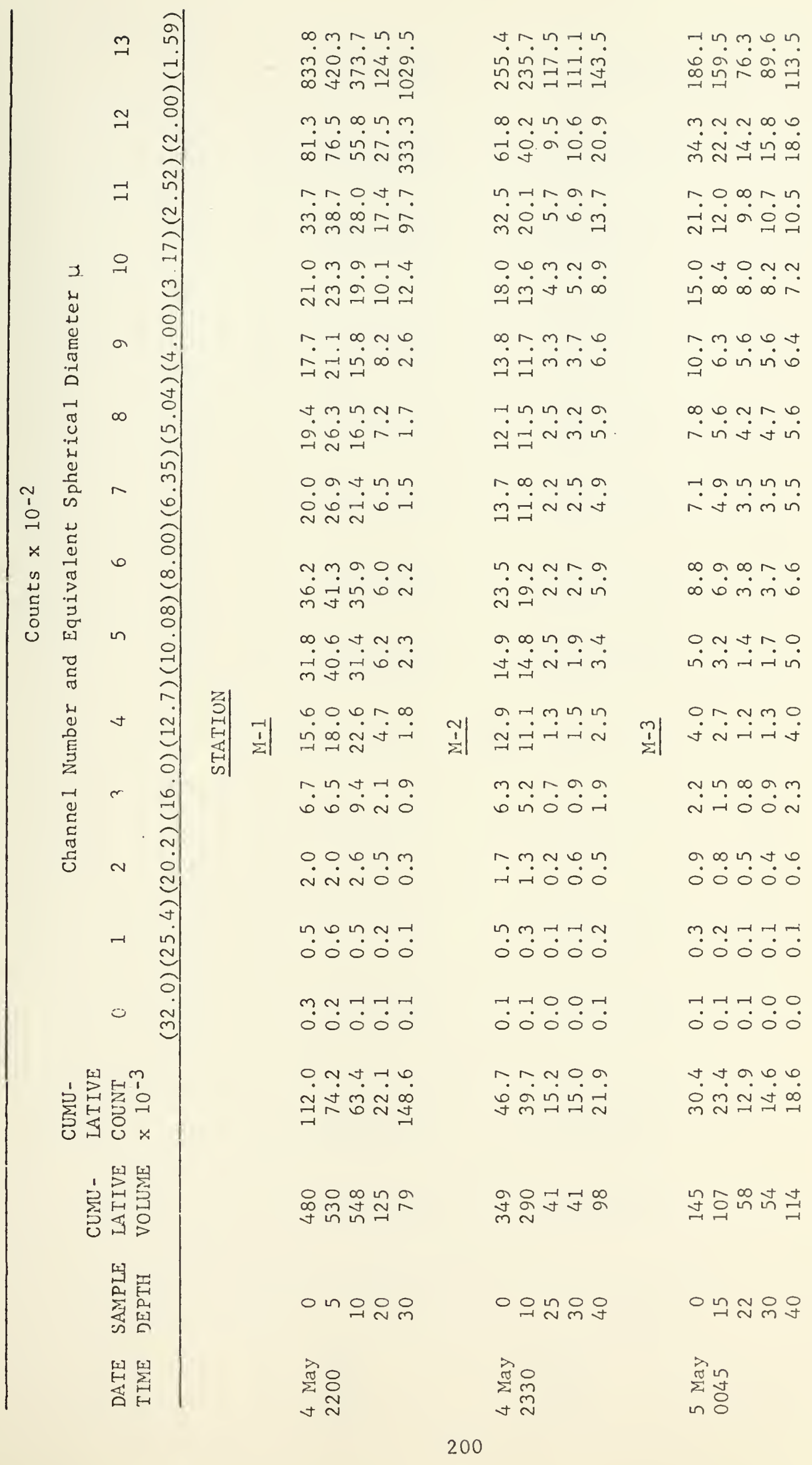





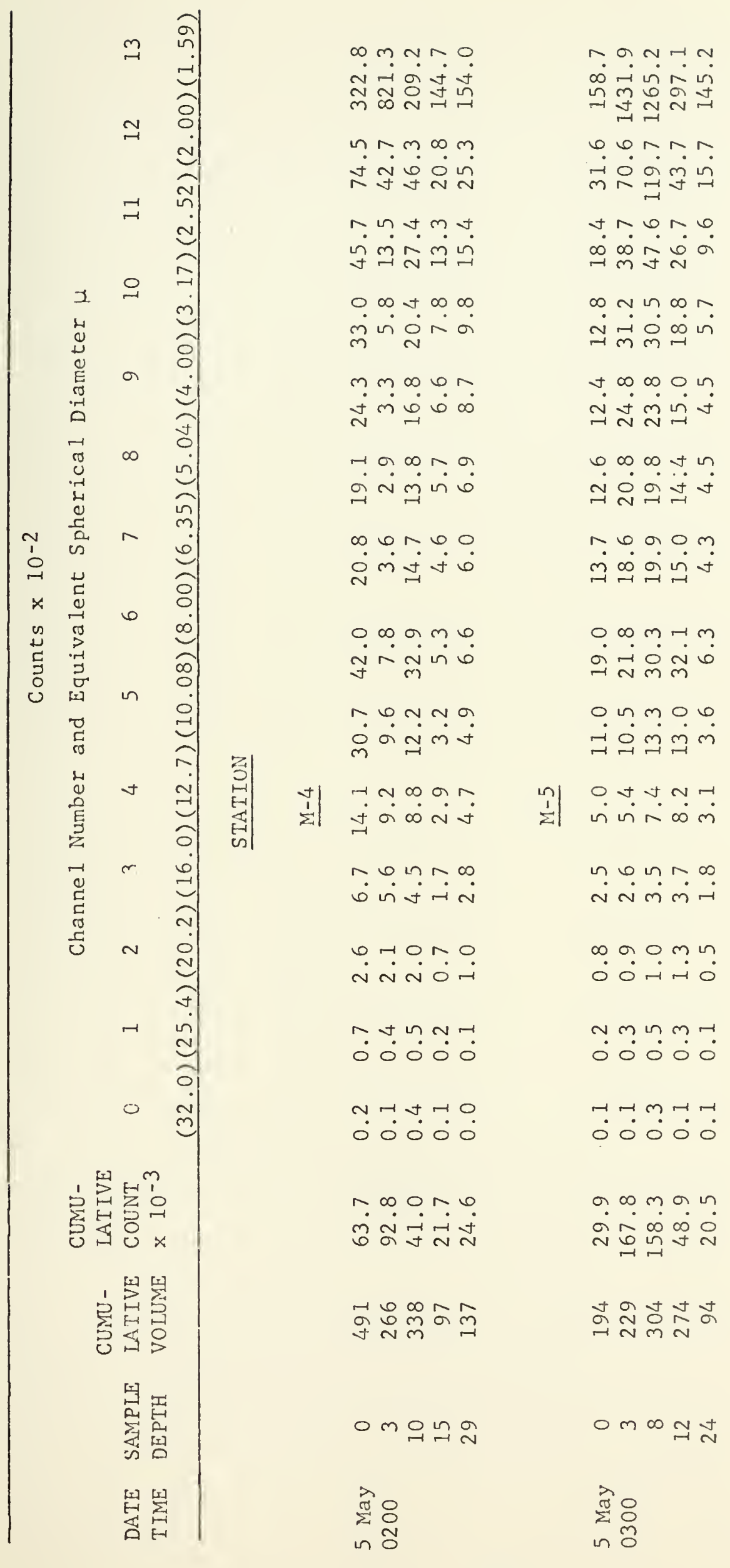





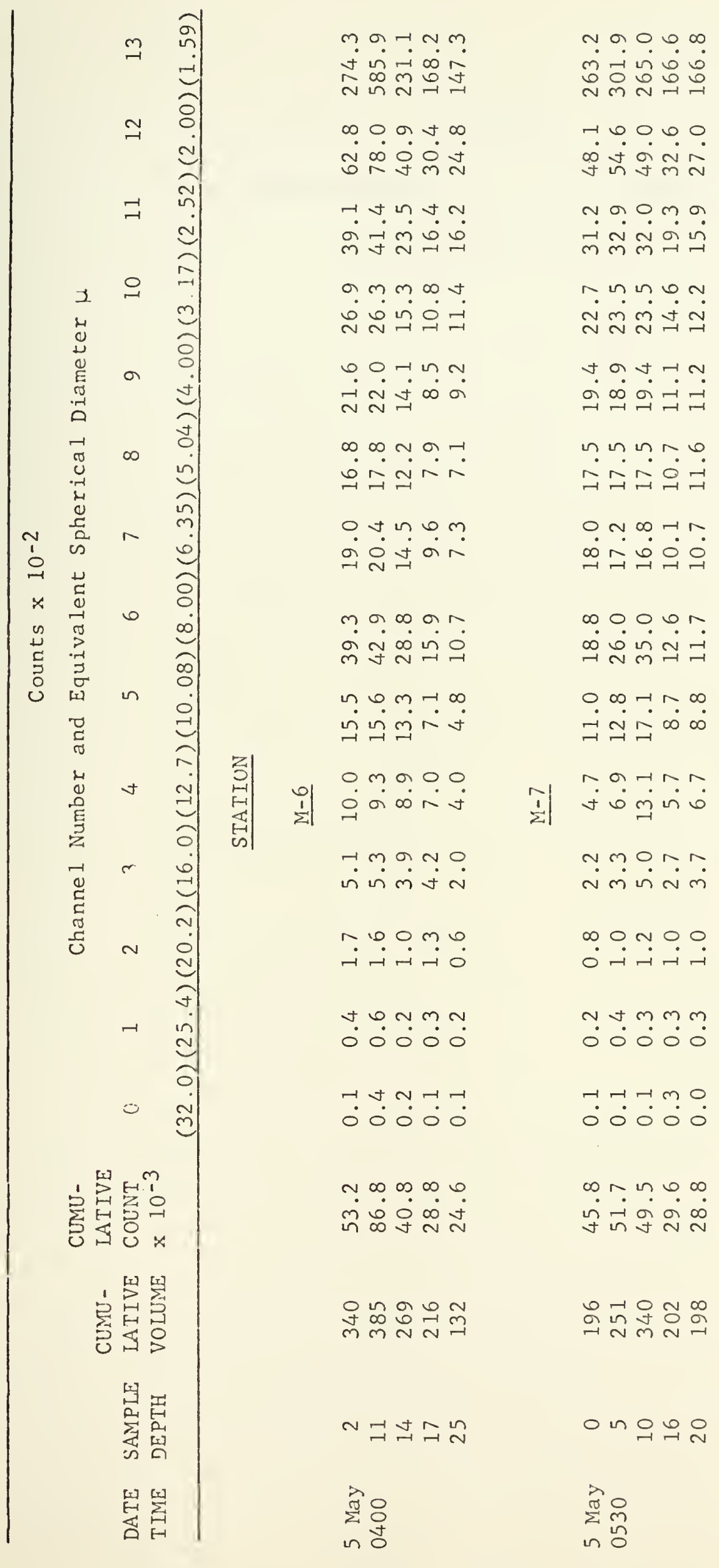





\section{APPENDIX}

Bathythermograph Traces with Temperatures

in ${ }^{\circ} \mathrm{C}$ and Depths in $\mathrm{m}$ 



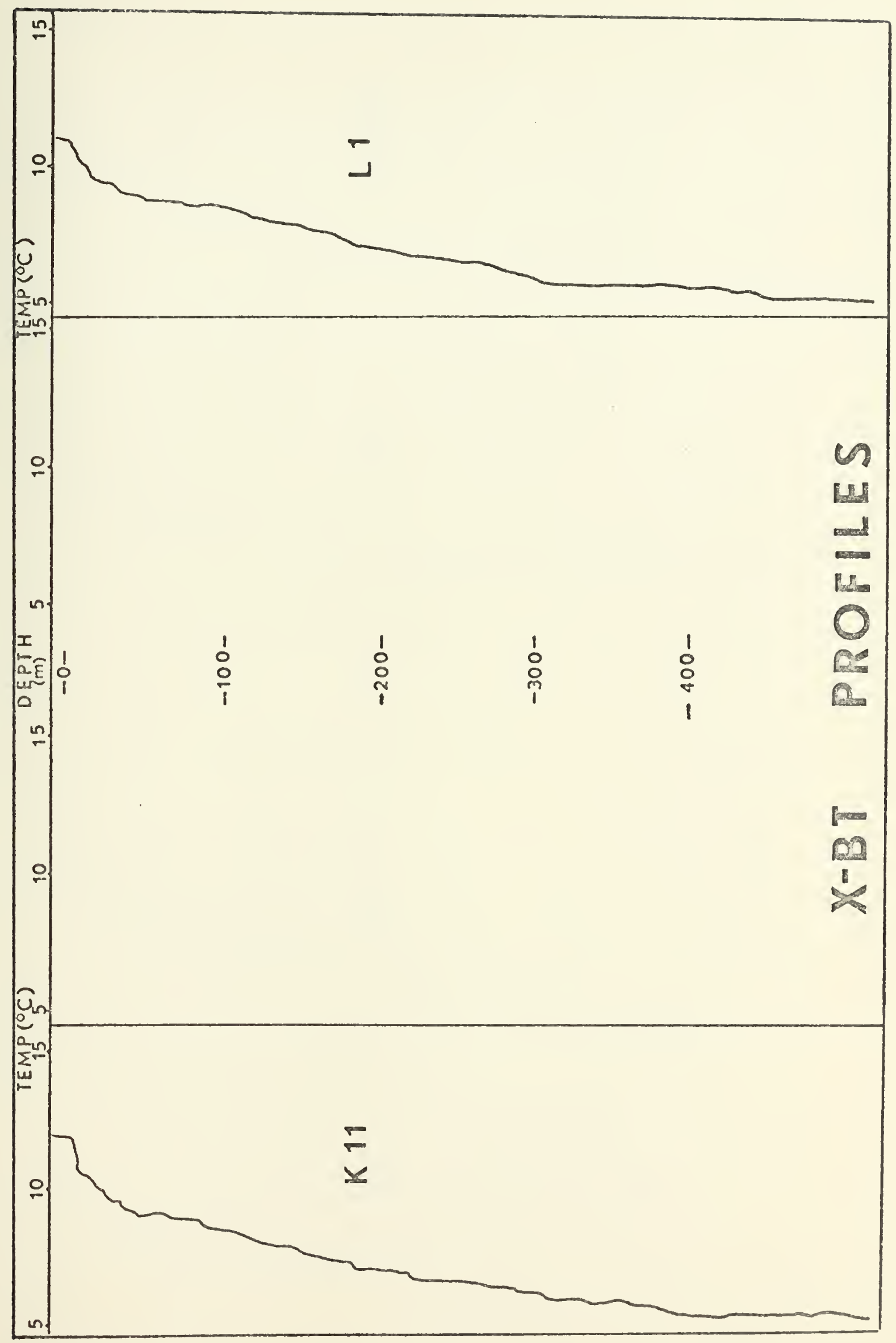





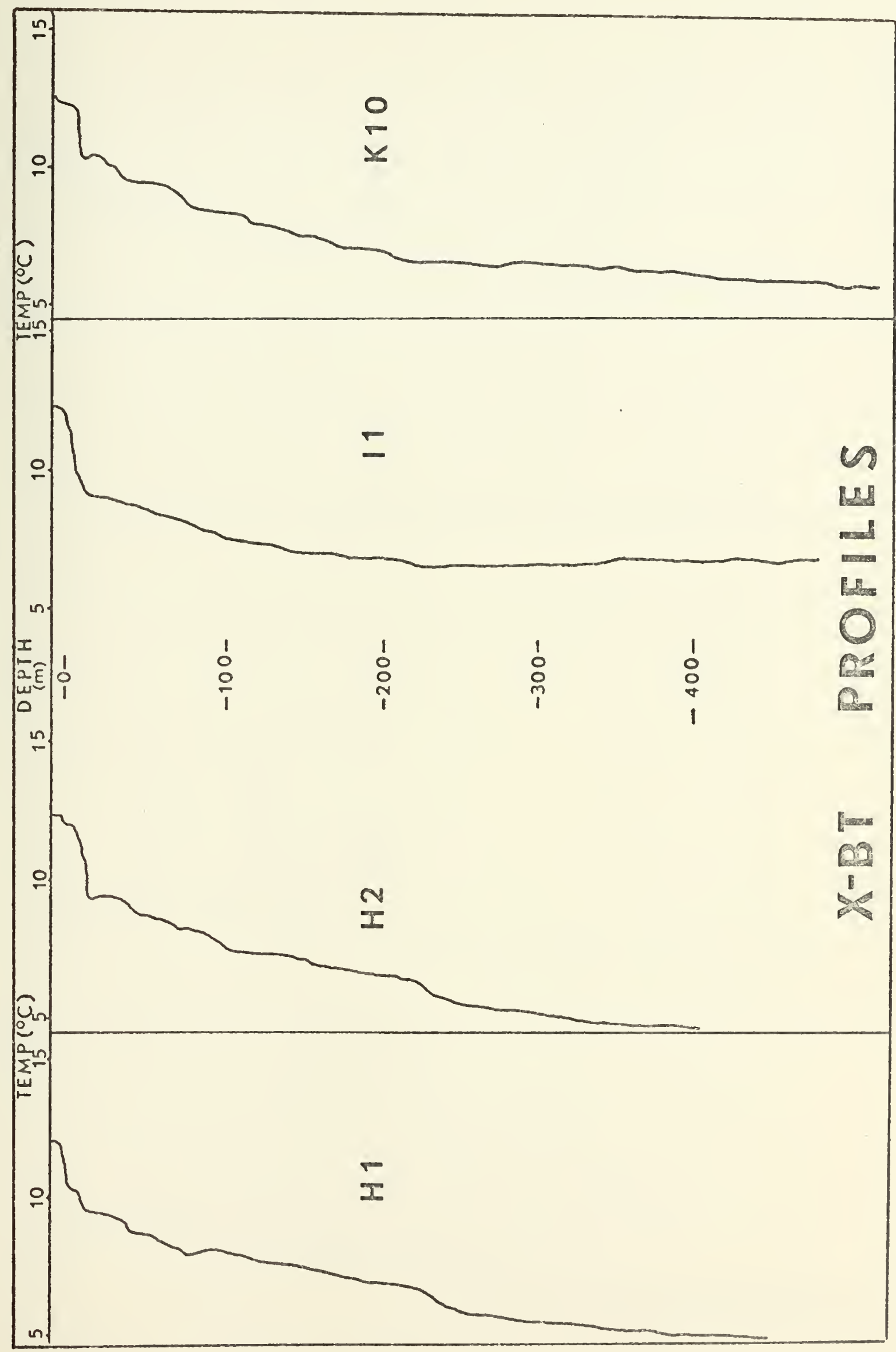





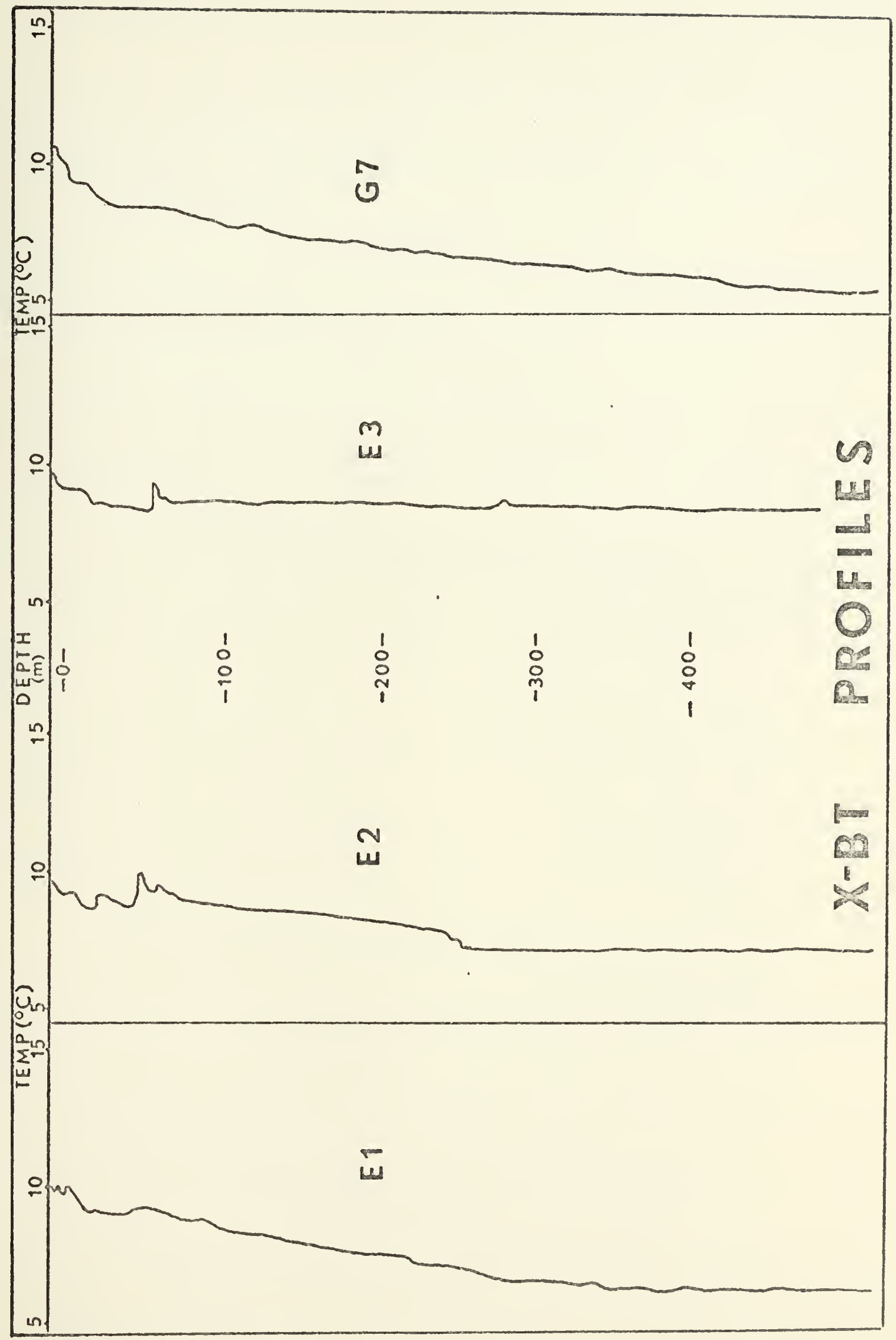





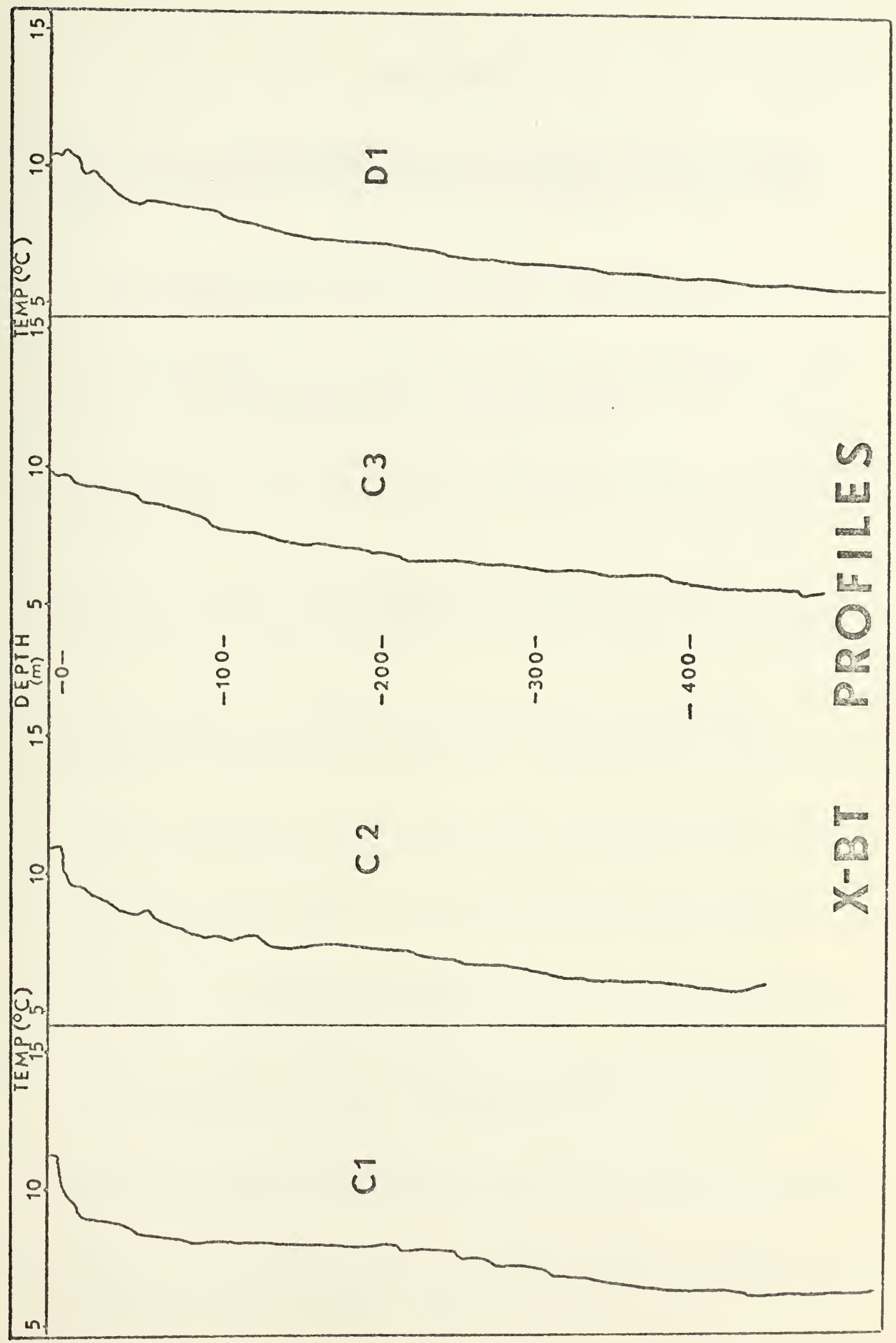





\section{BIBLIOGRAPHY}

1. Baker, R. E., The Comparison of Oceanic Parameters with Light Attenuation in the Waters Between San Francisco Bay and Monterey Bay, California, M.S. Thesis, Naval Postgraduate School, 1970, $206 \mathrm{p}$.

2. Bader, Henri, "The Hyperbolic Distribution of Particle Sizes". Journal of Geophysical Research 75 (15), 2822-2830, May 20, 1970.

3. Bolin, R. L. and Donald P. Abbot, "Studies on the Marine Climate and Phytoplankton of the Central Coastal Area of California, 19541960". California Cooperative Fisheries Investigations Progress Report 9, 1 July 1960 to 30 June 1962. 1962.

4. Bolin, Rolf L, and collaborators. "Hydrographic Data from the Area of the Monterey Submarine Canyon, 1951-1955". Final Report Hopkins Marine Station, Stanford University, Pacific Grove, California. July $30,1964$.

5. California Cooperative Oceanic Fisheries Investigations, Atlas Number 1, CALCOFI Atlas of 10-Meter Temperatures and Salinities, State of California, Department of Fish and Game, Marine Research Committee, July 1963.

6. Clarke, George L., Gifford C. Ewing, and Carl J. Lorenzen. "Spectra of Backscattered Light from the Sea obtained from Aircraft as a Measure of Chlorophyll Concentration". Science 167 (3921), 1119-1121, February 20, 1970.

7. Duntley, Seibert Q., "Iight in the Sea". Journal of the Optical Society of America 53 (2), 214-233, February 1963 .

8. Gordon, Howard R., Institute of Marine and Atmospheric Sciences, University of Miami, Miami, Florida. Personal communication. August 4, 1970 .

9. Jerlov, N. G., Optical Oceanography, Elsevier Publishing Company, Amsterdam, London, New York, 1968, 194 p.

10. Joseph, J., "Extinction Measurements to Indicate Distribution and Transport of Water Masses". Proceedings of UNESCO Symposium on Physical Oceanography, Tokyo, 59-75, 1955.

11. Labyak, P. S., An Oceanographic Survey of the Coastal Waters Between San Francisco Bay and Monterey Bay, M.S. Thesis, Naval Postgraduate School, 1969, $317 \mathrm{p}$.

12. Manheim, F. T. and R. H. Meade, "Suspended Matter in Surface Waters of the Atlantic Continental Margin from Cape Cod to the Florida Keys". Science 167 (3917), 371-376, January 23, 1970. 

13. Margalef, R., "Some Concepts Relative to the Organization of Plankton". Annual Review of Oceanography and Marine Biology, Harold Barnes (Editor), Vol. 5, 257-289, 1967.

14. Pak, Hasong, George F. Beardsley, Jr., and Robert L. Smith, "An Optical and Hydrographic Study of a Temperature Inversion off Oregon during Upwelling". Journal of Geophysical Research 75 (3), 629-636, January 20, 1970 .

15. Park, Kilho, June G. Pattullo, and Bruce Wyatt, "Chemical Properties as Indicators of Upwelling Along the Oregon Coast". Limnology and Oceanography 7 (3), 435-437, July 1962.

16. Pytkowicz, Ricardo, "Oxygen Exchange Rates off the Oregon Coast". Deep Sea Research 11 (3), 381-389, 1964.

17. Ramsey, Richard C., "Study of the Remote Measurement of Ocean Color, Final Report". TRW Systems Group, Reporting Period 28 August 1967 to 28 January 1968. Contract No. NASW-1658. Prepared for NASA Headquarters, Washington, D. C., January 26, 1968. 97 p.

18. Reid, Joseph L., Jr., Gunnar I. Roden, and John Wyllie, "Studies of the California Current System". California Cooperative Oceanic Fisheries Investigations Progress Report, 1 July 1956 to 1 January $1958,1958$.

19. Ryther, J. H., "Photosynthesis and Fish Production in the Sea". Science 166 (3901), 72-76, October 3, 1969.

20. Skogsberg, Tage, "Hydrography of Monterey Bay, California. Thermal Conditions, 1929-1933". Transactions of the American Philosophical Society, New Series, Vol. 29, December 1936.

21. Smith, R. L., "Upwelling". Annual Review of Oceanography and Marine Biology, Harold Barnes (Editor), Vol. 6, 11-46, 1968.

22. Stefansson, Unnsteinn and Francis A. Richards, "Distribution of Dissolved Oxygen, Density and Nutrients off the Washington and Oregon Coasts". Deep Sea Research 11 (3), 355-380, 1964.

23. Sverdrup, H. U., Martin W. Johnson, and Richard H. Fleming, The Oceans, Prentice Ha11, Englewood, New Jersey, 1942. 1087 p.

24. Yentsch, Charles S. and Carol A. Reichert, "The Interrelationships between Water Soluable Yellow Substances and Chloroplastic Pigments in Marine Algae". Bontanica Marina 3 (1), 65-74, Cram de Gruyter and Co., Hamburg, August 1961.

25. Yentsch, C. S. and R. F. Scage1, "Duirnal Study of Phytoplankton Pigments an in situ study in East Sound, Washington". Journal of Marine Research 17, 567-583, 1958.

26. Yeske, A. W. and R. D. Waer, The Correlation of Oceanic Parameters with Light Attenuation in Monterey Bay, California, M.S. Thesis, Naval Postgraduate School, 1968. 144 p. 

No. Copies

1. Defense Documentation Center

Cameron Station

Alexandria, Virginia 22314

2. Library, Code 0212

Naval Postgraduate School

Monterey, California 93940

3. Department of Oceanography

Naval Postgraduate School.

Monterey, California 93940

4. Officer in Charge

Fleet Numerical Weather Facility

Naval Postgraduate School

Monterey, California 93940

5. Commanding officer and Director

Naval Undersea Research \& Development Center

Attn: Code 2230

San Diego, California 92152

6. Director, Naval Research Laboratory

Attn: Tech. Services Info. Officer

Washington, D. C. 20390

7. Office of Naval Research

Department of the Navy

Washington, D. C. 20360

8. Department of Commerce, ESSA

Weather Bureau

Washington, D. C. 20235

9. Oceanographer of the Navy

The Madis on Building

$732 \mathrm{~N}$. Washington Street

Alexandria, Virginia 22314

10. Commandant (PTP)

U. S. Coast Guard

Washington, D. C. 20226

11. Library

USCG Oceanographic Unit

Bldg. 159-E, Navy Yard Annex

Washington, D. C. 20390 

12. Commandant (OMS)

U. S. Coast Guard

Washington, D. C. 20591

13. MST School

U. S. Coast Guard Training Center

Governors Island

New York, New York 10004

14. Department of Oceanography

U. S. Coast Guard Academy

New London, Connecticut 06320

15. Commander (oms)

Eastern Area, U. S. Coast Guard

Governors Is land

New York, New York 10004

16. Commander (oms)

Western Area, U. S. Coast Guard

630 Sansome Street

San Francisco, California 94126

17. Naval Oceanographic Office

Attn: Library

Washington, D. C. 20390

18. National Oceanographic Data Center

Washington, D. C. 20390

19. Mission Bay Research Foundation

7730 Hersche 1 Avenue

La Jolla, California 92038

20. Director, Maury Center of Ocean Sciences

Nava1 Research Laboratory

Washington, D. C. 20390

21. Mr. Roswe 11 W. Austin

Visibility Laboratory

Scripps Institution of Oceanography

La Jolla, California 92037

22. Mr. Thomas E. Bailey

Central Coastal Regional Water Quality Control Board 1108 Garden Street

San Luis Obispo, California 93401

23. Dr. George F. Beards ley

Department of Oceanography

Oregon State University

Corvallis, Oregon 97331 

24. Captain S. I. Bobczynski

Pacific Support Group

Naval Oceanographic Office

San Diego, California 92152

25. Dr. Wayne V. Burt

Department of Occanography

Oregon State University

Corvallis, Oregon 97331

26. Dr. Peyton Cunningham

Department of Physics

Naval Postgraduate School

Monterey, California 93940

27. Mr. Fred H. Dierke

Regional Water Quality Control Board

364 Fourteenth Street

Oakland, California 94612

28. Dr. Siebert Q. Duntley

Visibility Laboratory

Scripps Institution of Oceanography

La Jolla, California 92037

29. Mr. George Eck

Naval Air Development Center

Johnsville, Warminster, Pennsylvania 18974

30. Mr. Gary Gilbert

Stanford Research Institute

Menlo Park, California 94025

31. Dr. Eugene C. Haderlie

Department of Occanography

Naval Postgraduate School

Monterey, California 93940

32. Dr. R. C. Honey

Stanford Research Institute

Menlo Park, California 94025

33. Professor Alexandre Ivanoff

Laboratoire d'Oceanographie Physique

de la Faculte des Sciences de Paris

9, Quai Saint-Bernard

Paris $\left(V^{\mathrm{O}}\right)$, France

34. Dr. N. G. Jerlov

Institute for Physical Oceanography

Solvgade $83 \mathrm{~K}$

Copenhagen, $\mathrm{K}$, Denmark 

35. Mr. Kenneth V. Mackenzie

Ocean Sciences Department - Code D503

Naval Undersea Research \& Development Center

San Diego Division

San Diego, California 92152

36. Dr. Robert E. Morrison

$\mathrm{AE} 1$

Office of Environmental Systems

ESSA

6010 Executive Bivd.

Rockville, Maryland 20852

37. Mr. Jerry Norton

Oceanography Department

Naval Postgraduate School

Monterey, California 93940

38. Mr. Larry ott

Naval Air Development Center

Johnsville, Warminster, Pennsylvania 18974

39. Mr. Robert Owen

U. S. Bureau of Commercial Fisheries

La Jolla, California 92038

40. Dr. John H. Phillips

Hopkins Marine Station

Pacific Grove, California 93950

41. Mr. James Reese

Ocean Sciences Department - Code D503

Naval Undersea Research \& Development Center

San Diego Division

San Diego, California 92152

42. Mr. Tliomas J. Shopple

Naval Air Development Center

Johnsville, Warminster, Pennsylvania 18974

43. Dr. Warren Thompson

Department of Oceanography

Naval Postgraduate School

Monterey, California 93940

44. Dr. E. B. Thornton

Department of Oceanography

Naval Postgraduate School

Monterey, California 93940

45. Mr. S. P. Tucker

Department of Oceanography

Naval Postgraduate School

Monterey, California 93940 

46. Mr. B. L. Kolitz

Department of Mathematics

Naval Postgraduate School

Monterey, California 93940

47. Mr. John E. Tyler

Visibility Laboratory

Scripps Institution of Oceanography

La Jolla, California 92037

48. Mr. Lowell Van Billiard

Naval Ships Engineering Center

Prince Georges Center

Hyattsville, Maryland 20782

49. Mr. Raymond Walsh

San Francisco Bay Delta Water Quality Control Program

Resources Building, Room 144

1416 Ninth Street

Sacramento, California 95814

50. LCDR Lanny A. Yeske

1

USS BAYA, Fleet Post Office

San Francisco, California 96601

51. LCDR Robert E. Baker

U. S. Flcet Weather Central

COMNAVMARIANAS

Fleet Post Office

San Francisco 96630

52. Dr. Paul Titterton

Sylvania Electronic Systems - Western Division

P. O. Box 188

Mountain View, California 94040

53. Mr. R. J. Callaway

200 S. 35th Street

Corval1is, Oregon 97330

54. Mr. Alan Baldridge, Librarian

Hopkins Marine Station

Pacific Grove, California 93950

55. Mr. Ted Petzold

Visibility Laboratory

Scripps Institution of Oceanography

La Jolla, California 92037

56. Dr. Gary Griggs

Division of Natural Sciences - II

University of California, Santa Cruz

Santa Crux, California 95080 

57. Director

Moss Landing Marine Laboratories

Moss Landing, California 95039

58. Mrs. Elsie F. DuPre

Oceanography Branch, Optical Sciences Division

Naval Research Laboratory

Washington, D. C.

59. Dr. Rudolph W. Preisendorfer

Department of Mathematics

Naval Postgraduate School

Monterey, California 93940

60. Mr. W. J. Stachnik

Optical Systems

U. S. Navy Underwater Sound Laboratory

Fort Trumbu 11

New London, Connecticut 06320

61. Mr. Raymond N. Vranicar

Code AIR-370D

Naval Air Systems Command

Washington, D. C. 20360

62. Mr. Irvin H. Gatzke

Code AIR-370

Naval Air Systems Comnand

Washington, D. C. 20360

63. Dr. H. R. Gordon

Institute of Marine Sciences

University of Miami.

10 Rickenbacher Causeway

Miami, Florida 33149

64. Dr. Robert W. Holmes

Marine Sciences Institute

University of California

Santa Barbara, California 93106

65. Dr. Robert Andrews

Department of Oceanography

Naval Postgraduate School

Monterey, California 93940

66. Coastal Engineering Branch

Planning Division

U. S. Army Engineering Division, South Pacific 630 Sansome Street

San Francisco, California 94111 

67. Professor Glenn H. Jung

Department of Oceanography

Naval Postgraduate School

Monterey, California 93940

68. LT Arthur B. Shepard

USCGC Burton Is land WAGB-283

P.0. Box 20820

Long Beach, California 90801 




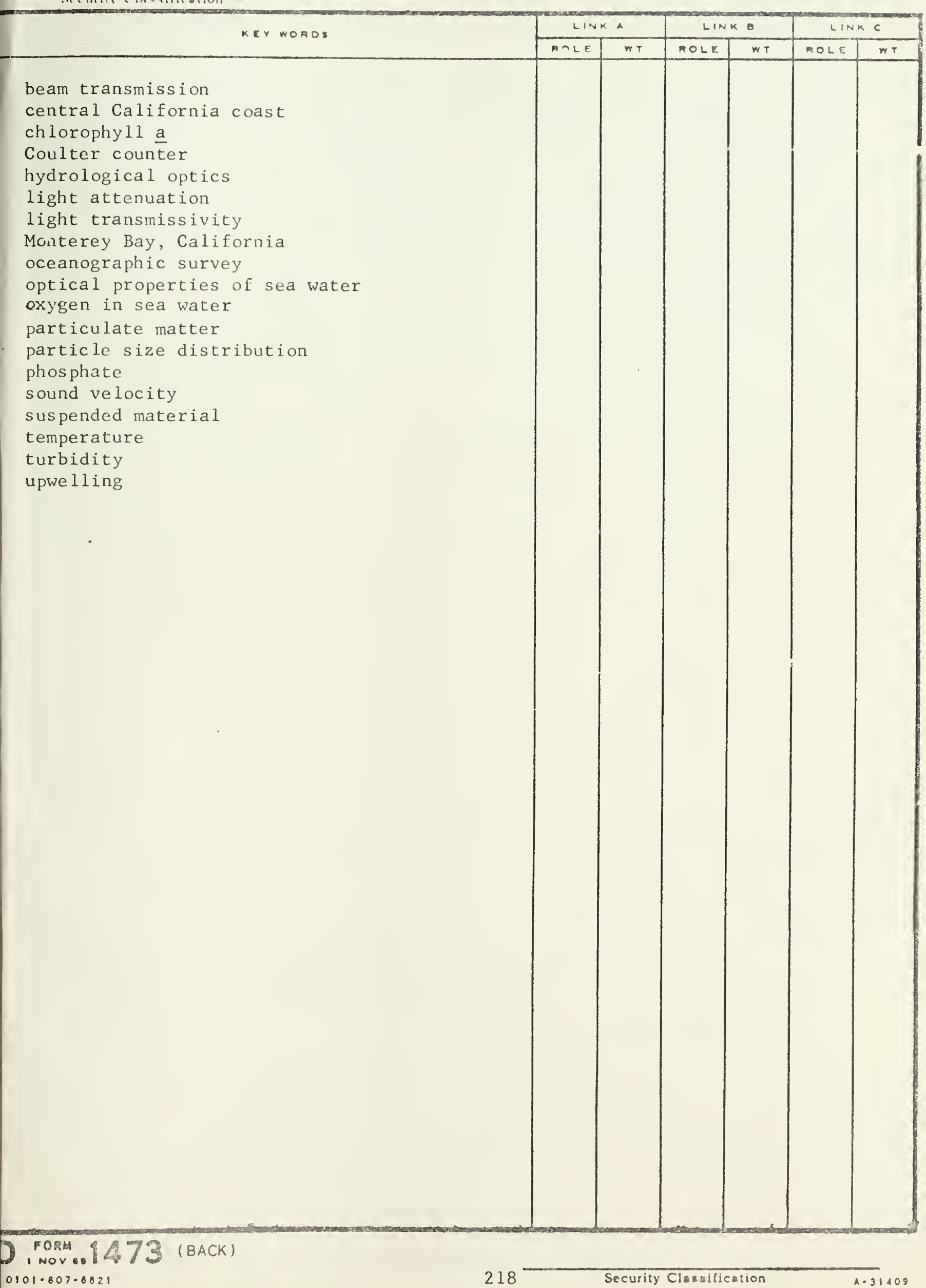





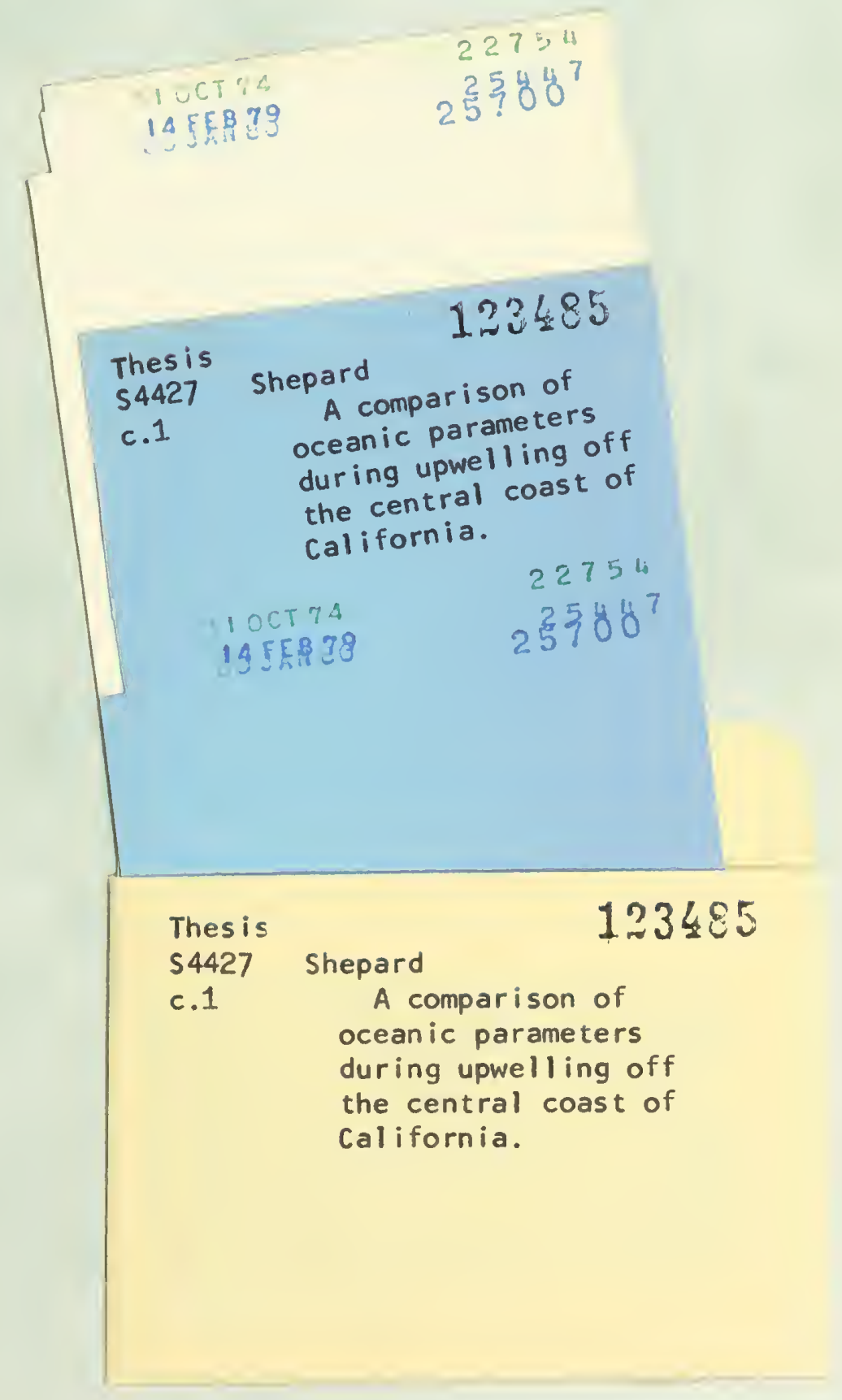


thes $\$ 4427$

A comparison of oceanic parameters durin

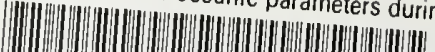

32768001954027

DUDLEY KNOX LIBRARY 